\title{
AN EXPLORATION OF THE UTILITY OF A SELF-REPORT EMOTIONAL INTELLIGENCE MEASURE
}

\section{KARINA BAILIE}

Thesis presented in partial fulfillment of the requirements for the degree of Master of Arts (Industrial Psychology) at the University of Stellenbosch.

\section{DECEMBER 2005}

Supervisor: MISS G EKERMANS 


\section{DECLARATION}

I, the undersigned, hereby declare that the work contained in this thesis is my own original work and that I have not previously, in its entirety or in part, submitted it to any university for a degree.

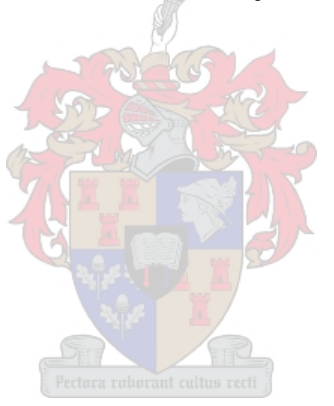

SIGNATURE:

DATE: 


\begin{abstract}
Several years of research have been dedicated to investigating the question of why intelligent and experienced leaders are not always successful in spite of having high levels of cognitive intelligence (IQ) and the suitable personality traits. Emotional Intelligence (EI) gained considerable popularity from the notion that it may underlie various aspects of workplace performance that could not be accounted for by IQ or personality and that it could be developed in promising individuals. Adjunct to this, the field of Positive Organisational Scholarship underscored the importance of cultivating positive emotions in individual organizational members and others, not just as end-states in themselves, but also as a means to achieving individual and organizational transformation; and hence optimal functioning over time. The Swinburne University Emotional Intelligence Test (SUEIT) is one of numerous models and measures of EI that have consequently been developed. The development of this measure was aimed at providing an assessment of the most definitive dimensions of the construct by incorporating six of the predominant models and measures into the development of EI to provide an assessment of the most definitive dimensions of the construct.
\end{abstract}

The current study was aimed at addressing the need for evidence in support of a self-report EI measures’ utility to predict e.g. effective organizational leadership over and above other established constructs. Specifically the study aimed to provide support for the utility of the SUEIT to predict variance in leadership competence indicated by Assessment Centre (AC) technology results, not accounted for by other psychometric tools, namely the Occupational Personality Questionnaire (OPQ32i), measuring personality. One of the biggest issues currently facing measures of EI is the discriminant validity from measures of personality. Research was necessary to add to the body of knowledge with regards to the relationship between EI and effective leadership, and to provide support for the incremental validity of an EI measure to predict effective leadership over and above other wellestablished models and measures.

The theoretical arguments that underlie the rationale for this study are encapsulated in the conceptual claims made about EI and organizational leadership, the IQ-EI debate as it pertains to leadership and the relationship between EI and effective leadership (i.e. the discriminant, predictive and incremental validity of EI related to organizational leadership). The constructs of EI, personality and AC leadership competencies were operationalised through the SUEIT, OPQ32i and leadership AC technology, 
respectively. The sample consisted of $49 \leq \mathrm{N} \leq 112$ (variation in the sample size was due to varying amount of missing cases in the different analyses done) middle managers from a company in the life assurance industry in South Africa. OPQ32i and AC data was extracted from archival records and EI data was collected on a separate occasion by means of an online version of the SUEIT. A controlled inquiry of non-experimental kind was followed and correlational and multivariate data analysis procedures were employed, using the SPSS (version 12) statistical package. The data analysis was aimed at determining whether relationships exist between the participants' scores on the different competencies as rated by means of the leadership AC technology and the dimensions measured by the psychometric instruments. It was also aimed towards finding evidence for the incremental validity of the SUEIT over the OPQ32i in predicting leadership competencies.

The results demonstrated the existence of various relationships between EI (as measured by the SUEIT) and specific leadership competencies measured by the AC technology employed by the sponsoring organisation. Adjunct to this, partial evidence has been obtained in support of the predictive validity of EI as operationalised by the SUEIT. In several instances it was found that there are overlap in the measurement of the underlying latent constructs by the different personality and EI dimensions from which such results were inferred. In order to compare these findings (with regards to the overlap between EI and personality traits) with previous research, conceptual links were drawn with other EI and personality measures used (e.g. the Bar-On EQi and NEO-FFI). Expected conceptual and theoretical equivalence in the measurement of personality and EI were confirmed. However, evidence for the incremental validity of the SUEIT (and specifically different dimensions thereof) was still found for most of the leadership competencies.

Based on the results it can be assumed that the SUEIT predicted scores on the examined leadership competencies when a measure of personality, namely the OPQ32i (already employed for this purpose) was controlled for. The results added to the understanding of what characteristics leaders in the sponsoring organization should possess to enable them and the organisation to be successful. The results provide preliminary evidence that the SUEIT could be useful to organizational decision makers, who need to select leaders that competently display leadership behaviours. It also provides preliminary evidence that EI and the SUEIT should be viewed as a useful construct and tool.

The use of archival data introduced several limitations to the study and will be discussed with suggestions for future research. 


\section{OPSOMMING}

Die vraagstuk rakende waarom intelligente en ervare leiers nie altyd suksesvol is nie, ten spyte van hoë vlakke van kognitiewe intelligensie (IK) en toepaslike persoonlikheidstrekke word reeds vir etlike jare ondersoek. Die konsep van Emosionele Intelligensie (EI) het reeds noemenswaardige populariteit verwerf as gevolg van die oortuiging dat dit verskeie aspekte van prestasie in die werksplek onderlê wat nie verklaar kan word deur IK of pesoonlikheid nie, asook dat dit ontwikkel kan word in individue met potensiaal. Die belangrikheid van die ontwikkeling en instandhouding van positiewe emosies in individuele lede van ' $n$ organisasie word deur die Positiewe Organisasie Gedrag dissipline beklemtoon, as ' $n$ wyse om individuele- en organisasie transformasie en optimale funsionering te bewerkstellig. Die Swinburne University Emotional Intelligence Test (SUEIT) is een van verskeie modelle en meetinstrument van EI wat sedertdien ontwikkel is. Tydens die ontwikkeling van die SUEIT is ses van die predominante modelle en metings van die EI konstruk geïnkorporeer ten einde 'n meting van die dimensies wat die kern van die EI konstruk definiëer te voorsien.

Die huidige studie was daarop gemik om bewyse ter ondersteuning van die nut van 'n self-evaluerings EI meting te genereer. Meer spesifiek, was die doelwit van die studie om ondersteuning te bied vir die SUEIT (as ' $\mathrm{n}$ meting van EI) om variansie in leierskap bevoegdheid (soos aangedui deur Takseersentrum tegnologie resultate) te verklaar, wat nie verklaar kan word deur ander psigometriese instrumente, naamlik die Beroeps Persoonlikheids Vraelys (Occupational Personality Questionnaire) nie. Tans is een van die belangrikste kwessies rakende metings van EI die onderskeidings geldigheid van metings van persoonlikheid. Navorsing was dus nodig ten einde kennis toe te voeg met betrekking tot die verhouding tussen EI en effektiewe leierskap, asook om ondersteuning te bewerkstellig vir die inkrementele geldigheid van ' $n$ EI meting, in die voorspelling van effektiewe leierskap bo en behalwe ander goed gegronde modelle en metings.

Die studie is gebaseer op die teoretiese argumente rondon EI en organisasie leierskap, die IK-EI debat met betrekking tot leierskap en die verhouding tussen EI en effektiewe leierskap (wat insluit die diskriminante-, voorspellings- en inkrementele geldigheid van EI rakende organisasie leierskap). EI, persoonlikheid en leierskapsbevoegdhede is elk geoperasionaliseer deur middel van die SUEIT, die OPQ32i en Takseersentrum tegnologie. Die steekproef is saamgestel uit $49 \leq \mathrm{N} \leq 112$ (variasie in die 
steekproef grootte was as gevolg van verskillende hoeveelhede verlore gevalle in die verskeie analises) middel vlak bestuurders in ' $n$ organisasie in die lewensversekerings industrie in Suid Afrika.

Die Beroeps Persoonlikheids Vraelys en Takseersentrum data is verkry vanaf bestaande rekords en die EI data is versamel deur middel van 'n elektroniese weergawe van die SUEIT. Pearson ProdukMoment Korrelasie en Veelvuldige Regressie Analise is gedoen deur van die SPSS (weergawe 12) statistiese pakket gebruik te maak. Die doel van die data analises was om die verhouding tussen deelnemers se tellings op die verskillende leierskap bevoegdhede (Takseersentrum tegnologie) en die dimensies, gemeet deur middel van die psigometriese instrumente, te ondersoek. Dit was ook gemik daarop om bewyse te vind vir die inkrementele geldigheid van die SUEIT bo die OPQ32i, in die voorspelling van leierskapsbevoegdhede.

Die resultate het gedui op verhoudings tussen verskeie EI dimensies (die SUEIT) en spesifieke leierskap bevoegdhede (soos gemeet deur die Takseersentrum tegnologie wat gebruik word deur die borg organisasie). Gedeeltelike bewyse is ook gevind ter ondersteuning van die voorspellingsgeldigheid van die SUEIT. In verskeie gevalle is oorvleueling gevind tussen die meting van die onderliggende latente konstrukte deur die verskillende persoonlikheids en EI dimensies waarvan die resultate afgelei is. Dit is geïnterpreteer om konseptuele en teoretiese ekwivalense in die meting van persoonlikheid. Nietemin is bewyse gevind vir die inkrementele geldigheid van (spesifieke dimensies van die) die SUEIT vir verskeie leierskap bevoegdhede.

Die resultate het daarop gedui dat die SUEIT sukses in hierdie leierskap bevoegdhede kan help voorspel bo en behalwe die meting van persoonlikheid, naamlik die OPQ32i wat alreeds vir hierdie doeleinde gebruik word. Die resultate voeg kennis toe tot die veld aangesien dit ' $n$ beter begrip van die eienskappe waaroor die leiers in die borg-organisasie behoort te beskik ten einde hul in staat te stel om suksesvol te wees, verskaf. Die SUEIT blyk van nut te wees aangesien dit deur besluitnemers in organisasies as hulpmiddel gebruik kan word om individue te selekteer wat bevoeg sal optree in ' $\mathrm{n}$ leierskap rol. Die resultate dui ook daarop dat EI beskou kan word as ' $n$ nuttige en waardevolle konstruk. Die beperkings van die studie (hoofsaaklik gekoppel aan die gedeeltelike gebruik van argivale data) en voorstelle vir toekomstige navorsing word bespreek. 


\section{ACKNOWLEDGEMENTS}

I would like to extend my gratitude and appreciation to the following people and institutions for their valuable contributions to make this study possible.

- My supervisor, Miss Gina Ekermans, for her commitment, encouragement, and much valued advice and input into this study.

- Prof. Nel from the Centre for Statistical Consultation for his advice and assistance with some of the statistical analyses.

- The Human Resources department of the sponsoring organisation who allowed me to extract data from their records.

- The group of managers from the sponsoring organisation who participated by completing the SUEIT and gave their consent to use their assessment data.

- Swinburne University (Prof Con Stough and Luke Downey) for advice and willingness to score the data and provide SUEIT reports for the participants.

- My husband, Francois Bailie, for his love, support, understanding and prayers throughout the process of completing my studies

- My family (Johan, Magda, Monica \& Phillip, Anel, Jana \& Riaan) for their prayers, love, support and interest in my studies.

- Lastly, but most of all, my thanks and praises goes to God, my Father for granting me the strength, ability and perseverence in order to complete my studies. 


\section{TABLE OF CONTENTS}

ABSTRACT

OPSOMMING iv

ACKNOWLEDGEMENTS vi

LIST OF TABLES $\quad$ xi

LIST OF APPENDICES $\quad$ xii

CHAPTER 1: INTRODUCTION AND THEORETICAL FRAMEWORK 1

$\begin{array}{ll}1.1 \text { INTRODUCTION } & 1\end{array}$

1.2 EI AND ORGANISATIONAL LEADERSHIP 4

1.2.1 The IQ-EI debate as it pertains to organizational leadership $\quad 4$

$\begin{array}{ll}\text { 1.2.2 EI and effective leadership } & 4\end{array}$

1.3. THE THEORETICAL FRAMEWORK 10

1.3.1 Brief history and overview of the personality construct $\quad 10$

1.3.1.1 The psychoanalytic approach to personality 11

1.3.1.2 The psychometric approach to personality 11

1.3.1.3 The occupational personality questionnaire (OPQ) model 13

1.3.1.4 Personality traits and leadership success 14

1.3.1.5 Personality traits and EI 15

1.3.2 Emotional Intelligence 17

1.3.2.1 Early antecedents of the EI construct $\quad 18$

1.3.2.2 Categorisation of different models and measures of EI 18

a) Mayer and Salovey’s Ability Model of EI 22

b) Goleman’s Competency Model of EI 29

c) The Schutte Self-Report Inventory (SSRI) 31

d) The Bar-On model and theory of EI 32

1.3.2.3 The "problem” of multiple theories of EI 36

1.3.2.4 Palmer and Stough’s model of EI 37

$\begin{array}{ll}\text { 1.3.3 Leadership } & 41\end{array}$

1.3.3.1 Leadership ACs - underlying assumptions and methodology 42

1.4 THE INCREMENTAL VALIDITY OF EI 46

1.5. RATIONALE AND OBJECTIVES OF THE STUDY 47 
$\begin{array}{ll}\text { 1.5.1 Rationale for this study } & 47\end{array}$

$\begin{array}{ll}\text { 1.5.2 Aim and objectives of this study } & 47\end{array}$

$\begin{array}{ll}\text { 1.6. SUMMARY } & 48\end{array}$

CHAPTER 2: RESEARCH METHODOLOGY 50

$\begin{array}{ll}2.1 \text { INTRODUCTION } & 50\end{array}$

2.2 RESEARCH DESIGN 49

2.3 PARTICIPANTS

2.4 MEASURING INSTRUMENTS $\quad 56$

2.4.1 Leadership: Assessment Centre Technology 56

2.4.2 Emotional Intelligence: The SUEIT 61

2.4.3 Personality: The Occupational Personality Questionnaire (OPQ32i) 63

2.5 RESEARCH AIM AND HYPOTHESES 66

2.6 SAMPLE AND DATA COLLECTION 67

$\begin{array}{ll}2.7 & 67\end{array}$

$\begin{array}{ll}2.8 \text { SUMMARY } & 69\end{array}$

CHAPTER 3: RESULTS

$\begin{array}{ll}3.1 \text { INTRODUCTION } & 71\end{array}$

$\begin{array}{ll}3.2 \text { RESULTS: RELIABILITY } & 71\end{array}$

$\begin{array}{ll}\text { 3.3 THE SAMPLE } & 71\end{array}$

3.4 CORRELATION RESULTS: EMOTIONAL INTELLIGENCE, PERSONALITY 72 AND LEADERSHIP COMPETENCIES

3.4.1 Emotional Intelligence and Leadership Competencies

3.4.1.1 Customer Focus $\quad 74$

3.4.1.2 Building Working Relationships 75

3.4.1.3 Gaining Commitment 76

$\begin{array}{ll}\text { 3.4.1.4 Developing Others } & 77\end{array}$

$\begin{array}{ll}\text { 3.4.1.5 Problem Solving } & 78\end{array}$

$\begin{array}{ll}\text { 3.4.1.6 Stress Tolerance } & 78\end{array}$

3.4.2 Personality traits and leadership competencies $\quad 79$

$\begin{array}{ll}\text { 3.4.2.1 Customer Focus } & 81\end{array}$ 
3.4.2.2 Building Working Relationships $\quad 81$

3.4.2.3 Gaining Commitment 84

3.4.2.4 Developing Others 85

3.4.2.5 Analysis 86

3.4.2.6 Problem Solving 87

3.4.2.7 Initiating Action $\quad 88$

3.4.2.8 Planning and Organising 88

3.4.2.9 Stress Tolerance $\quad 89$

3.4.2.10 Continuous Learning 90

3.5 MULTIPLE REGRESSION RESULTS: EMOTIONAL INTELLIGENCE, PERSONALITY 90 AND LEADERSHIP COMPETENCIES

$\begin{array}{ll}3.5 .1 \text { Introduction } & 90\end{array}$

3.5.2 Hierarchical Regression Results 91

3.5.2.1 Customer Focus $\quad 92$

3.5.2.2 Building Working Relationships 92

3.5.2.3 Gaining Commitment 93

3.5.2.4 Developing Others 93

3.5.2.5 Problem Solving $\quad 93$

3.5.2.6 Stress Tolerance $\quad 95$

3.5.3 Standard Multiple Regression Analyses Results 95

3.5.3.1 Continuous Learning 95

3.5.3.2 Customer Focus 96

3.5.3.3 Building Working Relationships 97

3.5.3.4 Gaining Commitment 98

3.5.3.5 Developing Others 98

3.5.3.6 Analysis 99

$\begin{array}{ll}\text { 3.5.3.7 Problem Solving } & 100\end{array}$

3.5.3.8 Planning \& Organising 101

$\begin{array}{ll}\text { 3.5.3.9 Stress Tolerance } & 101\end{array}$

3.6 CORRELATION RESULTS: EMOTIONAL INTELLIGENCE AND PERSONALITY 102

3.6.1 Introduction 102 
3.6.1.1 Emotional Recognition and Expression 103

3.6.1.2 Understanding Emotions External 104

3.6.1.3 Emotional Control 106

$\begin{array}{ll}\text { 3.6.1.4 Emotional Management } & 107\end{array}$

3.6.1.5 Emotion Direct Cognition 108

$\begin{array}{ll}\text { 3.7 SUMMARY } & 104\end{array}$

CHAPTER 4: DISCUSSION 111

$\begin{array}{ll}\text { 4.1 INTRODUCTION } & 111\end{array}$

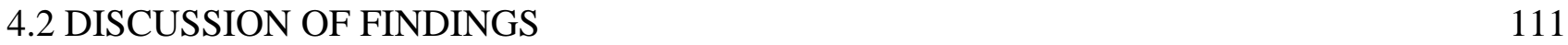

4.2.1 Customer Focus 111

4.2.2 Building Working Relationships 113

4.2.3 Gaining Commitment 116

4.2.4 Developing Others 118

4.2.5 Problem Solving 121

4.2.6 Stress Tolerance 123

4.3 LIMITATIONS OF THE STUDY AND FUTURE RESEARCH 125

4.4 CONCLUSION 126

REFERENCES 129 


\section{LIST OF TABLES}

Table $1.1 \quad$ Summary of different EI models and measures 20

Table 2.1 Leadership competencies assessed by Assessment Centres in this study 60

$\begin{array}{lll}\text { Table } 2.2 & \text { OPQ32i scales and subscales } & 64\end{array}$

Table 2.2 Reliability statistics for the OPQ32i 65

Table 3.1 The current study's reliability statistics for the SUEIT

Table 3.2 Pearson Product-Moment correlations between EI dimensions and AC $\begin{array}{ll}\text { competencies } & 74\end{array}$

Table 3.3 Spearman correlations between OPQ32i dimensions (violating assumptions of normality) and Leadership competency scores indicated to have significant Pearson Correlations.

Table 3.4 Coefficients obtained for the Standard Regression: Continuous Learning, and the significant correlates 96

Table 3.5 Coefficients obtained for the Standard Regression: Customer Focus 96

Table 3.6 Coefficients obtained for the Standard Regression: Building Working

$\begin{array}{ll}\text { Relationships } & 97\end{array}$

Table 3.7 Coefficients obtained for the Standard Regression: Gaining Commitment 98

Table 3.8 Coefficients obtained for the Standard Regression: Developing Others 99

Table 3.9 Coefficients obtained for the Standard Regression: Analysis 100

Table 3.10 Coefficients obtained for the Standard Regression: Problem Solving 100

Table 3.11 Coefficients obtained for the Standard Regression: Planning and Organising 101

Table 3.12 Coefficients obtained for the Standard Regression: Stress Tolerance 102 


\section{LIST OF APPENDICES}

$\begin{array}{ll}\text { APPENDIX 1: } & \text { Shapiro-Wilck Tests for Normality }\end{array}$

1.1 Shapro-Wilck statistics for the OPQ32i 140

1.2 Shapiro-Wiclk statistics for the SUEIT 140

APPENDIX 2: $\quad$ Histograms and normal probability plots for regression models

2.1. Histogram and normal probability plot obtained for Regression:

Customer Focus on Understanding Emotions External,

Outgoing, Affiliative, \& Emotionally Controlled

2.2 Histogram and normal probability plot obtained for Regression:

Building Working Relationships on Understanding Emotions

External, Emotional Control, Persuasive, Independent Minded,

Affiliative, Socially Confident, Democratic, Behavioural,

Emotionally Controlled \& Decisive

143

2.3 Histogram and normal probability plot obtained for Regression:

Gaining Commitment on Understanding Emotions External, Independent Minded, Socially Confident, Behavioural and

Relaxed

2.4 Histogram and normal probability plot obtained for

Regression: Developing Others on Emotional Recognition and

Expression, Emotional Control, Outgoing, Democratic, Relaxed and Tough Minded

2.5 Histogram and normal probability plot obtained for Regression:

Analysis on Controlling, Evaluative and Tough Minded

2.6. Histogram and normal probability plot obtained for Regression:

Problem Solving on Emotional Management, Controlling and

Tough Minded

2.7. Histogram and normal probability plot obtained for Regression:

Initiating Action on Tough Minded

2.8 Histogram and normal probability plot obtained for Regression:

Planning and Organising on Outspoken, Socially Confident, and 
2.9. Histogram and normal probability plot obtained for Regression:

Stress Tolerance, on Emotion Direct Cognition, Emotional

Control, Independent Minded, Behavioural, Worrying and

Emotionally Controlled

APPENDIX 3:

Results of Pearson Product-Moment correlations

159

3.1 Pearson Product-Moment correlation between dimensions of the OPQ32i and AC leadership competency scores

3.2 Pearson Product-Moment correlations between SUEIT dimensions and OPQ32i

4.2. Hierarchical regression analysis with Building Working Relationships

4.3. Hierarchical regression analysis with Gaining Commitment

4.4 Hierarchical Regression analysis with Developing Others 


\section{CHAPTER 1: INTRODUCTION AND THEORETICAL FRAMEWORK}

\subsection{INTRODUCTION}

In recent years substantial research has been conducted regarding the characteristics employees need to possess in order to enable organizations to achieve a competitive advantage in its industry. The notion that effective leaders contribute most to effective organizational performance, underpinned over 50 years of rigorous research efforts in order to identify the traits or characteristics associated with effective leadership (Higgs \& Aitken, 2003). The search for the traits of effective leaders has been combined with an extensive period of research into identifying leadership potential (e.g. Thornton and Byham, 1982). In this domain, one of the most thoroughly researched methods of identifying leadership potential has been the Leadership Assessment Centre (AC). However, questions regarding why intelligent and experienced leaders are not always successful in spite of having high cognitive intelligence (IQ) and the suitable personality traits still largely remain unanswered.

More recently it has been asserted that irrespective of the model of leadership that is being examined, successful leadership is largely underpinned by the need of leaders to possess Emotional Intelligence (EI) (Goleman, 1995). Frederickson (2003) places the dynamics that produce extraordinary outcomes in organizations within the framework of positive organizational scholarship. This framework creates a context within which the relationship between EI and organizational functioning is underscored and thus can be explored. More specifically, her broaden-and-build theory explains the importance of cultivating positive emotions in individual organizational members and others, not just as end-states in themselves, but also as a means to achieving individual and organizational transformation; and hence optimal functioning over time (Frederickson, 2003).

Adjunct to the views of Frederickson (2003) on the potential utility of emotions in organizational outcomes, other authors (Palmer, Gardner \& Stough, 2003a) point out that EI is increasingly becoming popular within industrial and organizational psychology as a determinant of occupational success. Much of this popularity stems from the notion that EI may underlie various aspects of workplace performance that could not be accounted for by IQ or personality. Unlike 
intelligence and personality, which are relatively fixed throughout working life, it has been claimed by Goleman (1998) that well developed training programmes could enhance emotional abilities within, and amongst employees, and thus positively influence overall organizational performance and success.

Coinciding with the intense interest in the construct by both academics and practitioners has been the development of numerous models and measures of EI (Mayer, Caruso, \& Salovey, 2000). Consequently, different views emerged with regards to how the EI construct should be used and measured, as is evident in the distinction between ability, trait, and mixed models of EI. Parallel to this, the debate over self-report versus performance based measures of EI add further distinctions in the conceptualization and operationalization of the construct (Mayer, Salovey \& Caruso, 2000b). Confusion was created by the different conceptualizations and as a result EI has been branded as an elusive construct with fuzzy boundaries (Stough, Palmer, Gardner, Papageorgiou \& Redman, 2002).

Given the ambiguous perspectives relating to the EI construct, Stough et al. (2002) identified the need to develop the Swinburne University Emotional Intelligence Test (SUEIT) to provide an assessment of the most definitive dimensions of the construct by incorporating the predominant models and measures of EI at that time (e.g. models and measures developed by Mayer, Salovey, \& Carusso, 1999; Bar-On, 1997; Bagby, Taylor \& Parker, 1994; Schutte, Malouff, Hall, Haggerty, Cooper, Golden, \& Dornheim, 1998, and Tett et al. cited in Palmer \& Stough, 2001). Henceforth, the need for research to provide evidence for the practical utility of Palmer \& Stough's theory (The SUEIT, 2001), with specific application for the leadership domain, was identified. Therefore, in the current study the predictive and discriminant validity of the SUEIT was investigated in order to determine whether this measure of EI could explain variance in predicted leadership competence, over and above variance that is not accounted for by other psychometric tools (e.g. measures of personality) that are typically utilized to predict leadership competence. The use of EI measures to identify competent leaders could assist organizational decision makers in recruiting and developing individuals that have the necessary qualities to ensure successful organizational leadership and overall organizational success. 
Up to date only a few studies have investigated the utility of the SUEIT as a self-report measure of EI. Firstly, in a study where the average EI scores of executive and general normative groups were compared, it was found that the mean scores of the executive normative sample on the SUEIT is significantly higher than the mean scores of the general normative sample (Palmer et al., 2003a). This confirmed the independent t-tests results reported in the technical manual (Palmer \& Stough, 2001) which show that executives score significantly higher on the Emotional Recognition and Expression, Understanding Emotions, Emotional Management and Emotional Control subscales, compared to non-executives. Palmer et al. (2003a) concluded that these findings suggest that EI (as measured by the SUEIT) is related to occupational success, at least in terms of one's position in an organization. Secondly, in order to investigate whether EI underlies leadership success, Palmer et al. (2003a) examined the relationship between scores on the SUEIT and scores on the Multifactor Leadership Questionnaire (MLQ) in a sample of 231 senior executives. It was expected that EI would have a positive relationship with transformational leadership and a negative relationship with laissez-faire leadership. To determine whether this variance in leadership behaviour was accounted for, over and above that accounted for by personality, the relationship between scores on the SUEIT and the NEO Five Factor Personality Inventory (NEO FFI) were also determined (Palmer et al., 2003a). The stepwise regression results indicated that Understanding Emotions $(\mathrm{t}=6.0)$, Extraversion $(\mathrm{t}=3.5)$ and Emotional Recognition and Expression ( $\mathrm{t}=2.4)$ accounted for the most variance in transformational leadership (51.4\%). However the most important predictor was Understanding Emotions accounting for $41 \%$ of the transformational leadership variance. These results indicated that EI, as measured by the SUEIT, accounted for variance in transformational leadership over and above dimensions of personality (operationalised by the NEO-FFI) (Palmer et al., 2003a). Palmer et al. (2003a), however, concluded that while their research findings show that the SUEIT comprises good psychometric properties, a great deal more research is needed in order to substantiate and better understand the role EI plays in various aspects of working life. Specifically, the question of whether the EI construct (operationalised by the SUEIT) can account for variance in leadership competence, not accounted for by a personality measure (the Occupational Personality Questionnaire - OPQ), was investigated in the current study. The OPQ is a well-established, wellvalidated tool already utilized for the purpose of identifying leaders in organizations. The current 
study aimed to clarify the question of the utility of the EI construct (and the SUEIT) by exploring its incremental validity in predicting leadership competence, over and above personality traits.

This chapter continues to provide a discussion of the theoretical arguments that underlie the rationale for this study. To this end it presents the arguments surrounding EI and organizational leadership, the IQ-EI debate as it pertains to leadership, the relationship between EI and effective leadership and the discriminant and predictive validity of EI related to organizational leadership. Thereafter a brief discussion on personality theory, EI and leadership as well as the case for investigating the incremental validity of EI is presented. This chapter concludes by briefly summarizing the rational, aim and objectives of this study.

In order to orientate the reader, the structural outline of this thesis is briefly presented next. Chapter one discusses the theoretical framework for this study. It aims to logically present the reasoned argument that underlies the necessity for this study. Chapter two presents the research methodology employed to conduct the research. It includes a discussion of the research design, measuring instruments, the research aim and hypotheses, the sample and data collection and analyses methods utilised in this study. Chapter three reports the data analyses results, including that of the correlation and multiple regression data analyses. A discussion of the evidence that was found related to the predictive and discriminant validity of the SUEIT per leadership competency is covered in chapter four. Evidence with regards to the incremental validity of the SUEIT, or lack thereof, for each of the competencies are discussed whilst comparisons are made with previous research findings.

\subsection{EI AND ORGANISATIONAL LEADERSHIP}

\subsubsection{The IQ-EI debate as it pertains to organisational leadership}

According to Emmerling and Goleman (2003) traditional measures of intelligence, although providing some degree of predictive validity, have not been able to account for a large portion of the variance in work performance and career success. Goleman (1996) went so far as to claim that because IQ is thought to account for about $20 \%$ of variance in life success, EI is likely to account for the remaining $80 \%$. He further claimed that, because EI affects almost every aspect of work life, employees who are high in EI are star performers. Goleman (1996) argued that it is not 
that IQ and technical skills are irrelevant. In his view they do matter, but mainly as threshold capabilities, meaning they are the entry-level requirements for executive positions. Further to this he also claims that EI is a learnable construct and improves with age.

Deguara and Stough (2002) documented arguments from literature that EI enhances leaders' performance by fostering emotional resilience and empathy. Further to this, O’Connor and Little (2003) also provided arguments in support of the potential value of EI for improving a leader's professional and personal life. They support the notion, that suggests that EI is a more effective predictor of success in a leadership role and life achievement, than general intelligence. Emmerling and Goleman (2003) however point out that the issue of separating abilities related to cognitive intelligence from abilities, traits and competencies related to EI, remains a complex one. One of their central contentions is that people who have a good mix of IQ and EI tend to be more successful in their chosen fields of endeavour than those who have outstanding IQ and under-developed EI (Emmerling \& Goleman, 2003). In spite of the arguments for the importance of EI for the prediction of success in leadership, life and organizations, limited empirical evidence supporting these arguments currently exist. The current study aimed to contribute to the body of evidence in support of the predictive validity of the SUEIT. In reviewing the literature it is clear that various researchers have been investigating the impact of EI on organizational leadership and its effect on leadership success and subordinate performance. A more in-depth review of the findings will be discussed in the sections to follow.

\subsubsection{EI and effective leadership}

Goleman (1998) claimed to have found that effective leaders are alike in one crucial way - they all have a high degree of what he has come to term as EI. His research at nearly 200 large, global companies revealed that EI, especially at the highest levels of a company, is the imperative for successful leadership. Without it, a person can have first-class training, an incisive mind, and an endless supply of good ideas, but he still won't make a great leader (Goleman, 1998). According to Stuart and Paquet (2001) EI is a vital factor in determining one's ability to succeed in life and directly influences one's psychological wellbeing or overall degree of emotional health. They therefore postulated that emotional health should also have some impact on the presence or absence of leadership ability (Stuart \& Paquet, 2001). Other researchers believe that it is required 
from people in a leadership role to possess the ability to identify emotions in themselves and others, use emotions in their thought processes, understand and reason with emotion, and manage emotions in one's self and others (Vitello-Cicciu, 2002).

According to O'Grady (2003) it has become clear that the role of the leader has particular behavioural and performance requirements that have a specific important and enduring impact on the organization. The importance of the leader to the culture and context of the organisation is increasingly evident. O'Grady (2003) furthermore argues that the mood, attitude, and adjacent patterns of interaction of the leader with the staff and others, have a tremendous effect on the culture, context, and content of work. Because of this, leaders must have a sense of their own personal emotional patterns and an awareness of the impact of significant emotional events on their own leadership behaviour. The expectations of successful leadership reflect the need for consistent applications of the role so that staff can depend on the emotional and behavioural integrity, and balance of the leader as he or she consistently applies their leadership skills.

Research results from a study by Gardner and Stough (2002) proposes that emotionally intelligent leaders are thought to be happier and more committed to their organization; achieve greater success; take advantage of and use positive emotions to envision major improvements in organizational functioning, as well as use emotions to improve their decision making. In addition, such leaders generally also instill a sense of enthusiasm, trust and co-operation in other employees through interpersonal relationships. A growing body of research attests to the importance of studying the role of EI in successful leadership (Carmeli, 2003). The central notion underlying this research is the view that people with high EI competencies are more likely than less emotionally intelligent people to gain success in the workplace. Social skills are essential for executive level leaders and as individuals ascend the organizational hierarchy, social intelligence (Thorndike, 1920) seems to become an increasingly relevant determinant of leadership success. According to Palmer, Gardner and Stough (2003b) leaders who are socially adapted, were also found to display emotionally intelligent behaviours. Such leaders seemed more likely to be aware of their own emotions and how they impact on their outward displays and behaviours; they expressed their emotions more appropriately to others; were generally better at reading and 
responding to the emotions of others at work and tended to be more capable of managing both their own and the emotions of others in the workplace (Palmer et al., 2003a).

McClelland (as cited in Snow, 2001) found a strong link between organisational success and the EI of its leaders. Gardner and Stough (2002) have also investigated leadership and EI and proposed that EI enhances leaders' ability to solve problems and to address issues and opportunities facing them and their organisation. However, Carmeli (2003) argues that statements, claiming that managers with high EI competencies are likely to provide their organizations with a unique contribution, have not yet received sufficient empirical attention and support. This is true particularly with regards to various important work-related attitudes, behaviour and outcomes. Further research is thus necessary to empirically support the claims about the theoretical and conceptual link between EI and organizational leadership. Research has yet to identify the effect of leaders' emotions on their work and subordinates, and in general the role emotions play in leadership (Gardner \& Stough, 2002). There is thus merit in a study examining the relationship between EI and leadership competence, as the present study intends to do. To this end, the predictive and discriminant validity of the EI construct will be explored.

The claims regarding the relationship between EI and leadership success is one of the most contentious aspects of the current debate on EI. Despite the assertions about the relationship between EI and leadership success, few published studies have demonstrated these relationships empirically. Much of the popular management literature on EI has described the construct as a key attribute of successful leaders. Based on this notion, it has been postulated by Palmer et al. (2003a) that screening for EI in the recruitment process may help identifying potentially more successful leaders. In addition to this, developing leaders' EI through training programmes may enhance their practical and social skills, and therefore their overall leadership success. In order to verify the EI-leadership success relationship, and that (for example), screening for EI in the recruitment process will aid in the identification of potentially more successful leaders, Palmer et al. (2003a) concluded that evidence needs to be found in support of a meaningful relationship between EI and various indices of leadership success. 
In 2002, Gardner and Stough (2002) investigated some tentative hypotheses relating the EI dimensions measured by the SUEIT to dimensions of leadership, as defined in terms of different styles of leading encapsulated in the Multifactor Leadership Questionnaire. It was hypothesised that there would be a relationship between transformational leadership (measured by the Multifactor Leadership Questionnaire, MLQ) and overall EI (measured by the SUEIT), as well as that there will be no relationship between transactional and laissez faire leadership and EI (Gardner \& Stough, 2002). The results of the research supported the existence of a strong positive correlation between the MLQ dimension, transformational leadership and total EI as well as a negative correlation between laissez-faire leadership and EI. Alternatively, a positive relationship was found between components of the MLQ dimension, transactional leadership, namely contingent rewards, which was in line with previous research. However, other than defining Leadership in terms of the different styles of leading encapsulated in the Multifactor Leadership Theory, leadership success can also be defined in terms of leadership competencies identified and required of the leaders of an organisation to ensure that it gains and retains a sustainable advantage in industry. The competency related definition of leadership was used for the purpose of this study.

Whilst it would seem that the construct of EI offers significant potential to account for variance in leadership success, the need for rigorous research to underpin this notion in the organisational setting is still evident. Determining whether a measure of EI predicts leadership competencies can provide evidence for the utility of the construct. This evidence may influence decision makers, who as yet, remain skeptical about the concept of EI, even though it is claimed to have an astounding impact on leadership success. Therefore, the first objective of this study was to establish whether EI and personality traits predict leadership competence. To this end it was explored whether EI (as measured by the SUEIT) and personality traits (as measured by the OPQ32i) would significantly predict leadership competence ratings, which was obtained through leadership assessment center technology.

While exploring how the EI construct is different from other established constructs within psychology, and what other variables it predicts, Emmerling and Goleman (2003) came to the conclusion that evidence continues to mount that suggests the construct represents a constellation 
of traits and abilities that are not fully accounted for by cognitive intelligence and traditional measures of personality. However, the evidence remains murky. Henceforth, measures of EI need to be not only meaningfully related to various indices of leadership success, but should also demonstrate that they can account for variance in leadership success not accounted for by other psychometric tools that are typically utilized in leadership recruitment (e.g. measures of personality). The question that could be asked here, and constituted the second research objective of this study, is whether EI can predict leadership competence over and above established constructs (e.g personality traits). In short, the aim was to investigate whether EI has incremental validity over personality traits in predicting leadership competencies.

Through evaluating the amount of variance in leadership competency ratings (obtained during a leadership AC) that personality and EI accounts for respectively, the type of characteristics that are emphasized as important and grown in leaders in this specific organization, to ensure successsful leadership, can be clarified.

Furthermore, proponents of intelligence research (e.g. Mayer, Caruso, \& Salovey, 2000) express caution about the use of the term "intelligence" for the EI construct. They (Mayer et al., 2000) argue that in order for a construct to be determined as intelligence, it must reflect mental performance rather than personality traits, preferred ways of behaving, or a person's self-esteem. It is therefore important to determine whether the EI construct and subsequent measurement thereof, represent something over and above that represented by personality traits and established personality measurement instruments. Therefore, the third research objective of this study was to investigate the overlap between EI and personality traits (i.e. the discriminant validity from measures of personality).

It was expected that the results of this study would demonstrate the existence of a positive relationship between EI (as measured by the SUEIT), personality traits (as measured by the OPQ32i) and leadership competence (as measured by a leadership AC). Furthermore, it was expected that the results would provide evidence that EI (and hence the SUEIT) measures something new and unique that is distinct from personality (as measured by the OPQ32i) and that it could provide a prediction of leadership competence, over and above that which is provided by 
the OPQ32i (measuring personality traits). Gaining knowledge about the nature of the relationship between EI and leadership competencies should assist organizational role players to more accurately select and develop individuals that would be successful in leadership roles. Moreover, the results should provide insight into whether EI is indeed a useful and valuable construct and tool.Therefore, the contribution of this study is to add to the body of knowledge in support of the utility of the EI construct, and specifically the SUEIT.

\subsection{THE THEORETICAL FRAMEWORK}

\subsubsection{Brief history and overview of the personality construct}

There are considerable variations among psychologists in their definitions of personality (Saville, Cramp \& Henly, 1994). Research suggest that whilst we are able to adapt our behaviour to particular circumstances, there is nevertheless considerable consistency in our behaviour across situations and over time (Saville et al., 1994). It is these consistencies in behaviour that constitute the essence of most definitions of personality.

The different definitions of personality includes amongst others, the conceptualisation of the roletheorists that regard personality as nothing more than a series of assumed roles which individuals act out in different circumstances (e.g. in Oldham, Skodol \& Bender, 2005). Carl Rogers (1959) alternatively defined personality as the 'self', a permanent subjective entity at the heart of our experiences. Rogers (1959) thus equated personality with the self-concept. In his view, the way we perceive ourselves influences both the way we perceive the rest of the world and our behaviour. Cronbach (1995), on the other hand, defines personality as a 'behavioural posture', i.e. one’s preferred style of behaviour. Lastly, Cattell (in Cattell, Eber, \& Tatsuoka, 1970), author of the $16 \mathrm{PF}$, defines personality as characteristics that allow for the prediction of behavioural outcomes in real life situations.

According to Kaplan and Sacuzzo (2001) knowledge of personality traits provides a convenient way of organising information about others - for describing how they have behaved in the past and for predicting how they will act in future. Much of the study of personality has been devoted to creating categories of traits, developing methods for measuring them, and finding out how groups of traits cluster. The concept underlying the construct of personality traits is that the 
characteristics of a person are stable over time. Some of the different ways of conceptualising and assessing personality will briefly be discussed next. The discussion includes the earlier theories of personality, i.e. the psychoanalytic conceptualization of personality by Freud, as well as the psychometric approach to the personality construct, applicable to the current study.

\subsubsection{The psychoanalytic approach to personality}

Possibly the most famous of all personality theorists was Sigmund Freud, the "Father of Psychoanalysis” (cited in Greenspan \& Pollock, 1997). Although there is little measurement in Freud's work, many more recent theorists have drawn on his ideas. Among his major theoretical contributions was the proposal that there are three main components to human personality, namely the 'id' (the primary source of psychic energy and motivation that works on the pleasure principle, seeking immediate gratification of instinctive needs), the 'ego' (operating on the reality principle, attempting to control the 'id' by postponing action until the desired object can be achieved) and the 'super ego' (developed by socialization in childhood and the moral or judicial branch of personality, enforcing control over the 'ego' by rewards and punishments such as anxiety and depression). Although the impact of Freudian theory on occupational assessment is viewed as very limited, Jung for example, was able to develop measures of personality based on the psychoanalytical theories of personality (Greenspan \& Pollock, 1997).

Jung (1910) developed a personality type theory, according to which there are four main ways in which individuals experience, or come to know the world. These include sensing (knowing through sight, hearing, touch, etc.), intuition (inferring what underlies sensory inputs), feeling (focusing on the emotional aspect of experience) and thinking, (reasoning or thinking abstractly). Jung argued, that although there is a need to thrive for balance in the four modes, each person naturally emphasise one over the others. In addition, Jung believed that one could distinguish all individuals in terms of introversion versus extroversion. Personality measures developed with Jung's theory as basis are, for example the Meyers-Briggs test developed by Katherine Briggs and Isabel Myers-Briggs (Bradley and Hebert, 1997; Fitzgerald, 1997; Kaplan and Sacuzzo, 2001). 


\subsubsection{The psychometric approach to personality measurement}

In contrast to psychoanalytic theories, which are based heavily on clinical interpretation, theories of personality rooted in the psychometric tradition are statistically derived (Saville et al., 1994). The personality theory of Hans Eysenck (1916) has been one such model. Eysenck initially proposed that there are two main dimensions of personality, namely Extroversion-Introversion and Neuroticism-Stability. Later, he added a third factor, namely Tough versus TenderMindedness or Psychoticism (Eysenck \& Wilson, 1976). Eysenck viewed the Extroversion and Stability dimensions of personality as independent of each other which makes it possible to group adults into four major types: Stable Extroverts, Unstable Extroverts, Unstable Introverts and Stable Introverts (Eysenck \& Wilson, 1976; Eysenck, 1981).

More popular than Eysenck's model in the world of work has been the model proposed by Raymond Catell (Cattell et al., 1970), which is the basis of his well known 16 Personality Factor Questionnaire (16PF). Using a statistical technique known as factor analysis, Cattell came to the conclusion that personality is best described in terms of 16 personality traits (Cattell et al., 1970).

Alternatively, several personality tests have evolved from a theoretical strategy to evaluate the self concept - the set of assumptions a person holds about him- or herself (Kaplan \& Sacuzzo, 2001). According to the self-concept theory of personality, what individuals believe to be true about themselves will strongly affect their behaviour. If they believe they are honest, then they will tend to act in conformity with this belief. If they believe they are effective with others, they will more likely assume a leadership role than if they believed they were ineffective. Furthermore, the extent to which individuals use their leadership skills or other abilities is influenced by their self-concept (Rogers, 1959; Rogers, 1980). Gough's Adjective Checklist, the Piers-Harris Children's Self Concept Scale, and Tennessee Self-Concept Scale are examples of personality measures based on this theory of the self-concept (Kaplan \& Sacuzzo, 2001). Alternatively, Carl Rogers's (1959) theory of the self gave way to a new approach to the assessment of personality. According to Rogers, the self is organised to remain consistent. New experiences, which are not consistent with a person's self-concept, are subconsciously distorted to fit a person's existing self-perception. Rogers (1959) used the Q-Sort technique to assess the self-concept conceptualised in this way. 
Recent years have witnessed a rebirth of interest in the utility of personality testing in work settings, mainly due to the emergence of a consensus on a preferred taxonomy in personality classification. The Five Factor Model (FFM) or "big five” of personality represents a taxonomy to describe the human personality sphere in a parsimonious and comprehensive way (Costa \& McCrae, 1995). It consists of the following traits: neuroticism, extraversion, openness, agreeableness and conscientiousness (Costa \& McCrae, 1995). Extraversion refers to tendencies towards sociability, assertiveness, activity and the experience of positive emotional states. Openness encompasses open-mindedness, adventure seeking, imaginativeness and broadness of interests. Agreeableness refers to the disposition to trust others, to be friendly, sensitive and altruistic. Lastly, conscientiousness reflects the tendency to be industrious, achievement striving, dutiful and disciplined (Costa \& McCrae, 1995). This model has gained acceptance as a personality model that can provide consistency across samples and contexts (Leung and Bozionelos, 2004).

\subsubsection{The occupational personality questionnaire (OPQ) model}

The OPQ model of personality is based on Saville et al.’s (1994) conceptualization suggesting that personality can be defined as, “...that which is concerned with a person's typical or preferred way of behaving, thinking and feeling in three main areas or domains” (p.5). The first domain encapsulates how an individual relates to others - the 'Relationships with People' domain (characterized by such traits as influence, sociability and empathy). Secondly, there is how an individual typically thinks, the 'Thinking Style' domain (covering traits like analysis, creativity and change and structure). Lastly there are the emotions - the 'Feelings and Emotions' domain (including traits such as energy and dynamism). The OPQ32i assesses personality across thirtytwo dimensions and is designed to examine behavioural preferences and make predictions about how these preferences will manifest in the work environment and the way a person approaches work (Saville et al, 1994).

The definition and structure of personality, discussed above, are based on a few general assumptions about the nature of personality. It includes, for example, the notion that there are definite individual differences between people that are consistent to a great extent (Saville et al., 
1994). Saville et al. (1994) furthermore argue that despite variations in individual behaviour, there will be certain behaviour styles which some individuals are likely to find difficult to adopt (Saville, et al., 1994). In this regard the desired behaviour - known to be a result of a constellation of certain personality traits - for given job activities may be difficult for some individuals to maintain (Saville et al., 1994).

\subsubsection{Personality traits and leadership success}

Various indices of human behaviour in the work place have been defined in terms of personality traits, including the behaviour of employees and subsequent organizational behavioural processes, such as leadership (e.g. Cames, Vinnicombe \& Singh, 2001; Dakin, Nilikant \& Jensen; Havaleschka, 1999; Kinder \& Robertson, 1994; Leung \& Bozionelos, 2004). Trait theories of leadership, for example, were largely designed in an attempt to predict whether an individual would be effective in a leadership role. In spite of an initial lack of research supporting the relationship between individual traits and leadership, there has been some renewed interest in trait theories (Mello, 1999).

Measures of personality have been shown to correlate with ratings of leadership effectiveness. More specifically, the 'big-five' model of personality structure is perceived to encompass some of the personality factors that best relates to leadership (Horner, 1997). For example, Leung and Bozionelos (2004) reported that certain personality traits are associated with leader emergence the probability that an individual will be perceived as an effective leader and assume a leadership position in the group, regardless of the individual's actual effectiveness in attaining group goals. They conducted systematic investigations on leader emergence with the utilization of the Five Factor Model. Extraversion was the trait that most potently and consistently related to perceptions of effective leadership (conceptualized as the transformational leadership style) (Leung \& Bozionelos, 2004). The Conscientiousness, Openness and Neuroticism dimensions have also been related to perceptions of effective leadership, but in a less potent manner (Leung \& Bozionelos, 2004). They concluded that individuals with certain personality profiles, especially profiles that include the positive poles of extraversion and conscientiousness, are more likely to be perceived as or assigned the characteristics of transformational leaders. 
Alternatively, Kinder and Robertson (1994) conducted an investigation where they focused on the relationship between personality traits and a range of competencies that are considered to be important in successful leadership and management. They explored the links between specific job competencies and the OPQ scales. The areas of job competence were grouped into 12 general criterion areas (Analysis and judgement; Planning and Organising, Innovativeness, Decision Making, Managing Staff, Persuasiveness, Interpersonal Sensitivity, Communication, Adaptability, Resilience, Energy and Resilience, and Business Sense). Kinder and Robertson's (1994) findings indicated that the Persuasive, Socially Confident and Traditional (low) OPQ dimensions have moderate relationships with the Communication competency (defined as the ability to communicate logically, clearly, effectively, and confidently). Moderate correlations were also reported between the Resilience competency (defined as emotional stability, the ability to cope under pressure) and the Change Orientated, Relaxed, Tough Minded, Emotional Control and Optimistic OPQ dimensions. The Manage Staff competency (defined as leadership, supervising, training and delegating) was found to have moderate relationships to the Persuasive, Controlling, Socially Confident and Behavioural dimensions of the OPQ. Additionally, the Energy competency (defined as achievement motivation, and the ability to follow through own ideas, being ethical, and motivated) was found to have a moderate relationship with the Achieving OPQ dimension. Strong relationships were found between the Data Rational, Conceptual, Forward Planning and Critical OPQ dimensions and the Analysis competency (defined as identifying and recognizing the causes of problems, strategic thinking, objective judgment given data, analysis of courses of action). The Innovativeness competency (defined as the ability to come up with new ideas, and to offer many alternative solutions) was also found to have a strong relationship with the Change Orientated, Conceptual and Innovative OPQ dimensions (Kinder \& Robertson, 1994). The OPQ measurment instrument was utilised in this study and therefore, special attention was attributed to explore whether these research findings could be replicated.

\subsubsection{Personality traits and EI}

Trait EI theories is one conceptualization of the EI construct that has gained considerable attention and debate in literature. According to the trait approach, EI is viewed as a dispositional tendency, which can therefore be measured by self-report questionnaires to assess cross- 
situational consistencies in behaviour, similar to normal personality traits. Both Goleman (1995) and Bar-On (1997), two of the most prominent authors in EI literature, describes the construct as a disposition or an affect rather than as a cognitive ability.

There is evidence to suggest that self-report measures of EI correlate with personality (Rosete and Ciarrochi, 2005), providing initial support for the expected results of the current study. Studies of trait EI have found moderate, and in some cases large correlations between measures of the EI construct and personality traits. Trait EI measures generally show large significant positive and negative correlations respectively, with Extraversion and Neuroticism, whilst smaller significant positive correlations with Openness, Agreeableness and Conscientiousness have also been found (Dawda \& Hart, 2000; Petrides and Furnham, 2001; Schutte, Malouff, Hall, Haggerty, Cooper, Golden, \& Dornheim, 1998). Substantial correlations with the Cattell 16PF scales have also been reported (Newsome, Day and Catano, 2000). As is evident, quite a few researchers have been investigating the overlap between personality and EI. A more substantial review of empirical findings related to the overlap between EI and personality traits will be discussed in section 1.3.1.5. At this point, however, it is important to note that the aformementioned overlap may make the interpretation of such studies difficult. This is due to the fact that research will always be questioned about whether a result involving self-reported trait EI is replicating a result obtained by using a similar personality measure. It is mostly this argument that has led to much skepticism regarding the trait EI theoretical approach, as well as the notion that objective measures of EI are unreliable. Simultaneously, however, research supporting the view that measures of personality can add significantly to the prediction of workplace success (Newsome et al., 2000), increasingly caused researchers to question the utility of the EI construct.

Opposing the abovementioned criticism, Palmer et al. (2003b) argued that some overlap between EI and personality could be expected, as it is reasonable to expect that the emotionally intelligent should be low in Neuroticism, relatively high in Extraversion, Openness, Agreeableness and Conscientiousness. In their view, the question that needs to be asked is whether EI can predict theoretically related life criteria (i.e. life satisfaction, stress, leadership success) over and above personality traits, which is well-established and validated as an aid in the selection and development of leaders in organisations (Palmer et al., 2003b). This brings the argument, once 
again, back to the fact that measures of EI need to be not only meaningfully related to various indices of leadership success, but also demonstrate that they can account for variance in leadership success, not accounted for by other psychometric tools that are typically utilized in leadership recruitment (e.g. measures of personality). The current study attempted to address this question, by investigating whether the SUEIT can account for variance in leadership competencies in a life assurance organisation, over and above the variance accounted for by a well-validated personality measure normally used for this purpose (the OPQ32i). The outcomes of this study therefore aim to provide much needed evidence for the utility of the EI construct and specifically, the SUEIT as a tool, which can be used in the recruitment, and development of leaders in organisations

\subsubsection{Emotional Intelligence}

The concept of EI goes back to early studies in the 1920's when scholars began to systematically conceptualise the idea of EI (Carmeli, 2003). Since then EI has become what Mayer, Salovey and Caruso (2000a, p. 92) referred to as, “... a designation of a zeitgeist, or cultural trend and spirit of this age, an intellectual or passionate trend." The publication of the book "Emotional Intelligence” by Goleman (1995), made popular the notion of viewing the experience and expression of emotions as a domain of intelligence. The notion of EI, which has generally been defined as the ability to perceive, understand, and manage one's emotions, has been purported by Mayer et al. (2000) to be distinct from traditional Intelligence (IQ) and crucial in predicting many real-life outcomes. For example, Ciarrochi, Chan and Caputi (2000) found that EI (operationalised by the Multifactor Emotional Intelligence Scale - MEIS) is related to life satisfaction and relationship quality when IQ and personality traits are controlled for. Similarly Salovey, Mayer, Caruso and Lopes (2001) also provided evidence that EI (operationalised by the Mayer Salovey Caruso Emotional Intelligence Test - MSCEIT) is related to patterns of substance abuse among southern California teenagers. Youths with higher EI scores were less likely to have ever smoked cigarettes or to have smoked recently, and were less likely to have used alcohol in the recent past (Salovey et al. 2001). Furthermore, the history of research on intelligence has made it clear that an individual's success in career and personal life depends not only on IQ but also on other personal factors (Derksen, Kramer \& Katzko, 2002). Conceptual arguments and initial research findings exist, relating EI to leadership success, over and above traditional 
measures used to predict this construct (i.e. IQ and personality). An overview of the early models of EI, followed by research findings on the predictive and discriminant validity of EI related to leadership, will be discussed next.

\subsubsection{Early antecedents of the EI construct}

As early as 1920, Thorndike proposed a model of intelligence which included not only the traditional intellectual factors, but also what he called social intelligence, defined as the ability to understand and manage others - to act wisely in human relations. Thorndike's (1920) definition of social intelligence has a cognitive and behavioural component. It firstly implies that the ability to understand and manage people is an intellectual capacity. Secondly it implies that this intellectual capacity is different from the abstract-verbal and concrete-mechanical aspects of intelligence (Derksen et al., 2002). Research on the social intelligence construct have been problematic - firstly - because it was difficult to define, with different researchers having different definitions; and - secondly - it was difficult to measure social intelligence in a psychometrically valid way (Derksen et al., 2002).

Several years later Gardner (1983) developed his Multiple Intelligence Theory, which combined cognitive and emotional aspects of intelligence. The Multiple Intelligence Theory consists of seven independent types of intelligence, one of which is Personal Intelligence. Personal Intelligence can be divided into Intrapersonal Intelligence (the knowledge of one's internal processes and feelings) and Interpersonal Intelligence (the ability to determine other people's reactions, needs, emotions and intentions). Following Thorndike, Gardner (1983) included social intelligence as one of the seven intelligence domains in his theory of multiple intelligences. Gardner's (1983) concept of social and personal intelligence as well as Steiner's (1984) work on emotional literacy analysis formed the basis of conceptualizing and measuring non-traditional or non-academic intellectual factors. One approach to conceptualizing and measuring nontraditional intellectual factors was the notion of "EI", first introduced by Salovey and Mayer (as cited in Mayer, Salovey and Caruso, 2000a) and popularized by Goleman (1995). After gaining considerable popularity, various conceptualizations and measurement approaches to EI emerged. The way in which these can be categorized will be discussed next. 


\subsubsection{Categorisation of different models and measures of EI}

A number of scales have been developed based on the EI theory or model and measurement approach underlying the scale. The distinction between ability, trait and mixed-personality theories of EI constitute three ways in which the term EI is used (Mayer et al. 2000 a). Trait models, e.g. the model of Bar-On (2000), are perceived to incorporate a wide range of personality variables as opposed to Mayer and Salovey's (1997) ability model, which is a strongly cognitive based definition of EI. Trait models tend to sample a broad range of individual differences and show substantial overlap with the Big Five (Daus \& Ashkanasy, 2003).

Ability models, however, have been identified as those that define EI as "intelligence" in the traditional sense (Palmer, Manocha, Gignac \& Stough, 2003). According to Mayer et al. (2000b), there has been a reassessment of exactly what mental abilities are - principally in response to the writings of Howard Gardner (Gardner, 2003). He proposed that, along with widely accepted intelligences such as verbal and spatial intelligence, other intelligences were also identified, such as physical, bodily, and personal intelligences (Gardner, 2003). Within the ability view, EI is perceived as a conceptually related set of mental abilities to do with emotions and the processing of emotional information, that are a part of and contribute to logical thought and intelligence in general. According to this framework, ability approaches to EI define the construct as the ability to solve emotional problems which is developed in childhood and can be strengthened over time (Daus \& Ashkanasy, 2003). Furthermore, this view of EI involves problem solving with and about emotions.

On the other hand, mixed models of EI have been identified as those that define EI as a mixture of emotion-related competencies, personality traits and dispositions, e.g. the SUEIT (Palmer \& Stough, 2001) and Goleman's (1995) conceptualization of EI. According to Ciarrochi et al. (2000) there are a number of other EI measures that attempt to assess not only emotional abilities, but also a number of non-ability characteristics that relate to personality, chronic mood and character (e.g. the 20-item Toronto Alexithymia Scale by Parker, Taylor and Bagby, 2003) but a discussion of these fall outside the scope of this study. 
Furthermore, measurement approaches of EI fall into three categories, namely, self-report measures of EI, informants, and performance-based (objective) measures. Self-report measures ask respondents to endorse a series of descriptive statements, indicating the extent to which these describe or do not describe themselves (Mayer et al. 2000b). Self-report measures pertaining to ability models of EI are purported to assess individuals' beliefs about their emotional abilities rather than their actual capacity (Palmer et al., 2003a). Self-report measures pertaining to trait models are believed to be embedded within the personality framework, and henceforth assess cross-situational consistencies in behaviour. An example of a measure assessing EI within this framework is the Bar-On EQi (2000). The use of informants are a second method sometimes employed to measure EI (Mayer et al. 2000b). Using informants primarily yields information about how a person is perceived by others. Some, however, argue that utilising this approach essentially only measures a person's reputation (Mayer et al. 2000b) and could thus not considered to be a valid indication of a person's EI. Thirdly, performance-based measures of EI pertain to ability models and involve a series of emotion-related questions for which there are more and less correct answers according to consensual responses. Mayer, Salovey and Caruso (1999) developed a measure, the Mayer, Salovey and Caruso Emotional Intelligence Test (MSCEIT), designed to measure EI according to this framework. Given the divergence of the available models and measures of EI, an overview of the most important models and existing scales of measurement is provided in table 1.1

Table 1.1: Summary of different EI models and measures

\begin{tabular}{|c|c|c|c|}
\hline Model & Definition of EI & Framework & Measure \\
\hline 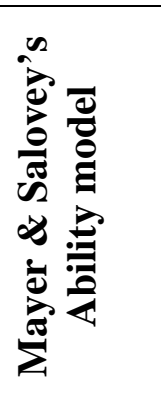 & $\begin{array}{l}\text { The ability to perceive emotions, to access } \\
\text { and generate emotions so as to assist } \\
\text { thoughts, to understand emotions and } \\
\text { emotional knowledge, and to reflectively } \\
\text { regulate emotions so as to promote } \\
\text { emotional and intellectual growth (Mayer } \\
\text { et al. 2000a). }\end{array}$ & $\begin{array}{l}\text { Four central abilities: } \\
\text { (1) Perception of emotion. } \\
\text { (2)Emotional facilitation of } \\
\text { thought. } \\
\text { (3) Understanding emotion. } \\
\text { (4) Managing emotions. } \\
\text { (Lopes, Salovey \& Straus, } \\
\text { 2003). }\end{array}$ & $\begin{array}{l}\text { (1) Multifactor } \\
\text { Emotional Intelligence } \\
\text { Scale (MEIS). } \\
\text { (2) Trait meta-mood } \\
\text { scale. } \\
\text { (3) Mayer, Salovey, } \\
\text { Caruso Emotional } \\
\text { Intelligence Test } \\
\text { (MSCEIT). } \\
\text { (Mayer et al. 2000b) }\end{array}$ \\
\hline
\end{tabular}




\begin{tabular}{|c|c|c|c|}
\hline 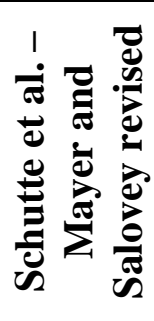 & $\begin{array}{l}\text { Schutte et al. (1998) adopted the definition } \\
\text { of Mayer et al. 2000a. }\end{array}$ & $\begin{array}{l}\text { Three dimensions, namely: } \\
\text { (1) Appraisal an expression of } \\
\text { emotion in self and others. } \\
\text { (2) Regulation of emotion in } \\
\text { self and others. } \\
\text { (3) Utilization of emotions in } \\
\text { solving problems (Schutte et } \\
\text { al., 1998). }\end{array}$ & $\begin{array}{l}\text { (1) Schutte Self Report } \\
\text { Inventory (SSRI). } \\
\text { The pool of items used } \\
\text { represent all categories } \\
\text { and components of the } \\
\text { theoretical EI model of } \\
\text { Mayer et al. (2000a). }\end{array}$ \\
\hline 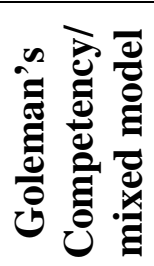 & $\begin{array}{l}\text { The ability to motivate oneself and persist } \\
\text { in the face of frustration; to control } \\
\text { impulses and delay gratification; to } \\
\text { regulate one's moods and keep distress } \\
\text { from swamping the ability to think; to } \\
\text { empathise and to hope (Goleman, 1998). }\end{array}$ & $\begin{array}{l}\text { Four general competencies: } \\
\text { (1) Self Awareness } \\
\text { (2) Self Regulation } \\
\text { (3) Motivation } \\
\text { (4) Empathy } \\
\text { (5) Social skill. }\end{array}$ & $\begin{array}{l}\text { Emotional Competence } \\
\text { Inventory (ECI) } \\
\text { (Boyatsis, R., Goleman, } \\
\text { D., and Hay/McBer, } \\
\text { 1999) }\end{array}$ \\
\hline 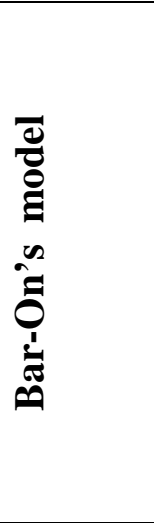 & $\begin{array}{l}\text { A multi-factorial construct, an array of } \\
\text { non-cognitive capabilities, interrelated } \\
\text { emotional, personal and social } \\
\text { competencies and skills that influence } \\
\text { one's ability to succeed in coping with } \\
\text { environmental demands and pressures } \\
\text { (Bar-On, 1997). }\end{array}$ & $\begin{array}{l}15 \text { Conceptual non-cognitive } \\
\text { variables that resemble } \\
\text { personality factors and pertain } \\
\text { to five specific dimensions, } \\
\text { namely: } \\
\text { 1) Intrapersonal EI } \\
\text { 2) Interpersonal EI } \\
\text { 3) Functioning adaptability EI } \\
\text { 4) Stress management EI, } \\
\text { 5) General mood EI (Bar-On, } \\
\text { 1997; 2000) }\end{array}$ & $\begin{array}{l}\text { Emotional Quotient } \\
\text { Inventory (EQI). } \\
\text { A self-report measure } \\
\text { that comprise } 15 \text { sub- } \\
\text { scales pertaining to the } \\
15 \text { components of Bar- } \\
\text { On's model, which } \\
\text { render } 15 \text { sub-scale } \\
\text { scores, five EI composite } \\
\text { scale scores and an } \\
\text { overall or total EI score } \\
\text { (Bar-On, 1997; 2000) }\end{array}$ \\
\hline 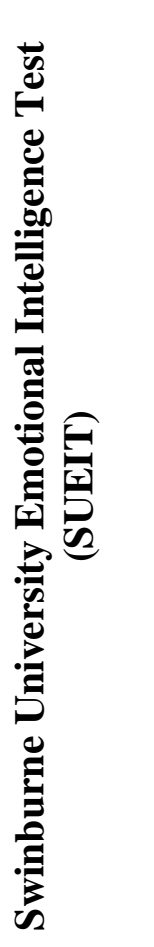 & $\begin{array}{l}\text { The capacity to deal effectively with one's } \\
\text { own and others' emotions. When applied to } \\
\text { the workplace, it involves the capacity to } \\
\text { effectively perceive, express, understand } \\
\text { and manage emotions in a professional and } \\
\text { effective manner at work (Palmer \& } \\
\text { Stough, 2001). }\end{array}$ & $\begin{array}{l}\text { Five subscales (Palmer \& } \\
\text { Stough,, 2001), including } \\
\text { (1) Emotional recognition and } \\
\text { Expression } \\
\text { (2) Emotions direct cognition } \\
\text { (3) Understanding of } \\
\text { emotions external } \\
\text { (4) Emotional management } \\
\text { (5) Emotional control }\end{array}$ & $\begin{array}{l}\text { SUEIT self-report } \\
\text { inventory and } 360^{\circ} \\
\text { version indexes the way } \\
\text { people typically think, } \\
\text { feel and act with } \\
\text { emotions at work. It } \\
\text { provides an overall score } \\
\text { that indicates an } \\
\text { individual's general } \\
\text { workplace EI and five } \\
\text { sub-scale scores that } \\
\text { indicate more specific } \\
\text { capacities according to } \\
\text { the five dimensions of } \\
\text { the model. Provides } \\
\text { insight into cross- } \\
\text { situational consistencies } \\
\text { in Emotionally } \\
\text { Intelligent behaviour in } \\
\text { the workplace and } \\
\text { underlying level of EI } \\
\text { (Palmer \& Stough, 2001) }\end{array}$ \\
\hline
\end{tabular}




\section{a) Mayer and Salovey's Ability Model of EI}

The concept of EI was first introduced by Mayer and Salovey in 1990 and since then gained considerable popularity (Ciarrochi et al., 2000). Mayer et al. (2000b) defined EI as the ability to monitor one's own and others' feelings and emotions, to discriminate among them and to use this information to guide your thinking and actions. Later on, they refined and defined EI as the ability to perceive emotions, to access and generate emotions so as to assist thoughts, to understand emotions and emotional knowledge and to reflectively regulate emotions so as to promote emotional and intellectual growth. This ability model defines EI as an "intelligence" in the traditional sense, that is, as a set of mental abilities to do with emotions and the processing of emotional information that are a part of, and contribute to, logical thought and intelligence in general (Gardner \& Stough, 2002).

Mayer and Salovey's (1997) model includes a set of three conceptually related mental processes:

1. Appraising and expressing emotions in the self and others: Individuals differ in the degree to which they are aware of their emotions (appraisal) and the degree to which the latter are verbally and non-verbally being expressed. Individuals who accurately appraise and express (perceive and respond to) their own emotions are likely to be better understood by the people they work with. They should also have the potential to better lead and manage people when they are able to perceive the emotions of the people around them and to develop the ability to understand and reexperience another's feelings (empathy).

2. Regulating emotions in the self and others: People differ in their ability to manage (monitor, evaluate, adjust to changing moods) their emotions, as well as in their ability to regulate and alter the affective reactions of others. Regulation of one's own emotions and moods results in positive and negative affective states. Emotionally intelligent individuals are adept at placing themselves in positive affective states and are able to experience negative affective states that have insignificant destructive consequences. Emotionally astute people can induce a positive affect in others that result in a powerful social influence (charisma), an important component of leadership.

3. Using emotions in adaptive ways: Individuals also differ in the ways (functional vs. dysfunctional) in which they utilize their emotions. According to this conceptualisation, emotions can firstly help in generating multiple future plans (flexible planning); secondly, 
improve the decision-making process due to a better understanding of one's emotional reaction (creative thinking); thirdly facilitate cognitive process such as creativity on the one hand and punctuality on the other hand (mood redirected attention) and lastly enhance persistence regarding challenging tasks (motivating emotions).

This theory thus provides a framework within which to investigate social and emotional adaptation, as it focuses on emotional skills that can be developed through learning and experience. It posits four central abilities (Lopes et al., 2003) namely perceiving, using, understanding, and managing emotions. They entail the following:

1. Perception of Emotion is the ability to perceive emotions in oneself and others, as well as in objects, art, and stories.

2. Emotional Facilitation of Thought is the ability to generate emotions in order to use them in other mental processes.

3. Understanding Emotions is the ability to understand and reason about emotional information and how emotions combine and progress through relationship transitions.

4. Managing Emotions is the ability to be open to emotions and to moderate them in oneself and others.

Proponents of Mayer et al.'s (1997) theory of EI state that it can be viewed as an intelligence because (a) it represent an intercorrelated set of competencies that can be statistically interpreted as a single factor with four sub factors mapping onto the four branches of the theoretical model, (b) it is distant from, but meaningfully related to abilities such as verbal intelligence and (c) it develops with age (Lopes et al., 2003)

Mayer, Salovey and Caruso $(1998,1999)$ developed of a number of tools to measure EI, as a set of mental abilities, which appears to be content and structurally valid and reliable. These include the Multifactor Emotional Intelligence Scale (MEIS), the Trait Meta-Mood Scale (TMMS) and the Mayer, Salovey, Caruso Emotional Intelligence Test (MSCEIT).

The MEIS was designed to measure the four hierarchical branches of EI (Mayer et al., 1998). Within this framework, the perception and appraisal of emotion is the most basic branch of EI 
and is measured by having people identify emotion in faces, stories, designs, and music. The second branch involves the ability to assimilate basic emotional experiences into mental life, including weighing emotions against one another as well as against other sensations and thoughts, and allowing emotions to direct attention. The third branch of EI involves understanding and reasoning about emotions. The fourth and highest branch involves the management and regulation of emotions in oneself and others, such as knowing how to calm down after feeling angry or being able to alleviate the anxiety of another person. Factor analysis of the MEIS has demonstrated that the above four branches can be reduced to three factors, namely perception and appraisal of emotion (branch 1), understanding emotions (combining branches 2 and 3), and managing emotions (branch 4) (Mayer et al., 1998).

After identifying a number of difficulties with the then existent EI related scales, Mayer et al. (1999) developed the Trait Meta-Mood Scale to measure attention to emotion, emotional clarity, and emotion repair. The TMMS was originally designed by Salovey, Mayer, Goldman, Turvey and Palfai in 1995 to evaluate “...differences in people’s tendency to attend to their moods and emotions, discriminate clearly among them and regulate them.” (Salovey et al., 1995, p. 128). As a further continuation of their work in this area, a revised research version of the MEIS, the MSCEIT, was released in 2000 by Mayer et al. (2000b), which according to Vitello-Cicciu (2002, p. 203), is shorter and more “...professionally developed”. The MSCEIT was developed to measure the four dimensions of EI as postulated by Mayer and Salovey (1997) and is based on the premise that EI involves problem solving with and about emotions.

Several studies have been conducted to examine the ability of Salovey and Mayer's model of EI to provide a prediction of theoretically related life criteria (i.e. life satisfaction, stress, drug abuse, etc.), over and above well-established measures used for this purpose, namely personality and IQ. Studies investigating the predictive validity of Mayer et al.’s (1997) ability model of EI with regards to leadership success are limited. Nevertheless, empirical findings on the general predictive and discriminant validity of the MEIS, TMMS and MSCEIT will be discussed next.

According to Mayer, Salovey and Caruso (1999) the MEIS has been used in a number of research studies to investigate its relationship with a number of important ability, personality and 
behaviour measures. Given that the Mayer, Solvey Emotional Intelligence Test (MSCEIT) is based upon an ability model of EI, the authors postulated that moderate correlations with measures of general or analytical intelligence could be expected. Consistent with their expectation, correlations between the MSCEIT total score and several scales of General Intellectual Ability emerged. This includes the Army Alpha Vocabulary Scale in three samples ( $r$ $=0.36, \mathrm{n}=503 ; r=0.38, n=239$; and $r=0.37, n=208, p<0.01)$, the Wonderlic Personnel Test ( $r=0.59, p<0.01)$, the 16PF Reasoning Scale $(r=0.18, p<0.05$ ), self reported grade point average $(r=0.53, p<0.01)$ and self reported intelligence $(r=0.38, p<0.01)$ (Mayer, et al., 1999). They also report various correlations between the MSCEIT and different personality scales. Firstly, the Extroversion $(r=0.26, p<0.01)$ and Open to Feelings $(r=0.24, p<0.01)$ dimensions of the NEO and secondly, the Sensitivity ( $r=0.22, p<0.01)$, Vigilance $(r=-0.17, p$ $<0.05$ ), Self-Reliance ( $r=-0.14, p<0.05)$, Extraversion $(r=0.16, p<0.05)$, and Tough Minded $(r=-0.19, p<0.05)$ dimensions of the $16 \mathrm{PF}$ (Mayer et al., 1999).

A study conducted by Rice (1999) exploring the relationship between a shortened version of the MEIS and team leaders' ratings obtained during performance appraisals indicated a positive correlation between EI and team leader performance $(r=0.51, p<0.01)$. The average MEIS scores of each of the teams, the 'team EI', were also related to the manager's ratings of the team performance in customer service $(r=0.46 p<0.01)$. This provides preliminary evidence for the usefulness of EI (as measured by the MEIS) in workplace situations specifically related to team leaders and effective customer service (Rice, 1999).

Ciarrochi et al. (2000) critically evaluated the EI construct (as measured by the MEIS) by examining it's predictive validity with regards to theoretically related life criteria (i.e. empathy and relationship quality, life satisfaction and parental warmth) when other well-established measures were controlled for (i.e. personality - the NEO-PI-R, and IQ - Raven's standard progressive matrices test). They found that total EI (as measured by the MEIS) did not correlate significantly with IQ (as measured by the Raven's standard progressive matrices test), $(r=0.05$, $\mathrm{p}>.01)$, while correlations with Empathy $(r=0.43)$, Extraversion $(r=0.26)$, Openness to Feelings $(r=0.24)$, and Self Esteem $(r=0.31)$ were significant $(p<.005)$. Correlations between Overall EI and Neuroticism $(r=0.04)$ and Openness to Aesthetics $(r=0.09)$ were non- 
significant. In addition it was found that overall EI was significantly related to Life Satisfaction ( $r$ $=0.28)$ and Relationship Quality $(r=0.19)$.

They also addressed the issue of whether EI relates to the abovementioned life criteria after controlling for IQ and personality variables. Partial correlations were computed between the EI variables and Relationship Quality, Life Satisfaction and Parental Warmth, while controlling for IQ and various personality variables (Extraversion, Neuroticism, Empathy, Openness to Feelings and Self-Esteem). A significant relationship $(p<0.05)$ was found between Overall EI and Relationship Quality ( $r=0.22)$, Life Satisfaction $(r=0.19)$ and Parental Warmth $(r=0.22, p<$ 0.05). The remaining partial correlations were non-significant $(p>0.1)$ (Ciarrochi et al., 2000). These findings provide support for Ciarrochi et al.'s (2000) proposition that EI, generally, relates to variables it ought to relate to (i.e. Relationship Quality, Life Satisfaction, Parental Warmth, etc.) The result also provide support for the discriminant validity of EI, in that EI explains variance in real-life criteria after well-established measures (i.e. IQ and personality) are controlled for, suggesting that EI is a distinctive and useful construct.

Palmer, Donaldson and Stough (2002) examined the relationship between EI (measured with the TMMS and 20-item Toronto Alexithymia Scale - TAS-20) and life satisfaction (measured with the Satisfaction With Life Scale - SWLS). To determine the nature of this relationship, personality constructs known to predict life satisfaction were also assessed. Only the Clarity subscale $(r=0.45, p<0.001$ ) of the TMMS (which indexes perceived ability to understand and discriminate between moods and emotions), and the Difficulty Identifying Feelings ( $r=-0.32, p$ $<0.01$ ) sub-scale of the TAS-20 were found to significantly correlate with life satisfaction. Subsequent analysis revealed that only the Clarity sub-scale accounted for further variance in life satisfaction not accounted for by positive and negative affect. This finding provided further evidence that components of the EI construct account for variance in human behaviour not accounted for by personality. Palmer et al. (2002) suggested that future research should compare measures of EI with measures of personality in predicting other theoretically related variables, known to play an important role in occupational success. This provided further support for the merit of the current study, which aimed to explore how EI relates to leadership success in an organizational setting, when personality traits are controlled for. 
Lopes et al. (2003) explored the links between EI (measured as a set of abilities) and personality traits, as well as the contribution of the perceived quality of one's interpersonal relationships. They found that both EI and personality traits were associated with concurrent self-reports of satisfaction with social relationships. Individuals scoring highly on the managing emotions subscale of the MSCEIT, were more likely to report positive relations with others, as well as perceived parental support and less likely to report negative interactions with close friends. These associations remained statistically significant even when controlling for significant Big Five personality traits (NEO-FFI) and verbal intelligence (WAIS III) (Lopes et al., 2003). Henceforth, the authors concluded that the study provides preliminary evidence for the convergent, disciminant and incremental validity of EI in relation to verbal intelligence and personality measures. There was a general pattern of low correlations between scores on the EI test, on the one hand, and personality traits and verbal intelligence on the other hand. Furthermore, EI showed significant correlations with several indicators of quality of social interaction. These findings provided some evidence of both the convergent and discriminant validity of the MSCEIT, whilst Multiple Regression Analysis provided preliminary support for the incremental validity of the MSCEIT in relation to personality and verbal intelligence.

O’Connor and Little (2003) conducted a study to determine whether EI (operationalised by both the MSCEIT and the Bar-On EQ-i) predicts academic achievement. Result indicated that EI is not a strong predictor of academic achievement regardless of the type of instrument used to measure it. However, a construct validity examination revealed that the MSCEIT correlated highly with indices of cognitive ability (ACT and 16PF reasoning test), but minimally with personality (operationalised by the 16PF) dimensions. Significant correlations were found between the MSCEIT total score and 16PF Reasoning (which provides an indication of cognitive functioning) ( $r=0.24, p<0.01)$. In contrast, the Bar-On EQ-i failed to correlate with indices of cognitive ability but correlated substantially with numerous personality dimensions. Significant correlations were indicated between the EQ-i total scores and Extraversion $(r=0.34, p<0.01)$, Anxiety $(r=-0.76, p<0.1)$ and Independence $(r=0.43, p<0.05)$ as measured by the 16PF. The MSCEIT total score was only correlated with the 16PF dimension of Anxiety $(r=-0.24, p<$ 0.05). In addition, most of the scale scores for the MSCEIT were not related to 16PF dimensions 
(O’Connor and Little, 2003). O'Connor and Little (2003) came to the conclusion that EI (measured by the MSCEIT) represents a construct that is not significantly related to personality, but rather to cognitive intelligence, whereas EI (measured by the Bar-On EQ-i) is closely related to personality traits.

Other researchers, Day and Carroll (2004), explored the predictive validity of the MSCEIT with regards to performance on a work-related cognitive decision-making task on a managerial level. They also looked at its relationship to citizenship behaviour. Additionally they investigated the MSCEIT's discriminant validity from measures of personality (operationalised by the NEO-FFI). Openness to experience was the only personality scale that was related to all four MSCEIT scales ( $r$ ranged from 0.13 to 0.23 , all significant at $p<0.05$ ). Extraversion was related to Emotional Understanding and Integration ( $r=-0.15, p<0.05 ; r=-0.11, p<0.05$ respectively) and Agreeableness was related to Emotional Management $(r=0.16, p<0.01)$. Neuroticism was only related to emotional perception $(r=-0.11, p<0.05$ ). Conscientiousness was unrelated to all four MSCEIT scales (Day and Carroll, 2004). With regards to EI and individual and group performance, only the Emotional Perception Scale of the MSCEIT correlated with individual task performance $(r=0.17, p<0.01)$. None of the other four MSCEIT scale scores correlated with overall group performance. Alternatively, none of the correlations between an individual's citizenship behaviour and the MSCEIT subscales were significant. Day and Carroll (2004) concluded that although they found some evidence for the construct validity of the MSCEIT, its criterion-related validity was weak. Therefore, they concluded that it might be premature to use EI (operationalised by the MSCEIT) as a decision-making tool in an organizational setting, until its validity as a predictor of work-related behaviours is established. Henceforth, the value of the current study is embedded in the exploration of the relationship between EI and successful leadership, specifically in order to help validate the utility of EI (as operationalised by the SUEIT) as a decision-making tool in the organizational setting.

This review on the ability based EI measure is concluded with a look at a study by Rosete and Ciarrochi (2005). These researchers investigated the relationship between EI (the MSCEIT), personality (16PF), cognitive intelligence (Wechsler Abbreviated Scale of Intelligence - WASI), and leadership effectiveness (using an objective measure of performance, a performance 
management system and a $360^{\circ}$ assessment). Correlational and regression analyses revealed that higher EI scores were associated with higher leadership effectiveness, and that EI explained variance in leadership effectiveness not explained by either personality or IQ. A relationship between the total EI score and leadership performance ratings was indicated by the results ( $r=$ 0.384, $p<0.05$ ), supporting the notion that EI is related to a leaders' effectiveness in being able to achieve organizational goals. Furthermore, significant correlations amongst various branches of the EI construct and the multi-rater leadership instrument were indicated. Stepwise Regression Analysis revealed that the MSCEIT dimension, Perceiving Emotions, contributed most significantly to the prediction of performance measures of leadership effectiveness. To investigate the incremental value of Perceiving Emotions, hierarchical regression was conducted entering the Big Five personality factors and cognitive intelligence first and Perceiving Emotions second. According to the results, Perceiving Emotions predicted performance measures of leadership effectiveness, over and above the other variables. None of the other variables predicted significant variance. No significant correlations were found between the total EI score and any of the 16PF factors. Small correlations were found between total EI and Warmth $(r=0.37)$, Vigilance $(r=-0.33)$ and Privateness $(r=-0.38)$ and Understanding Emotions at the $p<0.05$ levels. Similarly, Warmth $(r=0.32, p<0.05)$, Social Boldness $(r=0.31, p<0.05)$ and Privateness $(r=-0.44, p<0.01)$ correlated with Managing Emotion. Only Vigilance $(r=-0.33$, $p<0.05)$ correlated significantly with Perceiving Emotion. They came to the conlusion that EI (measured by the MSCEIT) is not significantly related to personality dimensions (as measured by the 16PF) (Rosete \& Ciarrochi, 2005). This finding confirmed the findings made by O'Connor and Little (2003) discussed previously. Correlations were found between EI and verbal and performance IQ, suggesting that the MSCEIT and hence the ability-based EI construct, does constitute a cognitive ability. The results of this study show that EI may be useful in identifying and distinguish between leaders likely to deal effectively with colleagues and staff. It also indicates that the MSCEIT has incremental value over personality, showing that the MSCEIT is distinguishable from personality (Rosete \& Ciarrochi, 2005).

\section{b) Goleman's Competency Model of EI}

Goleman (1998, p. 93) defined EI as, “...the ability to motivate oneself and persist in the face of frustration, to control impulses and delay gratification, to regulate one's moods and keep distress 
from swamping the ability to think, as well as the ability to empathise and hope”. According to this framework, EI consists of the components of self-awareness, self-regulation, motivation, empathy, and social skill (Goleman, 1998).

According to Gardner and Stough (2002) the competency-based model of EI by Goleman (1998) is specifically designed for workplace applications. It is described as a mixed model of EI that involves five first order and 20 second order competencies (a learned capability based on EI that results in outstanding performance at work) that distinguish individual differences in workplace performance. Goleman's (1998) five EI competencies can be divided into two groups. The first three competencies are self-management skills. The last two concern a person's ability to manage relationships with others. The five competencies are as follows:

1. Self-Awareness, which is defined as the ability to recognize and understand your own moods, emotions, and drives, as well as their effect on others. Self-awareness also encapsulate the ability to make an accurate self-assessment, which stems from having to have a deep understanding of one's emotions, strengths, weaknesses, needs, and drives.

2. Self-Regulation, which encapsulates the ability to manage internal states, impulses and resources. Self-regulation furthermore includes the propensity to consider the impact of one's behaviour, before acting.

3. Motivation includes a passion to work for reasons that go beyond money or status. It includes the drive to achieve beyond expectations. Being motivated by a deeply embedded desire to achieve, for the sake of achievement, forms part of this definition.

4. Empathy is defined as the ability to understand the emotional makeup of other people and thoughtfully considering their feelings - along with other factors - in the process of making intelligent decisions. Empathy furthermore encapsulates the skill of treating people according to their emotional reactions.

5. Social Skills centres around an individual's adeptness at inducing desirable responses in others, including wielding effective tactics for persuasion, listening openly and sending convincing messages, negotiating and resolving disagreements, inspiring and guiding individuals and groups, initiating or managing change, nurturing instrumental relationships, working with others toward shared goals and creating group synergy in pursuing collective goals 
Daniel Goleman and Richard Boyatzis developed a test entitled the Emotional Competence Inventory (ECI, based on Goleman's 1998 Emotional Competence Theory). The tool allows a person to self evaluate his EI competence, as well as obtain a $360^{\circ}$ assessment from other individuals based on the five aforementioned competencies. Gardner (2003) criticized Goleman for departing from the scholarly sense of EI, stating that the empirical basis for the claimed predictive validity of his EI model and the Emotional Competence Inventory could be questioned. Nevertheless, some of the work related to the instrument will be discussed next.

Goleman (1998) analyzed competency models from 188 corporate companies in order to determine which personal capabilities drove certain leaders to perform more effectively than others. His findings indicated that generally, intellectual capabilities can be considered as a driver of outstanding performance, including cognitive skills such as big-picture thinking and long-term vision. Nevertheless, he claimed that EI proved to more important than IQ for effective performance in jobs at all levels. Goleman (1998) moreover claims that his analysis showed that EI played an increasingly important role at the highest levels of the company, where differences in technical skills are of negligible importance.

Cavallo and Brienza (2001) conducted a study to determine if there are specific EI competencies (as operationalised by Goleman's theory of EI) that distinguish high performers from average performers. The results revealed that supervisors rated high-potential leaders significantly higher on the Self Awareness, Self-Regulation, and Social Skills dimensions of the ECI (Cavallo and Brienza, 2001). The study also revealed a strong relationship between superior performing leaders and emotional competence on the ECI, supporting the suggestion that EI is a distinguishing factor in leadership performance. These findings linking EI, and specifically, Goleman's (1998) model of EI to successful leadership, provide preliminary evidence for the predictive validity of the EI construct and tool, according to Goleman's theory.

\section{c) The Schutte Self-Report Inventory (SSRI)}

The SSRI is a self-report measure that was developed and validated by Schutte, Malouff, Hall, Haggerty, Cooper, Golden and Dornheim (1998). The conceptual framework for this measure 
was based on the original and revised EI model of Mayer et al. (1997), which they believed to be the most cohesive and comprehensive model of EI at that time (Schutte et al., 1998).

Scale items were developed that represented each of the following categories: appraisal and expression of emotion in the self and others, regulation of emotion in the self and others and utilization of emotions in solving problems (Schutte et al., 1998). The 33-item mixed EI model scale developed through factor analysis showed good internal reliability and test-retest reliability. The scale also showed evidence of discriminant validity. It proved to not be significantly related to four of the big five personality dimensions (Schutte et al., 1998). This finding served as initial proof that EI, is a new construct that is unique from personality traits. Schutte et al. (1998) concluded that the findings indicate that the scale holds promise as a reliable, valid measure of EI as conceptualized by Mayer et al. (2000b).

Saklofske, Austin and Minski (2003) investigated the ability of EI (measured by the SSRI) to predict a range of outcomes that are theoretically related to it (i.e. life satisfaction, subjective happiness and depression proneness). Furthermore, the relationship between EI and personality traits, as well as the incremental validity of EI over personality traits in the prediction of the abovementioned outcomes were also investigated. The results indicated a negative relationship between EI, loneliness and depression-proneness as well as positive relationships with subjective happiness and life satisfaction. The total EI scores were found to be negatively and significantly correlated with Neuroticism ( $r=-0.37, p<0.001)$ and positively and significantly with Extraversion ( $r=0.51, p<0.001)$, Openness $(r=0.27, p<0.001)$, Agreeableness $(r=0.18, p<$ $0.01)$ and Conscientiousness $(r=0.28, p<0.001)$. Regression analysis indicated that EI accounted for variance in the abovementioned life outcomes when personality traits were controlled for, indicating that personality and EI are distinctive, although strongly correlated. This provides preliminary evidence for the discriminant validity of the SSRI. The current study aims to partially replicate the findings of Saklofske et al. (2003). This would be valuable, because similarly to the SUEIT, the SSRI is a mixed model of EI.

\section{d) The Bar-On model and theory of EI}

Bar-On (1997) defines EI as an array of non-cognitive capabilities, interrelated emotional, personal, and social competencies and skills that influence one's ability to succeed in coping with 
environmental demands and pressures. According to Bar-On (1997), EI is an important factor in determining one's ability to succeed in life and has a direct influence on an individual's general well being. It is generally reported that the Bar-On EQ-i was one the first researched psychometric test for EI.

Bar-On's (1997) conceptualization of EI encapsulates individuals' ability to effectively understand and express themselves, to understand and relate well to others and to successfully cope with daily demands and pressures. This ability to understand and express emotions is based on an individual's intrapersonal ability, which means to be aware of yourself, to understand your strengths and weaknesses, and to express thoughts and feelings non-destructively. On the interpersonal level, being emotionally and socially intelligent encompasses the ability to be aware of others' emotions, feelings and needs, and to establish and maintain cooperative, constructive and mutually satisfying relationships. According to Bar-On (2003), ultimately being emotionally and socially intelligent means to effectively manage personal, social and environmental changes by coping with the immediate situation and solving problems realistically and flexibly (Bar-On, 2003).

Bar-On (2000) has operationalised his theory of EI according to 15 conceptual components that pertain to five specific dimensions of emotional and social intelligence. These are, Intrapersonal (representing abilities, capabilities, competencies and skills pertaining to inner self), Interpersonal (representing interpersonal skills) and Functioning Adaptability (representing how successfully one is able to cope with environmental demands by effectively sizing up and dealing with problematic situations), Stress Management (concerning the ability to manage and cope effectively with stress) and General Mood (pertaining to the ability to enjoy life and to maintain a positive disposition). The 15 components of the model are described as non-cognitive variables that resemble personality factors.

As with other self-report measures of EI, the EQ-i is described to provide an index of crosssituational consistencies in (emotionally and socially) competent behaviour and as such, provides an estimate of an individual's EI. According to the EQ-i technical manual, the test has relatively good internal consistency and test-retest reliability scores not unduly influenced by response 
styles (Bar-On, 1997). Vitello-Cicciu (2002) also points out that one should note that these factors relate to personality traits and even mood states and not necessarily to the ability to perceive, use, understand, and manage emotions as Mayer et al., (2000b) envisioned. The resemblance to personality factors once again leads to the question of the discriminant validity of EI and more specifically to the EQ-i.

In the Bar-On EQ-i (1997) technical manual it is argued that non-cognitive intelligence (as measured by Bar-On's EQi) is not merely another form of cognitive intelligence (as measured by IQ). The total EQ-i scale demonstrated a very low correlation with IQ $(r=0.12)$ in a North American sample of 40 subjects who completed the EQ-i together with the Wechsler Adult Intelligence Scale (WAIS). Total EQ $(r=0.13)$ and the Problem Solving subscale $(r=0.15)$ did also not significantly correlate with Factor B of the 16PF, which measures abstract versus concrete thinking based on questions that tap verbal, numerical, and logical reasoning. This indicates the distinctiveness of the EQ-i from more "cognitive” measures (Bar-On, 1997).

Bar-On (1997) reported significant correlations between many sub-scales of the EQ-i and the 16PF. In data presented to support the construct validity of the EQ-i, correlations between the Emotional Stability (16PF dimension) and total EQ-i score ranged from 0.51 to 0.72 in several studies (Bar-On, 1997). Furthermore, Emotional Stability significantly correlated with Optimism ( $r=0.65)$, Stress Tolerance $(r=0.67)$, and Self-Regard $(r=0.64)$. This indicates the EQ-i's questionable discriminant validity from other measures of personality.

Newsome et al. (2000) conducted a study to determine the incremental validity of the Bar-On EQ-i in prediciting academic achievement, over and above personality traits (operationalised by the 16PF) and cognitive ability (operationalised by the Wonderlic Personnel Test). They found that none of the EQ-i dimensions, nor total EQ was significantly related to academic achievement, while high multicollinearity was indicated among the dimensions of the EQ-i and the 16PF factors (Newsom et al., 2000). With the exception of the Tough-Mindedness factor, all of the 16PF factors (i.e. Extraversion, Anxiety, Independence, Self Control) emerged to be significantly correlated with the EQ-i total score and the five EQ-i composite scores ( $r=0.18$ to 0.77 , all significant at $p<0.05$ ). The Anxiety dimension of the 16PF was highly correlated with 
the Total EQ-i score $(r=-0.77, p<0.001)$ and with its five factors $(r=-0.38$ to $r=-0.71, p<$ 0.001). This indicates that individuals who are low on EI also tend to be highly anxious and neurotic. According to Newsom et al. (2000) these findings indicate considerable overlap in what the two scales are measuring. They argued that self-report EI, as measured by the Bar-On EQ-i, tends to be indistinguishable from established personality traits. Further to this they argued that, even if one accepts Bar-On' dispositional view of EI, the 16PF still did a better job of prediction of academic achievement (Newsome et al., 2000). Given that neither the total score nor the five factors scores of the EQ-i were significantly correlated with academic achievement, the incremental validity of the EQ-i was not investigated further. Newsome et al. (2000) concluded that there was inadequate data, at that time, to justify the use of EI and the EQ-i as a selection tool and that it was premature to use measures of EI as decision-making aids. Further research is thus necessary in order to better understand, define, and measure the construct of EI (specifically from a mixed model perspective, as is the purpose of the current study.

A study by Stuart and Paquet (2001) investigated the predictive validity of EI (operationalised by the Bar-On EQ-i) by comparing the EI scores of employees (from a financial institution) who displayed leadership potential, with scores of a group who displayed little leadership potential. Leadership was rated by ascertaining the presence of transformational behaviour. Statistically significant differences were indicated between leaders and non-leaders. The Positive Impression, Self-Actualisation, Self Regard and Optimism (EQ-i dimensions) made statistically significant contributions to the discrimination between the two criterion groups. Results indicated that the Optimism and Self-Actualisation (EQ-i) dimensions were significantly higher for the leader group. Together these results provide evidence for the predictive validity of EI in leadership, pertaining specifically to the abovementioned EQ-i dimensions.

Sivanathan and Fekken (2001) investigated transformational leadership by evaluating its associations with EI (measured with the Bar-On EQi), moral reasoning and leader effectiveness. Regression analysis was conducted to investigate the influence of EI and moral reasoning on transformational leadership. The authors report that the results revealed that EI significantly accounted for variance in transformational leadership, indicating that leaders reporting greater EI were perceived to display greater transformational behaviour (Sivanathan \& Fekken, 2001). 
Rahim and Minors (2003) conducted a study where they explored the relationships of three dimensions of EI (Self-Awareness, Self-Regulation and Empathy) to leaders' concern for the quality of products and services, as well as problem-solving behaviour of subordinates during conflict. The results of the Hierarchical Regression Analysis showed that Self-Awareness and Self-Regulation were positively associated with Problem Solving. Self-Regulation was positively associated with concern for quality, providing partial evidence for the predictive validity of these EI dimensions of the Bar-On EQ-i. There was a marginally significant main effect for Empathy on quality and an interaction effect of Self-Regulation and Empathy on concern for quality. The authors note that the implications of this study could be that supervisors, who are 'deficient' in EI, should be provided with appropriate training as it should improve their concern for quality and problem solving (Rahim \& Minors, 2003).

Palmer et al., (2003b) documented research findings on the EQ-i's discriminant validity from personality traits. They point out that the study by Newsome et al (2000) reported numerous correlations between personality factors of the 16PF and the five EQ-i composite scores. The highest correlation in this study was between the total EQ scale score of the EQ-i and the Anxiety factor of the $16 \mathrm{PF}$, leading these researchers to conclude that the EQ-i is largely a measure of neuroticism (Palmer et al., 2003). Given this overlap with personality, Palmer et al., (2003) concluded that it is possible that the EQ-i may be predicting theoretically related life criteria because it is measuring personality traits and dispositions known to account for these important human values. They therefore argued that the discriminant validity of the EQ-i from personality traits and dispositions, and indeed whether it accounts for variance in life satisfaction, job

performance and psychological well-being not accounted for by well established personality traits, has not yet been empirically substantiated and needs be addressed by future research. This conclusion supports the value of this study, i.e. adding to the body of knowledge with regards to the discriminant validity of EI measures from measures of personality.

\subsubsection{The "problem" of multiple theories of EI}

As can be seen from the different conceptualizations and measures of the EI construct presented above, there exists not one, but several theories within the EI paradigm. The construct validity - 
the extent to which the items accurately reflect or measure the behaviour of interest (Elmes, Kantowitz \& Roediger, 1999) - therefore becomes problematic in the sense that the content of EI tests vary greatly due to the fact that interpretations of the meaning of the term EI vary widely (Mayer et al., 2000b). In the view of Emmerling and Goleman (2003), some might argue that the goal of research should be to identify and define a singular theoretical framework to be labeled as the "correct" version of EI, however, another approach would be to acknowledge that having multiple theories can often serve to elucidate additional aspects of complex psychological constructs. Furthermore, they perceive the existence of several theoretical viewpoints within the EI paradigm, as not indicative of a weakness, but rather the robustness of the field. They (and others) also point out that although definitions within the field of EI vary; they tend to be complementary rather than contradictory (Ciarrochi et al., 2000; Emmerling and Goleman, 2003). Ultimately, all theories within the EI paradigm seek to understand how individuals perceive, understand, utilize and manage emotions in an effort to predict and foster personal effectiveness (Emmerling \& Goleman, 2003).

Gardner and Stough (2002) also acknowledged the fact that a large number of variables have been placed under the banner of EI and that reviews in this domain have branded EI as a popular but elusive construct with fuzzy boundaries. Given this ambiguity they argued that there would be utility in developing a measure of EI that provides an assessment of the most definitive dimensions of the construct (Stough et al., 2002). They viewed extant measures as either too narrow in focus (e.g. Trait Meta Mood Scale), or too broad (Bar-On EQ-i). At the time, common elements of the construct have not been identified, as there was no consensual definition of the term "EI" and boundaries of the construct had not been established (Palmer et al., 2003a). Toward this goal they developed the workplace Swinburne University Emotional Intelligence Test (SUEIT), designed to assess five core dimensions of EI, determined from a large factor analytic study involving six of the predominant models and measures of EI at that time (Palmer et al., 2002).

\subsubsection{Palmer and Stough's model of EI}

Palmer and Stough (2001) define EI as the capacity to deal effectively with you own and others' emotions which involves the capacity to effectively perceive, express, understand and manage 
emotions in a professional and effective manner at work. To identify the most definitive measures of EI, Palmer and Stough (2001) performed a large factor analytical study involving six of the predominant models and measures of EI including: (1) the Mayer, Salovey and Caruso Emotional Intelligence Scale (MSCEIT, Mayer et al., 1999); (2) the Bar-On Emotional Quotient Inventory (Bar-On, 1997); (3) the Trait Meta-Mood Scale (Mayer et al., 1998); (4) the twenty-item Torronto Alexithymia Scale-II (Parker et al., 2003); (5) the scale by Schutte et al (Schutte et al., 1998); and finally, (6) the scale by Tett et al. (1997, cited in Palmer \& Stough, 2001). According to Palmer and Stough (2001) this battery of EI measures was fairly representative of the various models and measures of EI available at that time and thus constituted a valid platform from which to determine the most definitive dimensions of the EI construct. Two Australian normative databases have been established; (1) general workplace norms comprising a large number of individuals all at a general level in the workplace and (2) executive workplace norms, comprising a large number of individuals all at a senior executive level or above in the workplace.

Based on the empirically derived five-factor model of EI, they developed the workplace Swinburne University Emotional Intelligence Test (the SUEIT), a self-report inventory that indexes the way people typically think, feel and act with emotions at work. It provides an overall score that indicates an individual's general workplace EI and five sub-scale scores that indicate more specific capacities according to the five dimensions of the model (Palmer \& Stough, 2001). The five subscales that the test include are (1) Emotional Recognition and Expression, (2) Emotions Direct Cognition, (3) Understanding of Emotions External,(4) Emotional Management, and (5) Emotional Control.

The SUEIT comprises both self-report and 360-degree rating forms and five sub-scale scores are provided that indicate an individuals' capacities according to the five dimensions of the model (Palmer et al., 2003a). In summary, the test provides insight into cross-situational consistencies in emotionally intelligent behaviour in the workplace and hence one's underlying level of EI. The SUEIT was utilized to assess EI in this study. The psychometric properties of the instrument will be discussed at a later stage. 
According to Palmer et al. (2003a) the discriminant validity of EI from measures of personality is especially challenging for self-report measures of EI. Therefore, several studies have focused on investigating this. The available empirical research on the predictive and discriminant validity of EI, as operationalised by the SUEIT, will be discussed next.

Gardner and Stough (2002) conducted a study to determine whether EI measured by the SUEIT predicted transformational, transactional and laissez-faire leadership styles measured by the multifactor leadership questionnaire (MLQ) (Bass \& Avolio, 2000). Effective leaders were identified as those who reported transformational, rather than transactional behaviours. A strong positive relationship was found between transformational leadership and total EI scores $(r=$ $0.675, p<0.01)$, a negative relationship between total EI and laissez-faire leadership $(r=-0.464$, $p<0.01$ ) and no relationship between total EI and transactional leadership. EI correlated highly with all components of transformational leadership. The strongest correlation was found between Individual Consideration and Understanding Emotions External $(r=0.585, p<0.01)$. Total EI and the five components of EI correlated moderately with the Contingent Rewards dimension of transactional leadership, whilst Contingent Rewards correlated most highly with the Understanding Emotions External dimension of EI $(r=0.557, p<0.01)$. Each outcome of leadership (extra effort, effectiveness and satisfaction) correlated significantly with the five EI dimensions. Outcomes of leadership as a whole produced a strong positive correlation with total EI $(r=0.572, p<0.01)$, with Understanding Emotions External producing the highest correlation of all the EI dimensions with outcomes of leadership. The dimensions of Understanding Emotions External and Emotional Management emerged as the best predictors of the transformational leadership style. The findings of this study provide evidence for the utility of EI, as measured by the SUEIT, in identifying effective leaders. Preliminary evidence was provided for the utility of the workplace SUEIT as a tool for the selection of leaders, as it seems that the SUEIT assesses five competencies of EI that appear integral to effective leadership. Future empirical research was suggested to achieve a fuller understanding of the relationship between the SUEIT dimensions and workplace behaviours (e.g. leadership) in different cases of organizational culture, climate and performance. The current study aims to partially address this objective in the sense that the relationship between the SUEIT dimensions and dimensions 
identified as crucial for leadership success (i.e. leadership competencies) will be explored within the context of a South African life assurance organisation.

In a study conducted by Palmer et al. (2003b), correlations in three samples between the SUEIT and the Neuroticism, Extraversion, and Openness to Experience facets of the NEO personality scale were investigated. In the first sample, they found small to moderate negative correlations between Neuroticism and all five SUEIT sub-scales (Palmer et al, 2003). These correlations ranged from $r=-0.207, p<.001$ between Neuroticism and Emotions Direct Cognition to $r=$ 0.436, $p<.001$ for Neuroticism and Emotional Management (Palmer et al., 2003). Small positive correlations were found between Extraversion and Emotional Recognition and Expression $(r=$ 0.210, $p<0.001)$ and Openness and Emotional Recognition and Expression $(r=0.211, p<.001)$. In sample two only small correlations were found between scores on the SUEIT and Neuroticism , Extraversion and Openness. Small negative correlations were found between Neuroticism and all five SUEIT sub-scales ranging from $r=-0.09$ for Emotional Recognition and Expression to $r$ $=-0.177$ for Understanding Emotions (Palmer et al., 2003). These correlations suggest that the subscales from the SUEIT are distinct from the Neuroticism personality trait, which is a good result, as correlations between this personality trait and the Bar-On EQi dimensions were found to be problematic. In sample 3 they found moderate correlations between the SUEIT and some of the five facets assessed by the NEO FFI (Palmer et al, 2003). In particular, Emotional Management was found to correlate $r=-0.636,0.534$ and 0.466 with Neuroticism, Extraversion and Openness respectively. Similarly, there were moderate correlations between Understanding Emotions and Openness $(\mathrm{r}=0.422)$ and between Emotional Control and Conscientiousness $(\mathrm{r}=$ 0.495). These correlations suggest considerable overlap between some of the SUEIT subscales and facets of personality. They conclude that this finding suggests that the relationship between EI and personality differs according to sample type and that in order to substantiate the relationship between EI and personality, large representative population samples are required (Palmer et al., 2003).

Gardner and Stough (2003), furthermore, investigated the relationship between scores on the SUEIT, the MLQ and personality traits (the NEO-FFI) in order to determine whether EI accounts for additional variance in successful leadership over an above measures of personality. The 
results revealed moderate correlations between the SUEIT and some of the five facets assessed by the NEO-FFI. In particular Emotional Management was found to correlation $r=-0.63,0.53$, and 0.46 with Neuroticism, Extraversion and Openness respectively $(p<0.01)$. Moderate correlations were also found between Understanding Emotions and Openness $(r=0.42)$ and between Emotional Control and Conscientiousness ( $r=0.49)$. Gardner and Stough (2003) argued that these correlations suggest some overlap between some of the SUEIT subscales and facets of personality. Facets of the SUEIT and the NEO-FFI were alternatively found to significantly correlate with transformational and laissez-faire leadership, while neither correlated with transactional leadership (with the exception of Openness for which there was a small negative correlation) (Gardner \& Stough, 2003). Regression analysis revealed that Understanding Emotions External was the most important predictor of transformational leadership. Gardner and Stough (2003) concluded that this result suggested that EI as measured by the SUEIT, specifically the capacity to perceive and understand the emotions of others, accounted for most of the variance in transformational leadership. Alternatively, this EI dimension proved to predict transformational leadership over and above dimensions of normal personality. This study provided preliminary evidence for the utility of the SUIET as a workplace measure of EI, in spite of some overlap between the SUEIT and personality (Gardner \& Stough, 2003). The current study seeks to replicate these findings in the South African life assurance context with ' $\mathrm{n}$ different conceptualization of leadership (leadership competencies) and personality (the OPQ32i) to broaden the understanding of the EI construct and its relationship to leadership success.

\subsubsection{Leadership}

From the discussion about the empirical findings relating to the relationship between EI and organizational leadership, it is evident that the leadership construct has largely been studied in terms of different styles of leading encapsulated in the Multifactor Leadership Theory (Bass \& Avolio, 2000). The theory includes the transformational, transactional and laissez-faire leadership styles, with the transformational style being largely associated with leadership success (Gardner \& Stough, 2002). Other than defining leadership in terms of the different styles of leading encapsulated in the Multifactor Leadership Theory, leadership success can also be defined and assessed in terms of leadership competencies identified and required of the leaders in an organization to ensure that it gains and retains a sustainable advantage in industry (Higgs \& 
Aitken, 2003). Such competencies could typically be assessed via simulation exercises during a leadership Assessment Centre (AC), where activities are developed that are intended to elicit the behaviours deemed most crucial for leadership success.

The concept of the AC is not new. As early as during World War II, the US Office of Strategic Services used AC's for the selection of secret intelligence agents and propaganda experts for foreign assignments (Brownell, 2005). In 1989, the International Personnel Management Association published a document called Guidelines and Ethical Considerations for Assessment Center Operations. These guidelines were updated in 2000 and endorsed by the $28^{\text {th }}$ International Congress on Assessment Center Methods (Brownell, 2005). Research on the value and validity of assessment centers began in the late 1960's. Accumulated literature has clearly established the value of AC activities in evaluating a wide range of pre-determined knowledge and skills. Brownell (2005) found that the majority of researchers subsequently have concluded that the AC method has a sufficiently high criterion-related validity to be considered a reliable indicator of an individual's future performance.

Brownell (2005) additionally provided evidence that ACs, when systematically developed with clear outcomes in mind, can successfully be used to make informed judgments about critical indicators of leadership effectiveness (e.g. leadership competencies). In the wider sense, competencies are defined as the job behaviours people need to display in order to do a job effectively (Woodruffe, 1993) or as the underlying characteristic of a person which results in effective and or superior performance in a job (Boyatzis,1982). Leadership competencies therefore refer to knowledge, behaviours, and attitudes - that when applied appropriately - result in desired outcomes for a person in a leadership role (Brownell, 2005). Such leadership competencies could include, for example, the development of others, to build working relationships in order to attain work objectives, as well as working with complex information to arrive at practical solutions.

\subsubsection{Leadership Assessment Centres - underlying assumptions and methodology}

Leadership Assessment Centres (AC) grew from the assumption that it is possible and realistic to identify, observe, analyse and infer characteristics of people that predict future success and that 
these characteristics could be fostered and grown in promising individuals (Wilson, 1996). The leadership AC can therefore be described as a method of evaluating individuals' knowledge and skills, by using a series of work samples or simulations that resemble what they might be called on to do in an actual leadership role (Appelbaum, Harel \& Shapiro, 1998; Brownell, 2005). The leadership AC has been classified as the method of pragmatists (Bols, Van Bree, Bolton \& Gijswijt, 1996). In other words, it was not developed from theoretical models, but from practice, from the idea that if you want to know whether someone can do something well; you should assess the individual in situations where the skills have an opportunity to be shown (Bols et al., 1996).

The leadership AC is perceived as a structured combination of assessment techniques that could be used to provide a wide-ranging, holistic assessment of each participant, as a method of predicting performance in a leadership role (Bols et al., 1996; Garavan \& Morley, 1998). According to Brownell (2005), the process of AC development begins by clearly defining desired outcomes. Company-specific information must be collected, the most critical of which pertains to the organisation's mission and its vision for the future (Brownell, 2005). This knowledge helps to predict the kinds of challenges and dilemmas its leaders are most likely to confront, and to determine the behavioural requirements necessary to be able to successfully address those dilemmas. The organization needs to decide what the critical behavioural criteria, i.e. dimensions or competencies and psychological determinants are to enable leadership to take the organization into the future. Then, activities are developed that are intended to elicit the behaviours deemed most crucial for success in a leadership role. Evaluators or assessors are trained to observe, appraise, and record participants' performance during these exercises using structured feedback forms. Results of standardized tests are often used to supplement assessors' observations. Behaviourally Anchored Rating Scales (BARS) are developed so that objective, concrete feedback can be provided to each participant on each dimension that is being assessed. Inter-rater reliability is increased through the use of the AC technique, which provides descriptions of outstanding, average, and poor behavioural responses for each item (Brownell, 2005). After a day or more of activities, assessors meet to develop a consensus evaluation of each participant on the specific dimensions of concern before sharing their evaluations with the assessee. Frequently, a specific plan for professional development is also suggested. 
According to Wilson (1996), the principal features of leadership ACs are the direct observation of participants' performance in exercises and the assessment by trained observers of that performance against criteria that have a known validity to predict future performance in a leadership role - i.e. leadership potential. This process is contrasted, according to Wilson (1996) with the more traditional inference of potential from reported accounts of past experience plus educational and vocational qualifications.

Garavan and Morley (1998) conducted an extensive literature review on leadership ACs and identified several features that nearly all ACs, including leadership ACs, share and that are distinctive to the approach. The first of these features is that assessment takes place in groups, implying that small groups of participants are always assessed simultaneously. The second distinctive feature of ACs is 'assessment by groups'. The assessment team may be made up of managers, psychologists, consultants or a combination of these three groups. Each participant's behaviour is observed and evaluated by a number of different assessors and the final rating represents the assessment team's consensus regarding the participant. Thirdly, the 'use of multiple techniques' is considered a distinctive feature of ACs (Garavan \& Morley, 1998). AC activities generally include psychometric tests, interviews, peer evaluations and simulation exercises. The central assumption is that each technique has its strengths and weaknesses and that a combination of diverse techniques is necessary to capitalize on the strengths of each individual technique. Fourthly, the 'use of situational tests' is perceived to be a unique feature of ACs. Many ACs use some type of work sample or situational tests, for example in-basket and leaderless group discussion methods are popular, as are role-playing exercises. Lastly, 'assessment along multiple dimensions' is considered a feature of ACs. This implies that each exercise in the AC typically provides information relevant to one or more dimensions (e.g. different leadership competencies) and ratings on a specific competency might reflect data obtained from several different exercises.

The concept of the developmental leadership AC is almost as old as that of traditional ACs. Providing of feedback was the critical addition that was necessary to make the transition from a traditional AC to a developmental AC (Wilson, 1996). Developmental leadership ACs became 
fully formed with the addition of personal development plans (PDPs) in the late 1980's (Wilson, 1996). Like ACs, developmental leadership ACs involves a battery of tests and exercises, which measures people's abilities against certain agreed criteria. However, while leadership ACs were originally designed to select leaders, the focus of development centers is on helping people already in a leadership role in an organization to improve their performance (Applebaum et al., 1998). While traditional leadership ACs have passive candidates who are only tested by assessors for selection purpose, developmental leadership ACs have active participants who take part in a collaborative venture with the aid of facilitators or observers (Vloeberghs \& Bergham, 2003). Leadership ACs allow the organization to select leaders who meet its criteria. Developmental ACs allow leaders to get an indication of their own abilities against the organisation's criteria, identify their development needs, begin to meet these, and plan further development activities (Applebaum et al., 1998). It could thus be concluded that contemporary developmental leadership ACs all in some way assess or profile leaders' characteristics, provide feedback on this assessment and produce an action or personal development plan to deal with the implications of the feedback (Wilson, 1996). The AC feedback is then considered as a leadership development tool (Vloeberghs \& Bergham, 2003). The leadership AC method could also be used to identify high potentials very early in their careers so that the organization can provide them with specific, personal development programs. Here the underlying purpose is to motivate and involve the organisation's best people. According to Vloeberghs and Bergham (2003) the leadership AC tool could also be utilised for organizational development and planning purposes, for example identifying areas where widespread leadership skill deficiencies exist or to aid in the facilitation of cultural change.

The leadership AC methodology is not only proven to be an effective tool for organizations to determine and predict future success of its leaders, but also a tool to make visible and develop the values and characteristics deemed important for their success. In this way, these leadership characteristics could be fostered and grown in promising individuals, in order to sustain or adapt core strategic organisational capabilities. It has become important for organisations to determine what the criteria are for individuals to be successful in a leadership role and to take the organisation successfully into the future. As explained by Frederickson's (2003) broaden-andbuild theory it is important to cultivate positive emotions in individual organizational members 
and others, as a means to achieving individual and organizational transformation and optimal functioning over time. This highlights the importance for organizations to add EI to the values and characteristrics that they expect of, and henceforth will pay for, in their leaders. Evaluating the amount of variance in AC behaviour that personality and EI accounts for respectively, will clarify the type of characteristics that are made visible and grown in leaders in this specific organisation. Alternatively, it will serve to shed light on the incremental validity of EI to predict leadership competence obtained on an AC, over and above a well-established measure of personality (namely the OPQ32i). This should provide evidence for the utility of EI and the SUEIT as an aid in selecting and developing successful leaders, resulting in successful organizational performance.

\subsection{THE INCREMENTAL VALIDITY OF EI}

Goleman (1995) suggested that successful life outcomes are more a function of EI rather than cognitive intelligence or personality traits. The success of Goleman's book and subsequent media reports concerning EI and its measurement suggested this construct is novel, alluring, and popular. Gardner and Stough (2003) also acknowledged the fact that much of the popular management literature on EI has described the construct as an underlying attribute of leadership success, and that it has been proposed that screening for EI in the recruitment process may aid in the identification of potentially more successful leaders. However, a series of studies on EI have found moderate and in some cases large correlations between these measures and personality traits. Given the considerable overlap with traditional measures of personality, researchers started to question the reliability of objective measures of EI. These relationships with personality raise the question of the distinctiveness of EI from the personality domain. If EI is no more than a "repackaging" of well-established personality traits then it is unlikely to be a useful tool over and above these well-validated constructs. In order to show that the construct is useful as a decision making tool (i.e. screening for EI in the recruitment process will aid in the identification of potentially more successful leaders), measures of EI need to demonstrate that they are meaningfully related to various indices of leadership success. One way to assess the issue of the distinctness of EI is to examine its incremental validity in the prediction of life outcomes - i.e. its ability to predict leadership competence when the effects of personality are controlled for. This will serve to clarify the relative decision-making validity of EI (as measured by the SUEIT), in 
comparison to existing well validated constructs (i.e. personality traits) used to select and develop leaders in an organizational setting.

\subsection{RATIONALE AND OBJECTIVES OF THE STUDY}

\subsubsection{Rationale for this study}

As evident from the literature review in this chapter, EI as a construct has gained considerable popularity, as well as support, in empirical literature as a means of identifying and developing successful leaders in organizations. The support towards the EI construct is partially based on the assumption that it can account for variance in performance, not accounted for by IQ or personality traits, and that it could be developed in promising individuals. Numerous models and measures of the construct have been generated.

However, research indicated some overlap between EI and other well-established, well-validated tools utilised for the purpose of identifying leaders, for example personality measures. The current study aimed to clarify the question of the utility of the EI construct (and the SUEIT) by exploring its incremental validity in predicting leadership competence, over and above personality traits.

\subsubsection{Aim and objectives of this study}

In order to be useful to organizational decision makers (e.g. recruitment and selection, learning and development), measures of EI need to demonstrate that they can account for variances in predicted leadership competence over and above, variance that is not accounted for by other psychometric tools (e.g. measures of personality) that are typically utilized to identify leaders. In other words, evidence needs to be found in support of EI theories' and measures' utility to predict e.g. effective organizational leadership through predicted leadership competence, over and above other established constructs. As was argued from the literature, however, One of the biggest issues currently facing measures of EI is its discriminant validity from measures of personality (Palmer et al., 2003). Furthermore, a need has also been identified for research that can add to the body of knowledge with regards to the relationship between EI and effective leadership, and to provide support for the merit of an EI measure to help predict effective leadership over and above 
other well established models and measures. The aim of this study is therefore to provide support for the utility of the SUEIT to predict variance in predicted leadership competence indicated by AC technology results, not accounted for by other psychometric tools, namely the OPQ32i (measuring personality).

The main objective of this study is to determine whether the SUEIT accounts for variance in predicted leadership competence (measured with the Assessment Centre technology) in the workplace additional to the variance accounted for by personality (as measured by the OPQ32), in other words, to determine whether the SUEIT predicts something new and distinct, other than related constructs (e.g. personality) which is being used to predict leadership competence. Hence,

1. The first objective was to establish whether EI and personality predicts leadership competence. It is therefore firstly expected that EI (as measured by the SUEIT) and personality (as measured by the OPQ32i) will significantly predict leadership competence ratings (which was obtained through AC technology).

2. The second objective is to investigate the incremental validity of EI over personality traits. This should provide an indication of whether EI (as measured by the SUEIT) provides a prediction of leadership competence not accounted for by a measure of personality (as measured by the OPQ32).

3. The third objective is to determine the relationship between EI (measured by the SUEIT) and personality traits (measured by the OPQ32). This should clarify the question of overlap between EI and personality traits and provide in indication of whether the SUEIT measures a construct that is different and unique, as opposed to the construct of personality measured by means of the OPQ32i.

\subsection{SUMMARY}

Several promising theoretical conceptualizations exist that relate EI to indices of occupational success, including leadership. However, mixed findings have been obtained in the existing empirical research on the predictive and disciminant validity of the EI construct. Whilst EI remains a popular and attractive construct, it is not possible as yet, to use measures of EI with confidence as a reliable decision-making tool in organisations. The current study aimed to 
provide clarity on the relationship between EI and leadership competence, by investigating whether EI could account for variance in leadership competence when personality traits are controlled for. This investigation should provide evidence for the practical utility of EI, and the SUEIT, as an aid to identify and develop potentially successful leaders in an organisational context.

Hence, in section two the research methodology will be discussed. Included in this discussion is the research design utilized in order to explore the relationships between leadership AC results, EI and personality traits. This is followed by a discussion of the limitations of the research design related to the use of archival data, self report- and ipsative measuring instruments, as well as AC methodology. The participants and measuring instruments (utilised to assess EI, personality traits, and leadership competence) will also be discussed and the section will be concluded with a description of the research aim and hypotheses, sample and data collection and data analysis procedures employed. 


\section{CHAPTER 2: RESEARCH METHODOLOGY}

\subsection{INTRODUCTION}

As discussed in section one, the aim of the current study is to provide support for the utility of the SUEIT (measuring EI) to predict variance in leadership competence indicated by AC technology results, not accounted for by other psychometric tools, namely the OPQ32i (measuring personality). The research methodology utilised to support this aim will be discussed next. Firstly, the research design will be described.

\subsection{RESEARCH DESIGN}

In order to explore the relationships between leadership AC results, EI and personality traits, a controlled inquiry of non-experimental kind was followed. Non-experimental research is a process of systematic empirical inquiry in which the direct control of independent variables does not exist, because they are inherently not manipulable, such as the constructs measured in this study (Kerlinger \& Lee, 2000). Inferences about relations among variables are made, without direct intervention from variation of independent and dependent variables (Kerlinger \& Lee, 2000). Relational research attempts to determine how two or more variables are related to each other (Elmes et al., 1999). Typically, relational research does not involve manipulation of variables, as do experiments, so the data that are related are often called ex post facto data. For the purpose of this study, correlational and multivariate research as a type of relational research was employed, as it allows the researcher to simultaneously determine the degree and direction of the relationship between the dependent and independent variables.

The sources of data used in this study are twofold. Firstly, archival records - sources of information about phenomena that had already occurred (Graziano \& Raulin, 2000) - are used. The data utilized from the archival records consisted of observer ratings and psychometric test data. More specifically, ratings obtained on the different competencies measured by means of AC exercises as well as test scores of the OPQ32i measuring personality were obtained and utilised for the purpose of this study. All of these measures could be obtained through the ACs utilised by the sponsoring organization. It was thus necessary to use archival data obtained from participant files and an electronic database containing the necessary data. EI data was collected on a separate 
occasion by means of an online version of the SUEIT. De-briefing sessions were held after the EI questionnaires (the SUEIT) were completed, where candidates were provided with more information on the current study, as well as on their EI profiles and possible development actions (as encapsulated in the individual reports). The data on these constructs were collected in order to determine the incremental validity of the SUEIT (and hence EI) over and above personality in terms of its predictive validity in the specific leadership competencies relevant in this study. Several limitations of the research design have been identified and will be discussed next.

\subsubsection{Limitation of the research design}

The use of archival data introduced various obstacles and limitations to the study. Firstly, informed consent had to be acquired from participants in order to comply with ethical regulations when archival data is being used. Participants needed to be made aware that participating in this study implies that their confidential assessment data would be extracted. To enable the participants to make an informed decision about the use of their data in the study (Graziano \& Raulin, 2000) they were briefed via an e-mail message containing the objective of this study, as well as the data that was needed for this purpose. They could indicate informed consent by replying back to the e-mail.

A limitation posed by the use of archival records was that sampling was out of the researcher's control. Inclusion of participants in the study was limited to those individuals selected by the sponsoring organization to attend a leadership AC. Leaders or managers who are perceived to have potential in a leadership role, are sent on a leadership AC by their seniors. Potential in a leadership role is evaluated against and defined by the dimensions or competencies related to job success in the present organization. Two other constraints resulted from the fact that sampling was out of the researcher's control. These included missing cases in the data, as well as questions about the representativity and generalisability from the results. The data used in this study was drawn from files and electronic databases. Standard procedures for dealing with missing data from the different datasets, as well as the omission of some cases, were followed. Furthermore, it was particularly challenging to trace individuals' results back to the raw data needed for this study. Additionally, the sample in the current study, consisted of individuals from a specific organization with its own unique culture and generally accepted behaviours, that could differ 
from other organizations. The question of how well it represents the larger population of leaders in different organizations, needs to be addressed and should be seen as another limitation of the study. Furthermore, the means of assessing leadership behaviour and the dimensions/ competencies identified as critical for success in a leadership role might be different in other organizations and therefore care needs to be taken when interpreting results and generalising findings of this study to the general population.

Further limitations of the data used in this study can be linked to the ongoing debate that emerged in the EI and personality measurement literature regarding whether or not self-report measures, such as the SUEIT or the OPQ32i, provide an accurate assessment of an individual's standing on these constructs. Self-report measures ask people to endorse a series of descriptive statements, indicating to what extent these describes or do not describe themselves (Mayer et al., 2000b). Thus, self-reported abilities and traits rely on the individual's self-understanding. If a person's self concept is accurate, then these sorts of measures can often serve as an accurate measure of the actual ability or trait. If the person's self concept is inaccurate, then self-report measures yield information concerning only the person's self-concept, rather than the actual ability or trait (Mayer et al., 2000b).

Newsome et al., (2000) further noted that with self-report measures, people may distort to create a favourable impression, or when no incentive exists for participants to try to create a favourable impression, because it is anonymous, unintentional self-deception may be evident. These claims have been made regarding measures of EI and measures of personality. According to Topping and Gorman (1997), the transparent wording of self-report personality tests provides the opportunity for respondents to present a particular view of themselves. This is a frequently cited reason for not using these tests to aid decision making in personnel selection, and is supported by considerable evidence that, when instructed to do so, respondents can distort their responses on self-report tests to create a favourable (fake good) or unfavourable (fake bad) impression. That is, the mean scores for a range of self-report personality tests have been shown to differ significantly and substantially among groups asked to fake good, fake bad, or respond honestly. Topping and Gorman (1997) conducted a study on a sample of 121 university students asked to complete the NEO-FFI either as part of a norming exercise (honest condition) and under explicit instructions to 
create a favourable impression of themselves (fake good condition). They furthermore had judges who knew the students for at least 12 months rate them, using scales based on the NEO-FFI. Mean scores on four of the five NEO-FFI scales (Extraversion, Neuroticism, Agreeableness, and Conscientiousness) differed significantly between the two conditions. Correlational analysis indicated that, with the exception of agreeableness, there were statistically significant reductions in the validity of the scales against judges' ratings in the fake good as compared with the honest condition. A series of moderated regression analyses confirmed the inferences from the correlational analysis in all cases, except for Neuroticism. It was concluded that consistent with the popular view of self-report tests of personality, deliberate attempts to fake, could seriously compromise the validity of these tests.

One could however argue that the test administrator's instructions plays a major role in the extent to which faking will actually take place. Where respondents are instructed to answer open and honestly, making them aware that a social desirability scale is included in their results, and the meaning thereof, would most probably decrease the extent to which faking will take place. In the present study this instruction was provided to respondents. For the sample used in the current study, the mean social desirability score was calculated, and was found to be a sten score of 5.2 with a standard deviation of 2.2. There was therefore not a substantial amount of faking present within the respondents' data.

While Mayer et al., (2000b) argued that the most direct assessment is expected to be gained from performance-based measures they also noted that self-report measures might assess more internal experiences related to emotional thinking, which may be difficult to obtain with performance measures. Moreover, people often act on their beliefs (or self-concept) as opposed to their actual abilities. As such, Stough and Palmer (2002) argue that although the most direct assessment of EI may be gained from performance-based measures, it appears as though these different approaches to the measurement of EI (e.g. self report measures) offer additive or alternative utilities. Selfreport scales are typically less time consuming and can be self administered, which is important criteria to consider when selecting tests particularly in organisational applications (Stough \& Palmer,2002). 
Thirdly, the use of AC's to obtain leadership competency ratings, as was the case in this study, introduced further limitations to the interpretation of the results. According to Lievens (2000) there has been no formal longitudinal study to gauge the accuracy, in terms of the reliability and validity of the leadership $\mathrm{AC}$ in general, as a means to measure leadership competencies. Both participants and assessors express support and confidence in leadership AC results, however no systematic, up to date evidence has been gathered to support the notion that the competencies as assessed by the leadership AC directly contributes to leaders' career success.

In addition, a number of authors have reviewed the potential problems associated with the validity and reliability of leadership AC competency results (Brownell, 2005). Problems would readily arise if the center is poorly designed, if the link between organisational values and leadership AC activities is weak, or if assessors are untrained. Design considerations outlined by Brownell (2005) applied to address these issues, are the use of a limited number of dimensions, the careful training of assessors, and the use of psychologists as assessors. Use of behavioural check-lists (i.e. Behaviourally Anchored Rating Scales, BARS) also increases dimension variance to ensure that the competencies do not overlap, but describe unique behaviour required for leadership success. The organisation in which the current study was conducted does meet all the above requirements outlined by Brownell (2005), and therefore the AC was assumed to be a reliable method of measuring leadership competence as an indicator of leadership potential (future success in a leadership role).

Fourthly, much has been written about the difficulties and limitations of using ipsative measurement and forced choice response styles in the assessment of personality (e.g. the OPQ32i that was utilised in this study) using multi-scale questionnaires (Baron, 1996). Critics of ipsative measurement argue that, although psychological benefits are to be reaped from the use of ipsative questionnaires, they cannot be used for comparing individuals across scales, and therefore they are inappropriate in selection (Dakin et al.,1994). According to Baron (1996), some have argued that the problems of ipsative data are such that it is impossible to analyse or interpret using standard procedures or that it can only be used in restricted contexts. Proponents however, argue that ipsative questionnaires provide a useful alternative to norm-referenced questionnaires and their inherent fakeability, and suggest that any scaling technique has some 
inherent bias. Other research comparing the reliability and validity of normative and ipsative approaches indicates that there is little difference between the two (Dakin, et al., 1994). Others have contended that ipsative data are amenable to analysis using standard techniques and that its other properties often make it at least as useful as normative data (Baron, 1996).

After a literature survey and analysis of these arguments, Baron (1996) came to the conclusion that the artificial interdependence between ipsative scores does affect their psychometric properties. These effects tend to be the greatest where an instrument has few scales and there are higher underlying intercorrelations between the constructs measured. However, with around 30 scales (the OPQ32i has 32), ipsative measurement does provide some interpretable psychometric parameters (Baron, 1996). Baron (1996) however stated that much larger numbers of scales seem to be needed before factor analytic results resemble those provided by normative data. Ipsative profiles result in similar criterion related validity coefficients but, in addition, may also control for much of the bias inherent in Likert type responses. Next, the participants that were involved in this study will be discussed.

\subsection{PARTICIPANTS}

The participants was selected amongst the middle managers from a company in the life assurance industry in South Africa. Only employees that have attended the relevant leadership AC were considered for inclusion in the study. Employees in the general population of the organisation were divided into five hierarchical levels at the time of the study. These included Clerical (level five), Techical/professional/Department Heads (level four), Assistant Divisional Managers (level three), Divisional Managers (level two) and Executive Managers (level one). The study focused on middle management and therefore all possible participants in level three (middle managers) that have attended the relevant leadership $\mathrm{AC}$ were approached to participate. However, all possible participants also needed to be willing to complete an online version of the SUEIT questionnaire - which further influenced the sample size. 


\subsection{MEASURING INSTRUMENTS}

In order to be useful to organisational decision makers (e.g. recruitment and selection, learning and development), measures of EI need to demonstrate that they can account for variances in predicted leadership competence over and above, variance that is not accounted for by other psychometric tools (e.g. measures of personality) that are typically utilized for this purpose. In other words, evidence was needed in support of EI theories' and measures' utility to predict e.g. effective organizational leadership through predicted leadership competence, over and above other established constructs. One of the biggest issues currently facing measures of EI is the incremental validity from measures of personality (Palmer et al., 2003b). A need has also been identified for research that can add to the body of knowledge with regards to the relationship between EI and effective leadership, and to provide support for the merit of an EI measure to help predict effective leadership over and above other well established models and measures. The aim of this study is therefore to provide support for the utility of the SUEIT to predict variance in predicted leadership competence indicated by AC technology results, not accounted for by other psychometric tools, namely the OPQ32i measuring personality.

The constructs of EI, personality and AC leadership competencies was operationalised through the SUEIT, OPQ32i and leadership AC technology respectively, each of which will be discussed in the following section.

\subsubsection{Leadership - Assessment Centre Technology}

As mentioned in section 1.3.3.1, leadership Assessment Centres grew from the assumption that it is possible and realistic to identify, observe, analyse and infer characteristics of people that predict future success and that these characteristics could be fostered and grown in promising individuals (Wilson, 1996). According to Brownell (2005) the AC can be described as a method of evaluating individuals' knowledge and skills using a series of exercises or activities designed to elicit a range of responses. In her article, "Predicting Leadership", Brownell (2005) demonstrated how AC's could be designed to meet the extended goals of assessing critical indicators of leadership effectiveness. The leadership AC is shown to be a valuable means of both assessing and predicting leadership talent and through that accomplish the organisation's goal of preparing for, and responding to, future leadership requirements (Brownell, 2005). 
The development and use of the leadership AC methodology, utilised in the present study, commenced with a number of personnel practitioners visiting the USA to be trained by W.C. Byham, a scholar and pioneer of the AC methodology (e.g. Byham, 1970; 1971; 1980; 1982) (and specifically on Middle Manager/leadership ACs). The dimensions, also called competencies, identified through job analysis as critical to success at middle management level, was validated through a process where the dimensions were matched to the realities of work at a middle managerial level within the participating organisation. The validation was completed with the assistance of the organisation's executive team. Simulation exercises were then designed to provide assessors on the leadership $\mathrm{AC}$ with an opportunity to observe the participants in situations where the behaviour, specified by the competencies identified above, are required. This enables assessors to evaluate the participants against the criteria specified by the relevant competency. The AC consisted of, amongst others, in-baskets, leaderless group discussions and role-plays (Human Resources department of the sponsoring organization, personal communication, 1 July 2005).

Observer training followed the validation process in order to ensure that all observers understood and knew how to assess the different dimensions (Human Resources department of the sponsoring organization, personal communication, 1 July 2005). All Assistant Divisional Managers and Divisional Managers within the participating organisation had to be trained as observers and had to observe a centre at least twice per year. The leadership Assessment Centress as used in the sponsoring organisation ran over a period of five days at an external venue and comprised of two administrators, six observers, four role-players and twelve candidates. After some time it became apparent that proper research had to be conducted to ensure that the leadership Assessment Centres fit into the organisational and South African context. This was conducted during 1980 by looking at existing jobs within the participating organisation and rating people on their performance and potential. This was done through the use of repertory grid exercises, interviews and psychometric testing. An average of 40 people were assessed per band/level. The sample included a minimum of 15 good to average and 15 bad performers (Human Resources department of the sponsoring organization, personal communication, 1 July 2005). 
As a result of this research a new set of dimensions, identified as critical to success in a leadership role in the sponsoring organisation, as well as behavioural assessments were designed (Human Resources department of the sponsoring organization, personal communication, 1 July 2005). The dimensions were validated across the lines of business through the use of interviews and $360^{\circ}$ questionnaires. A set of Behavioural Anchored Rating Scales (BARS) were also developed which led to improved consistency in ratings, and shortened the time for integration and observer training (Human Resources department of the sponsoring organization, personal communication, 1 July 2005). The initial work in the field of Organisational Behaviour for BARS was conducted by Smith and Kendall (1963), and was refined by Landy and Farr (1983). Campbell and Cairns (1994) defined BARS as an instrument, which examines leadership behaviours displayed in an organization by comparing them with a range of predetermined behaviours. The outcomes are then displayed on a Likert-type scoring scale to provide a measurement of the gap between actual and desired performance (Campbell \& Cairns, 1994). On a leadership AC in the sponsoring organisation, one would evaluate a participant's behaviour observed during a simulation exercise (e.g. a role play) against the predetermined behavioural criteria as set out in the leadership competency BARS. The person are rated according to the degree to which he or she met the criteria as set out in the competency BARS $(1=$ development area; 2 = coaching area; $3=$ competent; $4=$ exceeds requirements; $5=$ outstanding), with criteria set out for ratings 1 to 5. For example, the criteria in the BARS to be rated "competent" for the leadership competency, Building Working Relationships would be, (1) Gains agreement from others to support team objectives; (2) Probes for and provides information to clarify situations; (3) Making other people feel included in discussions; (4) Gives recognition to others; empathizes appropriately, etc. To be rated "coaching area", the criteria that should be met are, (1) Builds interpersonal relationships by making others feel valued, appreciated (2) Builds relationships in a routinely fashion, etc (Human Resources department of the sponsoring organization, personal communication, 1 July 2005).

As is evident, the BARS consists of clearly defined, observable workplace behaviour; are written in positive language and linked to the level of functioning where the expected complexity level of the behaviour increases as the person advances to the next leadership level e.g. "attending to 
detail in one's own tasks" at the department head level becomes "monitors quality of a whole unit's production outputs" when the person moves to the Assistant Divisional Manager level.

This scale, according to Campbell and Cairns (1994) provides a very clear visual indication of which behaviours need to be focused on to reduce the gap between desired and actual leadership behaviour. By using this measurement method each scale has a specific dimension of performance to be assessed. The anchors that appear at intervals on the scale provide examples of the behaviours associated with a particular level of performance rather than just words indicating particular attributes of levels of agreement or disagreement on the continuum (Campbell \& Cairns, 1994).

During the early 1980's cross-cultural research within the South African context was conducted on the AC (Human Resources department of the sponsoring organization, personal communication, 1 July 2005). Results revealed that the low level of education of black participants had a significant impact on overall performance in the centers. Coaching sessions prior to centre attendance were therefore introduced and those with lower education levels were given extra time to complete the exercises. This resulted in more consistent results and greater acceptance of the practice by black employees. It also led to the implementation of modular training per dimension (Human Resources department of the sponsoring organization, personal communication, 1 July 2005).

The need for a development-focused assessment at the different leadership levels within the sponsoring organization was highlighted after the need for a leadership culture with a focus on growth at both an individual and organisational level was identified (Human Resources department of the sponsoring organization, personal communication, 1 July 2005). It is within this background that three levels of organisation specific development leadership ACs were developed during 2002, which constituted the leadership ACs completed by the participants of the current study. A job analysis process was used to extract the needed generic leadership competencies per level (Divisional Manager, Assistant Divisional Manager, Department Head) (Human Resources department of the sponsoring organization, personal communication, 1 July 2005). As explained earlier, Woodruffe (1993) defines competencies as the job behaviours people 
need to display in order to do a job effectively. This include the job behaviours of significance to leadership effectiveness, for example the development of subordinates to equip them to do their assigned tasks better, building of working relationships to ensure that team objectives are met, and the ability to work with complex information in order to generate implementable solutions. Table 2.1 provides a list of the leadership competencies assessed for the purpose of this study.

These competency sets were then validated to ensure that it is generic to leadership throughout all the business units. In other words all leaders will be evaluated against the same leadership competencies and behavioural criteria regardless of the business unit (for example Retail, Finance, Marketing, Client Services) within which they operate (Human Resources department of the sponsoring organization, personal communication, 1 July 2005). Assessment material were designed to reflect scenarios relevant at each leadership level (e.g. a development discussion with a subordinate at the Department Head level) and links were made to the Behavioural Anchored Rating Scales (BARS) to ensure inter-rater reliability (Human Resources department of the sponsoring organization, personal communication, 1 July 2005). According to Kerlinger and Lee (2000) a measure can be considered reliable when the same set of objects are measured again and again with the same or comparable measuring instrument and the same or similar result will be obtained. Inter-rater reliability is obtained when different assessors' agree on the meaning of a specific dimension, rating scale and the rating process to be followed, that they would obtain the similar result when assessing the same participant. This is essential to ensure that all participants are assessed in a consistent and comparable manner, when assessed by different assessors and that an accurate measure of the dimension measured could be obtained without distortion (Elmes et al., 1999; Kerlinger \& Lee, 2000).

Table 2.1: Leadership Competencies assessed by ACs in this study
1. Customer Focus
5. Analysis
2. Building Working Relationships
6. Problem Solving
3. Gaining Commitment
7. Planning and Organizing
4. Developing Others
8. Stress Tolerance 
Employees are assessed in order to identify areas of strength and development within each of the competencies, which are generic to the middle management level within the organization sponsoring the study.

The leadership competency AC data utilized for the purpose of this study, included scores on the following exercises:

1. In-basket or written exercises - simulation exercises where the participant, for example as department head, needs to plan and implement a project, deal with subordinates, peers, seniors and clients, while working through the items in his or her in-basket.

2. Group discussion - Participants participate in a leaderless group discussion where they need to state their points and reach agreement on a specific project's objectives and processes to be followed for implementation.

3. Role-play - A simulation exercise where the participants, for example, need to take on the role of a newly appointed department manager having a meeting with one of the staff members who has asked to speak to him or her specifically about career development.

4. Competency-based interview - The participants are asked questions designed to elicit responses yielding information about the degree to which the individual would use the behaviour specified by the competencies, in relevant situations.

The results of all the above exercises are integrated and scored against the competency BARS. Results are then plotted on an assessment grid used to integrate the data obtained on all the competencies - by means of the different exercises - into single competency scores.

\subsubsection{Emotional Intelligence: The SUEIT}

In this study EI was measured with the SUEIT (Palmer \& Stough, 2001). The SUEIT is a selfreport instrument specifically designed for use in the workplace. It indexes individuals' perceptions of the way they feel, think and act at work, with emotions, on the basis of emotional information. The development of the SUEIT was initiated by Palmer and Stough (2001) in order to determine the most definitive dimensions of the EI construct out of a great plethora of different EI models and measures. They performed a large factor analytic study with a sample that was representative of the Australian general population $(\mathrm{N}=310)$, involving the six predominant 
measures, at the time, purporting to assess EI (Palmer \& Stough, 2001). As a result, five factors were identified. In order to assess EI according to the empirical model, items had to be conceptualized for each of the five dimensions. The test in its most recent form contains 64 items with good internal consistency and reliability (Palmer \& Stough, 2001).

The SUEIT provides an overall score that indicates individuals' general workplace EI as well as five sub-scale scores that indicate individuals' EI according to the five dimensions of the model. The five factors are:

1. Emotional recognition and expression (in oneself) - the ability to identify one's own feelings and emotional status, and the ability to express those inner feelings to others.

2. Emotions direct cognition - the extent to which emotions and emotional knowledge are incorporated into decision-making and/or problem solving.

3. Understanding of emotions external - the ability to identify and understand the emotions of others and those that manifest in external stimuli.

4. Emotional management - the ability to manage positive and negative emotions within both oneself and others.

5. Emotional control - how effectively emotional states experienced at work, such as anger, stress anxiety and frustration are controlled.

Test takers respond to the items of the test on a five-point scale $(1=$ never, $2=$ seldom, $3=$ sometimes, $4=$ usually, 5 = always) that ask them to indicate the extent to which the statements are true of the way they typically think, feel and act with emotions at work. Two sets of Australian normative datasets currently exists.

Research with the SUEIT has demonstrated that it has good internal consistency and test retest reliability (Palmer et al., 2003a). Coefficient alpha's have been found to range from a low of $\alpha$ $=0.70$ for the Emotions Direct Cognition subscale to a high of $\alpha=0.91$ for the Emotional Recognition and Expression subscale (Palmer et al., 2003a). The SUEIT has been found to have high test retest reliability in over a one month period with stability coefficients ranging from a low of 0.82 for the Emotional Recognition and Expression subscale to a high of 0.92 for the Understanding Emotions subscale. In summary, the findings of these studies by Palmer and 
Stough (2002) indicate that the SUEIT exhibits high internal consistency and test-retest reliability. The SUEIT's reliability statistics for the current study were also calculated and are displayed in Table 2. This confirmed that the instrument has got good reliability.

\subsubsection{Personality: The Occupational Personality Questionnaire (OPQ32i)}

For the purposes of this study, the Occupational Personality Questionnaire (OPQ32i) was used to measure personality. The OPQ32 $\mathrm{i}$ is designed to assess the typical or preferred behaviour, inherent to the personality traits individuals possess in a way that is relevant to the world of work (Saville et al., 1994). The questionnaire offers the choice of two scoring approaches. The normative approach employs a rating scale whilst the ipsative version forces respondents to choose between the most and least preferred aspects of their personalities. All responses add up to a constant. The latter is thought to be more effective in controlling for distortion due to response bias (Saville et al., 1994). The ipsative version was used for this study and therefore subsequent limitations were presented earlier in this chapter. The questionnaire consists of 40 blocks of four statements and it is required of respondents to indicate which behaviour are most and least true of them. The individual is forced to choose between different options measuring aspects of personality, thus giving a profile of relative preferences (Saville et al., 1994).

The reliability of the OPQ32i was published in the OPQ32 technical manual by SHL group PLC (2005). Table 2.3 (taken from the OPQ32i technical manual, SHL group plc, 2005) provides the alpha coefficients for the OPQ32i. 
Table 2.2: Reliability Statistics for the OPQ32i

\begin{tabular}{|l|l|}
\hline \multicolumn{1}{|c|}{ OPQ32i dimensions } & \\
\hline Persuasive & .81 \\
\hline Controlling & .87 \\
\hline Outspoken & .76 \\
\hline Independent Minded & .72 \\
\hline Outgoing & .85 \\
\hline Affiliative & .82 \\
\hline Socially Confident & .83 \\
\hline Modest & .81 \\
\hline Democratic & .68 \\
\hline Caring & .78 \\
\hline Data Rational & .88 \\
\hline Evaluative & .67 \\
\hline Behavioural & .82 \\
\hline Conventional & .74 \\
\hline Conceptual & .79 \\
\hline Innovative & .88 \\
\hline Variety Seeking & .72 \\
\hline Adaptable & .82 \\
\hline Forward Thinking & .75 \\
\hline Detail Conscious & .80 \\
\hline Conscientious & .82 \\
\hline Rule Following & .84 \\
\hline Relaxed & .85 \\
\hline Worrying & .88 \\
\hline Tough Minded & .82 \\
\hline Optimisitic & .80 \\
\hline Trusting & .81 \\
\hline Emotionally Controlled & .85 \\
\hline Vigorous & .75 \\
\hline Competitive & .86 \\
\hline Achieving & .79 \\
\hline Decisive & .80 \\
\hline & \\
\hline & \\
\hline
\end{tabular}

The table is based on the standardisation sample $(n=807$; including government departments, local authorities, engineering, banking and finance, manufacturing, retail and public services from e.g. Australia, Belgium, Canada, Denmark, Germany, Hong Kong, Ireland, Italy, Korea, Poland, Saudi Arabia, Singapore, South Africa, United Kingdom and the USA). The internal consistencies range from $\alpha=0.67$ to 0.88 , with a median of $\alpha=0.81$. These are high values, with only two scales with lower variance, falling below $\alpha=0.7$. The composite scales and sub-scales are summarized in table 2.3 . 
Table 2.3: OPQ32i scales and subscales

\begin{tabular}{|c|c|c|c|}
\hline \multirow{10}{*}{ 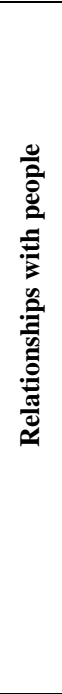 } & \multirow[t]{4}{*}{ Influence } & Persuasive & $\begin{array}{l}\text { The extent to which the individual enjoys selling, is comfortable using negotiation, and likes to } \\
\text { change other people's views. }\end{array}$ \\
\hline & & Controlling & $\begin{array}{l}\text { The extent to which an individual prefers to be in charge, take the lead, tell others what to do and } \\
\text { take control }\end{array}$ \\
\hline & & Outspoken & $\begin{array}{l}\text { The extent to which an individual prefer to freely express opinions, makes disagreement clear, } \\
\text { and is prepared to criticize others. }\end{array}$ \\
\hline & & Independent Minded & $\begin{array}{l}\text { The extent to which an individual prefers to follow his/her own approach, and is prepared to } \\
\text { disregard majority decisions }\end{array}$ \\
\hline & \multirow[t]{3}{*}{ Sociability } & Outgoing & $\begin{array}{l}\text { The extent to which an individual is lively and animated in groups, talkative, and enjoys } \\
\text { attention. }\end{array}$ \\
\hline & & Affiliative & $\begin{array}{l}\text { The extent to which an individual enjoys others' company, likes to be around people, and can } \\
\text { miss the company of others }\end{array}$ \\
\hline & & Socially Confident & $\begin{array}{l}\text { The extent to which a person feels comfortable when first meeting people, at ease in formal } \\
\text { situations }\end{array}$ \\
\hline & \multirow[t]{3}{*}{ Empathy } & Modest & $\begin{array}{l}\text { The extent to which a person dislikes discussing achievements, keeps quiet about personal } \\
\text { success }\end{array}$ \\
\hline & & Democratic & $\begin{array}{l}\text { The extent to which a person consults widely, involves others in decision-making, less likely to } \\
\text { make decisions alone }\end{array}$ \\
\hline & & Caring & $\begin{array}{l}\text { The extent to which a person is sympathetic and considerate towards others, helpful and } \\
\text { supportive, gets involved in others' problems }\end{array}$ \\
\hline \multirow{12}{*}{ 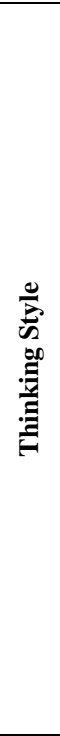 } & \multirow[t]{3}{*}{ Analysis } & Data Rational & $\begin{array}{l}\text { The extent to which a person likes working with numbers, enjoys analysing statistical } \\
\text { information, bases decisions on facts and figures }\end{array}$ \\
\hline & & Evaluative & $\begin{array}{l}\text { The extent to which a person critically evaluates information, looks for potential limitations, } \\
\text { focuses upon errors }\end{array}$ \\
\hline & & Behavioural & The extent to which a person tries to understand motives and behaviours, enjoys analysing people \\
\hline & \multirow[t]{5}{*}{$\begin{array}{l}\text { Creativity \& } \\
\text { Change }\end{array}$} & Conventional & $\begin{array}{l}\text { The extent to which a person prefers well-established methods, favours a more conventional } \\
\text { approach }\end{array}$ \\
\hline & & Conceptual & The extent, to which a person is interested in theories, enjoys discussing abstract concepts \\
\hline & & Innovative & $\begin{array}{l}\text { The extent to which a person generates new ideas, enjoys being creative, thinks of original } \\
\text { solutions }\end{array}$ \\
\hline & & Variety Seeking & $\begin{array}{l}\text { The extent to which an individual prefers variety, tries out new things, likes changes to regular } \\
\text { routine, can become bored by repetitive work }\end{array}$ \\
\hline & & Adaptable & $\begin{array}{l}\text { The extent to which an individual changes behaviour to suit the situation, adapts approach to } \\
\text { different people }\end{array}$ \\
\hline & \multirow[t]{4}{*}{ Structure } & Forward Thinking & $\begin{array}{l}\text { The extent to which an individual takes a long-term view, sets goals for the future, more likely to } \\
\text { take a strategic perspective }\end{array}$ \\
\hline & & Detail Conscious & $\begin{array}{l}\text { The degree to which a person focuses on detail, likes to be methodical, organised and systematic, } \\
\text { may become preoccupied with detail }\end{array}$ \\
\hline & & Conscientious & The degree to which an individual focuses on getting things finished, persists until the job is done \\
\hline & & Rule Following & $\begin{array}{l}\text { The degree to which the individual follows rules and regulations, prefers clear guidelines, finds it } \\
\text { difficult to break rules }\end{array}$ \\
\hline \multirow{10}{*}{ 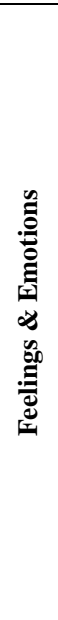 } & \multirow[t]{6}{*}{ Emotion } & Relaxed & $\begin{array}{l}\text { The degree to which a person finds it easy to relax, rarely feels tense, generally calm and } \\
\text { untroubled }\end{array}$ \\
\hline & & Worrying & $\begin{array}{l}\text { The extent, to which an individual feels nervous before important occasions, worries about things } \\
\text { going wrong }\end{array}$ \\
\hline & & Tough Minded & $\begin{array}{l}\text { The degree to which a person is not easily offended, can ignore insults, may be insensitive to } \\
\text { personal criticism }\end{array}$ \\
\hline & & Optimistic & $\begin{array}{l}\text { The extent to which an individual expects things will turn out well, looks to the positive aspects } \\
\text { of a situation, has an optimistic view of the future }\end{array}$ \\
\hline & & Trusting & $\begin{array}{l}\text { The degree to which a person trusts people, sees others as reliable and honest, believes what } \\
\text { others say }\end{array}$ \\
\hline & & $\begin{array}{l}\text { Emotionally } \\
\text { Controlled }\end{array}$ & The extent to which an individual can conceal feelings from others, rarely displays emotion \\
\hline & \multirow[t]{4}{*}{ Dynamism } & Vigorous & The extent to which a person thrives on activity, likes to keep busy, enjoys having a lot to do \\
\hline & & Competitive & The degree to which an individual has a need to win, enjoys competitive activities, dislikes losing \\
\hline & & Decisive & $\begin{array}{l}\text { The extent to which an individual is ambitious and career-centered, likes to work to demanding } \\
\text { goals and targets }\end{array}$ \\
\hline & & Consistency & $\begin{array}{l}\text { The degree to which an individual makes fast decisions, reaches conclusions quickly, less } \\
\text { cautious }\end{array}$ \\
\hline
\end{tabular}




\subsection{RESEARCH AIM AND HYPOTHESES}

The aim of this study was to provide support for the utility of the SUEIT to predict variance in leadership competence indicated by AC technology results, not accounted for by other psychometric tools, namely the OPQ32i (measuring personality). The main objective of this study was therefore to determine the SUEIT's incremental validity over a measure of personality (the OPQ32i) in this regard. This will give an indication of whether EI (as measured by the SUEIT) accounts for variance in predicted leadership competence (measured with the AC technology) in the workplace, additional to the variance accounted for by personality (as measured by the OPQ32i). This finding would also indicate whether the SUEIT predicts something new and distinct, other than related constructs (e.g. personality) which are generally being used to predict leadership competence.

Hence, the first objective was to establish whether EI and personality dimensions significantly correlates with leadership competency scores. It was therefore firstly investigated whether EI (as measured by the SUEIT) and personality (as measured by the OPQ32i) correlated with leadership competence ratings, which were obtained through $\mathrm{AC}$ technology. It was thus hypothesized that,

Hypothesis 1: There will be a significant relationship (i.e. significant correlations) between the five EI dimensions measured by the SUEIT and the ten leadership competency scores obtained through leadership AC simulation exercises.

Hypothesis 2: The 32 sub-dimensions of personality (measured by the OPQ32i) will significantly correlate with the ten leadership competency scores obtained through leadership AC simulation exercises.

The second objective was to investigate whether EI (as measured by the SUEIT) has incremental validity over a measure of personality (as measured by the OPQ32i) when utilized to predict leadership competence. This will indicate if EI measured by the SUEIT, provide a prediction of leadership competence not accounted for by a measure of personality (the OPQ32i). Investigating 
this should provide an indication of whether the SUEIT measures a construct that is different and unique, as opposed to the construct of personality measured by means of the OPQ32i. To examine whether EI accounts for additional variance in predicted leadership competence over and above the measure of personality (OPQ32i) it was thus be proposed that,

Hypothesis 3: Scores obtained on the SUEIT dimensions will explain additional variance in predicted leadership competence, as measured by the AC technology, over variance explained by the OPQ32i scores.

Hypothesis 4: The scores on the SUEIT dimensions will not correlate significantly with the dimension scores of the OPQ32i measuring personality.

\subsection{SAMPLE AND DATA COLLECTION}

The sample consisted of $49 \leq \mathrm{N} \leq 112$ middle managers that was sent on leadership Assessment Centres by the organization sponsoring the study (where $\mathrm{N}=$ sample size). The difference in sample size was due to varying amount of missing cases in the different analyses. Leadership ACs were designed and operated by the Human Resources Department of the sponsoring organisation. Trained observers were used during the leadership AC with the ratio of participants to observers being 3:1. Assessments were conducted during career interviews, in-basket exercises, role-play sessions and group discussions. Participants furthermore completed personality measurement by filling out the OPQ32i. On a separate occasion data was collected from the same participants through an online version of the SUEIT, used to measure EI. Archival data was extracted from company records where needed.

\subsection{DATA ANALYSIS}

The data analysis was conducted with the SPSS (version 12) statistical package and was aimed at determining whether relationships exist between the participants' scores on the different competencies as rated by means of the leadership AC technology and the dimensions measured by the psychometric instruments. It was also aimed at finding evidence for the incremental validity of the SUEIT over the OPQ32i in predicting variance in leadership competency scores. Pearson Product-Moment Correlations were firstly calculated in accordance with hypotheses one, 
two and four. Secondly, a series of Multiple Regression Analyses were conducted in accordance with hypothesis three with the different leadership competencies regressed on the significantly correlated EI and OPQ32i dimensions.

The Pearson Product-Moment correlations coefficient is designed for interval level (continuous) variables. It is used to describe the strength and direction of the linear relationship between two variables. The use of the Pearson Product-Moment correlation is based on the assumptions of normality and linearity of data. These assumptions were checked by means of the Shapiro-Wilck statistic, where a $p>.05$ indicates normality (Kerlinger \& Lee, 2000). In cases where these assumptions were violated but significant correlation was indicated by the Pearson ProductMoment Coefficient, the Spearman Rank Order Correlation (designed for use with ordinal level or ranked data) were also calculated.

Alternatively, Multiple Regression Analysis can be used to analyze the relationship between a single dependent (criterion) variable - the leadership Assessment Centre results in the current study - and several independent (predictor) variables - dimensions of personality and EI. The objective of multiple regression analysis is to use the independent variables whose values are known to predict the single dependent value selected by the researcher (Kerlinger \& Lee, 2000). Each independent variable is weighted by the regression analysis procedure to ensure maximal prediction from the set of independent variables. The weights denote the relative contribution of the independent variables to the overall prediction and facilitate interpretation as to the influence of each variable in making the prediction. The "best" independent variable can be selected by means of regression, based on the correlation coefficients. A higher correlation coefficient indicates a stronger relationship and greater predictive accuracy (Kerlinger \& Lee, 2000). Multiple Regression are also based on the assumptions of normality, linearity and homoscedasticity, and these were checked by inspecting the histograms and normal probability plots of the regression standardized residuals.

Two types of regression analyses were conducted. Hierarchical regression analysis was firstly conducted with the different leadership competencies as dependent variables whilst the OPQ32i dimension data was entered into the equation first (EI second). Each independent variable 
(OPQ32i and EI dimensions respectively) were assessed in terms of what it adds to the prediction of the specific leadership competency. The overall model (OPQ32i and EI together) was then assessed in terms of its ability to predict the leadership competency in question. The relative contributions of each block of variables (OPQ32i and EI respectively) were also assessed (Kerlinger \& Lee, 2000) and interpreted to provide evidence for EI's incremental validity in the specific equation. Standard multiple regression was secondly conducted to determine how much variance in leadership competencies EI and OPQ32i dimensions were able to explain. This approach was used to get an indication of how much unique variance in leadership competence could be explained by OPQ32i and EI dimensions respectively (Kerlinger \& Lee, 2000).

\subsection{SUMMARY}

The research methodology utilised in the current study was relational research of nonexperimental kind. Inferences were made about relations among variables without direct intervention from variation of independent and dependent variables. The participants consisted of a sample of middle managers that underwent a leadership AC in the sponsoring organisation. The OPQ32i and SUEIT data were collected by means of psychometric instruments and additionally AC data was extracted from archival records. Pearson Product-Moment Correlations were calculated to investigate whether EI (as measured by the SUEIT) and personality traits (as measured by the OPQ32i) were meaningfully related to leadership competency scores (obtained on AC simulation exercises). Furthermore, a series of Multiple Regression Analyses were conducted in order to investigate whether a measure of EI (the SUEIT) has incremental validity over a measure of personality (the OPQ32i), when predicting leadership competency scores. It was thus aimed at providing an indication of whether the SUEIT measures a construct that is different and unique, as opposed to the construct of personality measured by means of the OPQ32i, and whether it can predict variance in leadership competency scores, over and above the variance accounted for by a construct and tool generally used for this purpose (i.e. the OPQ32i).

In chapter three the results obtained from the Pearson Product-Moment Correlations will be discussed, indicating whether evidence was found in support of relationship between EI, personality traits and leadership competencies. Pearson Product-Moment Correlation results between EI (the SUEIT) and personality traits (the OPQ32i), indicating overlap between these 
two measures will also be discussed. The chapter concludes with a discussion of the Multiple Regression Analyses results and the evidence in support of the incremental validity of the SUEIT (measuring EI) over the OPQ32i (measuring personality).

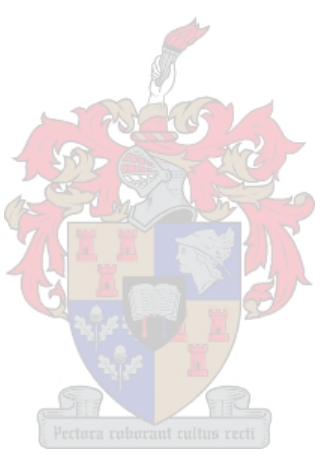




\section{CHAPTER 3: RESULTS}

\subsection{INTRODUCTION}

The aim of this study was to, by exploration, provide evidence for the incremental validity of EI by determining whether the SUEIT predicts something new and distinct, other than related constructs (e.g. personality), which is generally being used to predict leadership competence. Therefore the purpose of this study was to explore whether the SUEIT accounts for variance in leadership competencies indicated by ratings on $\mathrm{AC}$ simulation exercises used to predict leadership competence in the workplace, additional to the variance accounted for by personality (as measured by the OPQ32i). From the aim various objectives were derived for which corresponding hypotheses were formulated (presented in section 2.4). Appropriate data analysis techniques were employed to investigate and explore the hypotheses and objectives of the study. The results (per objective) are reported and discussed in this chapter.

\subsection{THE SAMPLE}

Due to missing cases in the data that varied between different analyses that was conducted, the sample consisted of $49 \leq \mathrm{N} \leq 112$ respondents. The total sample $(\mathrm{N}=112)$ consisted of 57 males $(50.5 \%)$ and 55 females (49.5\%) while ages of the respondents varied between 24 and 54, with the mean age being 36 . The respondents were all middle managers in the organisation sponsoring the study, with educational levels that varied from a grade 12 to post graduate qualifications.

\subsection{RESULTS: RELIABILITY}

The reliability statistics for the SUEIT as utilised in the current study was calculated and is summarized in table 3.1 below. 
Table 3.1: The current study's reliability statistics for the SUEIT.

\begin{tabular}{|l|r|}
\hline \multicolumn{1}{|c|}{ SUEIT dimensions } & \multicolumn{2}{|l|}{ Cronbach's } \\
Alpha
\end{tabular}

For the current study, the internal consistency reliability could not be calculated for the OPQ32i, due to the fact that the item scores were not available to the researcher. This should be viewed as a limitation of the study, which is linked to the use of archival records as sources of data.

\subsection{CORRELATION RESULTS: EMOTIONAL INTELLIGENCE, PERSONALITY AND LEADERSHIP COMPETENCIES}

The first objective was to establish whether EI and personality significantly predict with leadership competency scores. It was therefore firstly investigated whether EI (as measured by the SUEIT) and personality (as measured by the OPQ32i), have significant relationships with leadership competencies (AC scores), through determining the Pearson Product-Moment correlations.

The Shapiro-Wilck Statistic (presented in Appendix 1) was calculated for all the variables (SUEIT and OPQ32i dimensions) to test for normality. A Shapiro-Wilck statistic with $\underline{p}>0.05$ was assumed to indicate normality. The OPQ32i dimensions that were found to have violated the assumptions of normality are Controlling $(\underline{\mathrm{W}}=0.95213, \underline{\mathrm{p}}<.05)$; Socially Confident $(\underline{\mathrm{W}}=$ $0.93986, \underline{p}<.05)$; Relaxed $(\underline{\mathrm{W}}=0.13892, \underline{\mathrm{p}}<.05)$; Achieving $(\underline{\mathrm{W}}=0.94142, \underline{\mathrm{p}}<.05)$, Optimistic $(\underline{\mathrm{W}}=0.94450, \underline{\mathrm{p}}<.05)$ and Decisive $(\underline{\mathrm{W}}=0.94450 \mathrm{p}<.05)$. None of the EI dimensions were found to violate the assumptions of normality ( $\mathrm{p}>0.05)$. 


\subsubsection{Emotional Intelligence and Leadership Competencies}

As part of the first objective, to establish whether EI (as measured by the SUEIT) significantly correlate with leadership competency scores obtained on a leadership AC, and thus it was hypothesised that,

Hypothesis 1: There will be a significant relationship (i.e. significant correlations) between the five EI dimensions measured by the SUEIT and the leadership competency scores obtained through leadership AC simulation exercises.

Alternative hypothesis: There will not be significant relationships between the five EI dimensions measured by the SUEIT and the leadership competency scores obtained through leadership AC simulation exercises.

The relationship between the five dimensions of EI (as measured by the SUEIT) and ratings on the ten leadership competencies (obtained by means of four AC exercises used to assess leadership competence) was investigated by calculating the Pearson Product-Moment Correlation Coefficient. For the variables where the assumption of normality was violated and significant Pearson-Product Moment Correlations were indicated, non-parametric correlations (Spearman rho) were also calculated (table 3.2). This was to establish whether a violation of the assumption of normality had an impact on the significance of correlations indicated by the Pearson-Product-Moment correlations. The results of the correlations are summarized in tables 3.2 and 3.3 . 
Table 3.2: Pearson Product-Moment Correlations between dimensions of the SUEIT and leadership competencies

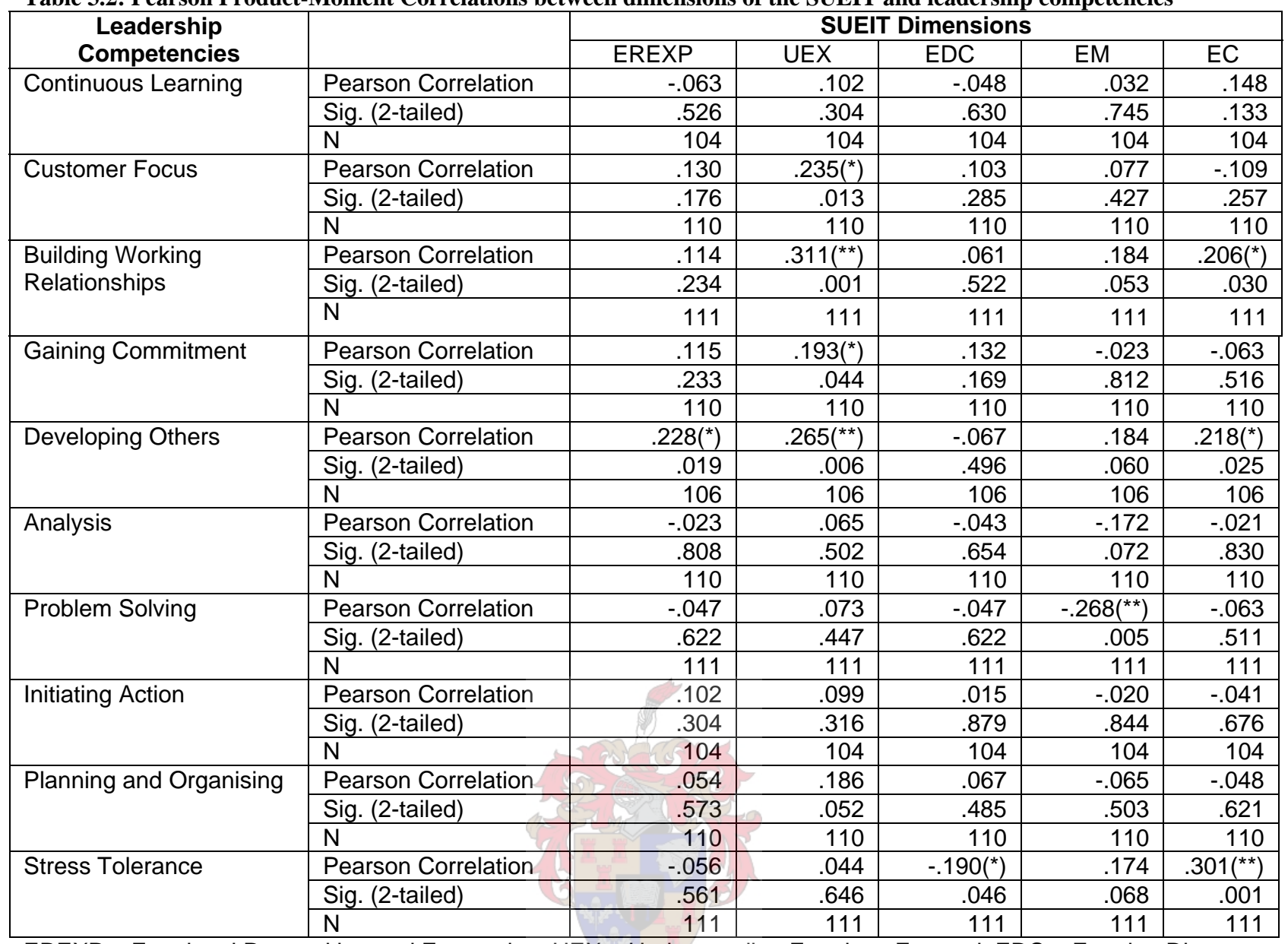

EREXP = Emotional Recognition and Expression; UEX = Understanding Emotions External; EDC = Emotion Direct Cognition; $E M=$ Emotional Management; $E C=$ Emotional Control

** Correlation is significant at the 0.01 level (2-tailed). * Correlation is significant at the 0.05 level (2-tailed).

The following section will briefly discuss the correlations that emerged per leadership competency.

\subsubsection{Customer Focus}

Firstly, there was a small but significant positive correlation between the EI dimension, Understanding Emotions External and the leadership competency, Customer Focus $[\underline{r}=0.235, \underline{n}$ $=110, \underline{p}<.05]$ with high scores on the Understanding Emotions External dimension of EI associated with high ratings on the leadership competency, Customer Focus. Therefore, it could be argued that individuals who are highly capable of perceiving and understanding the emotions of their customers and are able to "read" the emotions that they convey will be more competent in taking action according to their customers' needs and thus develop more productive and satisfying customer relations. 
A study by Nel, De Villiers and Engelbrecht (2003) corroborate these results. In their study the influence of EI on performance in a call centre environment was explored, where the client and client centeredness is perceived as a key focus of the environment. Total EI scores on the Emotional Competency Inventory (Hay \& McBer, in Nel et al., 2003) were found to have a significant positive relationship with effective performance in a customer orientated call centre environment $(r=0.559, p<0.01)$. Additionally, the Self Management $(r=0.604, p<0.01)$, Trustworthiness $(r=0.668, p<.01)$ and Emotional Self Awareness $(r=0.485, p<0.01)$ ECI dimensions also correlated significantly with effective performance in the customer orientated call centre environment ( $\mathrm{Nel}$ et al., 2003).

\subsubsection{Building Working Relationships}

In the current study, secondly, a moderate but significant positive correlation was found between the EI dimension, Understanding Emotions External, and the leadership competency, Building Working Relationships $[\underline{r}=0.311, \underline{\mathrm{n}}=111, \underline{\mathrm{p}}<.01]$ with high scores on the Understanding Emotions External dimension of EI associated with high ratings on the leadership competency, Building Working Relationships. These results can be interpreted to indicate that individuals with the ability to understand the emotions of their colleagues at work, as well as the impact that emotions have on the workplace, are more adept at developing and using collaborative relationships to facilitate the accomplishment of work goals. Individuals that are able to "read" the emotional overtones of workplace environments and discussions (e.g. staff meetings) will be able to proactively build effective relationships and reach work goals in a collaborative fashion, through giving recognition and empathising appropriately as well as facilitating conflict within the group. This partly corroborate with previous research results of Sarros and Santora (2001). They explored the nature of transformational and transactional leadership and concluded that transactional leaders achieve results through recognizing individuals' talents and building enthusiasm through appeals to their emotions, values and belief systems (contingent reward).

A small but significant positive correlation was also found between the EI dimension, Emotional Control and the leadership competency, Building Working Relationships $[\underline{r}=0.206, \underline{n}=111, \underline{p}=$ $<.05]$ with high scores on Emotional Control associated with high ratings on Building Working 
Relationships. The Spearman correlation between Emotional Control and Building Working Relationships was also calculated and indicated a small but significant positive correlation $[\underline{r}=$ $0.201, \underline{\mathrm{n}}=111, \underline{\mathrm{p}}<.05]$. These results suggest that leaders with high scores on this EI dimension are able to control their emotions (specifically strong emotions), preventing it from overriding their capacity to think and act appropriately. They will therefore not generally provoke anger, resentment or confusion by strong displays of emotion, but rather deal constructively with, for example conflict and through that build collaborative relationships to facilitate the accomplishment of work goals.

\subsubsection{Gaining Commitment}

There was also a small but significant positive correlation between the EI dimension, Understanding Emotions External and the leadership competency, Gaining Commitment $[\underline{r}=$ $0.193, \underline{n}=110, \underline{p}=<.05]$ with high scores on Understanding Emotions External associated with high ratings on Gaining Commitment. This could indicate that individuals who are able to perceive and understand the emotions and emotional responses of others, will be more competent at using the appropriate interpersonal styles and techniques to gain acceptance of their ideas or plans. Having an understanding of the impact of individuals' emotions and the collective emotions of a team on the way they act and think, enables an individual to modify his or her own behaviour to accommodate the situation and individuals involved. Once again, this finding partially confirms research done by Sarros and Santora (2001). In their explorative study of transformational and transactional leadership they concluded that transformational leaders are able to switch from one leadership style to another to suit the individual and the situation in order to maximize results (individualized consideration). This finding furthermore corroborate with previous results of Gardner and Stough (2003), which provided evidence that the Understanding Emotions External dimension of the SUEIT is the most important predictor of transformational leadership. Leaders that adopt the transformational leadership style are known to gain the commitment of employees to achieve extraordinary goals (Gardner \& Stough, 2003). 


\subsubsection{Developing Others}

Furthermore, a small but significant positive correlation was found between the EI dimension, Understanding Emotions External and the leadership competency, Developing Others $[\underline{r}=0.265$, $\underline{\mathrm{n}}=106, \underline{\mathrm{p}}<.01]$ with high scores on Understanding Emotions External associated with high ratings on Developing Others. Hence it would seem that leaders with an enhanced ability to understand the context in which the emotions of their subordinates arise as well as the appropriateness of emotional responses and behaviours, seem to be able to more accurately observe possible blind spots and other areas of weakness in the employee. Therefore leaders with this capability would more easily facilitate a process to gain insight into these development areas in a constructive manner.

A small but significant positive correlation was also found between the EI dimension, Emotional Recognition and Expression and the leadership competency, Developing Others $[\underline{r}=0.228, \underline{\mathrm{n}}=$ $106, \mathrm{p}<.05]$ with high ratings on Emotional Recognition and Expression associated with high scores on Developing Others. This might suggest that leaders scoring high on the Emotional Recognition and Expression EI dimension would more accurately and constructively express their feelings about a subordinate's non-performance, and facilitate insight in the subordinate into his/her weaknesses. Here the emphasis is also on the constructive expression of the leader's feelings about the subordinate's lack of performance in certain areas, by keeping strong negative emotions under control and through that ensuring that they will be committed to fulfill current or future job responsibilities more effectively.

This statement is supported by the small but significant correlation between the EI dimension, Emotional Control and Developing Others $[\underline{\mathrm{r}}=0.218, \underline{\mathrm{n}}=106, \underline{\mathrm{p}}<.05]$, with high scores on Emotional Control associated with high ratings on Developing Others. This could indicate that leaders who are able to express their feelings about their subordinates' development areas and lack of performance in these areas in a more constructive fashion, will be more successful in facilitating insight into, and growth in, their areas of development. 


\subsubsection{Problem Solving}

There was a small but significant negative correlation between the EI dimension, Emotional Management and the leadership competency, Problem Solving $[\mathrm{r}=-0.268, \underline{\mathrm{n}}=111, \underline{\mathrm{p}}<.01]$ with high scores on Emotional Management associated with low ratings on Problem Solving. In the organisation sponsoring the study (as a result of the industry the organisation operations in), it is required of leaders to thoroughly and accurately identify, define and analyze a problem with a view to select the most appropriate course of action once alternatives have been generated and assessed in terms of practicality, effectiveness and implications. In the light of this requirement, it could be argued that the organisation encourages the use of predominantly analytical processes in problem solving with moods and emotional information to be taken into account to a lesser extent. The emphasis is therefore on the use of facts and logic in order to derive solutions to complex problems, rather than fostering positive moods in oneself and others, as is required by the EI dimension, Emotional Management. This also explains the lack of correlation between Problem Solving and Emotional Direct Cognition, as emotional information is not taken into account in daily reasoning and decision-making. Solutions to problems are perceived as effective when it can be motivated logically, all the details are taken into account and relevant criteria are used.

\subsubsection{Stress Tolerance}

There was a small but significant negative correlation between the EI dimension, Emotion Direct Cognition and the leadership competency Stress Tolerance $[\underline{r}=-0.190, \underline{\mathrm{n}}=111, \underline{\mathrm{p}}<.05]$ with high scores on Emotion Direct Cognition associated with low ratings on Stress Tolerance. This result could suggest that leaders, who to a large extent incorporate emotional information in their daily reasoning, might find it more difficult to maintain stable performance under pressure or opposition and to handle stress in a manner that is acceptable to the organization. This confirmed that when employees deviate from the logical analytical decision making style that is the norm in the organisation (due to the industry) that they function in, the employee will probably experience some stress.

A moderate and significant positive correlation was also found between the EI dimension, Emotional Control, and the leadership competency, Stress Tolerance $[\underline{r}=0.301, \underline{\mathrm{n}}=111, \underline{\mathrm{p}}<$ 
.01] with high scores obtained on Emotional Control associated with high ratings on Stress Tolerance. Henceforth, this could indicate that leaders who have highly developed abilities to regulate and manage their own strong emotions on a daily basis will more effectively ensure that stable performance is maintained, although under pressure or opposition.

In conclusion to hypothesis one, the five different EI dimensions did have significant relationships respectively to six of the leadership competencies namely, Customer Focus, Building Working Relationships, Gaining Commitment, Developing Others, Problem Solving and Stress Tolerance. For these, hypothesis one could be accepted. EI did not have any significant relationships to four of the leadership competencies, namely Continuous Learning, Analysis, Initiating Action, as well as Planning and Organising. For these, hypothesis one is rejected and the alternative hypothesis is accepted.

\subsubsection{Personality traits and leadership competencies}

In the second instance, it was necessary to establish whether personality traits (as measured by the OPQ32i) significantly correlate with leadership competency scores (obtained on AC simulation exercises). It could thus be hypothesized that,

Hypothesis 2: The 32 sub-dimensions of personality (measured by the OPQ32i) will significantly correlate with the ten leadership competency scores obtained through leadership AC simulation exercises.

Alternative hypothesis: The 32 sub-dimensions of personality (measured by the OPQ32i) will not significantly correlation with the ten leadership competencies (obtained on AC simulation exercises).

To explain hypothesis two, the relationship between the sub-dimensions of the OPQ32i and scores on the ten leadership competencies (obtained by means of four AC exercises used to assess leadership competence) was investigated by calculating the Pearson Product-Moment Correlation Coefficient (the full correlation matrix is documented in Appendix 3.1). For the variables (i.e. the OPQ32i dimensions, Controlling, Socially Confident, Relaxed and Decisive and the leadership competencies, Analysis, Problem Solving, Continuous Learning, Building 
Working Relationships, Gaining Commitment, Planning and Organising, and Developing Others) where the assumption of normality was violated (see Appendix 1.1) and positive Pearson-product moment correlations were indicated, Spearman correlations were also calculated (see table 3.3). This was to establish whether a violation of the assumption of normality had an impact on the significance of correlations indicated by the Pearson-ProductMoment correlations.

Table 3.3: Spearman Correlations between OPQ32i dimensions - identified as violating assumptions of normality - and Leadership competencies

\begin{tabular}{|c|c|c|}
\hline $\begin{array}{c}\text { Leadership } \\
\text { Competencies }\end{array}$ & & OPQ32i Dimensions \\
\hline \multirow[t]{4}{*}{ Analysis } & & Controlling \\
\hline & Spearman Correlation & .247 \\
\hline & Sig. (2-tailed) & .074 \\
\hline & $\mathrm{N}$ & 53 \\
\hline \multirow[t]{4}{*}{ Problem Solving } & & Controlling \\
\hline & Spearman Correlation & .259 \\
\hline & Sig. (2-tailed) & .059 \\
\hline & $\mathrm{N}$ & 54 \\
\hline \multirow[t]{4}{*}{ Continuous Learning } & & Socially Confident \\
\hline & Spearman Correlation & $.317^{*}$ \\
\hline & Sig. (2-tailed) & .030 \\
\hline & 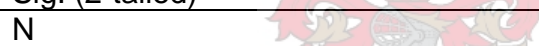 & 47 \\
\hline \multirow[t]{4}{*}{ Gaining Commitment } & 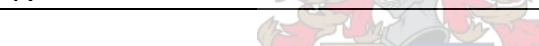 & Socially Confident \\
\hline & Spearman Correlation & $.435^{\star \star}$ \\
\hline & Sig. (2-tailed) & .001 \\
\hline & 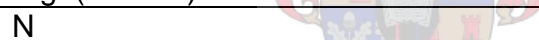 & 53 \\
\hline \multirow[t]{4}{*}{ Planning and Organising } & 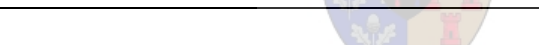 & Socially Confident \\
\hline & Spearman Correlation & $.312^{*}$ \\
\hline & Sig. (2-tailed) & .023 \\
\hline & $\mathrm{N}$ & 53 \\
\hline \multirow{8}{*}{$\begin{array}{l}\text { Building Working } \\
\text { Relationships }\end{array}$} & & Socially Confident \\
\hline & Spearman Correlation & $.387^{* *}$ \\
\hline & Sig. (2-tailed) & .004 \\
\hline & $\mathrm{N}$ & 54 \\
\hline & & Decisive \\
\hline & Spearman Correlation & $.302^{*}$ \\
\hline & Sig. (2-tailed) & .026 \\
\hline & $\mathrm{N}$ & 54 \\
\hline \multirow[t]{4}{*}{ Gaining Commitment } & & Relaxed \\
\hline & Spearman Correlation & -.169 \\
\hline & Sig. (2-tailed) & .227 \\
\hline & $\mathrm{N}$ & 53 \\
\hline \multirow[t]{4}{*}{ Developing Others } & & Relaxed \\
\hline & Spearman Correlation & .235 \\
\hline & Sig. (2-tailed) & .105 \\
\hline & $\mathrm{N}$ & 49 \\
\hline
\end{tabular}

** Correlation is significant at the 0.01 level (2-tailed). * Correlation is significant at the 0.05 level (2-tailed).

The following section will briefly discuss the correlations that emerged per leadership competency (refer to Table 3.3 and Appendix 3.1). 


\subsubsection{Customer Focus}

The Pearson Product-Moment correlations (Appendix 3.1) indicated that there was a moderate and significant positive correlation between the personality dimension, Outgoing, and the leadership competency, Customer Focus $[\underline{\mathrm{r}}=0.354, \underline{\mathrm{n}}=53, \underline{\mathrm{p}}<.01]$, with high scores on Outgoing associated with high ratings on Customer Focus. Highly outgoing leaders are generally sociable, talkative and fun to be with and would therefore more likely attract customers to him or her and develop and sustain productive customer relations, displaying customer focus and hence model the acceptable way of handling customers to their subordinates.

Furthermore, a moderate significant positive relationship was also found between the personality dimension, Affiliative and the leadership competency, Customer Focus $[\underline{\mathrm{r}}=0.471, \underline{\mathrm{n}}=53, \underline{\mathrm{p}}<$ .01] with high scores on Affiliative associated with high Customer Focus ratings. Forming friendships and having strong attachments to others are generally of high importance to highly affiliative leaders. They would therefore respond to customer needs with a sense of urgency, in order to ensure that they develop and sustain the relationship with the customer, hence displaying costumer focus.

Lastly, there was a modest but significant negative correlation between the personality dimension Emotionally Controlled and the leadership competency, Customer Focus $[\underline{r}=-0.348, \underline{n}=53, \underline{p}<$ .05] with low scores on Emotionally Controlled being associated with high scores on Customer Focus. It could be argued that because these individuals' emotional control is low, they will more likely express their enthusiasm about providing the best service towards customers and through that, motivate others to be more service orientated and be responsive to customer needs.

\subsubsection{Building Working Relationships}

There was a small but significant positive correlation between the OPQ32i dimension Persuasiveness and the leadership competency, Building Working Relationships $[\underline{\mathrm{r}}=0.271, \underline{\mathrm{n}}=$ 54, $\mathrm{p}<.05]$ with high scores on Persuasiveness associated with higher ratings on Building Working Relationships. This indicates that leaders, who enjoy negotiation and selling their ideas to colleagues should generally be more competent in gaining agreement from others to support team objectives, through the building of collaborative relationships. 
Furthermore, a small but significant negative correlation between the personality dimension, Independent Mindedness and the leadership competency, Building Working Relationships $[\underline{\mathrm{r}}=$ $0.272, \underline{\mathrm{n}}=54, \underline{\mathrm{p}}<.05]$ was found, with low scores on Independent Mindedness associated with high scores on Building Working Relationships. This result suggests that leaders who are prepared to compromise, instead of keeping strong views when they are in disagreement with others, would most probably place higher priority on team goals than on their own and therefore be able to build more collaborative relationships in the work environment to facilitate the accomplishment of work goals.

A moderate but significant correlation was found between the personality dimension, Affiliative and the leadership competency, Building Working Relationships $[\underline{\mathrm{r}}=0.308, \underline{\mathrm{n}}=54, \underline{\mathrm{p}}=.05]$ with high scores on Affiliative being associated with more competent ratings on Building Working Relationships. This result could be interpreted to mean that leaders who enjoy others' company and like to be around people would most probably build effective relationships with their coworkers in a pro-active manner.

Further to this, a moderate but significant relationship between the personality dimension, Socially Confident and the leadership competency, Building Working Relationships $[\underline{\mathrm{r}}=0.410, \underline{\mathrm{n}}$ $=54, \underline{\mathrm{p}}<.01]$ was also found, with high scores on Socially Confident associated with high ratings on the leadership competency, Building Working Relationships. It would seem, therefore, that when leaders are feeling self-assured and confident in their abilities as communicators, they more often seek and expand on others' ideas and through that enhance the partnership with followers' and stakeholders' objectives. The dimension Socially Confident was found to have violated the assumption for normality and therefore a Spearman correlation was calculated with Building Working Relationships. Again, a positive slightly smaller correlation was found between Socially Confident and Building Working Relationships $[\underline{\mathrm{r}}=0.387, \underline{\mathrm{n}}=54, \underline{\mathrm{p}}<.01]$ (refer to table 3.3).

Moreover, the results revealed that the strongest positive correlation was indicated between the personality dimension, Democratic and the leadership competency, Building Working Relationships $[\underline{\mathrm{r}}=0.512, \underline{\mathrm{n}}=54, \underline{\mathrm{p}}<.01]$ with high scores on Democratic associated with high 
scores on the leadership competency, Building Working Relationships. In interpreting this result, it would seem that a leader who consults widely and involves others in decision-making build collaborative relationships more effectively, because they are perceived as placing higher priority on the team's goals than on their own.

The moderate but significant correlation between the OPQ32i dimension Behavioural and the leadership competency, Building Working Relationships $[\underline{\mathrm{r}}=0.304, \underline{\mathrm{n}}=54, \underline{\mathrm{p}}<.05]$ further corroborate the aforementioned result. Leaders with high scores on the Behavioural dimension of personality would to a large extent try to understand colleagues' motives and behaviour and more likely look at the "human" side of a problem. Leaders with this preference would therefore more often seek and expand on others' ideas and may make decisions by taking into account the impact of the decision on subordinates and colleagues. This is a key requirement in order to build good interpersonal relationships; which in turn will result in the collaborative achievement of work goals.

Lastly, the results revealed small and moderate significant negative correlations respectively between the Personality dimensions, Emotionally Controlled $[\underline{\mathrm{r}}=-0.287, \underline{\mathrm{n}}=54, \underline{\mathrm{p}}<.05]$ and Decisive $[\underline{\mathrm{r}}=-0.324, \underline{\mathrm{n}}=54, \underline{\mathrm{p}}<.05]$ with the leadership competency, Building Working Relationships. It seems that leaders who tend to be upfront and open, letting others know exactly where they stand with them would more competently build collaborative relationships through creating an understanding of the situation and objectives to be met. Further to this, it would seem that highly decisive leaders, who like to take time to weigh things up slowly and carefully before making decisions, would more often seek others' ideas and gain agreement of his or her colleagues in a collaborative way. This would, in turn, result in shared commitment to decisions being made, between the leader and his or her subordinates, which more often results in good teamwork to achieve a common goal. Due to the violation of the assumption of normality for the Decisive dimension, the Spearman correlation with Building Working Relationships was also calculated $[\underline{\mathrm{r}}=.302, \underline{\mathrm{n}}=54, \underline{\mathrm{p}}<.05]$ (refer to table 3.3). 


\subsubsection{Gaining Commitment}

Further inspection of the correlation results revealed several significant relationships between various personality dimensions and the leadership competency, Gaining Commitment. Firstly, a small but significant negative correlation between the personality dimension, Independent Mindedness and the leadership competency, Gaining Commitment $[\underline{r}=-0.293, \underline{n}=53, \underline{p}=.05]$ emerged. This could indicate that leaders who are unlikely to keep to their views when others argue from a contrary position, would more likely find it easier to build harmonious relationships by establishing common ground between him or herself and their followers and utilize this to mobilize them towards action.

Secondly, a moderate but significant positive correlation was indicated between the personality dimension, Socially Confident, and the leadership competency Gaining Commitment $[\underline{r}=0.424$, $\underline{\mathrm{n}}=53, \underline{\mathrm{p}}<.01]$, indicating that leaders who feel self-assured and confident in their abilities to communicate with others would more easily gain acceptance of their ideas or plans through applying an appropriate interpersonal communication style. In this instance a Spearman correlation is also reported $[\underline{r}=0.435, \underline{n}=54, \underline{p}<.05]$ as the assumption of normality was violated (refer to table 3.3).

Thirdly, a moderate but significant positive relationship was indicated between the personality dimension, Behavioural and the leadership competency, Gaining Commitment $[\underline{r}=0.317, \underline{n}=53$, $\mathrm{p}<.05]$. It would seem that leaders with a preference for thinking through what motivate their subordinates and what their reactions to certain decisions being made are likely to be, would more readily adopt an appropriate interpersonal style, respond to individual needs and beliefs and attempt to establish acceptance of his or her ideas through creating a win-win situation.

Fourthly, a moderate but significant negative correlation between the personality dimension, Relaxed and the leadership competency, Gaining Commitment $[\underline{\mathrm{r}}=-0.323, \underline{\mathrm{n}}=53, \underline{\mathrm{p}}<.05]$ emerged. Leaders who score low on the Relaxed dimension of the OPQ32i, have a degree of nervous energy and may often be perceived as highly driven individuals by their subordinates and peers. This high level of energy displayed by the leader in pursuing his or her goals, may motivate subordinates to also invest their energy in working towards achieving these goals. The 
Relaxed dimension was found to have violated the assumption for normality. Therefore the Spearman correlation was also calculated with Gaining Commitment. The correlation was, however, not significant $[\underline{\mathrm{r}}=-0.169, \underline{\mathrm{n}}=53, \underline{\mathrm{p}}>.05]$ (refer to table 3.3) indicating that the Pearson Correlation should be interpreted with caution.

\subsubsection{Developing Others}

The correlation results between the various personality dimensions and the leadership competency, Developing Others, is reported next. There was a moderate but significant positive correlation between the personality dimension, Outgoing and the leadership competency, Developing Others $[\underline{r}=0.414, \underline{n}=49, \underline{p}<.01]$. It would seem from this result that more outgoing leaders are inclined to be more talkative and therefore will more likely provide timely feedback on observations regarding their subordinates' performance, as well as ask for the individual's perception regarding development areas and what needs to be done to achieve career goals. Possessing this personality trait could therefore enable the leader to facilitate the gaining of insight into behaviour and possible blind spots in subordinates, helping to develop them in order to fulfill current or future responsibilities more effectively.

In addition to this a moderate but significant positive correlation between the personality dimension, Democratic and the leadership competency, Developing Others $[\underline{r}=0.314, \underline{n}=49, \underline{p}<$ $.05]$ emerged, implying that leaders who score high on the Democratic scale generally might tend to listen more to others, encourage group discussion and value the contribution of others. Leaders who have the preference to be more democratic would firstly invest more time in developing their subordinates, because they value their contribution to the team objectives. Secondly, they will be more effective coaches, as they take time to listen to their subordinates' perceptions regarding development areas, encourage a discussion regarding what needs to be done to achieve career goals and would therefore be more accurate in their recommendation regarding courses or job related activities for development purposes.

Furthermore, the results revealed a small but significant negative correlation between the personality dimension, Relaxed and the leadership competency, Developing Others $[\underline{\mathrm{r}}=-0.287, \underline{\mathrm{n}}$ $=49, \underline{p}<.05]$. Again, individuals scoring low on the Relaxed dimension of the OPQ32i have a 
higher level of nervous energy, and would more likely drive their subordinates to fulfill responsibilities effectively who could contribute to their development. For this dimension a Spearman correlation needed to be calculated. The correlation $[\underline{r}=0.235, \underline{n}=49, \underline{p}>.05]$ (refer to table 3.3) was not significant and thus the Pearson Correlation needs to be interpreted with caution.

Lastly, there was a moderate but significant negative correlation between the personality dimension, Tough Minded and the leadership competency, Developing Others $[\underline{\mathrm{r}}=-0.343, \underline{\mathrm{n}}=$ $49, \mathrm{p}<.05]$. It would seem that individuals with lower scores on Tough Minded are more concerned about how others see them and are more easily affected by adverse criticism. This seems to motivate them to do well as a leader of a team and motivate, coach and support the development of their team members in order to avoid receiving criticism as a leader of team.

\subsubsection{Analysis}

The three correlations that emerged between the OPQ32i dimensions and the Analysis leadership competency, is discussed next. First there was a small but significant positive correlation between the personality dimension, Controlling, and the leadership competency, Analysis $[\underline{\mathrm{r}}=0.276, \underline{\mathrm{n}}=$ $53, \underline{p}<.05]$. However, a non-significant Spearman correlation was also calculated $[\underline{r}=0.247, \underline{n}$ $=53, \mathrm{p}>.05]$ (refer to table 3.3). For this result it could be argued (however, with caution) that it is important for a leader (in this organization) to be able to accurately analyse a situation by identifying the key issues and interpreting and appraising it, in order to be in control and take charge of a situation and individuals involved. This result makes sense in terms of the industry in which the employees in the sponsoring organization function, where thinking styles are mainly analytical (as it is considered to be effective behaviour).

Adjunct to this, there was a moderate but significant positive correlation between the personality dimension, Evaluative, and the leadership competency, Analysis $[\underline{r}=0.301, \underline{n}=53, \underline{p}<.05]$. It would seem that leaders who are more evaluative would to a larger extent prefer to critically evaluate information, and would therefore be more effective in analyzing a situation or information by identifying key issues, interpreting and appraising it. 
Lastly, there was a moderate but significant negative correlation between the personality dimension, Tough Minded and the leadership competency, Analysis $[\underline{\mathrm{r}}=-0.426, \underline{\mathrm{n}}=53, \underline{\mathrm{p}}<.01]$ with lower preference towards Tough Mindedness associated with higher ratings on Analysis. This correlation was somewhat surprising, as individuals with low ratings on the Tough Minded personality dimension would often become too emotionally involved in situations where their own feelings have been hurt. This characteristic may prevent the leader from logically analyzing causes and effects of problems (obtaining high scores on the Analysis leadership competency). One could however argue that leaders who are more sensitive towards criticism (obtaining low scores on the Tough Minded personality dimension) would probably try to prevent receiving it by putting in more effort to get to issues beneath the surface (score high on the Analysis leadership competency) and obtain additional information instead of accepting things at face value.

\subsubsection{Problem Solving}

Three correlations between different OPQ32i personality dimensions and the leadership competency, Problem Solving emerged. A moderate but significant positive correlation between the leadership competency, Problem Solving, and the personality dimension, Controlling $[\underline{r}=$ $.302, \underline{\mathrm{n}}=54, \underline{\mathrm{p}}<.05$ ] emerged. It is known that leaders who score high on this personality trait tend to prefer to feel in control of situations and their subordinates' behaviour. One could therefore probably argue that leaders with such a preference would always be actively involved in generating effective solutions to problems to ensure that they stay in control of situations where difficulties arise. The Controlling dimension was found to violate the assumption for normality (refer to Appendix 1) and thus a Spearman correlation (non significant) was calculated $[\underline{r}=0.259$, $\underline{\mathrm{n}}=54, \underline{\mathrm{p}}>.05]$ prompting a cautious interpretation of this finding.

There was a moderate but significant positive correlation between the Personality dimension, Evaluative and the leadership competency, Problem Solving $[\underline{r}=0.316, \underline{n}=54, \underline{p}<.05]$. Here it could be argued that leaders who tend to critically evaluate information would be able to thoroughly and accurately identify, define and analyse problems and select the most appropriate course of action to solve problems effectively. 
Furthermore, there was a moderate but significant negative correlation between the leadership competency, Problem Solving and the personality dimension, Tough Minded $[\underline{r}=-.388, n=53, p$ $<.01]$. It would seem that leaders who are less emotionally involved in situations would be able to more effectively establish the appropriate solution to complex problems, as they will be able to objectively analyze and interpret the information or situation at hand.

\subsubsection{Initiating Action}

The only significant correlation with the leadership competency Initiating Action that emerged, was a moderate but significant negative correlation with the Personality dimension, Tough Minded $[\underline{\mathrm{r}}=-0.329, \underline{\mathrm{n}}=54, \underline{\mathrm{p}}<.05]$ with low scores on Tough Minded being associated with higher ratings on Initiating Action. One could argue that his or her sensitivity towards criticism would drive the leader to be proactive and initiate action to achieve goals in order to avoid negative responses of others.

\subsubsection{Planning and Organising}

The correlation results related to the Planning and Organising leadership competency is reported next. There was a small but significant positive correlation between the Personality dimension, Outspoken and the leadership competency, Planning and Organizing $[\underline{\mathrm{r}}=.291, \underline{\mathrm{n}}=53, \underline{\mathrm{p}}<.05]$. This could indicate that more outspoken leaders are generally very clear about their own views and more often prepared to voice their views and stick to them if others argue from a contrary position. This type of leader would more likely be able to facilitate the following of established courses of action by clearly stating criteria and time allocation, whilst urging subordinates to stay on course and not get derailed.

Further to this, moderate but significant positive relationships between the personality dimensions Outgoing $[\underline{\mathrm{r}}=0.303, \underline{\mathrm{n}}=53, \underline{\mathrm{p}}<.05]$ and Socially Confident $[\underline{\mathrm{r}}=0.324, \underline{\mathrm{n}}=53, \underline{\mathrm{p}}<$ .05 ; and the Spearman correlation, $\underline{\mathrm{r}}=0.312, \underline{\mathrm{n}}=54, \underline{\mathrm{p}}<.05$ ] with the leadership competency, Planning and Organising, emerged. This could indicate that leaders who are more talkative as well as confident in their ability as communicators are more likely to effectively manage time of their subordinates by making known a sense of urgency and by clarifying available resources to accomplish goals effectively. 
Lastly, there was a moderate but significant negative correlation between the personality dimension, Data Rational and the leadership competency, Planning and Organising $[\underline{\mathrm{r}}=-.307, \underline{\mathrm{n}}=$ $53, \underline{\mathrm{p}}<.05]$. This could indicate that leaders who are rationally and analytically orientated, with a preference towards working with numbers and statistics (behaviour that is judged to be effective in the context of the sponsoring organization), may find it difficult to establish and implement courses of action in an area where hard data or clearly quantifiable trends are not available (this is increasingly the case as leaders progress to higher leadership levels in the organization).

\subsubsection{Stress Tolerance}

There was a small but significant positive relationship between the personality dimension, Behavioural and the leadership competency, Stress Tolerance $[r=.297, \underline{n}=54, \underline{p}<.05]$. Leaders who score high on the Behavioural personality dimension, are generally more introspective (trying to understand their own motives and reactions, etc.) and it could thus be argued that they will be able to more effectively identify situations which could cause them stress and develop mechanisms to avoid the situation or deal with it effectively. Adjunct to this, a moderate but significant negative correlation between the personality dimension, Worrying, and the leadership competency, Stress Tolerance $[\underline{r}=-.371, \underline{n}=54, \underline{p}<.01]$ emerged. Individuals that score low on the Worrying dimension, generally claim not to get nervous before important events and take mistakes in their stride without being prone to guilt. Hence, they keep calm when things go wrong or when the unexpected happens and would therefore be able to maintain stable performance when under pressure and handle stress in an acceptable manner (which explains this correlation). Lastly, there was a small but significant negative correlation between the personality dimension, Emotionally Controlled and the leadership competency, Stress Tolerance $[\underline{r}=-.274, \underline{n}$ $=54, \underline{p}<.05]$. Low scorers on the Emotionally Controlled personality dimension are generally more inclined to express their emotions. This could indicate that leaders, who don't believe in bottling up emotions and generally prefer to clear the air by expressing them in a constructive manner, should be able to handle stress more effectively. 


\subsubsection{Continuous Learning}

There was a moderate but significant positive correlation between the personality dimension, Socially Confident and the leadership competency, Continuous Learning $[\underline{r}=0.323, \underline{n}=47, \underline{p}<$ .05 ; Spearman correlation: $\underline{\mathrm{r}}=0.317, \underline{\mathrm{n}}=47, \underline{\mathrm{p}}<.05]$. This result could suggest that individuals who feel more comfortable in situations where they have to work with others and display confidence in their abilities as communicators would more effectively share information, collaborate with others and henceforth create and take advantage of learning opportunities for themselves. Furthermore, a moderate but significant positive correlation between the personality dimension, Conceptual and the leadership competency, Continuous Learning $[\underline{r}=.439, \underline{n}=47, \underline{p}$ $<.01]$ emerged. Leaders who generally obtain high scores on the Conceptual dimension are intellectually curious and enjoy mental challenges. The result might suggest that they would therefore find it easier to keep up with current developments and trends in their areas of expertise, actively identify new areas for learning and therefore regularly create and take advantage of learning opportunities.

In conclusion to hypothesis two, 17 of the 32 OPQ32i dimensions displayed respective significant relationships with the ten leadership competencies. With regards to these, hypothesis two can be accepted. Fifteen of the 32 sub-dimensions of the OPQ32i did not have significant relationships to any of the leadership competencies. They were, Modest, Caring, Conventional, Innovative, Variety Seeking, Adaptable, Forward Thinking, Detail Conscious, Conscientious, Rule Following, Optimistic, Trusting, Vigorous, Competitive, and Achieving. With regards to these dimensions, hypothesis 2 is rejected and the alternative hypothesis is accepted.

\subsection{MULTIPLE REGRESSION RESULTS: EMOTIONAL INTELLIGENCE, PERSONALITY AND LEADERSHIP COMPETENCIES}

\subsubsection{Introduction}

The first objective of this study was to investigate whether EI (as measured by the SUEIT) will provide a prediction of leadership competence not accounted for by a measure of personality (as measured by the OPQ32i). Secondly, the objective was to establish whether EI as measured by the SUEIT possesses incremental validity over personality traits as measured by the OPQ32 $\mathrm{i}$ in predicting leadership competency scores. This should provide an indication of whether the 
SUEIT measures a construct that is different and unique, as opposed to the construct of personality, measured by means of the OPQ32i. To examine the SUEIT (measuring EI) could account for additional variance in predicted leadership competence over and above the measure of personality (OPQ32i) it was thus proposed that,

Hypothesis 3: Scores obtained on the SUEIT dimensions will explain additional variance in predicted leadership competence, as measured by the AC technology, over variance explained by the OPQ32i scores.

Alternative hypothesis: Scores obtained on the SUEIT will not explain additional variance in predicted leadership competence, as measured by the AC technology, over variance explained by the OPQ32i scores.

Preliminary analysis, through generating a histogram and normal probability plot for the regression-standardized residuals, was conducted for each regression model to investigate whether the assumptions of linearity, normality and homoscedasticity was violated. The regression normal probability plots and histograms of residuals are presented in Appendix 2. The regression results were interpreted to the extent that these assumptions were not violated.

\subsubsection{Hierarchical Regression results}

Firstly, a series of Hierarchical Regressions were conducted with each of the ten leadership competencies entered as dependent variables and respective significant correlates of EI and personality entered as independent variables (the correlations discussed in section 3.3). Due to the small sample size, only the significant correlates of EI and personality were entered into the regression and the adjusted $\mathrm{R}$ square value is reported. The results provided information about the amount of variance in the respective leadership competency explained by each of the dependent variables (dimensions of EI and personality entered as two groups).

As the goal of these analyses were to explore the incremental validity of EI over and above personality in the prediction of leadership competency scores, the significant OPQ32i dimensions were first entered into the regression equation (refer to appendix 4), followed by the significant EI dimensions. By following this procedure, the amount of additional variance that EI accounts 
for in leadership competency scores when the personality dimensions are controlled for, was therefore determined. Regression Analyses were not conducted with the leadership competencies that did not correlate significantly with both the SUEIT and OPQ32i dimensions in section 3.3 (namely, Planning and Organising, Initiating Action, Analysis and Continuous Learning).

The results are presented per leadership competency. Additional tables can be viewed in Appendix 4.

\subsubsection{Customer Focus}

Firstly, a hierarchical regression analysis was conducted with the leadership competency, Customer Focus as dependent variable (see Appendix 4.1). When entering the OPQ32i dimensions first, EI and the OPQ32i together accounted for $30 \%$ of the variance in the Customer Focus competency scores. The OPQ32i significantly predicted Customer Focus with $\underline{\mathrm{R}}$ for regression significantly different from zero, $F(3,49)=8.300, \underline{p}<.01$. The OPQ32i accounted for 29.6\% variance in Customer Focus. When EI was added to the equation, $\underline{\mathrm{R}}$ for regression significantly different from zero, $\underline{\mathrm{F}}(4,48)=6.6, \underline{\mathrm{p}}<.05$. EI accounted for an additional $0.4 \%$ variance in Customer Focus when personality was controlled for. Given the regression results, a significant but very small amount of additional variance in Customer Focus could be explained by the EI dimension, Understanding Emotions External, over and above the personality variables entered into the regression. This provided evidence for the incremental validity of EI, and specifically the Understanding Emotions External dimension of the SUEIT in predicting variance in the Customer Focus leadership competency.

\subsubsection{Building Working Relationshiops}

Secondly, a Hierarchical Regression Analysis was executed with the leadership competency, Building Working Relationships as dependent variable (Appendix 4.2). As independent variables, the EI dimension Understanding Emotions External and OPQ32i dimensions Independent mindedness, Decisive, Persuasiveness, Affiliative, Socially Confident, Emotionally Controlled, Democratic, and Behavioural were included in the analysis. When entering the OPQ32i first, both groups of independent variables together accounted for $44.3 \%$ of the variance in Building Working Relationships, with $\underline{\mathrm{R}}$ for regression significantly different from zero, $\underline{\mathrm{F}}(8,45)=4.817$, 
$\mathrm{p}<.01$. OPQ32i dimensions together accounted for 36.6\% variance in the Building Working Relationships competency scores. When EI was added to the equation, the model significantly predicted Building Working Relationships, with $\underline{\mathrm{R}}$ for regression significantly different from zero, $\underline{\mathrm{F}}(10,43)=5.211, \underline{\mathrm{p}}<.01$. However, EI accounted for an additional $7.7 \%$ variance in Building Working Relationships competency scores when the OPQ32i dimensions were controlled for. This result indicates that in the prediction of variance in terms of this leadership competency, Building Working Relationships, EI explains a significant additional amount of variance, over and above the personality variables entered into the regression. This finding provides evidence for the incremental validity of EI (more specifically, the Understanding Emotions External dimension), specifically related to the Building Working Relationships leadership competency.

\subsubsection{Gaining Commitment}

Next, a Hierarchical Regression Analysis was conducted with the leadership competency, Gaining Commitment, as dependent variable (see Appendix 4.3). The applicable EI dimension Understanding Emotions External and the relevant personality traits (the OPQ32i dimensions, namely Independent Mindedness, Relaxed, Socially Confident and Behavioural) were entered as independent variables. When entering the OPQ32i dimensions first, all independent variables accounted for $26.5 \%$ variance in Gaining Commitment and $\underline{\mathrm{R}}$ for regression was significantly different from zero, $\underline{F}(6,46)=4.311, \underline{p}<.01$. The OPQ32i accounted for $27.8 \%$ variance in the leadership competency, Gaining Commitment. When adding EI, $\underline{\mathrm{R}}$ for regression was significantly different from zero, $\underline{\mathrm{F}}(7,45)=3.678, \underline{\mathrm{p}}<.05$. However, the EI dimension Understanding Emotions External explained no additional variance in the prediction of the leadership competency, Gaining Commitment, when personality traits were controlled for.

\subsubsection{Developing Others}

The next Hierarchical Regression Analysis was conducted with the leadership competency, Developing Others, as dependent variable and EI (including dimensions Emotional Control, Emotional Recognition and Expression, and Understanding Emotions External), as well as personality traits (which included the OPQ32i dimensions, Outgoing, Relaxed, Democratic and Tough Minded) as independent variables (see Appendix 4.4). When entering the OPQ32i 
dimensions measuring personality traits first, all independent variables (SUEIT and OPQ32i dimensions) accounted for $31.2 \%$ variance in Developing Others competency scores. $\underline{\mathrm{R}}$ for regression was significantly different from zero, $\underline{\mathrm{F}}(4,44)=5.448, \underline{\mathrm{p}}<.01$. The OPQ32i dimensions accounted for 27\% variance in Developing Others competency scores. When entering $\mathrm{EI}, \underline{\mathrm{R}}$ for regression was significantly different from zero $\underline{\mathrm{F}}(7,41)=4.117, \underline{\mathrm{p}}<.01$. Henceforth, EI accounted for an additional 4.2\% variance in Developing Others competency scores when OPQ32i dimensions (measuring personality) are controlled for. The results indicate that in the prediction of variance in terms of the leadership competency, Developing Others, EI explains a significant additional amount of variance, over and above the personality variables entered in to the regression. This provides evidence for the incremental validity of EI, specifically related to the Developing Others competency.

\subsubsection{Problem Solving}

Next, a Hierarchical Regression Analysis was conducted with the leadership competency, Problem Solving as dependent variable (see Appendix 4.5). The significantly correlated dimension of EI (Emotional Management) and the OPQ32i dimensions (Controlling, Tough Minded, Evaluative) were entered as independent variables. When entering the OPQ32i (measuring personality traits) first, all the independent variables (EI and personality) together accounted for $27.3 \%$ of the variance in Problem Solving competency scores, with $\underline{\mathrm{R}}$ for regression significantly different from zero $\underline{F}(3,50)=6.074, \underline{p}<.01$. The OPQ32i measuring personality traits accounted for a unique $22.3 \%$ of the variance in Problem Solving competency scores. When adding EI, $\underline{\mathrm{R}}$ for regression was significantly different from zero, $\underline{\mathrm{F}}(4,49)=5.976$, $\mathrm{p}<.01$. Thus EI accounted for an additional 5\% variance in Problem Solving competency scores when OPQ32i dimensions (measuring personality) were controlled for. The results indicate that in the prediction of variance in terms of the leadership competency, Problem Solving, EI explains a significant additional amount of variance, over and above the personality variables entered in to the regression. This provides evidence for the incremental validity of EI, specifically related to the Problem Solving competency. 


\subsubsection{Stress Tolerance}

Next, a Hierarchical Regression Analysis was conducted for the leadership competency, Stress Tolerance, as dependent variable (see Appendix 4.6). EI (including the Emotional Control and Emotion Direct Cognition dimensions) and the OPQ32i dimensions (Independent Mindedness, Emotionally Controlled, Behavioural and Worrying) were entered as independent variables. When entering the OPQ32i first, the two independent groups of variables together accounted for $18.5 \%$ of the variance in Stress Tolerance, with $\underline{\mathrm{R}}$ for regression significantly different from zero, $\underline{\mathrm{F}}(4,49)=3.842, \underline{\mathrm{p}}<.01$. The OPQ32i accounted for $17.7 \%$ variance in Stress Tolerance competency scores. When entering EI into the equation $\underline{\mathrm{R}}$ for regression was significantly different from zero, $\underline{\mathrm{F}}(6,47)=3.004, \underline{\mathrm{p}}<.01$. Therefore, EI accounted for $0.8 \%$ additional unique variance in Stress Tolerance competency scores when the OPQ32i (measuring personality traits) dimensions were controlled for. The results indicate that in the prediction of variance in terms of the leadership competency, Stress Tolerance, EI explains a small significant additional amount of variance, over and above the personality variables entered in to the regression. This provides evidence for the incremental validity of EI, specifically related to the Stress Tolerance competency.

\subsubsection{Standard Multiple Regression Analysis results}

Next, a series of Standard Regression analyses were conducted with the ten leadership competencies, as dependent variables and the significantly correlated EI and OPQ32i dimensions as independent variables. The purposes for this procedure was to determine how much unique variance in the leadership competencies, the specific EI and personality dimensions were able to explain respectively and as a group together. This would indicate which EI or personality dimensions accounts for the most unique variance in the respective leadership competency scores. Regression Analyses was not conducted with competencies that did not correlate significantly with more than one EI (the SUEIT) and personality dimension (the OPQ32i). Next, the results are presented per leadership competency.

\subsubsection{Continuous Learning}

Firstly, a Standard Regression Analysis was conducted with the leadership competency Continuous Learning as dependent variable, and the OPQ32i dimensions with which it correlated 
significantly, namely Conceptual and Socially Confident. The whole regression model explained $19.7 \%$ of the variance in Continuous Learning. $\underline{\mathrm{R}}$ for regression was significantly different from zero, $\underline{\mathrm{F}}(2,46)=6.65, \underline{\mathrm{p}}<.01$. Only the OPQ32i dimension, Conceptual made a significant unique contribution to the variance in Continuous Learning (see table 3.4 for the standardized coefficient).

Table 3.4: Coefficients obtained for the Standard Regression: Continuous Learning

\begin{tabular}{|c|c|c|c|c|c|c|}
\hline \multirow[t]{2}{*}{ Model } & & \multicolumn{2}{|c|}{ Unstandardized Coefficients } & Standardized Coefficients & \multirow[t]{2}{*}{$\mathrm{t}$} & \multirow[t]{2}{*}{ Sig. } \\
\hline & & B & Std. Error & Beta & & \\
\hline \multirow[t]{3}{*}{1} & (Constant) & 1.998 & .267 & & 7.491 & .000 \\
\hline & $\begin{array}{l}\text { Socially } \\
\text { Confident }\end{array}$ & .026 & .018 & .208 & 1.501 & .141 \\
\hline & Conceptual & .051 & .019 & $.376^{\star \star}$ & 2.708 & .010 \\
\hline
\end{tabular}

** Beta coefficient significant at $p<0.01 .{ }^{*}$ Beta Coefficient Significant at $p<0.05$

Dependent Variable: Continuous Learning

\subsubsection{Customer Focus}

Next, a Standard Regression Analysis was conducted with the leadership competency, Customer Focus as dependent variable and the significant correlates, namely Understanding Emotions External (EI), Outgoing, Affiliative and Emotionally Controlled (OPQ32i) as independent variables. The whole regression model explained $30 \%$ of the variance in Customer Focus. $\underline{\mathrm{R}}$ for regression was significantly different from zero, $\underline{F}(4,52)=6.56, \underline{p}<.01$. The standardized coefficients presented in table 3.5 indicate that the OPQ32i dimension, Affiliative made the largest and only significant unique contribution to explaining the variance in the Customer Focus leadership competency, followed by in order of contribution, Emotionally Controlled, Understanding Emotions External and Outgoing (OPQ32i, all not significant).

Table 3.5: Coefficients obtained for the Standard Regression:Customer Focus

\begin{tabular}{|c|c|c|c|c|c|c|}
\hline Model & & \multicolumn{2}{|c|}{ Unstandardized Coefficients } & \multirow{2}{*}{$\begin{array}{c}\text { Standardized Coefficients } \\
\text { Beta }\end{array}$} & \multirow[t]{2}{*}{$\mathrm{t}$} & \multirow[t]{2}{*}{ Sig. } \\
\hline & & B & Std. Error & & & \\
\hline \multirow[t]{5}{*}{1} & (Constant) & 1.212 & 1.203 & & 1.008 & .319 \\
\hline & Outgoing & .005 & .018 & .043 & .286 & .776 \\
\hline & Affiliative & .054 & .021 & $.387^{*}$ & 2.531 & .015 \\
\hline & Emotionally Controlled & -.037 & .020 & -.265 & -1.870 & .068 \\
\hline & $\begin{array}{l}\text { Raw score } \\
\text { Understanding } \\
\text { emotions external }\end{array}$ & .018 & .017 & .156 & 1.107 & .274 \\
\hline
\end{tabular}

** Beta coefficient significant at $p<0.01 .{ }^{*}$ Beta Coefficient Significant at $p<0.05$. Dependent Variable: Customer Focus 


\subsubsection{Building Working Relationships}

Next, a Standard Regression Analysis was conducted with the leadership competency, Building Working Relationships as dependent variable and the EI dimensions (Understanding Emotions External, Emotional Control) as well as the OPQ32i dimensions (Socially Confident, Democratic, Behavioural, Emotionally Controlled and Decisive) as independent variables. The whole model (all the independent variables together) explained $44.3 \%$ of the variance in Building Working relationships. $\underline{\mathrm{R}}$ for regression was significantly different from zero $\underline{F}(10,53)=5.21, \underline{\mathrm{p}}<.01$. According to the Standardized Coefficients $(\beta)$ reported in table 3.6, the EI dimension Understanding Emotions External, made the largest unique significant contribution to the leadership competency, Building Working relationships. See table 3.6 for the order of contributions of the other variables entered into the regression. Only the OPQ32i dimension, Democratic, and the EI dimension, Understanding Emotions External, made significant unique contributions to explaining the variance in the Building Working Relationships competency scores.

Table 3.6: Coefficients obtained for the Standard Regression: Building Working Relationships

\begin{tabular}{|c|c|c|c|c|c|c|}
\hline \multirow[b]{2}{*}{ Model } & & \multicolumn{2}{|c|}{$\begin{array}{l}\text { Unstandardized } \\
\text { Coefficients }\end{array}$} & \multirow{2}{*}{$\begin{array}{c}\text { Standardized } \\
\text { Coefficients } \\
\text { Beta }\end{array}$} & \multirow[b]{2}{*}{$\mathrm{t}$} & \multirow[b]{2}{*}{ Sig. } \\
\hline & & 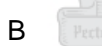 & Std. Error & & & \\
\hline \multirow[t]{11}{*}{1} & (Constant) & -1.061 & 1.151 & & -.922 & .362 \\
\hline & Persuasiveness & .009 & .018 & .061 & .488 & .628 \\
\hline & $\begin{array}{l}\text { Independent } \\
\text { mindedness }\end{array}$ & -.018 & .024 & -.095 & -.755 & .454 \\
\hline & Affiliative & .018 & .016 & .134 & 1.132 & .264 \\
\hline & Socially Confident & .019 & .017 & .137 & 1.119 & .269 \\
\hline & Democratic & .046 & .022 & $.276^{*}$ & 2.089 & .043 \\
\hline & Behavioural & -.012 & .022 & -.078 & -.561 & .578 \\
\hline & $\begin{array}{l}\text { Emotionally } \\
\text { Controlled }\end{array}$ & -.012 & .017 & -.088 & -.707 & .483 \\
\hline & Decisive & -.022 & .017 & -.165 & -1.295 & .202 \\
\hline & $\begin{array}{l}\text { Raw score } \\
\text { Understanding } \\
\text { emotions external }\end{array}$ & .036 & .017 & $.310^{*}$ & 2.130 & .039 \\
\hline & $\begin{array}{l}\text { Raw score } \\
\text { emotional control }\end{array}$ & .026 & .022 & .132 & 1.151 & .256 \\
\hline
\end{tabular}

** Beta coefficient significant at $p<0.01$. * Beta Coefficient Significant at $p<0.05$ Dependent Variable: Building Working Relationships 


\subsubsection{Gaining Commitment}

Next, a Standard Regression Analysis was conducted with the leadership competency, Gaining Commitment, as dependent variable and the significant correlates, Understanding Emotions External (EI dimension), and, Independent Minded, Socially Confident, Behavioural and Relaxed (OPQ32i dimensions) as independent variables. The whole model explained $26.5 \%$ of the variance in Gaining Commitment competency scores. $\underline{\mathrm{R}}$ for regression was significantly different from zero, $\underline{\mathrm{F}}(5,52)=4.74, \underline{\mathrm{p}}<.01$. The OPQ32i dimension, Socially Confident, made the largest unique significant contribution to Gaining Commitment competency scores (see table 3.7 for the standardized coefficients). The OPQ32i dimension, Relaxed, was the only other independent variable that made a unique significant contribution to Gaining Commitment competency scores (after Socially Confident).

Table 3.7: Coefficients obtained for the Standard Regression: Gaining Commitment

\begin{tabular}{|c|c|c|c|c|c|c|}
\hline \multirow[b]{2}{*}{ Model } & & \multicolumn{2}{|c|}{$\begin{array}{c}\text { Unstandardized } \\
\text { Coefficients }\end{array}$} & \multirow{2}{*}{$\begin{array}{c}\text { Standardized } \\
\text { Coefficients } \\
\text { Beta } \\
\end{array}$} & \multirow[b]{2}{*}{$\mathrm{t}$} & \multirow[b]{2}{*}{ Sig. } \\
\hline & & $\mathrm{B}$ & Std. Error & & & \\
\hline \multirow[t]{7}{*}{1} & (Constant) & 1.783 & .985 & & 1.810 & .077 \\
\hline & $\begin{array}{l}\text { Independent } \\
\text { mindedness }\end{array}$ & -.023 & .024 & -.122 & -.956 & .344 \\
\hline & $\begin{array}{l}\text { Socially } \\
\text { Confident }\end{array}$ & .046 & .017 & $.343^{* *}$ & 2.705 & .009 \\
\hline & Behavioural & .035 & .021 & .226 & 1.673 & .101 \\
\hline & Relaxed & -.001 & .001 & $-.256^{\star}$ & -2.073 & .044 \\
\hline & Raw score & Pect & 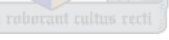 & & & \\
\hline & $\begin{array}{l}\text { Understanding } \\
\text { emotions external }\end{array}$ & & .016 & .000 & -.001 & .999 \\
\hline
\end{tabular}

** Beta coefficient significant at $p<0.01$. * Beta Coefficient Significant at $p<0.05$

Dependent Variable: Gaining Commitment

\subsubsection{Developing Others}

Next, a Standard Regression Analysis was conducted with the leadership competency, Developing Others as dependent variable, and as independent variables the significant correlates of the SUEIT and OPQ32i (that is documented in section 3.3). These included Emotional Recognition and Expression, Understanding Emotions External, and Emotional Control (all EI dimensions) as well as Outgoing, Democratic, Relaxed and Tough Minded (OPQ32i dimensions). The whole model explained $31.2 \%$ of the variance in the leadership competency, Developing Others. $\underline{R}$ for regression was significantly different from zero, $\underline{F}(7,48)=4.1, \underline{p}<.01$. According to the Standardized Coefficients $(\beta)$ presented in table 3.8, the OPQ32i dimension, Tough 
Minded made the largest significant unique contribution to Developing Others competency scores. This variable was followed by, in order of size of contribution indicated by the $\beta$ values presented in table 3.8, the EI dimension, Emotional Control, the OPQ32i dimensions, Outgoing, Democratic and Tough Minded and lastly the EI dimensions, Understanding Emotions External, and Emotional Recognition and Expression. Significant unique contributions was made by Outgoing, Democratic, Tough Minded (all OPQ32i dimensions), and Emotional Control (EI dimension).

Table 3.8: Coefficients obtained for the Standard Regression: Developing Others

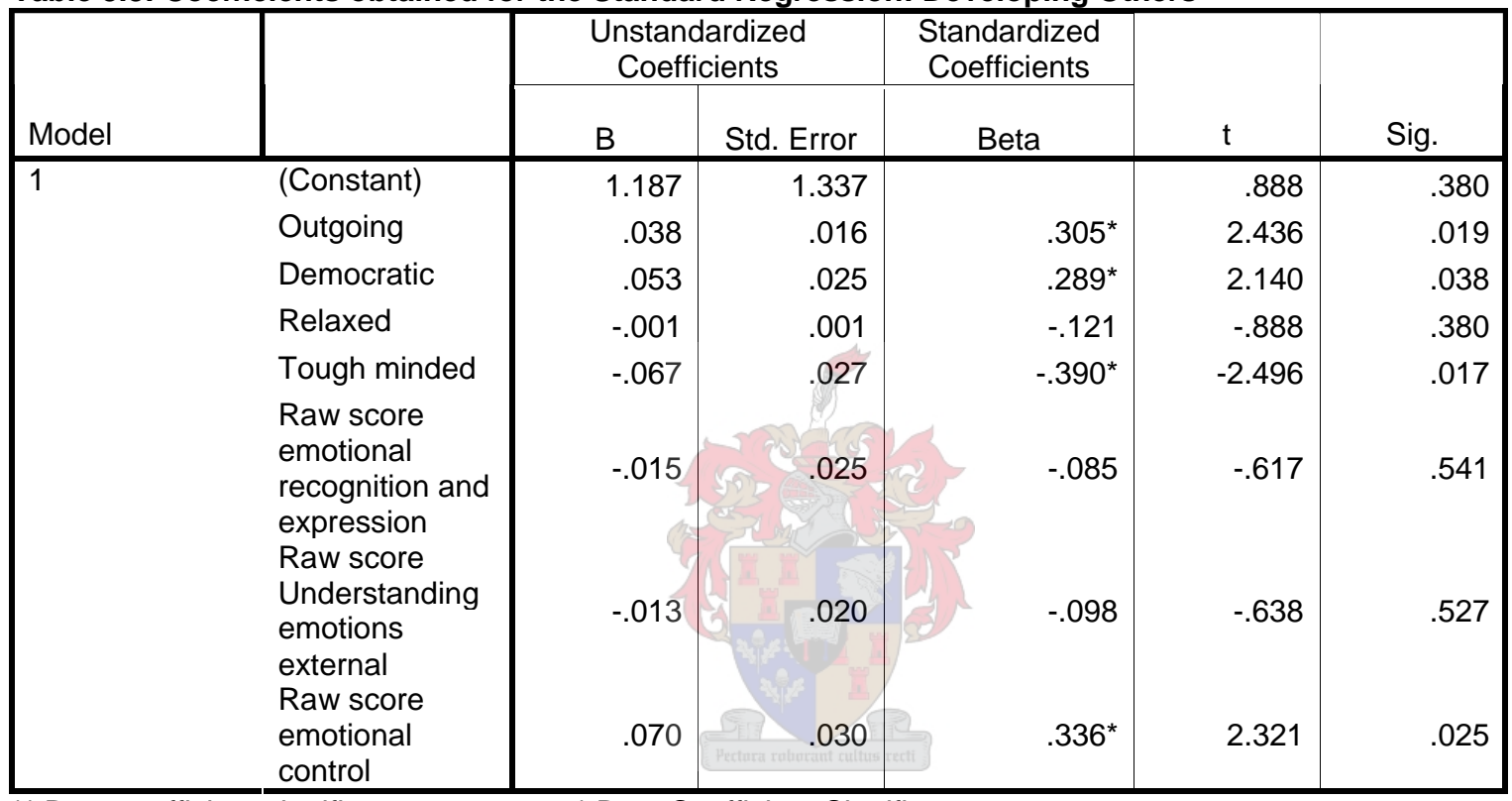

** Beta coefficient significant at $p<0.01$. * Beta Coefficient Significant at $p<0.05$

Dependent Variable: Developing Others

\subsubsection{Analysis}

A Standard Regression Analysis was conducted with the leadership competency, Analysis, as dependent variable and the significant correlates of the OPQ32i (Controlling, Evaluative and Tough Minded). No EI dimensions were included into the Regression Analysis. The whole model explained $21.7 \%$ of the variance in the leadership competency, Analysis. $\underline{\mathrm{R}}$ for regression was significantly different from zero, $\underline{\mathrm{F}}(3,52)=5.8, \underline{\mathrm{p}}<.01$. The OPQ32i dimension Tough Minded, made the largest unique contribution to this equation, followed by Evaluative and Controlling. Only Tough minded made a significant unique contribution to explaining the variance in the leadership competency, Analysis (see table 3.9 for the standardized coefficients). 
Table 3.9: Coefficients obtained for the Standard Regression: Analysis

\begin{tabular}{|c|c|c|c|c|c|c|}
\hline \multirow[b]{2}{*}{ Model } & & \multicolumn{2}{|c|}{$\begin{array}{c}\text { Unstandardized } \\
\text { Coefficients }\end{array}$} & \multirow{2}{*}{$\begin{array}{c}\begin{array}{c}\text { Standardized } \\
\text { Coefficients }\end{array} \\
\text { Beta } \\
\end{array}$} & \multirow[b]{2}{*}{$\mathrm{t}$} & \multirow[b]{2}{*}{ Sig. } \\
\hline & & B & Std. Error & & & \\
\hline \multirow[t]{4}{*}{1} & (Constant) & 2.026 & .696 & & 2.912 & .005 \\
\hline & Controlling & .033 & .019 & .234 & 1.736 & .089 \\
\hline & Evaluative & .053 & .027 & .263 & 1.969 & .055 \\
\hline & $\begin{array}{l}\text { Tough } \\
\text { minded }\end{array}$ & -.048 & .024 & $-.279 *$ & -2.014 & .049 \\
\hline
\end{tabular}

** Beta coefficient significant at $p<0.01$. * Beta Coefficient Significant at $p<0.05$

Dependent Variable: Leadership Analysis

\subsubsection{Problem Solving}

Standard Regression Analysis was conducted with the leadership competency, Problem Solving, as dependent variable and the significant EI (Emotional Management) and OPQ32i correlates (Controlling, Evaluative, and Tough Minded) as independent variables. The whole model explained $27.3 \%$ of the variance in Problem Solving, with $\underline{\mathrm{R}}$ for regression significantly different from zero, $\underline{F}(4,53)=5.9, \underline{p}<.01$. After inspecting the Standardized Coefficients $(\beta)$ in table 3.10 , it is reported that the OPQ32i dimension, Controlling, made the largest unique contribution to the equation, followed by the EI dimension, Emotional Management, and then the OPQ32i dimensions Evaluative and Tough Minded. The EI dimension, Emotional Management and the OPQ32i dimension, Controlling, both made significant unique contributions to explaining the variance in Problem Solving.

Table 3.10: Coefficients obtained for the Standard Regression: Problem Solving

\begin{tabular}{|c|c|c|c|c|c|c|}
\hline \multirow[b]{2}{*}{ Model } & & \multicolumn{2}{|c|}{$\begin{array}{l}\text { Unstandardized } \\
\text { Coefficients }\end{array}$} & \multirow{2}{*}{$\begin{array}{c}\text { Standardized } \\
\text { Coefficients } \\
\text { Beta }\end{array}$} & \multirow[b]{2}{*}{$\mathrm{t}$} & \multirow[b]{2}{*}{ Sig. } \\
\hline & & $\mathrm{B}$ & Std. Error & & & \\
\hline \multirow[t]{5}{*}{1} & (Constant) & 3.654 & 1.129 & & 3.237 & .002 \\
\hline & Controlling & .039 & .017 & $.287^{*}$ & 2.242 & .030 \\
\hline & Evaluative & .042 & .026 & .219 & 1.625 & .111 \\
\hline & Tough minded & -.034 & .022 & -.207 & -1.567 & .124 \\
\hline & $\begin{array}{l}\text { Raw score } \\
\text { emotional } \\
\text { management }\end{array}$ & -.043 & .020 & $-.261^{*}$ & -2.105 & .040 \\
\hline
\end{tabular}

** Beta coefficient significant at $p<0.01$. * Beta Coefficient Significant at $p<0.05$

Dependent Variable: Problem Solving 


\subsubsection{Planning and Organising}

A Standard Regression Analysis was conducted with the leadership competency, Planning and Organising as dependent variable and the significant OPQ32i correlates (none of the EI dimensions were found to significantly predict Planning and Organising) as independent variables. Those were, Outspoken, Outgoing, Socially Confident, and Data Rational. The whole model explained $16 \%$ of the variance in Planning and Organising, with $\underline{\mathrm{R}}$ for regression significantly different from zero, $\underline{F}(4,52)=3.47, \underline{p}<.05$. The Standardized Coefficients $(\beta)$ for each of the independent variables presented in table 3.11 indicate that the OPQ32i dimension, Outspoken accounted for most of the variance in Planning and Organising, followed by OPQ32i dimensions, Socially Confident, Data Rational and Outgoing. None of the independent variables, however, accounted for significant unique variance in the dependent variable, Planning and Organising.

Table 3.11: Coefficients obtained for the Standard Regression: Planning and Organising

\begin{tabular}{|c|c|c|c|c|c|c|}
\hline Model & & \multicolumn{2}{|c|}{$\begin{array}{l}\text { Unstandardized } \\
\text { Coefficients }\end{array}$} & $\begin{array}{c}\text { Standardized } \\
\text { Coefficients } \\
\text { Beta }\end{array}$ & $\mathrm{t}$ & Sig. \\
\hline \multirow[t]{5}{*}{1} & (Constant) & 1.962 & .465 & & 4.221 & .000 \\
\hline & Outspoken & .032 & .020 & .208 & 1.592 & .118 \\
\hline & Outgoing & .020 & .018 & .156 & 1.110 & .273 \\
\hline & $\begin{array}{l}\text { Socially } \\
\text { Confident }\end{array}$ & .030 & .020 & .204 & 1.506 & .139 \\
\hline & Data rational & -.018 & .016 & -.164 & -1.153 & .255 \\
\hline
\end{tabular}

** Beta coefficient significant at $p<0.01$. ${ }^{*}$ Beta Coefficient Significant at $p<0.05$

Dependent Variable: Planning and Organising

\subsubsection{Stress Tolerance}

Lastly, a Standard Regression Analysis was conducted with the leadership competency, Stress Tolerance as dependent variable and the EI dimensions, Emotion Direct Cognition and Emotional Control, as well as the OPQ32i dimensions Independent Minded, Behavioural, Worrying, and Emotionally Controlled as independent variables. The whole regression model accounted for $18.5 \%$ of the variance in Stress Tolerance, with $\underline{\mathrm{R}}$ for regression significantly different from zero, $\underline{F}(6,53)=3, \underline{p}<.05$. The Standardized Coefficients $(\beta)$ for each of the independent variables presented in table 3.12 indicate that the OPQ32i dimensions, Worrying made the biggest unique contribution to the equation. None of the dependent variables made significant unique contributions to the equation. 
Table 3.12 Coefficients for the Standard Regression: Stress Tolerance

\begin{tabular}{|c|c|c|c|c|c|c|}
\hline \multirow[b]{2}{*}{ Model } & & \multicolumn{2}{|c|}{$\begin{array}{l}\text { Unstandardized } \\
\text { Coefficients }\end{array}$} & \multirow{2}{*}{$\begin{array}{c}\text { Standardized } \\
\text { Coefficients } \\
\text { Beta }\end{array}$} & \multirow[b]{2}{*}{$\mathrm{t}$} & \multirow[b]{2}{*}{ Sig. } \\
\hline & & B & Std. Error & & & \\
\hline \multirow[t]{7}{*}{1} & (Constant) & 3.716 & .884 & & 4.206 & .000 \\
\hline & $\begin{array}{l}\text { Independent } \\
\text { mindedness }\end{array}$ & -.016 & .018 & -.124 & -.911 & .367 \\
\hline & Behavioural & .028 & .014 & .258 & 1.959 & .056 \\
\hline & Worrying & -.025 & .013 & -.306 & -2.002 & .051 \\
\hline & $\begin{array}{l}\text { Emotionally } \\
\text { Controlled }\end{array}$ & -.010 & .013 & -.108 & -.799 & .429 \\
\hline & $\begin{array}{l}\text { Raw score emotion } \\
\text { direct cognition }\end{array}$ & -.019 & .012 & -.207 & -1.561 & .125 \\
\hline & $\begin{array}{l}\text { Raw score } \\
\text { emotional control }\end{array}$ & -.005 & .020 & -.033 & -.227 & .822 \\
\hline
\end{tabular}

\subsection{CORRELATION RESULTS: EMOTIONAL INTELLIGENCE AND PERSONALITY}

\subsubsection{Introduction}

In the next section the relationships between the dimensions of the OPQ32i, measuring personality traits, and the, SUEIT, measuring EI will be explored through calculating the Pearson Product-Moment Correlation. Where correlations do exist between the dimensions of the two instruments, one can expect that there is similarity in what is measured, and hence that overlap exists in the measurement of the underlying latent constructs. It could therefore be hypothesised that,

Hypothesis 4: The scores on the SUEIT dimensions will not correlate significantly with the dimension scores of the OPQ32i measuring personality.

Alternative Hypothesis: There will be significant correlations between the scores on the SUEIT dimensions and the dimension scores of the OPQ32i

The relationship between the dimensions of the OPQ32i measuring personality and the five dimensions of EI, measured by the SUEIT, was investigated calculating the Pearson ProductMoment Correlation Coefficient. See appendix 3.2 for the full correlation matrix. Discussions of the correlations per SUEIT dimension follow. 


\subsubsection{Emotional Recognition and Expression}

Firstly, the correlations - and hence the overlap in what is measured - between the EI dimension, Emotional Recognition and Expression and the relevant OPQ32i dimensions will be discussed. There was a moderate significant positive correlation between the OPQ32i dimension Outspoken and the EI dimension, Emotional Recognition and Expression $[\mathrm{r}=0.439, \underline{\mathrm{n}}=54, \underline{\mathrm{p}}<.01]$ Generally, individuals that score high on the Outspoken dimension of personality are very clear about their own views and more likely to voice these views. Hence it could be argued that these individuals would more likely also perceive and express their own emotions.

There was a strong negative correlation between the OPQ32i dimension, Modest and the EI dimension, Emotional Recognition and Expression $[\underline{\mathrm{r}}=-.534, \underline{\mathrm{n}}=54, \underline{\mathrm{p}}<.01]$ with low scores on Modest associated with high scores on Emotional Recognition and Expression dimension. Individuals scoring low on the Modest dimension of the OPQ32i are more likely upfront in talking about themselves and may be seen as possessing openness, which make them easy to communicate with. These individuals may therefore find it easier to express their emotions to others (high in Emotional Recognition and Expression).

There was a small but significant positive correlation between the OPQ32i dimension, Detail Conscious and the EI dimension, Emotional Recognition and Expression $[\underline{r}=0.290, \underline{n}=54, \underline{p}<$ .05]. Generally, individuals who are high on Detail Consciousness prefer to employ an accurate and methodical approach with attention to detail when analyzing situations and people (including themselves) and one could therefore assume that these individuals will also more accurately perceive and express their own emotions. There was a small significant positive correlation between the Emotional Recognition and Expression EI dimension and Conventional (OPQ32i) [ $\underline{r}$ $=0.292, \underline{\mathrm{n}}=54, \underline{\mathrm{p}}<0.05]$.

Furthermore, there was a moderate but significant negative correlation between the OPQ32i dimension, Tough Minded and the EI dimension, Emotional Recognition and Expression $[\underline{r}=$ $.339, \underline{\mathrm{n}}=54, \underline{\mathrm{p}}<.05]$ with low scores on Tough Minded associated with high scores on Emotional Recognition and Expression. Generally, those with low scores on Tough Minded are inclined to become emotionally involved in situations at work, especially where they are 
criticized. Leaders with this preference are sensitive where their own feelings are concerned, and it could therefore be argued that they are very perceptive of their emotions and tend to communicate it towards others. There was a strong negative correlation between the OPQ32i dimension, Emotionally Controlled and the EI dimension, Emotional Recognition and Expression $[\underline{\mathrm{r}}=-.534 \underline{\mathrm{n}}=54, \underline{\mathrm{p}}<.01]$. Individuals scoring low on Emotionally Controlled believe it is important for those around them to know how they feel. They tend to be upfront and open, and therefore would most probably be more aware of their own emotions and communicating it to others.

\subsubsection{Understanding Emotions External}

Secondly, the correlations - and hence the overlap in what is being measured - between the EI dimension, Understanding Emotions External, and the OPQ32i dimensions will be discussed. There was a moderate but significant correlation between the OPQ32i dimension, Affiliative and the EI dimension, Understanding Emotions External $[\underline{r}=0.361, \underline{n}=54,, \underline{p}<.01]$ It would seem that individuals that value strong attachments to people, as well as maintaining strong interpersonal relationships, would develop a better understanding of their colleagues' emotions.

There was also a moderate but significant positive correlation between the OPQ32i dimension, Socially Confident and the EI dimension, Understanding Emotions External $[\underline{r}=0.306, \underline{n}=54, \underline{p}$ $<.05]$ This could indicate that individuals who feel more comfortable in the company of others (i.e. more socially confident) would probably find it easier to "read" the emotions that others convey as well as the emotional overtones of workplace environments and discussions. The reason for this could be that such individuals generally feel comfortable in the company of others and are not overly aware of their own feelings of nervousness or embarrassment, will be more attuned to the emotions of others and more easily pick up on the emotions conveyed in the environment. Also, others feel more comfortable with people who are at ease in interpersonal interactions and henceforth make them more approachable and easier to communicate feelings to.

There was also a moderate but significant negative relationship between the OPQ32i dimension, Modest and the EI dimension, Understanding Emotions External $[\underline{r}=-0.420, \underline{\mathrm{n}}=54, \underline{\mathrm{p}}<.01]$ with low ratings on Modest associated with high ratings on Understanding Emotions External. 
This result could indicate that individuals who are easy to get to know and communicate with will easier build acquaintances and due to this personality trait, might therefore have acquired the ability to be able to more accurately perceive and understand the emotions of others.

Furthermore, there was a moderate but significant positive correlation between the OPQ32i dimension, Democratic and the EI dimension, Understanding Emotions External $[\underline{r}=0.333, \underline{n}=$ $54, \mathrm{p}<.05]$. This result might suggest that individuals who tend to listen to others by asking for their input during discussions, will be able to more accurately perceive and understand their emotions.

There was also a small but significant positive correlation between the OPQ32i dimension, Caring and the EI dimension, Understanding Emotions External $[\underline{r}=0.295, \underline{\mathrm{n}}=54, \underline{\mathrm{p}}<.05]$. Individuals and especially leaders, with high scores on Caring, are generally interested in the welfare of others and would therefore take into account their understanding of the emotions of others when making decisions and the impact the decision will have on them (e.g. the subordinate's motivation to perform in the workplace).

There was a moderate significant positive relationship between the OPQ32i dimension, Behavioural and the EI dimension, Understanding Emotions External $[\underline{r}=0.412, \underline{n}=54, \underline{p}<.01]$. This result could be interpreted to indicate that individuals with a preference towards analyzing their own and others behaviours will as a result have a better understanding of emotions of others and the impact that emotions have on the atmosphere within a team and hence their motivation to perform well.

There was also a moderate significant negative correlation between Emotionally Controlled and the EI dimension, Understanding Emotions External $[\underline{r}=-0.383, \underline{n}=54, \underline{p}<.01]$. As mentioned earlier, individuals who are less emotionally controlled are more inclined to express their emotions more openly to others. It can therefore be argued that individuals who express their emotions more openly, enable others to respond more accurately to them, which in turn increases the extent to which they are able to perceive and understand others' emotions. 


\subsubsection{Emotional Control}

Thirdly, the correlations - and hence the overlap in what is being measured - between the EI dimension, Emotional Control, and the relevant OPQ32i dimensions will be discussed. There was a small but significant positive relationship between Socially Confident and the EI dimension, Emotional Control $[\underline{r}=0.292, \underline{\mathrm{n}}=54, \underline{\mathrm{p}}<.05]$. This could indicate that people who generally feel more comfortable in the company of others (Socially Confident) can more easily control strong negative feelings, for example nervousness when meeting strangers.

There was a small but significant positive correlation between the OPQ32i dimension, Tough Minded and the EI dimension Emotional Control $[\underline{r}=0.280, \underline{n}=54, \underline{p}<.05]$. Individuals scoring high on Tough Minded tend to not over-react to personal criticism and remain cool headed and thus they might also be able to more easily control strong emotional reactions to these events.

There was a small but significant positive correlation between the OPQ32i dimension, Achieving and the EI dimension, Emotional Control $[\underline{\mathrm{r}}=0.269, \underline{\mathrm{n}}=54, \underline{\mathrm{p}}<.05]$ with high ratings on Achieving associated with high scores on Emotional Control. Individuals scoring high on achieving are very task-orientated, and one could therefore argue that they would place priority on their work and their ability to do it effectively not allowing the emotions that they experience to have a negative influence on that ability.

A moderate negative correlation was found between Rule Following (OPQ32i) and Emotional Control $[\underline{\mathrm{r}}=-0.325, \underline{\mathrm{n}}=54, \underline{\mathrm{p}}<0.05]$, indicating that individuals who are less restricted by rules and procedures (scoring low on Rule Following) will find it easier to control strong negative emotions, as they are less likely to experience negative feelings as a result of restricting themselves by keeping to the rules at all cost.

In the last instance a moderate negative correlation was found between Worrying (OPQ32i) and Emotional Control $[\underline{\mathrm{r}}=-0.432, \underline{\mathrm{n}}=54, \underline{\mathrm{p}}<0.01]$. One can therefore argue that leaders who are free from worry and have a calm disposition (scoring low on OPQ32i dimension, Worrying) are more likely to stay calm under pressure and hence control strong negative feelings. 


\subsubsection{Emotional Management}

In the fourth instance, the correlations - and hence the overlap in what is being measured - by the EI dimension, Emotional Management, and the relevant OPQ32i dimensions will be discussed. Firstly, there was a small negative correlation between OPQ32i dimension, Modest and EI dimension, Emotional Management $[\underline{r}=-0.269, \underline{n}=54, \underline{p}<0.05]$. One may therefore assume that leaders who tend to talk about themselves (obtaining lower scores on Modest), would better be able to repair negative and foster positive emotions in themselves, as they would more easily find social support in the face of adversity by communicating their problems to others.

There was a small but significant negative correlation between the OPQ32i dimension Data rational and the EI dimension Emotional Management $[\underline{\mathrm{r}}=-0.284, \underline{\mathrm{n}}=54, \underline{\mathrm{p}}<.05]$. Individuals with low scores on Data Rational have a preference to function more intuitively than analytically, in other words, focus on feelings and opinions, rather than facts. This capability could help them repair negative emotional states (in themselves and others) in the face of problems where more subtle emotional issues need to be addressed.

There was a moderate but significant negative correlation between the OPQ32i dimension, Evaluative and the EI dimension, Emotional Management $[\underline{r}=-0.330, \underline{n}=54, \underline{p}<.05]$ with low scores on Evaluative associated with high scores on Emotional Management. This result might suggest that individuals who are less evaluative tend not to believe in being overly critical and voicing their criticism towards others and will through that maintain beneficial positive moods and emotions both within themselves and others at work.

There was a moderate but significant negative correlation between the OPQ $32 \mathrm{i}$ dimension, Worrying and the EI dimension, Emotional Management $[\underline{\mathrm{r}}=-0.428, \underline{\mathrm{n}}=54, \underline{\mathrm{p}}<.01]$ with low scores on Worrying associated with high ratings on Emotional Management. Those with low scores on Worrying tend to keep calm when things go wrong or when the unexpected happens and are not put off by being under pressure. These individuals might therefore be inclined to more easily maintain beneficial positive moods and emotions at work. 


\subsubsection{Emotion Direct Cognition}

Lastly, the correlations - and hence the overlap in what is being measured - by the EI dimension, Emotional Direct Cognition, and the relevant OPQ32i dimensions will be discussed. There was a moderate but significant negative correlation between the OPQ32i dimension, Forward Thinking and the EI dimension, Emotion Direct Cognition $[\underline{\mathrm{r}}=-.386, \underline{\mathrm{n}}=54, \underline{\mathrm{p}}<.01]$ with low scores on Forward Thinking Associated with high ratings on Emotion Direct Cognition. Individuals who score lower on Forward Thinking tend to be reactive rather than proactive, feeling that planning inhibits spontaneity. Without specific plans and structures in place for dealing with ambiguous situations (low in Forward Thinking), these individuals could most probably more likely rely on intuition and thus their feelings (emotional information) to guide reasoning and make decisions. There was also a small but significant negative correlation between the OPQ32i dimension, Tough Minded and the EI dimension, Emotion Direct Cognition[ $[\underline{r}=-.282, \underline{\mathrm{n}}=54, \underline{\mathrm{p}}<.05]$ with low scores on Tough Minded being associated with high scores on Emotion Direct Cognition. As mentioned earlier, individuals with low scores on Tough Minded tend to be more emotionally involved in situations, and hence it could be argued that because they are emotionally inclined individuals, they might more easily incorporate emotional information in reasoning and decision making.

For 16 of the OPQ32i dimensions, Hypothesis 4 could thus be rejected and the alternative hypothesis accepted. These personality dimensions had significant relationships to the five EI dimensions respectively. They were Outspoken, Affiliative, Modest, Democratic, Caring, Data rational, Evaluative, Behavioural, Conventional, Detail Conscious, Rule Following, Worrying Tough Minded, Emotionally Controlled, and Achieving. With the 16 other OPQ32i dimensions, no correlations was indicated with any of the five EI dimensions, and for them, hypothesis 4 could be accepted. 


\subsection{SUMMARY}

The purpose of the study was to provide evidence for the incremental validity of EI (as measured by the SUEIT) by exploring whether it accounts for variance in AC leadership competency scores over and above variance accounted for by the OPQ32i (measuring personality). Firstly, the relationship between the five dimensions of EI (as measured by the SUEIT) and 32 dimensions of personality (as measured by the OPQ32i) respectively and ratings on the ten leadership competencies (obtained by means of four AC exercises used to assess leadership competence) was investigated by calculating the Pearson Product-Moment Correlation Coefficients. The Customer Focus, Building Working Relationships, Developing Others, Gaining Commitment, Problem Solving and Stress Tolerance leadership competencies were found to significantly correlate with the EI dimensions, whilst significant correlations were indicated between 17 of the specific OPQ32i dimensions and the ten leadership competencies, respectively. Hierarchical and

Standard Regression Analyses were conducted for the relevant competencies and significantly correlated EI and personality dimensions (the SUEIT and the OPQ32i respectively) to determine whether the SUEIT has incremental validity over the OPQ32i in predicting variance in the leadership competency scores. In spite of the overlap that was found in the measurement of the underlying latent constructs by some of the SUEIT and (half of the) OPQ32i dimensions, evidence was obtained for the limited incremental validity of EI (as measured by the SUEIT) over personality (as measured by the OPQ32i) in predicting variance in the Customer Focus, Building Working Relationships, Developing Others, Problem Solving and Stress Tolerance leadership competencies.

In section four the findings of the current study, based on the results, will be discussed. This includes evidence supporting the existence of relationships between EI dimensions (as measured by the SUEIT) and specific leadership competencies measured by the AC technology employed by the sponsoring organisation. Adjunct to this, evidence obtained in support of the predictive validity of EI as operationalised by the SUEIT as well as overlap in the measurement of the underlying latent constructs by the different personality and EI dimensions from which such results were inferred will be discussed. Lastly, evidence found in support of the incremental validity of the SUEIT (and specifically different dimensions thereof) will be discussed. Conclusions will be drawn about whether the SUEIT predicted scores on the examined leadership 
competencies when a measure of personality, namely the OPQ32i (already employed for this purpose) was controlled for. Additionally, conclusions related to the utility of the SUEIT (measuring EI) for organizational decision makers who need to select leaders that competently display leadership behaviours, will also be presented. 


\section{CHAPTER 4: DISCUSSION}

\subsection{INTRODUCTION}

In light of the developments surrounding the EI construct highlighted in previous chapters, research was necessary to provide evidence for the practical utility of Palmer and Stough's distinctive theory and measure of EI (the SUEIT, 2001). More specifically, an exploration of the evidence for the predictive validity of EI in leadership competence, as well as investigating the discriminant validity of EI from personality in this context, was necessary. Hence, the main aim of this study was to explore the incremental validity of EI by determining whether the SUEIT predicts something new and distinct, other than related constructs (e.g. personality), which is being used to predict leadership competence. In order to derive empirical evidence for the incremental validity (or not) of the SUEIT, it was explored whether the SUEIT accounts for variance in leadership competency scores (indicated by ratings on AC simulation exercises) used to predict leadership competence in the workplace, additional to the variance accounted for by personality (as measured by the OPQ32i).

\subsection{DISCUSSION OF FINDINGS}

This section provides a consolidated discussion of the evidence that was found related to the predictive and discriminant validity of the SUEIT per leadership competency. Evidence with regards to the incremental validity of the SUEIT, or lack thereof, for each of the competencies will also be discussed. Where applicable, comparisons are made with previous research findings.

\subsubsection{Customer Focus}

The empirical results pertaining to the Customer Focus leadership competency indicated a relationship with the Understanding Emotions External EI dimension. Hence, it could be argued that leaders with high scores on the Understanding Emotions External dimension of EI, who are highly capable of perceiving and understanding the emotions of their customers and are able to "read" the emotions that they convey, are generally more competent in taking action according to their customers' needs and thus develop more productive and satisfying customer relations. Nel et al. (2003) and Langhorn (2004) conducted similar studies to investigate the relationship between EI and Customer Focus. Nel et al. (2003) investigated the relationship between EI 
(operationalised by the Emotional Competence Inventory/ECI of Hay \& McBer, 1999) and performance in call centers (characterized by client centeredness and the ability to maintain good customer relations). The evidence obtained in the current study replicates the results found by Nel et al. (2003) in that a positive relationship was indicated between EI (measured by the ECI) and performance in the client services call centre. The emotional competencies in the Self Management and Social Skills clusters of the ECI - managing one's internal states, and the effective handling of interpersonal relationships to induce desirable responses in others (the latter partially conceptually related to the Understanding Emotions External dimension) - explained the largest amount of variance in job performance in the call centre environment. Further confirmation of the abovementioned findings are evident in a study by Langhorn (2004) where the emotional competencies of individual general managers (measured with the Bar-On EQ-I) were related to the key performance outputs (e.g. customer satisfaction scores) under their direct control. A significant relationship was found between customer satisfaction scores and general mood (e.g. happiness and optimism). Hence, the author concluded that the ability to project a happy and optimistic outlook would seem to be beneficial in the development of customer satisfaction, once again corroborating the utility of EI in Customer Focus and satisfaction (as found in the current study).

Moderate correlations between the EI dimension of the SUEIT, Understanding Emotions External, and the OPQ32i dimensions, Affiliative and Emotionally Controlled were found. Hence, it is evident that there is a moderate degree of overlap in what is being measured by the SUEIT and the OPQ32i where the Understanding Emotions External (EI) and Affiliative and Emotionally Controlled (personality) dimensions are concerned. Given this overlap it can be argued that the Understanding Emotions External EI dimension does not have discriminant validity from the Affiliative and Emotionally Controlled OPQ32i dimensions. The Affiliative (significant unique contribution), Outgoing and Emotionally Controlled dimensions of the OPQ32i were furthermore also related to Customer Focus. Based on the results it could be argued that leaders with highly outgoing personalities were found to generally be more likely to attract customers to themselves and develop and sustain productive customer relations. Furthermore, the results also revealed that leaders who have more affiliative personality types are inclined to respond to customer needs with a sense of urgency, in order to ensure that they develop and sustain the relationship. Additionally, leaders with personality styles characterized by emotional 
expressiveness (low scores on Emotionally Controlled) were shown to more readily express their enthusiasm about providing the best service towards customers, hence motivating their subordinates to display customer focused behaviour

Whilst specific SUEIT and the OPQ32i dimensions explained variance in Customer Focus, the results presented in chapter three indicate that the OPQ32i dimension, Affiliative made the largest and only significant unique contribution in the prediction of Customer Focus. However, EI as measured by the SUEIT accounted for limited additional variance $(0.4 \%)$ in Customer Focus when personality traits (the OPQ32i dimensions) were controlled for (see results of hierarchical regression, section 3.4). Despite the degree of overlap between the EI and personality dimensions found to predict Customer Focus, EI (Understanding Emotions External) was still able to account for limited additional variance in Customer Focus, and hence evidence for incremental validity of EI in the Customer Focus leadership competency can be assumed.

\subsubsection{Building Working Relationships}

Partial evidence for the predictive validity of the SUEIT regarding the leadership competency, Building Working Relationships was found (as reported in the hierarchical regression results, section 3.4). Furthermore, the relationship (correlation) found between Understanding Emotions External (EI dimension) and the Building Working Relationships leadership competency could indicate that leaders who are able to understand the emotions of their colleagues at work as well as the impact that emotions have on the workplace (high on the EI dimension, Understanding Emotions External) are most likely more inclined to use collaborative relationships to facilitate the accomplishment of work goals. Leaders scoring high on the Understanding Emotions External EI dimension are generally more able to "read" the emotional overtones of workplace environments and discussions (e.g. staff meetings) more effectively. Hence, it could be argued that they would be able to proactively build effective relationships and reach work goals in a collaborative fashion through giving recognition and empathizing appropriately. This finding partially affirms previous research by Gardner and Stough (2002), which found a positive relationship between the Contingent rewards dimension of Transactional leadership (operationalised by the Multifactor Leadership Questionnaire of Bass \& Avolio, 2000), and the Understanding Emotions External SUEIT dimension $(r=0.557, p<0.01)$. Transactional leaders typically address the current needs of subordinates by focusing attention on recognition and 
punishment to obtain objectives (contingent rewards) (Bass \& Avolio, 2000). This definition of a transactional leader shows partial agreement with the definition of Building Working Relationships leadership competency, where recognition and empathy are utilized as a means to reach work goals. Therefore, the relationship between Understanding Emotions External and Building Working Relationships in this study partially replicates the finding of the relationship (between Contingent Rewards and Understanding Emotions External) found by Gardner and Stough (2002).

Furthermore, Gardner and Stough (2002) found a strong relationship between the Understanding Emotions External EI dimension and an outcome of leadership, namely Satisfaction, which is achieved when the individual is collaborating with other team members in a satisfying way. To this end it is argued that the relationship found between Understanding Emotions External and Building Working Relationships, which is partially defined as the building of relationships in order to collaborate effectively with team members in order to achieve work related goals, replicates the finding of Gardner and Stough (2002), namely that leaders high on Understanding Emotions External are more likely to collaborates satisfactory in a team. Correlation between Emotional Control and Building Working Relationships in the current study additionally indicated that leaders, who are generally more able to control their emotions (indicated by high scores on the Emotional Control dimension of the SUEIT), will among other things, deal more constructively with conflict and through that build collaborative relationships to facilitate the accomplishment of work goals. Lastly, it is noted that the result of this study (relationships between Understanding Emotions External and Building Working Relationships) also replicates research findings by Higgs and Aitken (2003). Higgs and Aitken (2003) operationalised EI by means of the EI Questionnaire Managerial (Dulewicz \& Higgs, 2000) and investigated the extent to which an individual's EI predict an assessment of leadership potential obtained through using AC methodology (Higgs \& Aitken, 2003). Their results indicated a correlation between the Building Relationships leadership competency (conceptually related to the Building Working Relationships competency in this study), and the EI dimension Interpersonal sensitivity (conceptually similar to the Understanding Emotions External SUEIT dimension), which is the ability to be aware of the needs and feelings of others and to use this effectively in interacting with colleagues (Higgs \& Aitken, 2003). 
The correlation between Emotional Control and Building Working Relationships found in this study, partially replicates a research finding by Higss and Aitken (2003). They found a strong relationship between the leadership competency, Building Relationships and the EI dimension Emotional Resilience (operationalised by the EI Questionnaire - Managerial by Dulewicz and Higgs, 2000). The Emotional Resilience dimension measures the ability to perform consistently when under pressure. This relates conceptually to the Emotional Control dimension of the SUEIT, as Emotional Control refers to the capacity to not let strong emotions (e.g. anger, stress) interfere with the ability to perform effectively in the workplace (also referred to as emotional "highjacking” by Goleman, 1998).

The results furthermore revealed correlations of a moderate degree between Understanding Emotions External and the Affiliative, Socially Confident, Democratic, Behavioural and Emotionally Controlled personality dimensions. Hence, moderate overlap in the measurement of the underlying latent constructs through the Understanding Emotions External dimension and the abovementioned dimensions of the OPQ32i are evident, and causes one to question the discriminant validity of this EI dimension from the OPQ32i dimensions. As expected, various significant relationships between the latter personality dimensions and the Building Working Relationships leadership competency also emerged.

In order to compare the findings in the current study (with regards to the overlap between EI and personality traits) with previous research where the NEO-FFI was used (e.g. Gardner \& Stough, 2003; Palmer et al., 2003) conceptual links were drawn between the relevant OPQ32i dimensions and the dimensions of the NEO-FFI where applicable (see Appendix 5). When comparing the OPQ32i dimensions with the dimensions of the NEO-FFI it is evident that the OPQ32i Behavioural dimension can conceptually be linked to the Openness dimension of the NEO-FFI. The Behavioural OPQ32i dimension refers to a person's inclination to be introspective and analyse his or her own and others feelings and incorporate it into decision-making (Saville et al., 1994). Similar to this, individuals scoring high on the Openness dimensions of the NEO-FFI are also generally more introspective, perceptive and analytical when it comes to their own and others' feelings (McCrae, 2000). The finding of the current study, demonstrating partial overlap between Understanding Emotions External (the SUIET dimension) and the OPQ32i Behavioural dimension, thus partially confirm previous research results of Gardner and Stough (2003). They 
reported an overlap of a moderate degree $(r=.42, p<0.01)$ between the Understanding Emotions External SUIET dimension and the Openness dimension of the NEO-FFI.

Specific dimensions of both the OPQ32i and the SUEIT were found to account for variance in the Building Working Relationships leadership competency. The results revealed that EI explained a significant additional amount of variance (7.7\%) in Building Working Relationships when the relevant OPQ32i dimensions were controlled for (see section 3.4). Furthermore, Understanding Emotions External made the largest significant unique contribution to predicting variance in the Building Working Relationships leadership competency. After consideration of all the results presented, it can, henceforth, be stated that the results provide evidence for the incremental validity of the SUEIT (measuring EI), specifically related to the leadership competency, Building Working Relationships.

\subsubsection{Gaining Commitment}

The results of this study provided evidence of a relationship between the Understanding Emotions External dimension of the SUEIT and the leadership competency Gaining Commitment. Thus it could be argued that leaders who are able to perceive and understand the emotions and emotional responses of others (high on Understanding Emotions External) would generally be more competent at adapting their interpersonal styles to the individual and situation, thereby subsequently gaining acceptance and commitment to their ideas or plans. This corroborates with the result of a study done by Gardner and Stough (2002) who found a strong relationship ( $r=0.585, p<0.01$ ) between Understanding Emotions External (the SUEIT) and the Individualized Consideration dimension of Transformational Leadership (MLQ, Bass \& Avolio, 2000). Individualized consideration is defined as the behaviour of treating individuals as important contributors to the workplace, in order to generate commitment within them and motivate them to do more than is expected of them. Hence this dimension was considered to be conceptually similar to the Gaining Commitment leadership competency in this study. Furthermore, moderate correlations were found between Understanding Emotions External and the Socially Confident and Behavioural OPQ32i dimensions. It can thus be assumed that there is moderate overlap (and questionable discriminant validity) in the measurement of the underlying 
latent constructs by the Understanding Emotions External dimension and the abovementioned dimensions of the OPQ32i.

The Socially Confident and Behavioural dimensions of the OPQ32i mentioned above did not only have a relationship with the EI dimension Understanding Emotions External, but were also not surprisingly found to have a relationship with the Gaining Commitment leadership competency. Thus, it could be argued that leaders who obtain high scores on the Socially Confident dimension of the OPQ32i are confident when they communicate and interact with others and henceforth would more easily gain acceptance of their ideas or plans through applying an appropriate interpersonal style (as required by the Gaining Commitment leadership competency). Furthermore, leaders who obtain high scores on the Behavioural dimension of the OPQ32i are more likely to take into account the impact of their decisions on followers. They would thus more readily adopt an appropriate interpersonal style, respond to individual needs and beliefs and attempt to establish acceptance of their ideas through creating a win-win situation (as is required by Gaining Commitment leadership competency).

In section 4.2.2 a conceptual linkage between the OPQ32i dimensions, Behavioural, and the Openness dimensions of the NEO-FFI was proposed - leading to the conclusion that these dimensions represent (and measure) related or similar underlying aspects of personality. In the current study, the overlap in the measurement of the underlying latent constructs through the Understanding Emotions External and the Behavioural (conceptually linked to Openness of the NEO-FFI) dimension of the SUIET and OPQ32i respectively, partly replicates a result from a study conducted by Palmer et al. (2003). They report overlap between the Understanding Emotions External (SUEIT) and Openness (NEO) dimensions $(r=.422, p<0.01)$.

Further investigation of the results pertaining to the Gaining Commitment leadership competency, revealed that the SUEIT did not explain any additional variance in Gaining Commitment when the OPQ32i was controlled for. The Socially Confident dimension of the OPQ32i made the largest - and together with the OPQ32i Relaxed dimension - the only significant contributions in the prediction of variance in the Gaining Commitment leadership competency scores. This finding underscores the importance for a leader of having confidence in 
social situations and communicating effectively in order to gain the commitment of subordinates. In light of the empirical evidence presented for the competency in question, however, it can be concluded that that the EI dimension Understanding Emotions External, has no incremental validity over the SUEIT in Gaining Commitment, as no additional variance were explained by the SUEIT over and above the variance explained by the OPQ32i.

\subsubsection{Developing Others}

From the empirical results related to the Developing Others leadership competency, various conclusions can be drawn. Firstly, a correlation emerged between the Understanding Emotions External dimension and the Developing Others competency, and hence it could be argued that leaders who obtain high scores on the SUIET EI dimension, Understanding Emotions External, better understand the context in which the emotions of their subordinates arise, as well as the appropriateness of emotional responses and behaviours. As a result, such leaders would more easily attain insight into employee's areas of weakness. Henceforth they would also generally motivate employees to take action in order to obtain the skills to fulfill their future responsibilities more effectively. This result is a partial replication of a finding reported in a study by Gardner and Stough (2002). They report a relationship between the Understanding Emotions External (SUEIT dimension) and Individualized Consideration (Transformational Leadership dimension of the MLQ) $(r=0.585, p<0.01)$ and the Extra Effort leadership outcome dimension ( $r=0.506, p<0.01)$. These results corroborate the view that transformational leaders are known to understand followers' needs and to react accordingly as well as motivate employees to do more than is expected (Gardner \& Stough, 2002). This is in accordance with the definition of the Developing Others leadership competency, which is concerned with understanding the development needs of individual subordinates, and motivating them to do more than is expected of them by providing the necessary development opportunities to equip them to fulfill future responsibilities more effectively.

Secondly, the results of the current study furthermore suggested that leaders who are able to constructively express their feelings about a subordinate's lack of performance in certain areas (obtaining high scores on the EI dimension, Emotional Recognition and Expression), whilst effectively controlling strong emotions (obtaining high scores on the EI dimension, Emotional 
Control), could enhance subordinates' commitment to develop themselves (Developing Others). This could consequently result in them fulfilling current or future job responsibilities more effectively. Adjunct to the research by Gardner and Stough (2002), Higgs and Aitken (2003) report similar results of correlations between comparable leadership and EI dimensions. The results of the current study indicating relationships between Developing Others and the EI dimensions, Understanding Emotions External and Emotional Control, corroborates with results of Higgs and Aitkens' (2003) study. They report relationships between Building Personalized Learning (that could be linked conceptually to Developing Others), Interpersonal Sensitivity (conceptually similar to Understanding Emotions External) and Emotional Resilience (conceptually similar to Emotional Control). More specifically, a positive correlation was found between the leadership competency, Building Personalised Learning (which could be linked to the Developing Others competency in the current study) and the EI dimensions Interpersonal Sensitivity $(r=0.17)$ and Emotional Resilience $(r=0.18)$. The Interpersonal Sensitivity dimension of Higgs and Aitken's (2003) model encapsulates the ability to be aware of the needs and feelings of others and to use this effectively in interacting with them (which could be linked to the SUEIT dimension, Understanding Emotions External). The Emotional Resilience EI dimension of Higgs and Aitken (2003) defines the ability to act consistently in when under pressure (which could be linked to the SUEIT dimension, Emotional Control) and hence the results of this study can be viewed as a partial replication of the results reported by Higgs and Aitken (2003).

Thirdly, the correlational results indicated relationships between Outgoing (OPQ32i dimension) and the Developing Others leadership competency. Leaders who have more outgoing personalities are known to be more talkative (scoring high on the Outgoing OPQ32i dimension), and it could therefore be argued that they are more likely to provide timely feedback on observations regarding their subordinates' performance, as well as ask for their input in what needs to be done to develop the relevant skills. Furthermore it can be argued that leaders who follow a more democratic approach would invest more time into developing and listening to their subordinates' perceptions regarding development areas (scoring high on the Democratic dimension of the OPQ32i), as well as encourage discussions regarding what needs to be done to achieve career goals (Developing Others) because they value their contribution to the team 
objectives. Hence they will most likely be more accurate in their recommendations regarding development actions to be taken to address areas of weakness. The results also indicated that leaders who display a degree of nervous energy (when low scores are obtained on the Relaxed personality dimension) would more likely drive their subordinates to fulfill responsibilities effectively and through that contribute to their development. Lastly, leaders who are more concerned about how others see them and are more easily affected by adverse criticism (scoring low on Tough Minded) will motivate their team members to do well, and more actively coach and support the development of subordinates in order to avoid receiving criticism as a team.

In the last instance, small correlations between the Emotional Control EI dimension and Tough Minded (from the OPQ32i) as well as the EI dimension, Understanding Emotions External and the OPQ32i dimension Democratic emerged (both found to predict Developing Others). Once again, these correlations can be interpreted to point towards an overlap in the SUEIT and OPQ32i in the measurement of the underlying latent constructs (EI and personality). Conceptually, it is possible to explain the overlap, and hence questionable discriminant validity, in the aforementioned measured constructs (operationalised through the dimensions in the measurement instruments). The Tough Minded dimension of the OPQ32i can partially be linked conceptually to the Neuroticism dimension of the NEO-FFI. The Tough Minded dimension is concerned with the extent to which individuals are sensitive and easily hurt by criticism and unfair remarks, which like Neuroticism, indicates whether a person is prone to insecurity. The overlap between the Tough Minded OPQ32i dimension and the EI dimension, Emotional Control found in the current study, therefore partly corroborates with a finding of Gardner and Stough (2003). They report overlap between the SUEIT dimension, Emotional Control and Neuroticism of the NEOFFI $(r=-.43, p<0.001)$.

The OPQ32i dimension, Tough Minded, accounted for most of the variance in the Developing Others leadership competency. Emotional Control was the only EI dimension that contributed significantly to predicting variance (and hence possesses predictive validity) in the Developing Others leadership competency, whilst the Outgoing and Democratic OPQ32i dimensions made further significant contributions. Furthermore, although various dimensions of both the OPQ32i and the SUEIT were found to significantly predict the Developing Others competency, EI 
explained a significant additional amount of variance (4.2\%) in the Developing Others leadership competency when personality was controlled for in the regression model. These results provide some empirical evidence for the incremental validity of an aspect of the EI construct in the prediction of variance in the leadership competency, Developing Others.

\subsubsection{Problem Solving}

The results of this study revealed partial evidence for the predictive validity of the SUEIT in the Problem Solving leadership competency. The negative relationship between the Emotional Management EI dimension and Problem Solving leadership competency can be explained by considering the context in which the current study was conducted, where leaders are largely encouraged and expected to follow a logical and rational approach to problem solving. The results suggest that the use of these analytical approaches will be enhanced if such leaders are able to effectively manage moods in themselves and subordinates (Emotional Management). In a study by Lyubomirsky and Nolen-Hoeksema (1995) it was found that people who focus on symptoms of distress and the circumstances surrounding those symptoms (a ruminative coping process) are likely to think about and focus on their negative moods without doing anything to relieve their symptoms. This finding sheds light on the negative relationship between Emotional Management and Problem Solving in the current study. It could be argued that when a person focuses on their emotions too extensively, these negative or positive emotions could "highjack" their thought processes (Goleman, 1998) through constant ruminations or meditation, which in turn could interfere with the ability to engage in effective problem solving (taking a logical and rational approach to problem solving, according to the definition of the problem solving leadership competency) (Lyubomirsky \& Nolen-Hoeksema, 1995).

A moderate correlation was found between the Emotional Management dimension of the SUEIT and the OPQ32i dimension, Tough Minded, also predicting Problem Solving. It could thus be ascertained that there is moderate overlap in the measurement of the underlying latent constructs by these two dimensions. In addition, the correlational results indicated that the Tough Minded personality dimension is related to the Problem Solving leadership competency. It can therefore be assumed that leaders who are less emotionally involved in situations (high scores obtained on Tough Minded) would be able to more effectively establish the necessary solutions to complex 
problems, as they will be able to objectively analyze and interpret the information or situation at hand - given that effective problem solving in this context (the financial services/insurance industry where the bulk of the problems are technical in nature) requires a rational and analytical approach. The results furthermore also revealed that leaders who tend to critically evaluate information (high scores on the Evaluative OPQ32i dimension) would generally display behaviours through which they would be able to thoroughly and accurately identify, define and analyze problems and select the most appropriate course of action. In the last instance, the correlational results between the Controlling OPQ32i dimension and the Problem Solving leadership competency indicate that it could be argued that leaders who tend to prefer to take control of situations and their followers (scoring high on the Controlling dimension) would actively generate solutions to problems to ensure that they stay in control. It was surprising however, that the results did not indicate a relationship between Emotion Direct Cognition and Problem Solving, as this EI dimension is concerned with the extent to which emotions and emotional knowledge are incorporated in decision-making and/or problem solving. This scale of the SUEIT has been shown to consistently be problematic in research and it could be that measurement issues in terms of the operationalisation of this specific dimension of EI plays a role in this problem.

As explained earlier, the Tough Minded dimension of the OPQ32i can partially be linked conceptually to the Neuroticism dimension of the NEO-FFI used by Palmer et al., (2003) in their study comparing EI (the SUEIT) with personality. The evidence of a relationship between Tough Minded (the OPQ32i dimension of personality) and Emotional Management (dimension of EI) in this study henceforth partially replicates the results reported by Palmer et al., (2003). They reported a correlation of $\mathrm{r}=-.436, \mathrm{p}<.001$ between Emotional Management and Neuroticism.

The Controlling dimension of the OPQ32i made the largest significant contribution in prediction of the variance in the leadership competency, Problem Solving, whilst the OPQ32i Evaluative dimension did not make a significant unique contribution in the regression model. However, the Emotional Management (SUIET dimension) also made a significant unique contribution (5\%) to the prediction of Problem Solving leadership competency scores - and can be assumed to have predictive validity in this regard. More importantly, when the OPQ32i dimensions were 
controlled for, the Emotional Management dimension of EI accounted for additional unique variance in Problem Solving competency scores. This finding provides partial evidence for the incremental validity of EI, specifically related to the Problem Solving competency.

\subsubsection{Stress Tolerance}

The Emotions Direct Cognition and Emotional Control dimensions of the SUEIT were found to have respective negative and positive significant relationships to the leadership competency, Stress Tolerance. Based on this it can be argued that leaders, who incorporate emotional information into their daily reasoning to a large degree (high on Emotions Direct Cognition), might find it more difficult to maintain stable performance under pressure or opposition and to handle stress in a manner that is acceptable to the sponsoring organisation, for rational and logical reasoning and subsequent behaviour are considered to be effective in this context (due to the industry the organisation operates in). In addition, it could also be argued that leaders who display the ability to effectively control strong emotional states experienced at work, such as anger, anxiety and frustration (high on Emotional Control EI dimension ) should be able to will more effectively maintain stable performance when they are under pressure (Stress Tolerance). This result corroborates in part with previous findings of Salovey et al. (1995) who investigated the relationship between EI (by means of the TMMS) and recovery of positive mood following a stressful event induced in a laboratory. The results of their study suggested that excessive attention to negative moods leads to rumination (Salovey, et al., 1995) where rumination is defined as passively and repetitively focusing on one's symptoms of distress and the circumstances surrounding those symptoms. Henceforth it can be argued that if a person is able to control potentially strong emotional states more effectively, less rumination should take place which should assist the individual to maintain stable performance more easily (i.e. the person is able to tolerate stress).

It is interesting to note that of the OPQ32i dimensions (Behavioural, Worrying and Emotionally Controlled) that were found to have significant relationships with Stress Tolerance, none emerged to also correlate with the Emotional Control and Emotions Direct Cognition EI dimensions. This was surprising, as one would expect that the Emotional Control EI dimension and the Emotionally Controlled dimension of the OPQ32i would have a relationship, due to their 
similar names. However on closer inspection of the results it became clear that these two dimensions measure different aspects of Emotional Control (the SUEIT Emotional Control dimension refers to the controlling of strong emotions whereas the OPQ dimension refers to the the extent to which individuals would express their emotions) Although on face value the results seem confusing, the results indicate that the two dimensions measure two different aspects of Emotional Control. Given the correlational results it can be argued that leaders concerned with what motivates their subordinates and the impact of their decisions on them (high scores obtained on the Behavioural personality dimension), will be better able to identify situations which could cause them stress and develop mechanisms to deal with it effectively. Furthermore, leaders who tend to remain calm before important events and take setbacks in their stride (scoring low in the Worrying personality dimension) will deal with stress in a more acceptable manner and maintain stable performance. Adjunct to this, leaders who are more inclined to express their emotions, preferring to clear the air by expressing them (scoring low on the Emotionally Controlled personality dimension), should be able to handle stress more effectively.

The OPQ32i dimension, Worrying, accounted for limited additional variance in the prediction of variance in the Stress Tolerance leadership competency scores and can therefore be assumed to have predictive validity in this leadership competency. However, when the OPQ32i was controlled for, the SUEIT (via Emotional Control and Emotion Direct Cognition dimensions) explained an additional amount variance (0.8\%) in the Stress Tolerance leadership competency scores (when personality was controlled for) and can thus have predictive validity. Henceforth, the results indicate that in the prediction of variance in terms of the leadership competency, Stress Tolerance, the EI dimensions (Emotional Control and Emotion Direct Cognition) explained a small significant amount of additional variance - providing partial evidence for the incremental validity of EI, specifically related to the Stress Tolerance competency.

In chapter two the limitations of the research design of the current study was identified. These will now briefly be revisited, as it needs to be taken into account when the findings and practical implications thereof are discussed. 


\subsection{LIMITATIONS OF THE STUDY AND FUTURE RESEARCH}

Several limitations of the current study's research design have been identified. The data sources partly consisted of archival data and therefore standard statistical procedures had to be followed to deal with missing cases. Sometimes the omission of cases was also necessary, as a specific respondent's raw data could not always be traced in the record keeping system of the sponsoring organisation. Due to this the sample sizes was much smaller and also differed in the different analyses that was conducted. As a result the comparability of the SUEIT and OPQ32i correlational results could have been influenced.

The sample in the current study furthermore consisted entirely of individuals from one specific organiation with its own unique culture and generally accepted behaviours that could differ from other organisations, which could have influenced the results. The model of leadership used in the current study is also an organisation-specific competency based model (consisting of the behavioural dimensions or competencies identified as critical to leadership and organisational success in the sponsoring organisation). The dimensions or competencies identified as critical for success in a leadership role in the sponsoring organisation might be different from other organisations.

Therefore, care needs to be taken when interpreting the results and generalising the findings of this study to the general population as a means of assessing effective leadership behaviour. Given these limitations it is clear that future research is needed to investigate the utility of the SUEIT in the general population of leaders in different organizations, by determining the extent to which the SUEIT (measuring EI) can be utilised over and above personality measures (i.e. the OPQ32i) to predict leadership in general.

Further limitations of the study relates to the measuring instruments that were used. As the SUEIT was developed in Australia, research is necessary to clarify the cross-cultural differences with regards to the tool and construct, in order to more reliably utilise the measure within the South African context. Secondly, both the SUEIT and the OPQ32i are self-report measures, believed to provide respondents with the opportunity to distort their responses to create a more 
favourable impression of themselves, due to the transparent nature of the questions (Mayer et al. 2000b).

Additionally, it has been argued that self-report measures provide a measure of the respondents' self-concept, rather than their actual abilities or traits. However proponents of self-report measures (Stough \& Palmer, 2002) argue that it provides a more accurate picture of the respondents' internal experiences related to emotional thinking, which may not necessarily be obtained through performance-based measures.

Thirdly, the use of AC methodology to obtain a measure of leadership competencies, indicating potential to function efficiently in a leadership role, places a further limitation on the study. To date no longitudinal studies (to the author's knowledge) exist to clarify the reliability and validity of the leadership AC in general, as a means to measure leadership competencies. However, here it can be pointed out that the sponsoring organisation tries to ensure the validity and reliability of the assessment centres, as far as possible, by adhering to the specific design considerations outlined in chapter two.

\subsection{CONCLUSION}

The results of the current study demonstrate the existence of various relationships between EI (as measured by the SUEIT) and the Customer Focus, Building Working Relationships, Gaining Commitment, Developing Others, Problem Solving and Stress Tolerance leadership competencies (as measured by the AC technology employed by the sponsoring organisation). In several instances it was found that there is overlap in the measurement of the underlying latent constructs by the different personality and EI dimensions from which such results were inferred. In order to compare these findings (with regards to the overlap between EI and personality traits) with previous research, conceptual links were drawn with other EI and personality measures used (e.g. the Bar-On EQi and NEO-FFI). Expected conceptual and theoretical equivalence in the measurement of personality and EI were confirmed. However, given the overlap found between the different measures, limited empirical evidence for the incremental validity of the SUEIT (and

specifically different dimensions thereof) was still found for the Customer Focus, Building 
Working Relationships, Developing Others, Problem Solving and Stress Tolerance leadership competencies.

In spite of the overlap identified between the five EI dimensions of the SUEIT and the OPQ32i, this study provided partial evidence that EI, as measured by the SUEIT, could add to our understanding of the characteristics leaders in the sponsoring organisation should possess to enable them (as leaders) and the organisation to be successful. Further research is necessary where different models and measures of leadership and personality traits are utilised in order to generalise the findings with regards to the relationship between EI, as measured by the SUEIT, and leadership and personality traits in general. The study contributes to the body of knowledge in support of the utility of the EI construct, and specifically the SUEIT in this regard. Based on the results it can be argued that the SUEIT (specific dimensions of the SUIET) can help predict success in the examined leadership competencies in the sponsoring organization, over and above the measure of personality, namely the OPQ32i, already employed for this purpose.

Having knowledge about the nature of the relationship between EI and leadership competencies could enable organisational decision makers in the sponsoring organisation to more effectively select and develop individuals that should be successful in leadership roles. The SUEIT seems to have utility in the sense that it provides a measure that could assist organisational decision makers who needs to select leaders that competently display the abovementioned leadership behaviours. These results therefore provide confirmation that EI should indeed be viewed as a useful and valuable construct and tool. 


\section{REFERENCES}

Appelbaum, S.H., Harel, V., \& Shapiro, B. (1998). The developmental assessment centre: the next generation. Career Development International, 3(1), 5-12.

Baron, H. (1996). Strengths and limitations of ipsative measurement. Journal of Occupational and Organizational Psychology, 69, 49-56.

Bar-On, R. (1997). BarOn Emotional Quotient Inventory: Technical Manual. Toronto: MultiHealth Systems.

Bar-On, R. (2003). How important is it to educate people to be emotionally and socially intelligent, and can it be done? Perspectives in education, 21(4), 3-13 .

Bar-On, R. (2000). Emotional and social intelligence: Insights from the Emotional Quotient Inventory (EQ-I). In R Bar-On \& J.D.A. Parker (Eds.), Handbook of Emotional Intelligence, (pp.363-388). San Francisco: Jossey-Bass.

Bass, B.M., \& Avolio, B.J. (2000). Multifactor Leadership Questionnaire. CA: Mind Garden, Redwood City.

Boyatzis, R. (1982). The Competent Manager - A Model for Effective Performance, New York: John Wiley and Sons.

Boyatsis, R., Goleman, D., \& Hay/McBer. (1999). Emotional Competence Inventory. San Francisco: Jossey Bass.

Bols, R., van Bree, J., Bolton, M., \& Gijswijt, J. (1996). Emerging issues in assessment and development. Career Development International, 1(6), 33-40. 
Bradley, J.H. \& Hebert, F.J. (1997). The effect of personality type on team performance. Journal of Management Development, 16(5), 337-353.

Brownell, J. (2005). Predicting leadership. The assessment center's extended role. International Journal of Contemporary Hospitality Management, 17(1), 7-21.

Byham, W.C. (1970). Assessment centers for spotting future managers. Harvard Business Review, 48, 150-160.

Byham, W.C. (1971). The assessment centre as an aid in management development. Training and Development Journal, 26, 12-22.

Byham, W.C. (1980). The assessment centre as an aid in management development. Training and Development Journal, 25(12), 10-22.

Byham, W.C. (1982). Starting an assessment centre the correct way. Personnel Administrator, 25(2), 27-32.

Cames, I., Vinnicombe, S., \& Singh, V. (2001). Profiles of “successful managers” held by male and female banking managers across Europe. Women in Management Review, 16(3), 108117.

Campbell, T. \& Cairns, H. (1994). Developing and measuring the learning organization. From buss words to behaviour. Industrial and Commercial Training, 26(7), 10-15.

Carmeli, A. (2003). The relationship between emotional intelligence and work attitudes, behaviour and outcomes. An examination among senior managers. Journal of Managerial Psychology, 18(8), 788-813.

Cavallo, K., \& Brienza, D. (2001). Emotional competence and leadership excellence at Johnson \& Johnson: The Emotional Intelligence and leadership study. The Consortium for 
Research on Emotional Intelligence in Organisations. Word Wide Web (http//www.EIConsortiu.org)

Cattell, R.B., Eber, H.W., \& Tatsuoka, M.M. (1970). Handbook for the Sixteen Personality Factor Questionnaire (16PF). Champaing, IL: Institute for Personality and Ability Testing.

Ciarrochi, J.V., Chan, A.Y.C., \& Caputi, P. (2000). A critical evaluation of the emotional intelligence construct. Personality and Individual Differences, 28, 539-561.

Costa, P.T., Jr., \& McCrae, R.R. (1995). Domains and facets: Hierarchical personality assessment using the revised NEO Personality Inventory. Journal of Personality Assessment, 64(1), 21-50.

Cronbach, L.J. (1995). Giving method variance its due. In P.E. Shrout and S.T. Fiske (Eds.), Personality Research, Methods, and Theory: A Festschrift Honoring Donald W. Fiske, (pp. 145147). Hillsdale, JJ: Erlbaum.

Dakin, S., Nilakant, V., \& Jensen, R. (1994). The role of personality testing in managerial selection. Journal of Managerial Psychology, 9(5), 3-11.

Day, A.L., \& Carroll, S.A. (2004). Using an ability-based measure of emotional intelligence to predict individual performance, group performance, and group citizenship behaviours. Personality and Individual Differences, 36, 1443-1458.

Dawda, D., \& Hart, S.D. (2000). Assessing emotional intelligence: reliability and validity of the Bar-On Emotional Quotient Inventory (EQ-i). Personality and Individual Difference, 28, 797812.

Daus, C.S., \& Ashkanasy, N.M. (2003). Will the real emotional intelligence please stand up? On the deconstructing the emotional intelligence “debate”. The Industrial-Organisational Psychologist, 41(2), 69-72. 
Deguara, D., \& Stough, C. (2002). Examining the relationship between emotional intelligence and workplace performance. Organisational Psychology Research Unit: Swinburne University.

Derksen, J., Kramer, I., \& Katzko, M. (2002). Does a self-report measure for emotional intelligence assess something different than general intelligence? Personality and Individual Difference, 32, 37-48.

Dulewicz, V., \& Higgs, M. (2000). Emotional intelligence. A review and evaluation study. Journal of Managerial Psychology, 15(4), 341-372.

Elmes, D.G., Kantowitz, B.H., \& Roediger, H.L. (1999). Research Methods in Psycholog (6 ${ }^{\text {th }}$ Edition). Johannesburg: ITP.

Emmerling, R.J., \& Goleman, D. (2003). Emotional intelligence: Issues and common misunderstandings. The Consortium for Research on Emotional Intelligence in Organisations. World Wide Web: (http//:www.EIConsortium.org).

Eysenck. H.J.(1916). In H.J. Eyseck, \& M.W., Eyseck. M.W. (Eds.) Personality and Individual Differences: A Natural Science Approach (pp414-424). Baltimore, MD: University Park Press.

Eysenck, H.J. \& Wilson, G.D. (1976). A Textbook of Human Psychology. Baltimore, Md.: University Park Press.

Eysenck, H.J. (1981). In: H.J. Eysenck and L.W. Lynn, Eds. Dimensions of Personality: Papers in Honour of H.J. Eysenck (pp. 387-389).

Fitzgerald, C. (1997). The MBTI and leadership development: Personality and leadership reconsidered in changing times. In C. Fitzerald, L.K. Kirby, et al. (Eds) (1997). Developing 
Leaders: Research and Applications in Psychological Type and Leadership Development: Integrating Reality and Vision, Mind and Heart (pp. 33-59).

Frederickson, B.L. (2003) Positive Emotions and Upward Spirals in Organisations. In: K.S. Cameron, J.E. Dutton, \& R.E. Quinn (Eds.) Positive Organisational Scholarship. Foundations of a New Discipline (pp.163-193). San Francisco: Berrett-Koehler Publisher, Inc,.

Garavan, T.N., \& Morley, M. (1998). Graduate assessment centres: an empirical investigation of effectiveness. Education \& Training, 40(5), 206-219.

Gardner, H. (1983). Frames of Mind: The Theory of Multiple Intelligences. New York: Basic Books.

Gardner, H. (2003). Frames of Mind. The Theory of Multiple Intelligences (10'th Anniversary Edition). USA: Basic Books.

Gardner, L., \& Stough, C. (2002). Examining the relationship between leadership and emotional intelligence in senior level managers. Leadership \& Organisation Development Journal, 32(2), 68-78.

Gardner, L., \& Stough, C. (2003). Measuring Emotional Intelligence in the workplace with the Swinburne University Emotional Intelligence Test. Proceedings of the First International Conference on Contemporary Management (pp. 91-100), Adelaide, 1-2 September 2003.

Gilligan, J.H., Treasure, T., \& Watts, C. (1996). Incorporating psychometric measures in selecting and developing surgeons. Journal of Management in Medicine, 10(6), 5-16.

Goleman, D. (1995). Emotional Intelligence. New York: Bantam Books.

Goleman, D. (1996). Emotional Intelligence: Why it can matter more than IQ. London: Bloomsbury. 
Goleman, D. (1998). What makes a leader? Harvard Business Review,76 (6), 93-104.

Graziano, A.M. \& Raulin, M.L. (2000). Research Methods: A Process of Inquiry. London: Allyn and Bacon.

Greenspan, S.I., \& Pollock, G.H. (1997). The Course of Life. Madison: International Universities Press.

Havaleschka. F. (1999). Personality and leadership: a benchmark study of success and failure. Leadership and Organisation Development Journal, 20(3), 114-132.

Higgs, M. \& Aitken, P. (2003). An exploration of the relationship between emotional intelligence and leadership potential. Journal of Managerial Psychology, 18(8), 814-823.

Horner, M. (1997). Leadership theory: past, present and future. Team Performance Management, 3(4), 270-287.

Jung, C.G. (1910). The association method. American Journal of Psychology, 21, 219-269.

Kaplan, R.M. \& Sacuzzo, D.P. (2001). Psychological Testing. Principles, Applications and Issues ( $5^{\text {th }}$ Edition). Australia: Wadsworth. Thomson Learning.

Kerlinger, F.N. \& Lee, H.B. (2000). Foundations of Behavioural Research (4 ${ }^{\text {th }}$ Edition). San Diego: Harcourt Publishers.

Kinder, A., \& Robertson, I.T. (1994). Do you have the personality to be a leader? The importance of personality dimensions for successful managers and leaders. Leadership and Organisation Development Journal, 15(1), 3-12. 
Landy, F.J., \& Farr, J.L. (1983). The Measurement of Work Performance: Methods, Theory and Applications. London: Academic Press.

Lievens, F. (2000). An examination of the accuracy of slogans related to assessment centres. Personnel Review, 31(1), 580-601.

Leung, S.L., \& Bozionelos, N. (2004). Five-factor model traits and the prototypical image of the effective leader in the Confucian cultur. Employee Relations,26(1), 62-71.

Lopes, P.N., Salovey, P., \& Straus, R. (2003). Emotional intelligence, personality, and the perceived quality of social relationships. Personality and Individual Differences, 35, 641-658.

Lyubomirsky, S., \& Nolen-Hoeksema, S. (1995). Effects of self-focused rumination on negative thinking and interpersonal problem solving.. Journal of Personality and Social Psychology, 69, 176-190.

Mayer, J., Caruso, D.R., \& Salovey, P. (2000). Emotional Intelligence meets traditional standards for an intelligence. Intelligence, 27(4), 267-298.

Mayer, J.D. \& Salovey, P. (1997). What is emotional intelligence. In P. Salovey, and D.J. Sloyter (Eds.) Emotional Development and Emotional Intelligence: Implications for Educators. Basic Books, New York.

Mayer, J.D., Salovey, P., \& Carusso, D.R. (1998). Multifactor Emotional Intelligence Test (MEIS). Durham: Conant Hall

Mayer, J.D., Salovey, P., \& Caruso, D. (1999). Test Manual for the MSCEIT V.2. . Toronto: Multi Health Systems Inc. 
Mayer, J.D., Salovey, P., \& Caruso, D. R. (2000a). Emotional Intelligence as Zeitgeist, as Personality, and as a Mental Ability. In R. Bar-On \& J. D. A. Parker (Eds), Handbook of Emotional Intelligence ( pp263-276). San Francisco: Jossey Bass.

Mayer, J.D., Salovey, P., \& Carusso. D. R. (2000b). Selecting a Measure of Emotional Intelligence. The Case for Ability Scales. In R. Bar-On \& J.D.A. Parker (Eds.), Handbook of Emotional Intelligence (pp. 320-342). San Francisco: Jossey Bass.

McCrae, R.R. (2000). Emotional Intelligence from the Perspective of the Five-Factor Model of Personality. In R. Bar-On \& J.D. Parker (Eds.), Handbook of Emotional Intelligence (pp. 263276). San Francisco: Jossey Bass.

Mello, J.A. (1999). Reframing leadership pedagogy through model and theory building. Career Development International, 4(3), 163-169.

Nel, H., De Villiers, W.S., \& Engelbrecht, A.S. (2003). The influence of Emotional Intelligence on performance in a call centre environment. Proceedings of the First International Conference on Contemporary Management, Adelaide, 1-2 September 2003.

Newsome, S., Day, A.L., \& Catano, V.M. (2000). Assessing the predictive validity of emotional intelligence. Personality and Individual Differences, 29, 1005-1016.

Oldham, J.M., Skodol, A.E., \& Bender, D.S. (2005). The Americal Psychiatric Publishing Textbook of Personality Disorders. Washington, DC: American Psychiatric Publishers.

O'Connor, R.M. \& Little, I.S. (2003). Revisiting the predictive validity of emotional intelligence: self-report versus ability-based measures. Personality and Individual Differences, 35, 1893-1902.

O’Grady, T.P. (2003). A different age for leadership, Part 1. JONA, 33(2), 105-110. 
Palmer, B., Donaldson, C., \& Stough, C. (2002). Emotional Intelligence and life satisfaction. Personality and Individual Differences, 33(7), 1091-1100.

Palmer, B.R., Gardner, L, \& Stough, C. (2003a). The relationship between emotional intelligence, personality and effective leadership. Paper accepted for presentation of the $5^{\text {th }}$ Australia Industrial \& Organisational Psychology Conference. Melbourne, 26-29 June 2003.

Palmer, B.R., Gardner, L., \& Stough, C. (2003b). Measuring Emotional Intelligence In The Workplace With The Swinburne University of Emotional Intelligence Test. Emotional Intelligence in Organisations. Proceedings of the First International Conference on Contemporary Management. (pp. 91-100), Adelaide, 1-2 September 2003.

Palmer, B.R., Manocha, R., Gignac, G., \& Stough, C. (2003). Examining the factor structure of the Bar-On Emotional Quotient Inventory with an Australian general population sample. Personality and Individual Differences, 35, 1191-1210.

Palmer, B., \& Stough, C. (2001). SUEIT Interim Technical Manual (Version 2). Swinburne University: Swinburne Organizational Psychology Unit.

Parker, J.D.A., Taylor, G.J., \& Bagby, R.M., (2003). The 20-item Torronto Alexitymia Scale III. Reliability and factorial validity in a community population. Journal of Psychosomatic Research, 55, 269-275.

Petrides, K.V., \& Furnham, A. (2000). On the dimensional structure of emotional intelligence. Personality and Individual Differences, 29, 331-320.

Rahim, A., \& Minors, P. (2003). Effects of emotional intelligence on concern for quality and problem solving. Managerial Auditing Journal, 18(2), 150-155.

Rice, C.L. (1999). A quantitative study of emotional intelligence and its impact on team performance. Unpublished master’s thesis, Pepperdine Unversity, L.A. 
Rogers, C. R. (1959). A theory of therapy, personality, and interpersonal relationships, as developed in the client-centered framework. In S. Koch (Ed.), Psychology: A Study of Science (Vol. 3). New York: McGraw-Hill.

Rogers, C.R. (1980). A Way of Being. Boston: Houghton Mifflin.

Rosete, D., \& Ciarrochi, J. (2005). Emotional intelligence and its relationship to workplace performance outcomes of leadership effectiveness. Leadership and Organisation Development Journal, 26(5), 388-399.

Saklofske, D.H., Austin, E.J., \& Minski, P.S. (2003). Factor structure and validity of a trait emotional intelligence measure. Personality and Individual Differences, 34, 707-721.

Salovey, P, Mayer, J.D., Caruso, D \& Lopes, P.N (2001). Measuring Emotional Intelligence as a Set of Abilities with the MSCEIT. In: S.J. Lopez and C.R. Snyder (Eds.), Handbook of Positive Psychology Assessment. Washington DC: American Psychological Association.

Sarros, C., \& Santora, J.C. (2001). The transformational-transactional leadership model in practice. Leadership and Organisational Development Journal, 22(8), 383 - 393.

Saville, P., Cramp p, L., \& Henley, S. (1994). OPQ32 Course Handbook. Surrey: Saville \& Holdsworth Ltd.

Salovey, P., Mayer, J.D., Goldman, S., Turvey, C. \& Palfai, T. (1995). Emotional attention, clarity, and repair: Exploring emotional intelligence using the Trait Meta-Mood Scale. In J. Pennebaker (Ed.), Emotion, Disclosure, and Health (pp. 125-154). Washington, DC: American Psychological Association 
Schutte, N.S., Malouff, J.M., Hall, L.E., Haggerty, D.J., Cooper, J.T., Golden, C.J., \& Dornheim, L. (1998). Development and validation of a measure of emotional intelligence. Personality and Individual Differences 25, 167-177.

SHL Group plc. (2005). OPQ Technical Manual. World Wide Web (http://www.shl.com)

Sivanatha, N., \& Fekken, G.C. (2002). Emotional intelligence, moral reasoning and transformational leadership. Leadership \& Organisation Development Journal, 23(4), 198-204.

Smith, P.C., \& Kendall, L.M. (1963). Retranslation of expectations: An approach to the construction of unambiguous anchors for rating scales. Journal of Applied Psychology, 47, 149155.

Snow, J.L. (2001). Looking beyond nursing for clues to effective leadership. JONA, 31(9), 440-443.

Steiner, C. (1984). Emotional Literacy. Transactional Analysis Journal, 14, 62-173.

Stough, C., Palmer, B.R., Gardner, L., Papageorgiou, V., \& Redman, S. (2002). The development of a workplace measure of emotional intelligence - The Swinburne University Emotional Intelligence Test (SUEIT). Symposium Proposal Submitted to the Third Conference on Emotional and Organisational Life, Gold Coast, Queensland, Australia. 14-16 June 2002.

Stough, C, and Palmer, B.R. (2002). The Reliability and Discriminant Validity of the Swinburne University Emotional Intelligence Test. Symposium paper delivered at the Third Conference on Emotional and Organisational Life, Gold Coast, Queensland, Australia, 14-16 June 2002.

Stuart, A., \& Paquet, A. (2001). Emotional intelligence as a determinant of leadership potential. Journal of Industrial Psychology, 27(3), 30-34. 
Thorndike, R.L. (1920). Intelligence and its uses. Harper’s Magazine, 140, 227-235.

Thornton, G.C. \& Byham, W.C. (1982). Assessment Centres and Managerial Performance, New York: Academic Press.

Topping, G.D. \& O’Gorman, J. G. (1997). Effects of faking set on validity of the NEO-FFI. Personality and Individual Differences, (23)1, 117 - 124.

Vitello-Cicciu, J.M. (2002). Exploring emotional intelligence. Implications for nursing leaders. JONA, 32(4), 203-210.

Vloeberghs, D., \& Bergham, L. (2003). Towards and effectiveness model of development centers. Journal of Managerial Psychology, 18(6), 511-540.

Wislon, D. (1996). The future for development centers. Career Development International, 1(6), 4-11.

Woodruffe, C. (1993). What is meant by a competency? Leadership and Organisational Development Journal, 14(1), 29-36. 


\section{APPENDIX 1: SHAPIRO-WILCK TESTS FOR NORMALITY}

\subsection{SHAPIRO-WILCK STATISTICS FOR THE OPQ32i}

\begin{tabular}{|c|c|c|}
\hline OPQ32i DIMENSIONS & \multicolumn{2}{|c|}{$\begin{array}{l}\text { SHAPIRO-WILCK STATISTIC } \\
(\mathrm{W})\end{array}$} \\
\hline Persuasiveness & 0.95906 & $p=0.06253$ \\
\hline Controlling & $0.95213 *$ & $p=0.03083$ \\
\hline Outspoken & 0.96510 & $p=0.11663$ \\
\hline Independent mindedness & 0.97877 & $p=0.44935$ \\
\hline Outgoing & 0.96069 & $p=0.07398$ \\
\hline Affiliative & 0.95972 & $p=0.06694$ \\
\hline Socially Confident & $0.93986 *$ & $p=0.00920$ \\
\hline Modest & 0.97337 & $p=0.28088$ \\
\hline Democratic & 0.96657 & $p=0.13581$ \\
\hline Caring & 0.96233 & $p=0.08766$ \\
\hline Data rational & 0.95753 & $p=0.05346$ \\
\hline Evaluative & 0.98540 & $p=0.75023$ \\
\hline Behavioural & 0.97676 & $p=0.37428$ \\
\hline Conventional & 0.96991 & $p=0.19107$ \\
\hline Conceptual & 0.97201 & $p=0.23594$ \\
\hline Innovative & 0.96639 & $p=0.13665$ \\
\hline Variety Seeking & 0.97449 & $p=0.33199$ \\
\hline Adaptable & 0.98647 & $p=0.79923$ \\
\hline Forward thinking & 0.98541 & $p=0.75053$ \\
\hline Detail conscious & 0.95953 & $p=0.65660$ \\
\hline Conscientious & 0.97505 & $p=0.31775$ \\
\hline Rule Following & 0.97136 & $p=0.22125$ \\
\hline Relaxed & $0.13892 *$ & $p=0.00000$ \\
\hline Worrying & 0.96432 & $p=0.10763$ \\
\hline Tough minded & 0.98848 & $p=0.88170$ \\
\hline Optimistic & $0.94465 *$ & $p=0.01464$ \\
\hline Trusting & 0.97280 & $p=0.25534$ \\
\hline Emotionally Controlled & 0.9603 & $p=0.07503$ \\
\hline Vigorous & 0.96607 & $p=0.12893$ \\
\hline Competitive & 0.96696 & $p=0.14124$ \\
\hline Achieving & $0.94142 *$ & $p=0.01068$ \\
\hline Decisive & $0.94450 *$ & $p=0.01442$ \\
\hline
\end{tabular}

$* p<0.05-$ assumptions of normality is violated

\subsection{SHAPIRO-WILCK STATISTICS FOR THE SUEIT}

\begin{tabular}{|l|ll|}
\hline \multicolumn{1}{|c|}{ SUEIT DIMENSIONS } & SHAPIR-WILCK STATISTIC (W) & \\
\hline Emotional Recognition \& Expression & 0.97745 & $p=0.05689$ \\
\hline Understanding Emotions External & 0.98167 & $p=0.13134$ \\
\hline Emotion Direct Cognition & 0.99085 & $p=0.66673$ \\
\hline Emotional Management & 0.98297 & $p=0.16955$ \\
\hline Emotional Control & 0.97626 & $p=0.4494$ \\
\hline
\end{tabular}

$* p<0.05-$ assumptions of normality is violated 


\section{APPENDIX 2: HISTOGRAMS AND NORMAL PROBABILITY PLOTS FOR REGRESSION MODELS}

\subsection{HISTOGRAM AND NORMAL PROBABILITY PLOT OBTAINED FOR}

REGRESSION: CUSTOMER FOCUS ON UNDERSTANDING EMOTIONS EXTERNAL, OUTGOING, AFFILIATIVE \& EMOTIONALLY CONTROLLED CONTINUOUS LEARNING ON SOCIALLY CONFIDENT \& CONCEPTUAL

\section{Histogram}

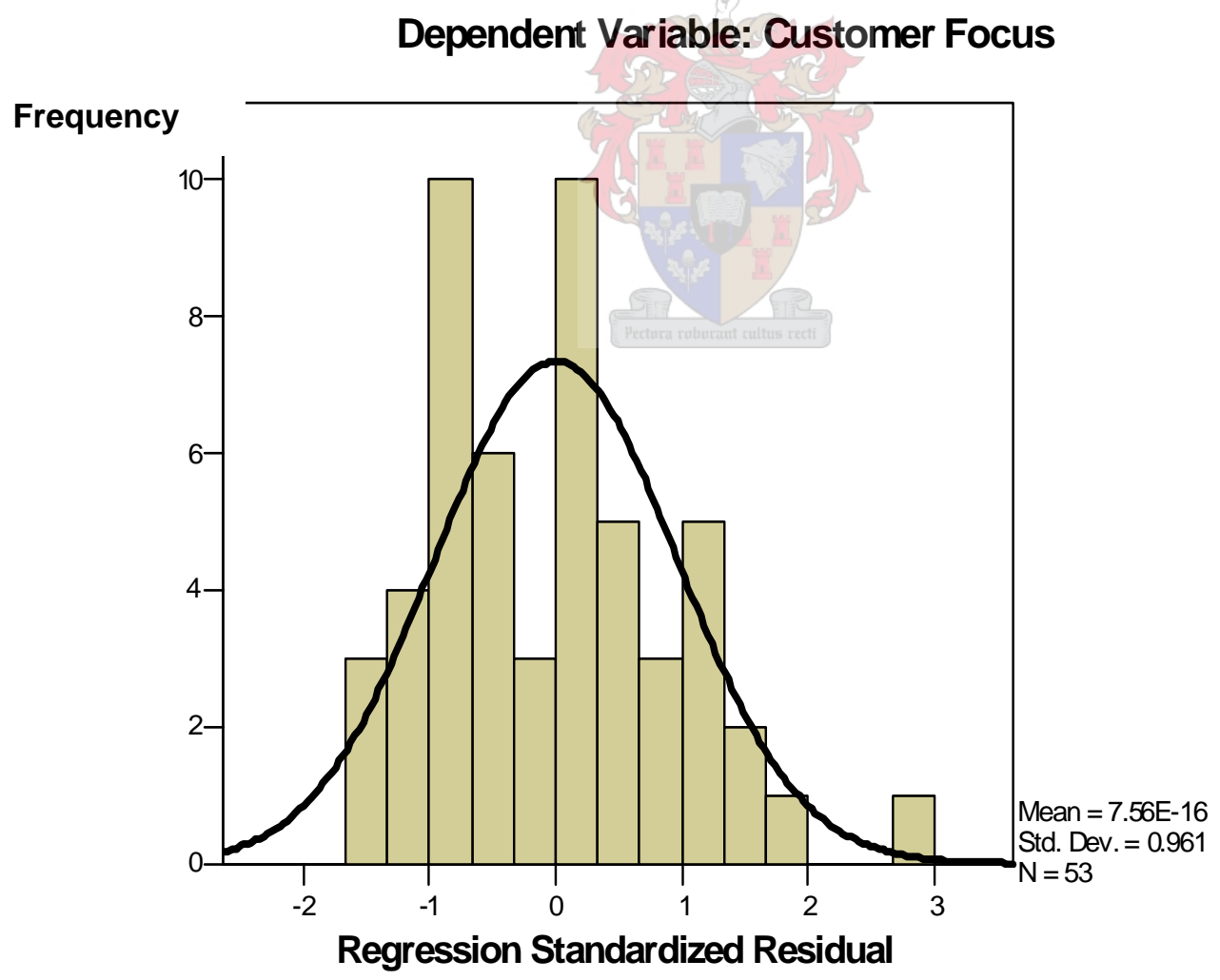




\section{Normal P-P Plot of Regression Standardized Residual}

Expected

Cum

Prob

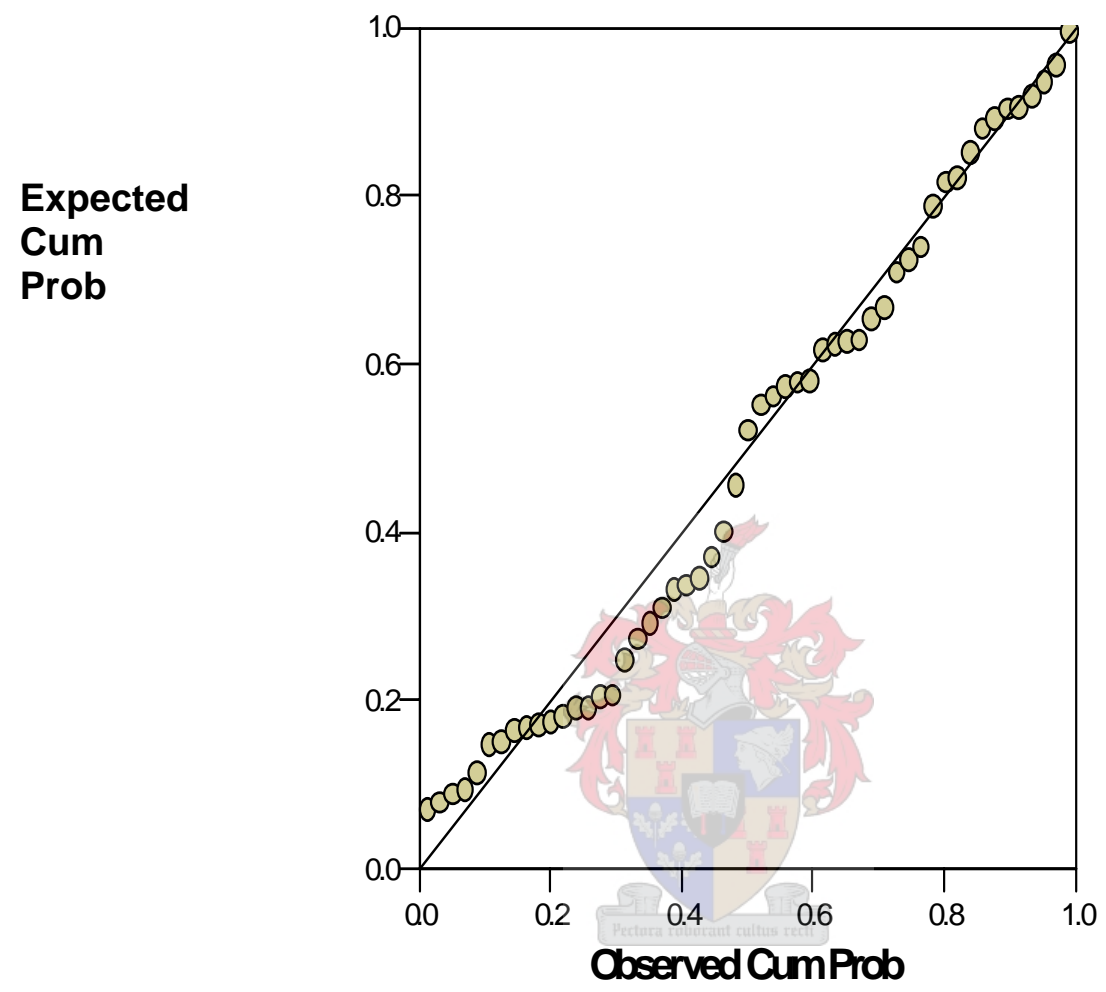


2.2 HISTOGRAM AND NORMAL PROBABILITY PLOT OBTAINED FOR REGRESSION: BUILDING WORKING RELATIONSHIPS ON UNDERSTANDING EMOTIONS EXTERNAL, EMOTIONAL CONTROL, PERSUASIVE, INDEPENDENT MINDED, AFFILIATIVE, SOCIALLY CONFIDENT, DEMOCRATIC, BEHAVIOURAL, EMOTIONALLY CONTROLLED \& DECISIVE

Histogram

Dependent Variable: Building Working Relationships

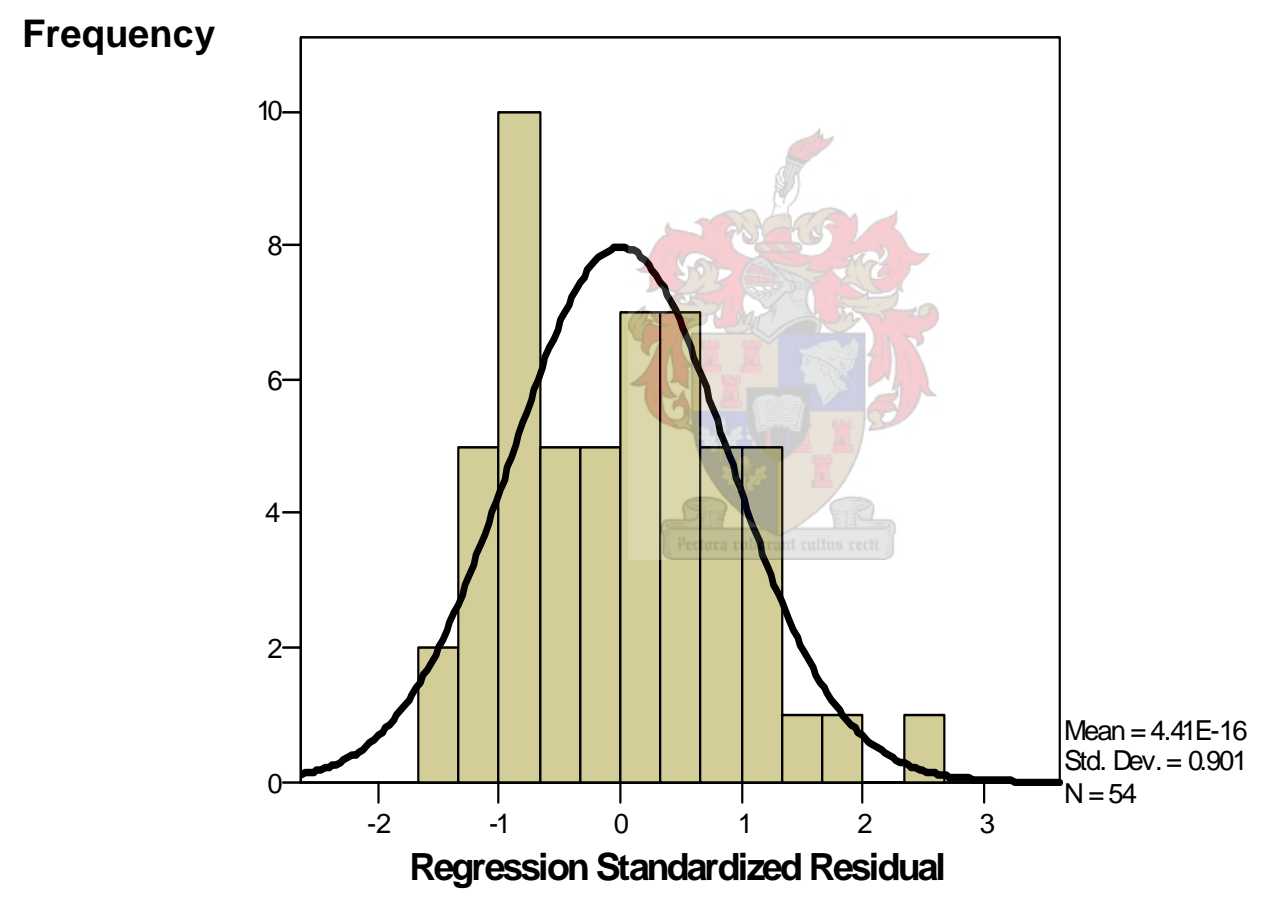




\section{Normal P-P Plot of Regression Standardized Residual}

\section{Dependent Variable: Building Working Relationships}

\section{Expected Cum Prob}

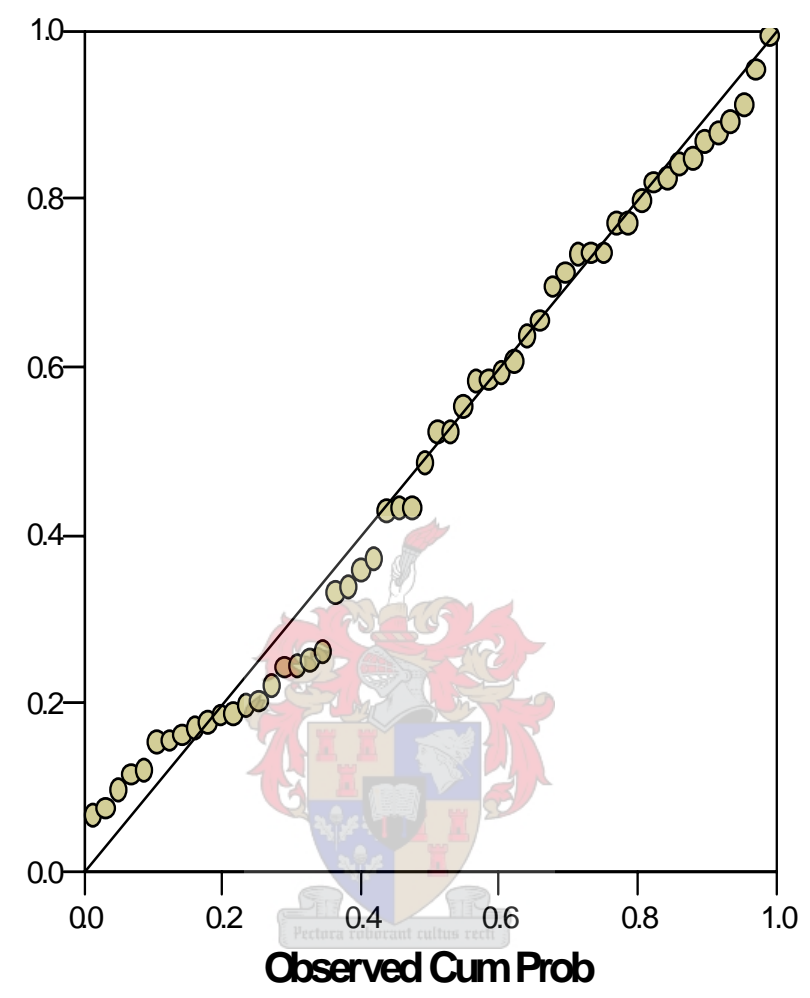




\subsection{HISTOGRAM AND NORMAL PROBABILITY PLOT OBTAINED FOR} REGRESSION: GAINING COMMITMENT ON UNDERSTANDING EMOTIONS

EXTERNAL, INDEPENDENT MINDED, SOCIALLY CONFIDENT, BEHAVIOURAL AND RELAXED

\section{Histogram}

Dependent Variable: Gaining Commitment

Frequency

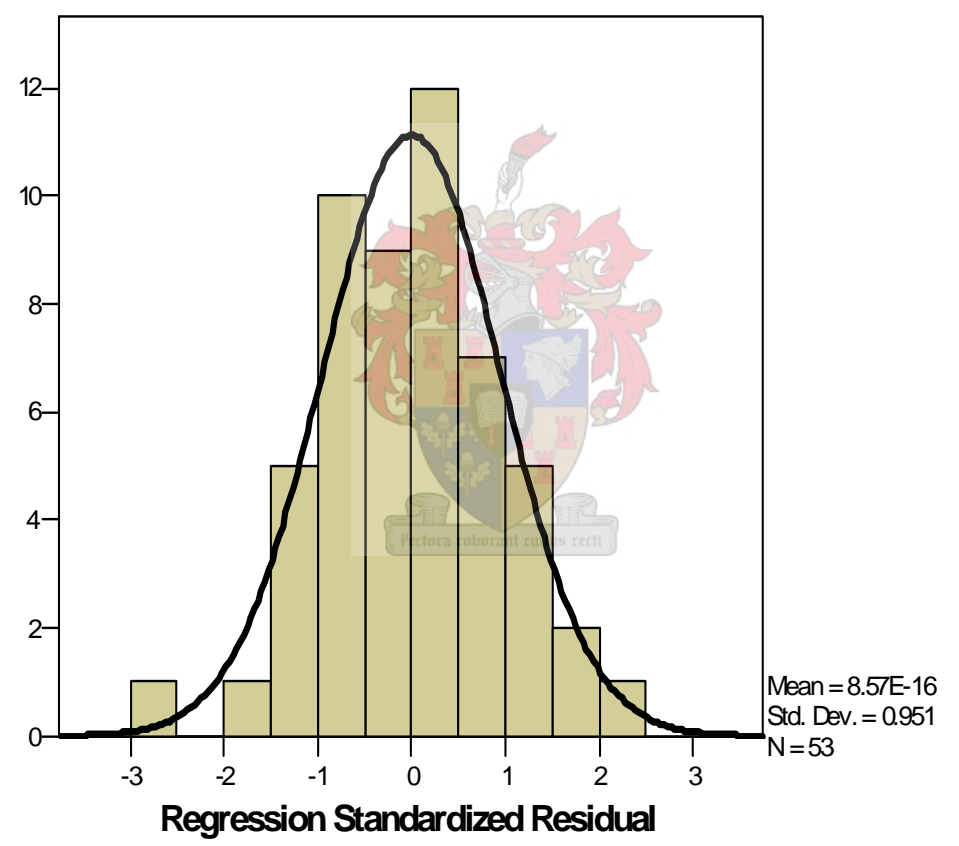




\section{Normal P-PPlot of Regression Standardized Residual}

Expected Cum Prob

\section{Dependent Variable Gaining Commitment}

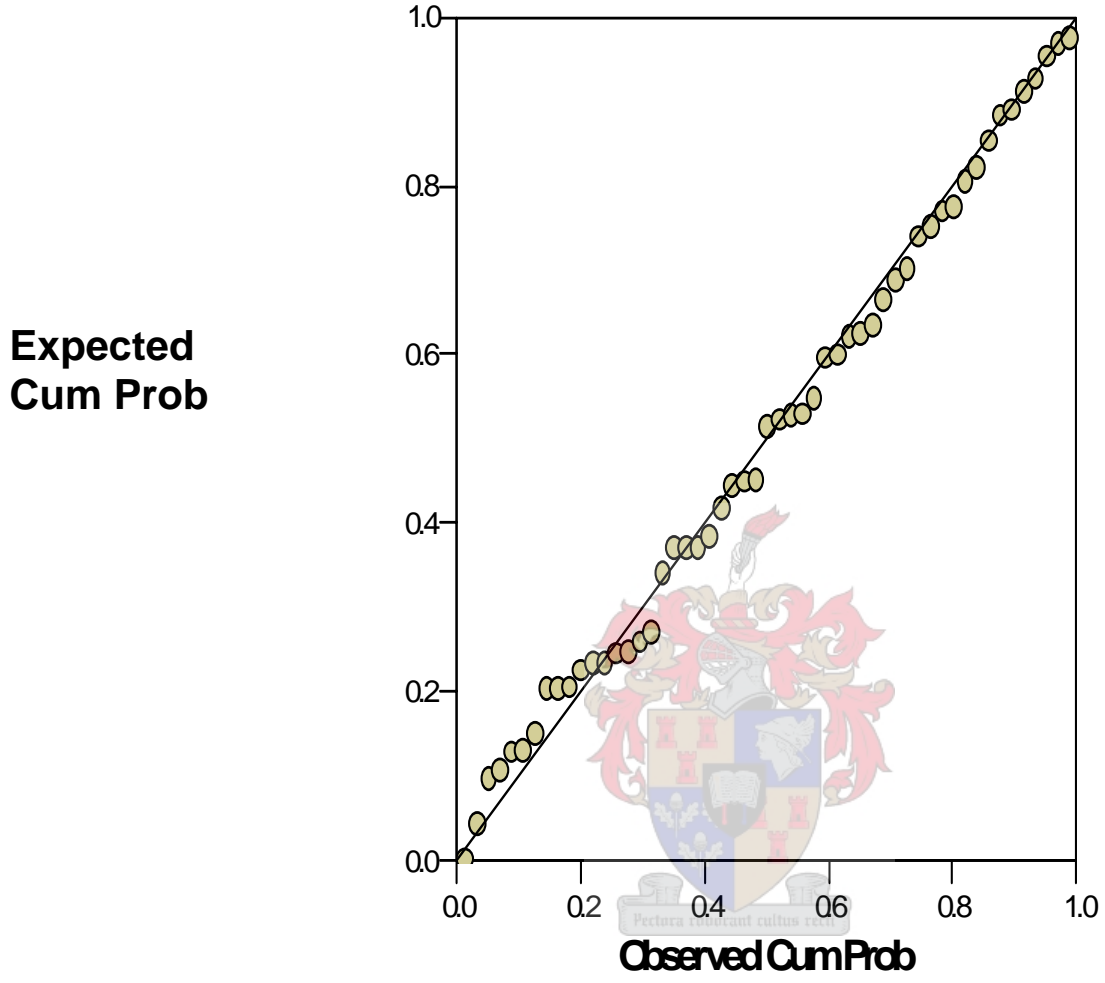


2.4 HISGTOGRAM AND NORMAL PROBABILITY PLOT OBTAINED FOR REGRESSION: DEVELOPING OTHERS ON EMOTIONAL RECOGNITION AND EXPRESSION, UNDERSTANDING EMOTIONS EXTERNAL, EMOTIONAL CONTROL, OUTGOING, DEMOCRATIC, RELAXED \& TOUGH MINDED

Histogram

Dependent Variable: Developing Others

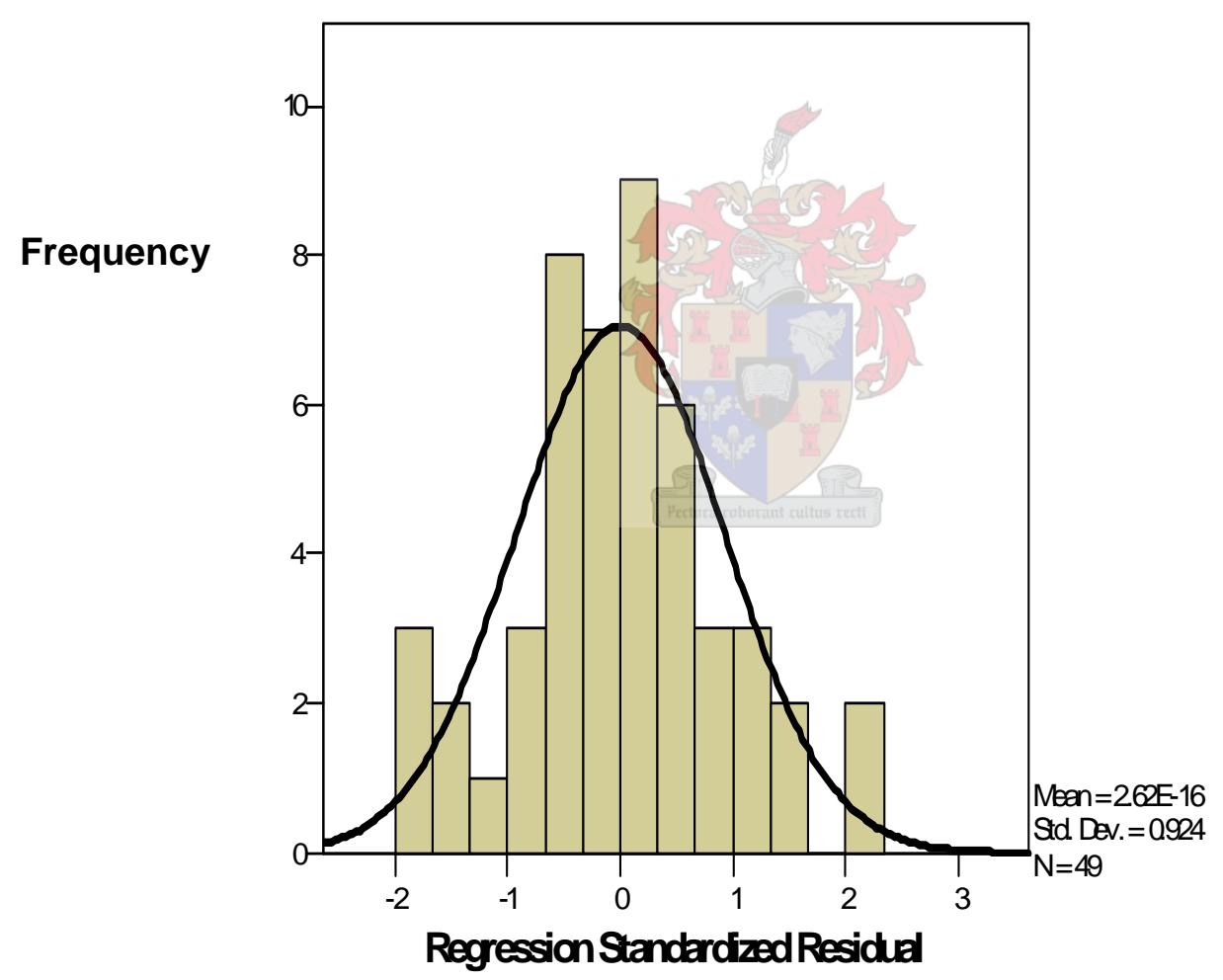


Normal P.PPlot of Regression Standardized Resichal

Expected

Cum

Prob

\section{Dependent Variable Develqping Others}

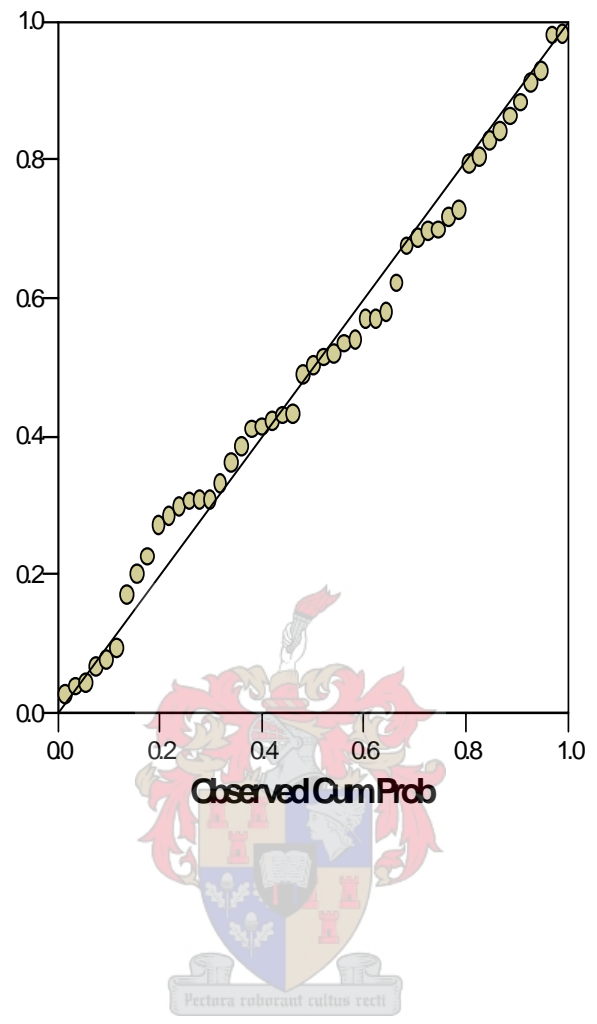




\subsection{HISTOGRAM AND NORMAL PROBABILITY OBTAINED FOR REGRESSION:}

ANALYSIS ON CONTROLLING, EVALUATIVE \& TOUGH MINDED

\section{Histogram}

\section{Dependent Variable: LeadershipAnalysis}

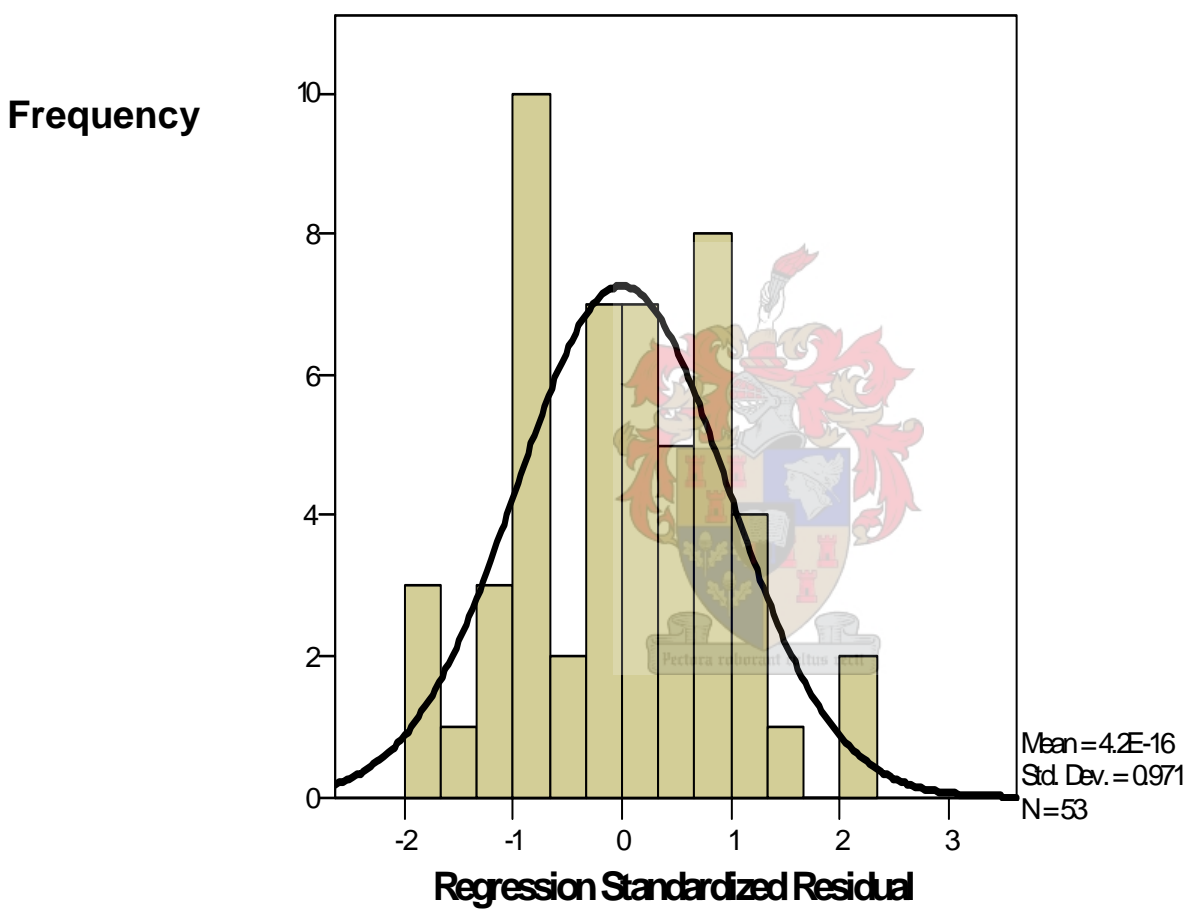




\section{Nommal PPPlat of Regression Standerdzed Residual}

\section{Expected Cum \\ Prob}

Dependent Variable: LeadershipAndysis

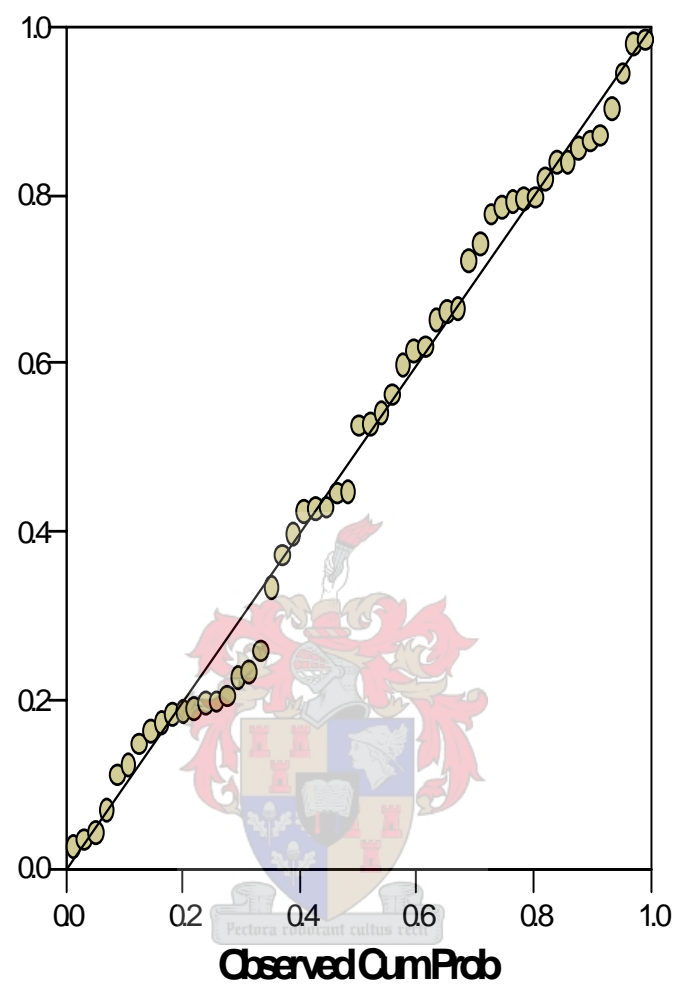


2.6 HISTOGRAM AND NORMAL PROBABILITY PLOT OBTAINED FOR: REGRESSION PROBLEM SOLVING ON EMOTIONAL MANAGEMENT, CONTROLLING, EVALUATIVE \& TOUGH MINDED

Histogram

Dependent Variable. ProblemSolving

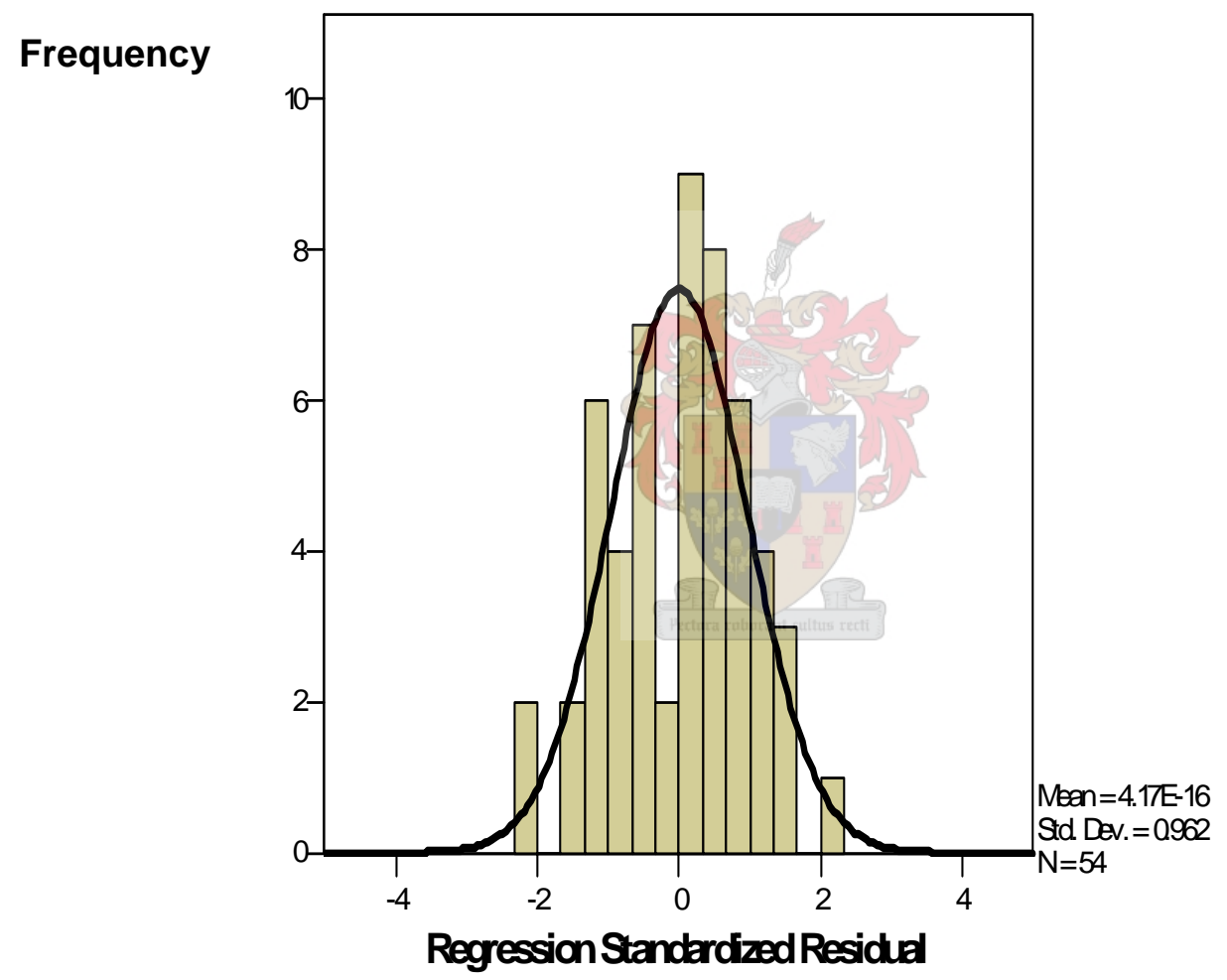




\section{Nonmal PPPlot of Regression Standardized Residual}

\section{Expected Cum \\ Prob}

\section{Dependent Variable: ProblemSolving}

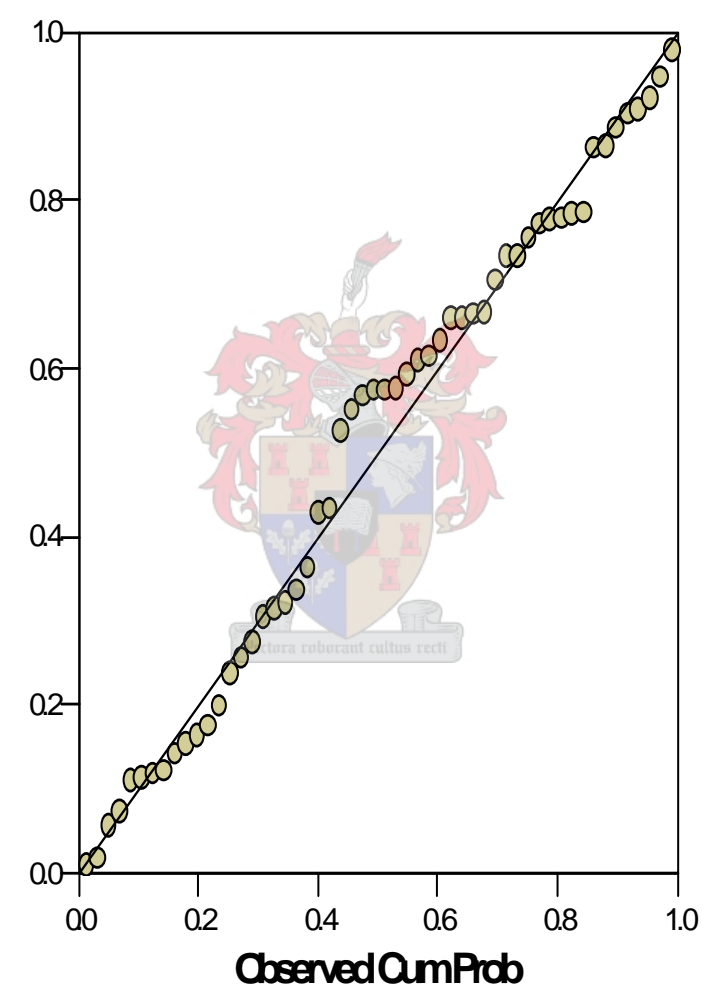




\subsection{HISTOGRAM AND NORMAL PROBABILITY PLOT OBTAINED FOR}

REGRESSION: INITIATING ACTION ON TOUGH MINDED

\section{Histogram}

\section{Dependent Variable Initiating Action}

Frequency

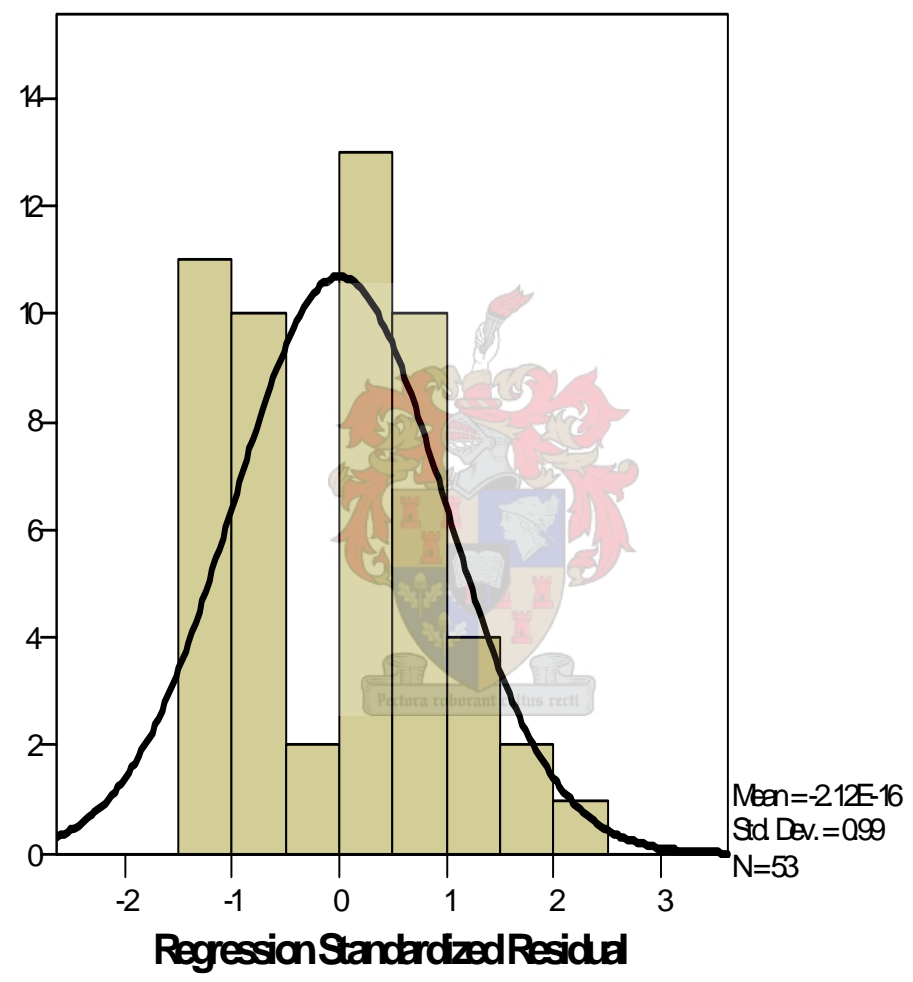




\section{Normal PPPlot of Regression Standardzed Residual}

\section{Dependent Variable Initiating Action}

\section{Expected \\ Cum \\ Prob}

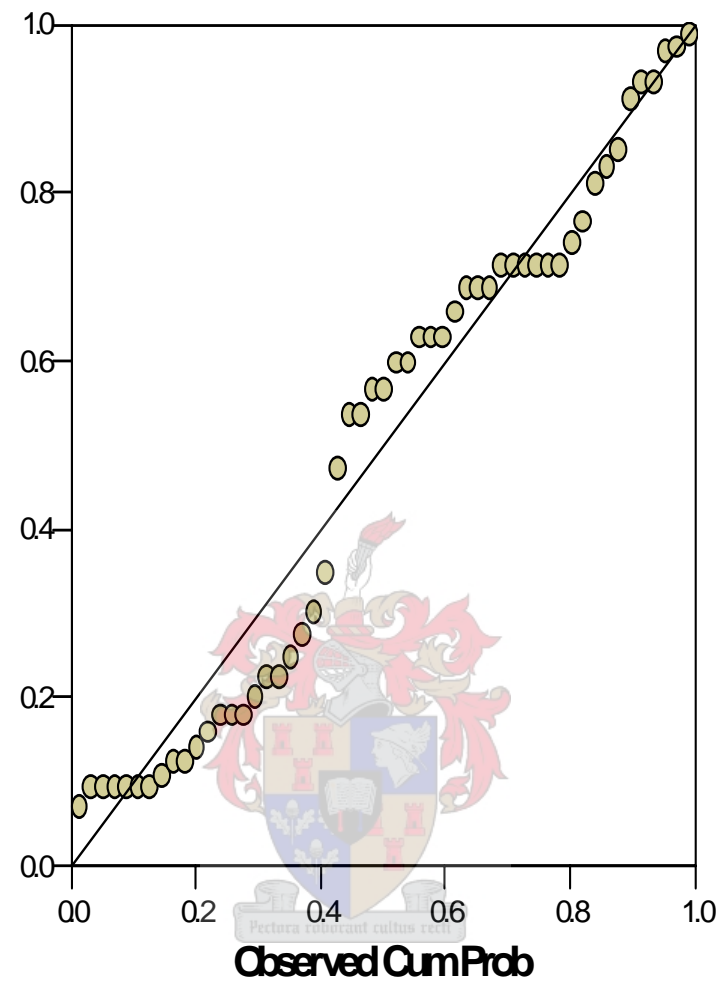


2.8 HISTOGRAM AND NORMAL PROBABILITY PLOT OBTAINED FOR:

REGRESSION PLANNING AND ORGANISING ON OUTSPOKEN, OUTGOING, SOCIALLY CONFIDENT \& DATA RATIONAL

Hstogram

Frequency

Dependert Variade PaningandOrgarising

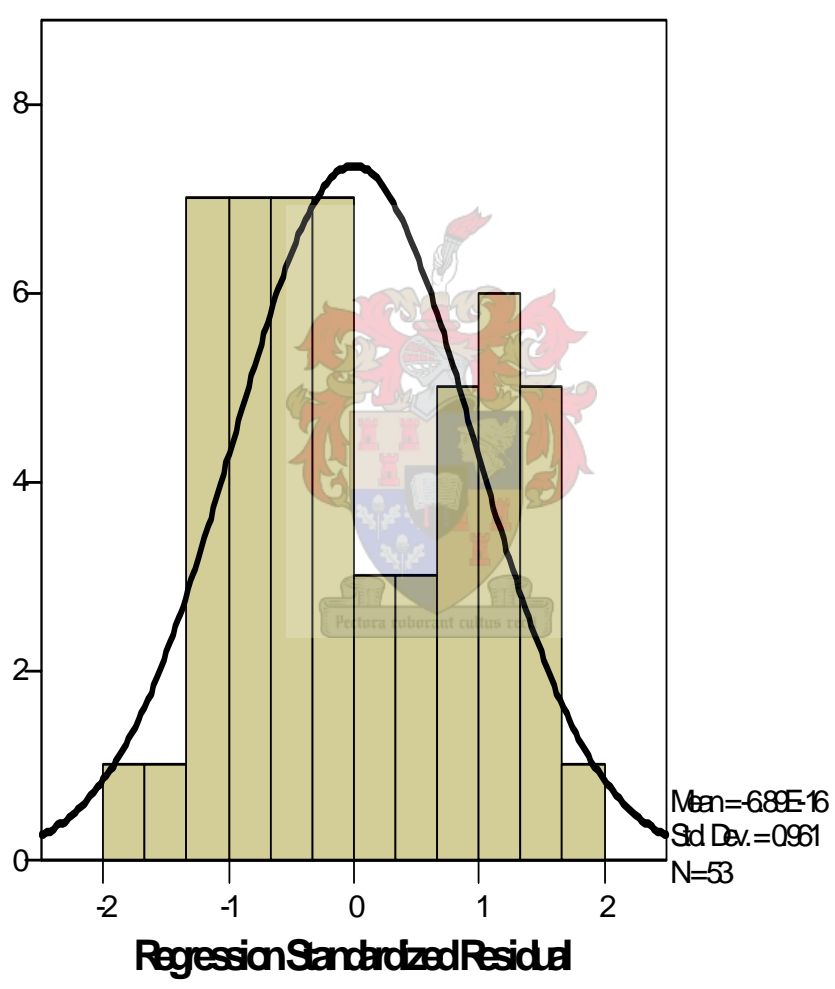




\section{Nbmbl PPPlat of Regression Standardzed Residual}

Expected
Cum Prob

Dependert Variable: Planingand Orgarising

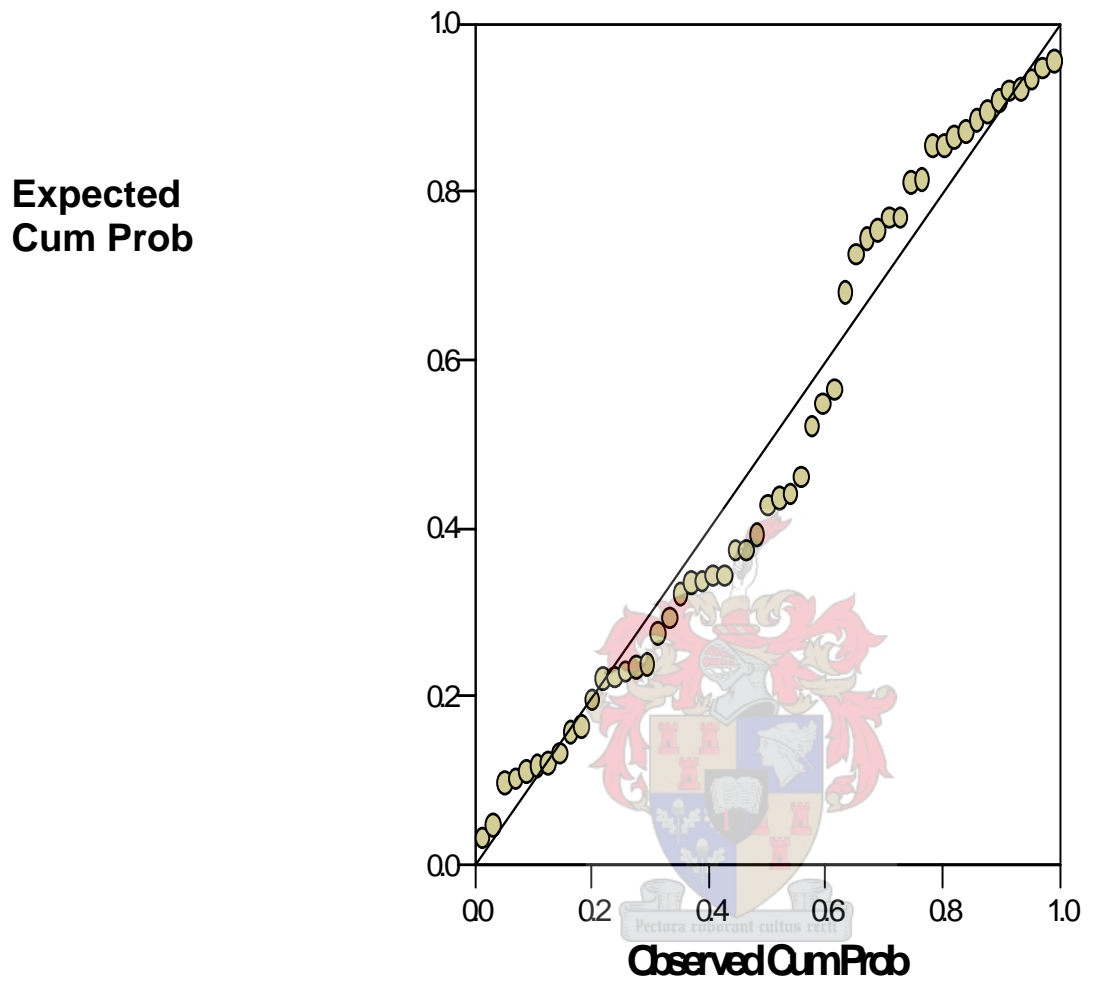


2.9 HISTOGRAM AND NORMAL PROBABILITY PLOT OBTAINED FOR:

REGRESSION STRESS TOLERANCE ON EMOTION DIRECT COGNITION, EMOTIONAL CONTROL, INDEPENDENT MINDED, BEHAVIOURAL, WORRYING \& EMOTIONALLY CONTROLLED

\section{Histogram}

\section{Dependent Variable: Stress Tderance}

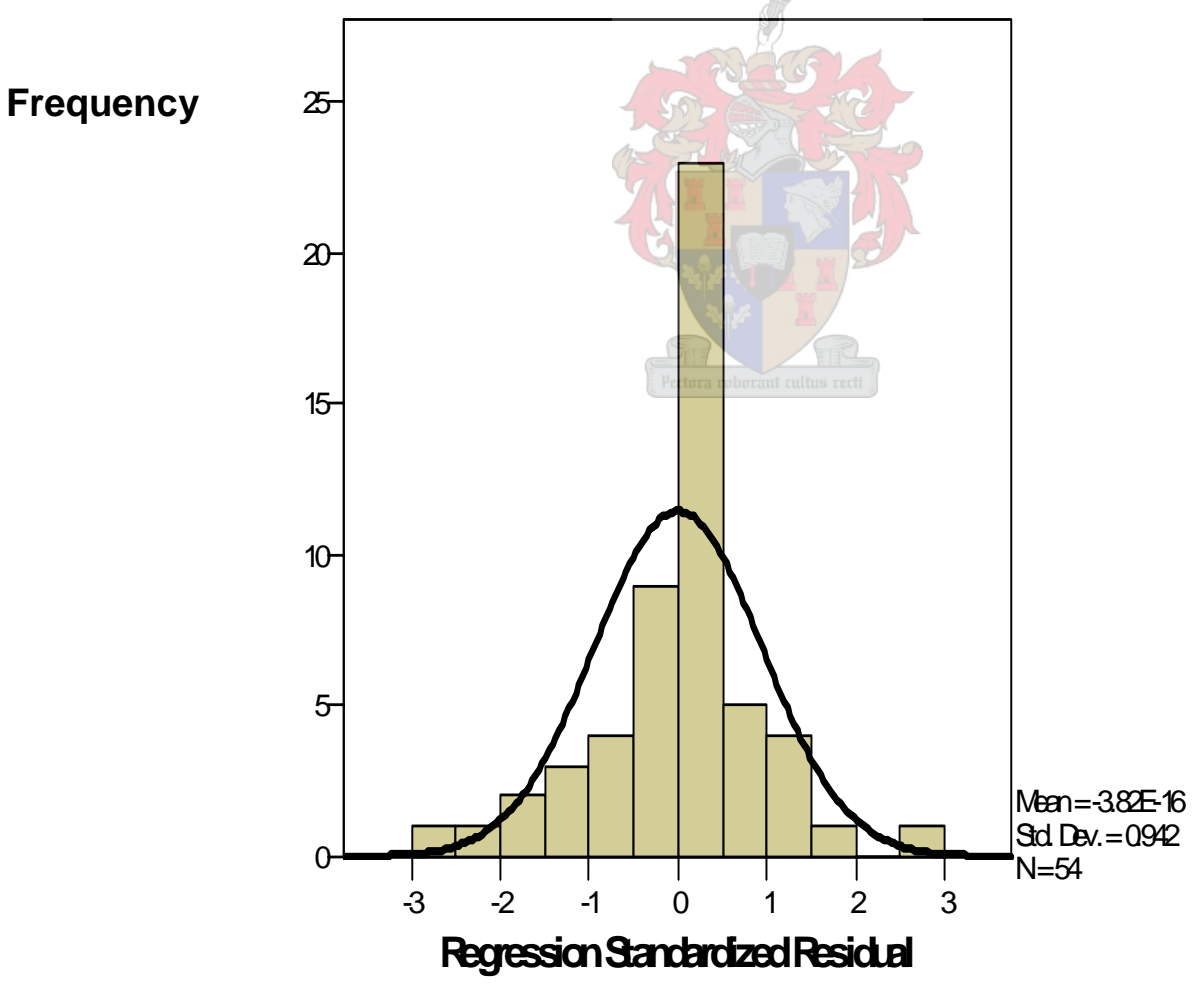




\section{Normal P-PPlot of Regression Standardized Residual}

\section{Dependent Variable: Stress Tolerance}

Expected

Cum

Prob

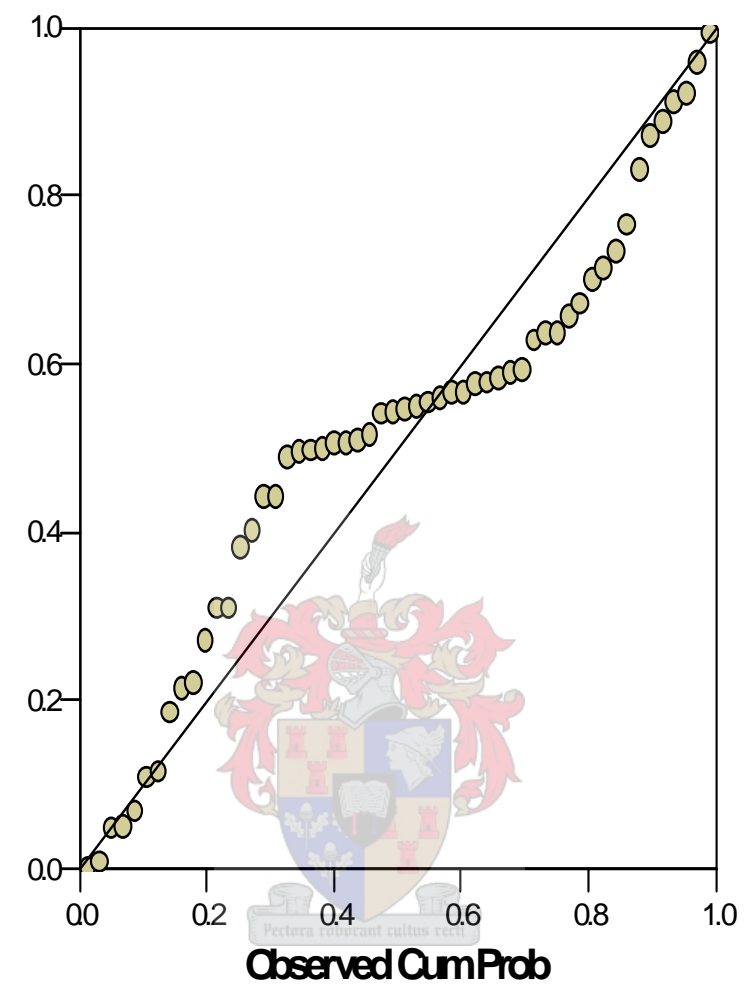


APPENDIX3: RESULTS OF PEARSON PRODUCT-MOMENT CORRELATIONS

3.1 PEARSON PRODUCT-MOMENT CORRELATIONS BETWEEN DIMENSIONS OF THE OPQ32I \& AC LEADERSHIP COMPETENCY SCORES

\begin{tabular}{|c|c|c|c|c|c|c|c|c|c|c|c|}
\hline $\begin{array}{c}\text { OPQ32i } \\
\text { DIMENSIONS }\end{array}$ & & \multicolumn{10}{|c|}{ LEADERSHIP COMPETENCIES } \\
\hline & & $\begin{array}{l}\text { Customer } \\
\text { Focus }\end{array}$ & $\begin{array}{c}\text { Building } \\
\text { Working } \\
\text { Relationships }\end{array}$ & $\begin{array}{c}\text { Gaining } \\
\text { Commitment } \\
\end{array}$ & $\begin{array}{c}\text { Developing } \\
\text { Others }\end{array}$ & Analysis & $\begin{array}{l}\text { Problem } \\
\text { Solving }\end{array}$ & $\begin{array}{l}\text { Initiating } \\
\text { Action }\end{array}$ & $\begin{array}{l}\text { Planning } \\
\text { and } \\
\text { Organising }\end{array}$ & $\begin{array}{c}\text { Stress } \\
\text { Tolerance }\end{array}$ & $\begin{array}{l}\text { Continuous } \\
\text { Learning }\end{array}$ \\
\hline \multirow[t]{3}{*}{ Persuasiveness } & $\begin{array}{l}\text { Pearson } \\
\text { Correlation }\end{array}$ & .014 & $.271\left(^{*}\right)$ & .114 & .157 & -.161 & -.081 & .133 & .042 & -.033 & -.158 \\
\hline & $\begin{array}{l}\text { Sig. (2- } \\
\text { tailed) }\end{array}$ & .923 & .047 & .415 & .283 & .248 & .562 & .343 & .767 & .814 & .289 \\
\hline & & 53 & 54 & 53 & 49 & 53 & 54 & 53 & 53 & 54 & 47 \\
\hline \multirow[t]{3}{*}{ Controlling } & $\begin{array}{l}\text { Pearson } \\
\text { Correlation }\end{array}$ & .094 & -.175 & .137 & .085 & $.276(*)$ & $.302(*)$ & .183 & .189 & .126 & .041 \\
\hline & $\begin{array}{l}\text { Sig. (2- } \\
\text { tailed) }\end{array}$ & .502 & .205 & .328 & .560 & .046 & .027 & .191 & .175 & .364 & .783 \\
\hline & $\mathrm{N}$ & 53 & 54 & 53 & 49 & 53 & 54 & 53 & 53 & 54 & 47 \\
\hline \multirow[t]{3}{*}{ Outspoken } & $\begin{array}{l}\text { Pearson } \\
\text { Correlation }\end{array}$ & .190 & -.050 & .160 & -.067 & .187 & .177 & .199 & $.291\left(^{*}\right)$ & .192 & .052 \\
\hline & $\begin{array}{l}\text { Sig. (2- } \\
\text { tailed) }\end{array}$ & .174 & .720 & .252 & .646 & .181 & .201 & .154 & .034 & .163 & .729 \\
\hline & $\mathrm{N}$ & 53 & 54 & 53 & 49 & 53 & 54 & 53 & 53 & 54 & 47 \\
\hline \multirow[t]{3}{*}{$\begin{array}{l}\text { Independent } \\
\text { mindedness }\end{array}$} & $\begin{array}{l}\text { Pearson } \\
\text { Correlation }\end{array}$ & -.048 & $-.272\left(^{*}\right)$ & $-.293(*)$ & -.142 & .057 & -.004 & -.071 & -.032 & $-.303(*)$ & .044 \\
\hline & $\begin{array}{l}\text { Sig. (2- } \\
\text { tailed) }\end{array}$ & .734 & .047 & .033 & .330 & .686 & .979 & .611 & .818 & .026 & .769 \\
\hline & $\mathrm{N}$ & 53 & 54 & 53 & 49 & 53 & 54 & 53 & 53 & 54 & 47 \\
\hline \multirow[t]{3}{*}{ Outgoing } & $\begin{array}{l}\text { Pearson } \\
\text { Correlation }\end{array}$ &. $.354(* *)$ & .206 & .112 & $.414(* *)$ & .129 & .090 & .167 & $.303(*)$ & .004 & .033 \\
\hline & $\begin{array}{l}\text { Sig. (2- } \\
\text { tailed) }\end{array}$ & .009 & .135 & .426 & .003 & .358 & .517 & .233 & .027 & .974 & .823 \\
\hline & $\mathrm{N}$ & 53 & 54 & 53 & 49 & 53 & 54 & 53 & 53 & 54 & 47 \\
\hline
\end{tabular}




\begin{tabular}{|c|c|c|c|c|c|c|c|c|c|c|c|}
\hline $\begin{array}{c}\text { OPQ32i } \\
\text { DIMENSIONS }\end{array}$ & & \multicolumn{10}{|c|}{ LEADERSHIP COMPETENCIES } \\
\hline & & $\begin{array}{l}\text { Customer } \\
\text { Focus }\end{array}$ & $\begin{array}{c}\text { Building } \\
\text { Working } \\
\text { Relationships }\end{array}$ & $\begin{array}{c}\text { Gaining } \\
\text { Commitment }\end{array}$ & $\begin{array}{c}\text { Developing } \\
\text { Others }\end{array}$ & Analysis & $\begin{array}{l}\text { Problem } \\
\text { Solving }\end{array}$ & $\begin{array}{l}\text { Initiating } \\
\text { Action }\end{array}$ & $\begin{array}{l}\text { Planning } \\
\text { and } \\
\text { Organising } \\
\end{array}$ & $\begin{array}{c}\text { Stress } \\
\text { Tolerance }\end{array}$ & $\begin{array}{l}\text { Continuous } \\
\text { Learning }\end{array}$ \\
\hline \multirow[t]{3}{*}{ Affiliative } & $\begin{array}{l}\text { Pearson } \\
\text { Correlation }\end{array}$ & $.471(* *)$ & $.308(*)$ & -.123 & .208 & .193 & .174 & .041 & .148 & -.229 & -.019 \\
\hline & $\begin{array}{l}\text { Sig. (2- } \\
\text { tailed) }\end{array}$ & .000 & .023 & .379 & .152 & .166 & .209 & .771 & .289 & .096 & .902 \\
\hline & $\mathrm{N}$ & 53 & 54 & 53 & 49 & 53 & 54 & 53 & 53 & 54 & 47 \\
\hline \multirow[t]{3}{*}{$\begin{array}{l}\text { Socially } \\
\text { Confident }\end{array}$} & $\begin{array}{l}\text { Pearson } \\
\text { Correlation }\end{array}$ & .174 & $.410(* *)$ & $.424(* *)$ & .248 & -.011 & .111 & -.046 & $.324(*)$ & .026 &. $.323(*)$ \\
\hline & $\begin{array}{l}\text { Sig. (2- } \\
\text { tailed) }\end{array}$ & .212 & .002 & .002 & .086 & .940 & .422 & .744 & .018 & .850 & .027 \\
\hline & $\mathrm{N}$ & 53 & 54 & 53 & 49 & 53 & 54 & 53 & 53 & 54 & 47 \\
\hline \multirow[t]{3}{*}{ Modest } & $\begin{array}{l}\text { Pearson } \\
\text { Correlation }\end{array}$ & -.141 & -.117 & -.162 & -.084 & -.090 & -.194 & -.130 & -.100 & -.181 & -.096 \\
\hline & $\begin{array}{l}\text { Sig. (2- } \\
\text { tailed) }\end{array}$ & .313 & .400 & .245 & .564 & .523 & .160 & .355 & .476 & .189 & .519 \\
\hline & $\mathrm{N}$ & 53 & 54 & 53 & 49 & 53 & 54 & 53 & 53 & 54 & 47 \\
\hline \multirow[t]{3}{*}{ Democratic } & $\begin{array}{l}\text { Pearson } \\
\text { Correlation }\end{array}$ & .245 & $.512(* *)$ & .223 & $.314(*)$ & -.133 & -.108 & .241 & .028 & .087 & .190 \\
\hline & $\begin{array}{l}\text { Sig. (2- } \\
\text { tailed) }\end{array}$ & .077 & .000 & .108 & .028 & .342 & .436 & .083 & .842 & .531 & .200 \\
\hline & $\mathrm{N}$ & 53 & 54 & 53 & 49 & 53 & 54 & 53 & 53 & 54 & 47 \\
\hline \multirow[t]{3}{*}{ Caring } & $\begin{array}{l}\text { Pearson } \\
\text { Correlation }\end{array}$ & .133 & .202 & -.021 & .185 & -.087 & -.232 & -.060 & -.025 & -.007 & .022 \\
\hline & $\begin{array}{l}\text { Sig. (2- } \\
\text { tailed) }\end{array}$ & .342 & .143 & .881 & .202 & .536 & .091 & .667 & .861 & .958 & .882 \\
\hline & $\mathrm{N}$ & 53 & 54 & 53 & 49 & 53 & 54 & 53 & 53 & 54 & 47 \\
\hline \multirow[t]{3}{*}{ Data rational } & $\begin{array}{l}\text { Pearson } \\
\text { Correlation }\end{array}$ & -.207 & -.061 & -.202 & -.245 & .006 & -.023 & -.132 & $-.307\left(^{*}\right)$ & -.003 & -.100 \\
\hline & $\begin{array}{l}\text { Sig. (2- } \\
\text { tailed) }\end{array}$ & .137 & .660 & .147 & .090 & .966 & .869 & .346 & .026 & .984 & .505 \\
\hline & & 53 & 54 & 53 & 49 & 53 & 54 & 53 & 53 & 54 & 47 \\
\hline \multirow[t]{2}{*}{ Evaluative } & $\begin{array}{l}\text { Pearson } \\
\text { Correlation }\end{array}$ & -.064 & -.057 & -.039 & .020 & $.301(*)$ & $.316(*)$ & .149 & .120 & -.089 & .208 \\
\hline & $\begin{array}{l}\text { Sig. (2- } \\
\text { tailed) }\end{array}$ & .647 & .681 & .781 & .894 & .028 & .020 & .288 & .393 & .522 & .160 \\
\hline
\end{tabular}




\begin{tabular}{|c|c|c|c|c|c|c|c|c|c|c|c|}
\hline $\begin{array}{c}\text { OPQ32i } \\
\text { DIMENSIONS }\end{array}$ & & \multicolumn{10}{|c|}{ LEADERSHIP COMPETENCIES } \\
\hline & & $\begin{array}{l}\text { Customer } \\
\text { Focus }\end{array}$ & $\begin{array}{c}\text { Building } \\
\text { Working } \\
\text { Relationships }\end{array}$ & $\begin{array}{c}\text { Gaining } \\
\text { Commitment }\end{array}$ & $\begin{array}{c}\text { Developing } \\
\text { Others }\end{array}$ & Analysis & $\begin{array}{l}\text { Problem } \\
\text { Solving }\end{array}$ & $\begin{array}{l}\text { Initiating } \\
\text { Action }\end{array}$ & $\begin{array}{l}\text { Planning } \\
\text { and } \\
\text { Organising }\end{array}$ & $\begin{array}{c}\text { Stress } \\
\text { Tolerance }\end{array}$ & $\begin{array}{l}\text { Continuous } \\
\text { Learning }\end{array}$ \\
\hline \multirow{4}{*}{ Behavioural } & $\mathrm{N}$ & 53 & 54 & 53 & 49 & 53 & 54 & 53 & 53 & 54 & 47 \\
\hline & $\begin{array}{l}\text { Pearson } \\
\text { Correlation }\end{array}$ & .223 & $.304(*)$ & $.317(*)$ & .036 & -.098 & .079 & .060 & .147 & $.297(*)$ & .286 \\
\hline & $\begin{array}{l}\text { Sig. (2- } \\
\text { tailed) }\end{array}$ & .108 & .025 & .021 & .808 & .485 & .573 & .668 & .293 & .029 & .051 \\
\hline & $\mathrm{N}$ & 53 & 54 & 53 & 49 & 53 & 54 & 53 & 53 & 54 & 47 \\
\hline \multirow[t]{3}{*}{ Conventional } & $\begin{array}{l}\text { Pearson } \\
\text { Correlation }\end{array}$ & -.004 & .109 & -.141 & .064 & .035 & .131 & .147 & .010 & -.129 & -.053 \\
\hline & $\begin{array}{l}\text { Sig. (2- } \\
\text { tailed) }\end{array}$ & .975 & .435 & .316 & .660 & .805 & .346 & .294 & .944 & .351 & .726 \\
\hline & $\mathrm{N}$ & 53 & 54 & 53 & 49 & 53 & 54 & 53 & 53 & 54 & 47 \\
\hline \multirow[t]{3}{*}{ Conceptual } & $\begin{array}{l}\text { Pearson } \\
\text { Correlation }\end{array}$ & .021 & .122 & .189 & .053 & .087 & .121 & -.081 & .004 & .030 & $.439(* *)$ \\
\hline & $\begin{array}{l}\text { Sig. (2- } \\
\text { tailed) }\end{array}$ & .880 & .381 & .176 & .716 & .535 & .383 & .565 & .980 & .829 & .002 \\
\hline & $\mathrm{N}$ & 53 & 54 & 53 & 49 & 53 & 54 & 53 & 53 & 54 & 47 \\
\hline \multirow[t]{3}{*}{ Innovative } & $\begin{array}{l}\text { Pearson } \\
\text { Correlation }\end{array}$ & -.187 & -.060 & .043 & -.110 & .029 & .004 & -.098 & -.084 & .117 & -.032 \\
\hline & $\begin{array}{l}\text { Sig. (2- } \\
\text { tailed) }\end{array}$ & .180 & .664 & .759 & .451 & .837 & .976 & .484 & .551 & .398 & .833 \\
\hline & $\mathrm{N}$ & 53 & 54 & 53 & 49 & 53 & 54 & 53 & 53 & 54 & 47 \\
\hline \multirow[t]{3}{*}{ Variety Seeking } & $\begin{array}{l}\text { Pearson } \\
\text { Correlation }\end{array}$ & -.017 & -.064 & -.047 & -.124 & .078 & -.026 & .071 & .105 & .018 & -.041 \\
\hline & $\begin{array}{l}\text { Sig. (2- } \\
\text { tailed) }\end{array}$ & .906 & .645 & .739 & .394 & .581 & .854 & .612 & .455 & .896 & .786 \\
\hline & $\mathrm{N}$ & 53 & 54 & 53 & 49 & 53 & 54 & 53 & 53 & 54 & 47 \\
\hline \multirow[t]{3}{*}{ Adaptable } & $\begin{array}{l}\text { Pearson } \\
\text { Correlation }\end{array}$ & -.006 & -.003 & .131 & .041 & -.062 & .056 & .228 & .136 & -.047 & .010 \\
\hline & $\begin{array}{l}\text { Sig. (2- } \\
\text { tailed) }\end{array}$ & .965 & .982 & .350 & .779 & .657 & .687 & .101 & .331 & .737 & .946 \\
\hline & $\mathrm{N}$ & 53 & 54 & 53 & 49 & 53 & 54 & 53 & 53 & 54 & 47 \\
\hline \multirow[t]{2}{*}{ Forward thinking } & $\begin{array}{l}\text { Pearson } \\
\text { Correlation }\end{array}$ & -.025 & .026 & .130 & -.099 & .172 & -.008 & -.127 & -.093 & .189 & .009 \\
\hline & $\begin{array}{l}\text { Sig. (2- } \\
\text { tailed) }\end{array}$ & .858 & .853 & .353 & .497 & .219 & .955 & .364 & .510 & .172 & .951 \\
\hline
\end{tabular}




\begin{tabular}{|c|c|c|c|c|c|c|c|c|c|c|c|}
\hline $\begin{array}{c}\text { OPQ32i } \\
\text { DIMENSIONS }\end{array}$ & & \multicolumn{10}{|c|}{ LEADERSHIP COMPETENCIES } \\
\hline & & $\begin{array}{c}\text { Customer } \\
\text { Focus }\end{array}$ & $\begin{array}{c}\text { Building } \\
\text { Working } \\
\text { Relationships }\end{array}$ & $\begin{array}{c}\text { Gaining } \\
\text { Commitment }\end{array}$ & $\begin{array}{c}\text { Developing } \\
\text { Others }\end{array}$ & Analysis & $\begin{array}{c}\text { Problem } \\
\text { Solving }\end{array}$ & $\begin{array}{l}\text { Initiating } \\
\text { Action }\end{array}$ & $\begin{array}{c}\text { Planning } \\
\text { and } \\
\text { Organising }\end{array}$ & $\begin{array}{c}\text { Stress } \\
\text { Tolerance }\end{array}$ & $\begin{array}{l}\text { Continuous } \\
\text { Learning }\end{array}$ \\
\hline \multirow{4}{*}{ Detail conscious } & $\mathrm{N}$ & 53 & 54 & 53 & 49 & 53 & 54 & 53 & 53 & 54 & 47 \\
\hline & $\begin{array}{l}\text { Pearson } \\
\text { Correlation }\end{array}$ & .076 & .044 & .092 & -.002 & -.027 & .088 & .094 & -.056 & .133 & -.039 \\
\hline & $\begin{array}{l}\text { Sig. (2- } \\
\text { tailed) }\end{array}$ & .589 & .754 & .514 & .989 & .849 & .525 & .503 & .690 & .337 & .794 \\
\hline & $\mathrm{N}$ & 53 & 54 & 53 & 49 & 53 & 54 & 53 & 53 & 54 & 47 \\
\hline \multirow[t]{3}{*}{ Conscientious } & $\begin{array}{l}\text { Pearson } \\
\text { Correlation }\end{array}$ & .068 & -.145 & -.042 & -.056 & -.193 & -.160 & -.006 & -.128 & .095 & -.168 \\
\hline & $\begin{array}{l}\text { Sig. (2- } \\
\text { tailed) }\end{array}$ & .626 & .294 & .764 & .701 & .166 & .248 & .965 & .361 & .496 & .258 \\
\hline & $\mathrm{N}$ & 53 & 54 & 53 & 49 & 53 & 54 & 53 & 53 & 54 & 47 \\
\hline \multirow[t]{3}{*}{ Rule Following } & $\begin{array}{l}\text { Pearson } \\
\text { Correlation }\end{array}$ & -.021 & -.210 & -.092 & -.096 & .002 & .025 & .038 & .042 & -.138 & -.272 \\
\hline & $\begin{array}{l}\text { Sig. (2- } \\
\text { tailed) }\end{array}$ & .881 & .127 & .514 & .512 & .988 & .856 & .790 & .766 & .320 & .065 \\
\hline & $\mathrm{N}$ & 53 & 54 & 53 & 49 & 53 & 54 & 53 & 53 & 54 & 47 \\
\hline \multirow[t]{3}{*}{ Relaxed } & $\begin{array}{l}\text { Pearson } \\
\text { Correlation }\end{array}$ & .038 & -.156 & $-.323(*)$ & $-.287(*)$ & -.140 & -.145 & .055 & -.135 & .043 & .021 \\
\hline & $\begin{array}{l}\text { Sig. (2- } \\
\text { tailed) }\end{array}$ & .788 & .259 & .018 & .045 & .318 & .295 & .698 & .334 & .758 & .888 \\
\hline & $\mathrm{N}$ & 53 & 54 & 53 & 49 & 53 & 54 & 53 & 53 & 54 & 47 \\
\hline \multirow[t]{3}{*}{ Worrying } & $\begin{array}{l}\text { Pearson } \\
\text { Correlation }\end{array}$ & -.067 & -.179 & -.255 & -.070 & .014 & .109 & .046 & -.156 & $-.371(* *)$ & -.052 \\
\hline & $\begin{array}{l}\text { Sig. (2- } \\
\text { tailed) }\end{array}$ & .632 & .195 & .065 & .634 & .919 & .433 & .746 & .264 & .006 & .729 \\
\hline & $\mathrm{N}$ & 53 & 54 & 53 & 49 & 53 & 54 & 53 & 53 & 54 & 47 \\
\hline \multirow[t]{3}{*}{ Tough minded } & $\begin{array}{l}\text { Pearson } \\
\text { Correlation }\end{array}$ & -.170 & -.005 & -.077 & $-.343(*)$ & $-.426(* *)$ & $-.388(* *)$ & $-.329(*)$ & -.250 & .024 & -.207 \\
\hline & $\begin{array}{l}\text { Sig. (2- } \\
\text { tailed) }\end{array}$ & .223 & .972 & .583 & .016 & .001 & .004 & .016 & .071 & .865 & .162 \\
\hline & & 53 & 54 & 53 & 49 & 53 & 54 & 53 & 53 & 54 & 47 \\
\hline \multirow[t]{2}{*}{ Optimistic } & $\begin{array}{l}\text { Pearson } \\
\text { Correlation }\end{array}$ & -.167 & .069 & .037 & .094 & .074 & -.066 & -.170 & .104 & -.063 & .192 \\
\hline & $\begin{array}{l}\text { Sig. (2- } \\
\text { tailed) }\end{array}$ & .232 & .622 & .795 & .522 & .600 & .634 & .224 & .460 & .651 & .196 \\
\hline
\end{tabular}




\begin{tabular}{|c|c|c|c|c|c|c|c|c|c|c|c|}
\hline $\begin{array}{c}\text { OPQ32i } \\
\text { DIMENSIONS }\end{array}$ & & \multicolumn{10}{|c|}{ LEADERSHIP COMPETENCIES } \\
\hline & & $\begin{array}{l}\text { Customer } \\
\text { Focus }\end{array}$ & $\begin{array}{c}\text { Building } \\
\text { Working } \\
\text { Relationships }\end{array}$ & $\begin{array}{c}\text { Gaining } \\
\text { Commitment }\end{array}$ & $\begin{array}{c}\text { Developing } \\
\text { Others }\end{array}$ & Analysis & $\begin{array}{l}\text { Problem } \\
\text { Solving }\end{array}$ & $\begin{array}{l}\text { Initiating } \\
\text { Action }\end{array}$ & $\begin{array}{l}\text { Planning } \\
\text { and } \\
\text { Organising }\end{array}$ & $\begin{array}{c}\text { Stress } \\
\text { Tolerance }\end{array}$ & $\begin{array}{l}\text { Continuous } \\
\text { Learning }\end{array}$ \\
\hline \multirow{4}{*}{ Trusting } & $\mathrm{N}$ & 53 & 54 & 53 & 49 & 53 & 54 & 53 & 53 & 54 & 47 \\
\hline & $\begin{array}{l}\text { Pearson } \\
\text { Correlation }\end{array}$ & -.015 & .112 & -.075 & .137 & -.119 & -.218 & -.015 & -.191 & -.107 & -.057 \\
\hline & $\begin{array}{l}\text { Sig. (2- } \\
\text { tailed) }\end{array}$ & .913 & .422 & .595 & .349 & .394 & .113 & .915 & .171 & .443 & .703 \\
\hline & $\mathrm{N}$ & 53 & 54 & 53 & 49 & 53 & 54 & 53 & 53 & 54 & 47 \\
\hline \multirow[t]{3}{*}{$\begin{array}{l}\text { Emotionally } \\
\text { Controlled }\end{array}$} & $\begin{array}{l}\text { Pearson } \\
\text { Correlation }\end{array}$ & $-.348(*)$ & $-.287(*)$ & -.203 & -.184 & -.062 & -.118 & -.224 & -.078 & $-.274(*)$ & -.028 \\
\hline & $\begin{array}{l}\text { Sig. (2- } \\
\text { tailed) }\end{array}$ & .011 & .035 & .145 & .204 & .657 & .397 & .106 & .581 & .045 & .851 \\
\hline & $\mathrm{N}$ & 53 & 54 & 53 & 49 & 53 & 54 & 53 & 53 & 54 & 47 \\
\hline \multirow[t]{3}{*}{ Vigorous } & $\begin{array}{l}\text { Pearson } \\
\text { Correlation }\end{array}$ & .112 & -.028 & .137 & -.045 & .031 & .098 & .087 & .074 & .135 & -.197 \\
\hline & $\begin{array}{l}\text { Sig. (2- } \\
\text { tailed) }\end{array}$ & .427 & .843 & .328 & .761 & .826 & .479 & .535 & .598 & .331 & .185 \\
\hline & $\mathrm{N}$ & 53 & 54 & 53 & 49 & 53 & 54 & 53 & 53 & 54 & 47 \\
\hline \multirow[t]{3}{*}{ Competitive } & $\begin{array}{l}\text { Pearson } \\
\text { Correlation }\end{array}$ & -.121 & -.221 & -.100 & -.120 & -.084 & -.048 & .053 & -.132 & .071 & -.060 \\
\hline & $\begin{array}{l}\text { Sig. (2- } \\
\text { tailed) }\end{array}$ & .387 & .109 & .476 & .412 & .548 & .729 & .705 & .345 & .612 & .689 \\
\hline & $\mathrm{N}$ & 53 & 54 & 53 & 49 & 53 & 54 & 53 & 53 & 54 & 47 \\
\hline \multirow[t]{3}{*}{ Achieving } & $\begin{array}{l}\text { Pearson } \\
\text { Correlation }\end{array}$ & -.143 & -.029 & .101 & .152 & -.095 & -.072 & .007 & -.137 & .132 & -.092 \\
\hline & $\begin{array}{l}\text { Sig. (2- } \\
\text { tailed) }\end{array}$ & .306 & .836 & .470 & .298 & .498 & .604 & .959 & .327 & .343 & .536 \\
\hline & $\mathrm{N}$ & 53 & 54 & 53 & 49 & 53 & 54 & 53 & 53 & 54 & 47 \\
\hline \multirow[t]{3}{*}{ Decisive } & $\begin{array}{l}\text { Pearson } \\
\text { Correlation }\end{array}$ & -.202 & $-.324(*)$ & -.201 & -.030 & .152 & .041 & .100 & .045 & .023 & -.182 \\
\hline & $\begin{array}{l}\text { Sig. (2- } \\
\text { tailed) }\end{array}$ & .147 & .017 & .149 & .838 & .276 & .771 & .476 & .749 & .869 & .220 \\
\hline & $\mathrm{N}$ & 53 & 54 & 53 & 49 & 53 & 54 & 53 & 53 & 54 & 47 \\
\hline
\end{tabular}

\footnotetext{
** Correlation is significant at the 0.01 level (2-tailed). * Correlation is significant at the 0.05 level (2-tailed).
} 


\subsection{PEARSON PRODUCT-MOMENT CORRELATIONS BETWEEN EI DIMENSIONS (MEASURED BY}

\section{THE SUEIT) \& PERSONALITY TRAITS (MEASURED BY THE OPQ32i)}

\begin{tabular}{|c|c|c|c|c|c|c|}
\hline \multirow[t]{2}{*}{$\begin{array}{c}\text { OPQ32i } \\
\text { DIMENSIONS }\end{array}$} & & \multicolumn{5}{|c|}{ EI DIMENSIONS (THE SUEIT) } \\
\hline & & $\begin{array}{l}\text { Emotional } \\
\text { Recognition and } \\
\text { Expression } \\
\end{array}$ & $\begin{array}{l}\text { Understanding } \\
\text { Emotions External }\end{array}$ & Emotion Direct cognition & $\begin{array}{l}\text { Emotional } \\
\text { Management }\end{array}$ & Emotional Control \\
\hline \multirow[t]{3}{*}{ Persuasiveness } & Pearson Correlation & .158 & .159 & .066 & .194 & .095 \\
\hline & Sig. (2-tailed) & .253 & .250 & .635 & .161 & .495 \\
\hline & $\mathrm{N}$ & 54 & 54 & 54 & 54 & 54 \\
\hline \multirow[t]{3}{*}{ Controlling } & Pearson Correlation & .168 & -.011 & .181 & .029 & -.063 \\
\hline & Sig. (2-tailed) & .224 & .936 & .190 & .834 & .652 \\
\hline & $\mathrm{N}$ & 54 & 54 & 54 & 54 & 54 \\
\hline \multirow[t]{3}{*}{ Outspoken } & Pearson Correlation & $.439 * *$ & .190 & -.132 & .036 & -.089 \\
\hline & Sig. (2-tailed) & .001 & .168 खण & .342 & .795 & .521 \\
\hline & $\mathrm{N}$ & 54 & 54 & 54 & 54 & 54 \\
\hline \multirow{3}{*}{$\begin{array}{l}\text { Independent } \\
\text { mindedness }\end{array}$} & Pearson Correlation & -.016 & -.044 & .009 & -.046 & -.053 \\
\hline & Sig. (2-tailed) & .906 & .750 & .950 & .741 & .701 \\
\hline & $\mathrm{N}$ & 54 & 54 & 54 & 54 & 54 \\
\hline \multirow[t]{3}{*}{ Outgoing } & Pearson Correlation & .231 & .160 & .266 & .087 & -.037 \\
\hline & Sig. (2-tailed) & .093 & .249 & .052 & .532 & .792 \\
\hline & $\mathrm{N}$ & 54 & 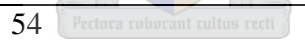 & 54 & 54 & 54 \\
\hline \multirow[t]{3}{*}{ Affiliative } & Pearson Correlation & .077 & $.361^{* *}$ & .243 & .092 & -.073 \\
\hline & Sig. (2-tailed) & .578 & .007 & .076 & .508 & .598 \\
\hline & $\mathrm{N}$ & 54 & 54 & 54 & 54 & 54 \\
\hline \multirow{3}{*}{$\begin{array}{l}\text { Socially } \\
\text { Confident }\end{array}$} & Pearson Correlation & .234 & $.306^{*}$ & .148 & .228 & $.292 *$ \\
\hline & Sig. (2-tailed) & .089 & .024 & .287 & .098 & .032 \\
\hline & $\mathrm{N}$ & 54 & 54 & 54 & 54 & 54 \\
\hline \multirow[t]{3}{*}{ Modest } & Pearson Correlation & $-.534^{* *}$ & $-.420 * *$ & -.023 & $-.269 *$ & -.183 \\
\hline & Sig. (2-tailed) & .000 & .002 & .870 & .049 & .186 \\
\hline & $\mathrm{N}$ & 54 & 54 & 54 & 54 & 54 \\
\hline \multirow[t]{3}{*}{ Democratic } & Pearson Correlation & .147 & $.333^{*}$ & .015 & .125 & .040 \\
\hline & Sig. (2-tailed) & .288 & .014 & .915 & .367 & .775 \\
\hline & $\mathrm{N}$ & 54 & 54 & 54 & 54 & 54 \\
\hline \multirow[t]{2}{*}{ Caring } & Pearson Correlation & -.244 & $.295^{*}$ & .194 & .252 & -.067 \\
\hline & Sig. (2-tailed) & .075 & .030 & .159 & .066 & .629 \\
\hline
\end{tabular}




\begin{tabular}{|c|c|c|c|c|c|c|}
\hline \multirow[t]{2}{*}{$\begin{array}{c}\text { OPQ32i } \\
\text { DIMENSIONS }\end{array}$} & & \multicolumn{5}{|c|}{ EI DIMENSIONS (THE SUEIT) } \\
\hline & & $\begin{array}{l}\text { Emotional } \\
\text { Recognition and } \\
\text { Expression }\end{array}$ & $\begin{array}{l}\text { Understanding } \\
\text { Emotions External }\end{array}$ & Emotion Direct cognition & $\begin{array}{l}\text { Emotional } \\
\text { Management }\end{array}$ & Emotional Control \\
\hline & $\mathrm{N}$ & 54 & 54 & 54 & 54 & 54 \\
\hline \multirow[t]{3}{*}{ Data rational } & Pearson Correlation & -.083 & -.183 & -.047 & $-.284^{*}$ & .048 \\
\hline & Sig. (2-tailed) & .552 & .184 & .738 & .038 & .732 \\
\hline & $\mathrm{N}$ & 54 & 54 & 54 & 54 & 54 \\
\hline \multirow[t]{3}{*}{ Evaluative } & Pearson Correlation & .071 & .008 & -.096 & $-.330^{*}$ & -.073 \\
\hline & Sig. (2-tailed) & .608 & .957 & .488 & .015 & .600 \\
\hline & $\mathrm{N}$ & 54 & 54 & 54 & 54 & 54 \\
\hline \multirow[t]{3}{*}{ Behavioural } & Pearson Correlation & .102 & $.412 * *$ & .185 & .136 & -.006 \\
\hline & Sig. (2-tailed) & .465 & .002 & .181 & .326 & .964 \\
\hline & $\mathrm{N}$ & 54 & 54 & 54 & 54 & 54 \\
\hline \multirow[t]{3}{*}{ Conventional } & Pearson Correlation & $.292 *$ & . & . 022 & -.138 & - \\
\hline & Sig. (2-tailed) & .032 & .934 & .874 & .319 & .313 \\
\hline & $\mathrm{N}$ & 54 & $54 \quad 2004$ & 54 & 54 & 54 \\
\hline \multirow[t]{3}{*}{ Conceptual } & Pearson Correlation & .043 & .173 & .109 & -.060 & .175 \\
\hline & Sig. (2-tailed) & .760 & 211 & .432 & .669 & .206 \\
\hline & $\mathrm{N}$ & 54 & 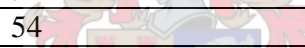 & 54 & 54 & 54 \\
\hline \multirow[t]{3}{*}{ Innovative } & Pearson Correlation & -.014 & .021 & .080 & .130 & .101 \\
\hline & Sig. (2-tailed) & .922 & .878 & .564 & .347 & .466 \\
\hline & $\mathrm{N}$ & 54 & 54 & 54 & 54 & 54 \\
\hline \multirow{3}{*}{$\begin{array}{l}\text { Variety } \\
\text { Seeking }\end{array}$} & Pearson Correlation & -.154 & -.180 & .145 & .013 & .034 \\
\hline & Sig. (2-tailed) & .267 & 192 & .294 & .923 & .805 \\
\hline & $\mathrm{N}$ & 54 & 54 & 54 & 54 & 54 \\
\hline \multirow[t]{3}{*}{ Adaptable } & Pearson Correlation & -.145 & .046 & -.135 & -.095 & .007 \\
\hline & Sig. (2-tailed) & .294 & . & .329 & .496 & .962 \\
\hline & $\mathrm{N}$ & 54 & 54 & 54 & 54 & 54 \\
\hline \multirow{3}{*}{$\begin{array}{l}\text { Forward } \\
\text { thinking }\end{array}$} & Pearson Correlation & -.130 & -.043 & $-.386^{* *}$ & .070 & .133 \\
\hline & Sig. (2-tailed) & .348 & .757 & .004 & .615 & .337 \\
\hline & $\mathrm{N}$ & 54 & 54 & 54 & 54 & 54 \\
\hline \multirow{3}{*}{$\begin{array}{l}\text { Detail } \\
\text { conscious }\end{array}$} & Pearson Correlation & $.290^{*}$ & -.049 & -.175 & -.041 & -.039 \\
\hline & Sig. (2-tailed) & .034 & .724 & .205 & .770 & .781 \\
\hline & $\mathrm{N}$ & 54 & 54 & 54 & 54 & 54 \\
\hline \multirow[t]{3}{*}{ Conscientious } & Pearson Correlation & .067 & -.114 & -.002 & .242 & .013 \\
\hline & Sig. (2-tailed) & .631 & .411 & .991 & .078 & .927 \\
\hline & $\mathrm{N}$ & 54 & 54 & 54 & 54 & 54 \\
\hline
\end{tabular}




\begin{tabular}{|c|c|c|c|c|c|c|}
\hline \multirow[t]{2}{*}{$\begin{array}{c}\text { OPQ32i } \\
\text { DIMENSIONS }\end{array}$} & & \multicolumn{5}{|c|}{ EI DIMENSIONS (THE SUEIT) } \\
\hline & & $\begin{array}{l}\text { Emotional } \\
\text { Recognition and } \\
\text { Expression }\end{array}$ & $\begin{array}{l}\text { Understanding } \\
\text { Emotions External }\end{array}$ & Emotion Direct cognition & $\begin{array}{l}\text { Emotional } \\
\text { Management }\end{array}$ & Emotional Control \\
\hline \multirow[t]{3}{*}{ Rule Following } & Pearson Correlation & .055 & -.178 & -.160 & -.203 & $-.325^{*}$ \\
\hline & Sig. (2-tailed) & .691 & .198 & .249 & .141 & .016 \\
\hline & $\mathrm{N}$ & 54 & 54 & 54 & 54 & 54 \\
\hline \multirow[t]{3}{*}{ Relaxed } & Pearson Correlation & .091 & -.074 & -.245 & .235 & .138 \\
\hline & Sig. (2-tailed) & .513 & .596 & .074 & .087 & .320 \\
\hline & $\mathrm{N}$ & 54 & 54 & 54 & 54 & 54 \\
\hline \multirow{3}{*}{ Worrying } & Pearson Correlation & -.088 & -.071 & -.073 & $-.428 * *$ & $-.432 * *$ \\
\hline & Sig. (2-tailed) & .525 & .610 & .598 & .001 & .001 \\
\hline & $\mathrm{N}$ & 54 & 54 & 54 & 54 & 54 \\
\hline \multirow[t]{3}{*}{ Tough minded } & Pearson Correlation & $-.339 *$ & -.194 & $-.282 *$ & .118 & $.280 *$ \\
\hline & Sig. (2-tailed) & .012 & .159 & .039 & .394 & .041 \\
\hline & $\mathrm{N}$ & 54 & 54 & 54 & 54 & 54 \\
\hline \multirow[t]{3}{*}{ Optimistic } & Pearson Correlation & .015 & -.009 & -.118 & -.010 & .222 \\
\hline & Sig. (2-tailed) & .914 & .946 & .396 & .942 & .106 \\
\hline & $\mathrm{N}$ & 54 & $54+x+1>0$ & 54 & 54 & 54 \\
\hline \multirow[t]{3}{*}{ Trusting } & Pearson Correlation & -.147 & -.019 & .087 & .245 & .154 \\
\hline & Sig. (2-tailed) & .287 & .893 & .533 & .074 & .267 \\
\hline & $\mathrm{N}$ & 54 & $54-5$ & 54 & 54 & 54 \\
\hline \multirow{3}{*}{$\begin{array}{l}\text { Emotionally } \\
\text { Controlled } \\
\end{array}$} & Pearson Correlation & $-.534 * *$ & $-.383 * *$ & -.080 & $-.270 *$ & -.148 \\
\hline & Sig. (2-tailed) & .000 & .004 & .567 & .049 & .287 \\
\hline & $\mathrm{N}$ & 54 & 54 & 54 & 54 & 54 \\
\hline \multirow[t]{3}{*}{ Vigorous } & Pearson Correlation & .156 & -.046 & .079 & -.038 & -.168 \\
\hline & Sig. (2-tailed) & .261 & .741 & .570 & .786 & .223 \\
\hline & $\mathrm{N}$ & 54 & 54 & 54 & 54 & 54 \\
\hline \multirow[t]{3}{*}{ Competitive } & Pearson Correlation & -.002 & -.144 & .218 & .140 & -.010 \\
\hline & Sig. (2-tailed) & .988 & .299 & .113 & .312 & .944 \\
\hline & $\mathrm{N}$ & 54 & 54 & 54 & 54 & 54 \\
\hline \multirow[t]{3}{*}{ Achieving } & Pearson Correlation & -.063 & .031 & -.177 & .228 & $.269 *$ \\
\hline & Sig. (2-tailed) & .652 & .822 & .201 & .098 & .049 \\
\hline & $\mathrm{N}$ & 54 & 54 & 54 & 54 & 54 \\
\hline \multirow[t]{3}{*}{ Decisive } & Pearson Correlation & .060 & -.070 & .037 & -.051 & -.016 \\
\hline & Sig. (2-tailed) & .668 & .615 & .790 & .716 & .910 \\
\hline & $\mathrm{N}$ & 54 & 54 & 54 & 54 & 54 \\
\hline
\end{tabular}

*Correlation is significant at the 0.05 level (2-tailed). ${ }^{* *}$ Correlation is significant at the 0.01 level (2-tailed) 


\section{APPENDIX4. HIERARCHICAL REGRESSION ANALYSES RESULTS}

\subsection{HIERARCHICAL REGRESSION ANALYSIS WITH CUSTOMER FOCUS}

\section{Model Summary}

\begin{tabular}{|l|l|r|r|r|}
\hline Model & $\mathrm{R}$ & R Square & $\begin{array}{c}\text { Adjusted R } \\
\text { Square }\end{array}$ & $\begin{array}{c}\text { Std. Error of } \\
\text { the Estimate }\end{array}$ \\
\hline 1 & $.580(\mathrm{a})$ & .337 & .296 & .57833 \\
2 & $.595(\mathrm{~b})$ & .353 & .300 & .57701 \\
\hline
\end{tabular}

1 Predictors: (Constant), Emotionally Controlled, Affiliative, Outgoing

2 Predictors: (Constant), Emotionally Controlled, Affiliative, Outgoing, Raw score Understanding emotions external

\section{ANOVA(c)}

\begin{tabular}{|l|l|r|r|r|r|l|}
\hline Model & & $\begin{array}{c}\text { Sum of } \\
\text { Squares }\end{array}$ & df & Mean Square & F & Sig. \\
\hline 1 & Regression & 8.328 & 3 & 2.776 & $8.300^{*}$ & $.000(\mathrm{a})$ \\
& Residual & 16.389 & 49 & .334 & & \\
& Total & 24.717 & 52 & & & \\
2 & Regression & 8.736 & 4 & 2.184 & $6.560^{*}$ & $.000(\mathrm{~b})$ \\
& Residual & 15.981 & 48 & .333 & & \\
& Total & 24.717 & 52 & & & \\
\hline
\end{tabular}

a Predictors: (Constant), Emotionally Controlled, Affiliative, Outgoing

b Predictors: (Constant), Emotionally Controlled, Affiliative, Outgoing, Raw score Understanding emotions external

c Dependent Variable: Customer Focus

* $p<0.01$ 


\subsection{HIERARCHICAL REGRESSION ANALYSIS WITH BUILDING WORKING RELATIONSHIPS}

\section{Model Summary}

\begin{tabular}{|l|l|r|r|r|}
\hline Model & $\mathrm{R}$ & R Square & $\begin{array}{c}\text { Adjusted R } \\
\text { Square }\end{array}$ & $\begin{array}{c}\text { Std. Error of } \\
\text { the Estimate }\end{array}$ \\
\hline 1 & $.679(\mathrm{a})$ & .461 & .366 & .54014 \\
2 & $.740(\mathrm{~b})$ & .548 & .443 & .50618 \\
\hline
\end{tabular}

a Predictors: (Constant), Decisive, Persuasiveness, Affiliative, Emotionally Controlled, Behavioural, Socially Confident, Independent mindedness, Democratic

b Predictors: (Constant), Decisive, Persuasiveness, Affiliative, Emotionally Controlled, Behavioural, Socially Confident, Independent mindedness, Democratic, Raw score emotional control, Raw score Understanding emotions external

\section{ANOVA(c)}

\begin{tabular}{|l|l|r|r|r|r|r|}
\hline Model & & $\begin{array}{c}\text { Sum of } \\
\text { Squares }\end{array}$ & df & Mean Square & F & Sig. \\
\hline 1 & Regression & 11.242 & 8 & 1.405 & $4.817^{*}$ & $.000(\mathrm{a})$ \\
& Residual & 13.129 & 45 & .292 & & \\
& Total & 24.370 & 53 & & & \\
2 & Regression & 13.353 & 10 & 1.335 & $5.211^{*}$ & $.000(\mathrm{~b})$ \\
& Residual & 11.017 & 43 & .256 & & \\
& Total & 24.370 & 53 & & & \\
\hline
\end{tabular}

a Predictors: (Constant), Decisive, Persuasiveness, Affiliative, Emotionally Controlled, Behavioural, Socially Confident, Independent mindedness, Democratic

b Predictors: (Constant), Decisive, Persuasiveness, Affiliative, Emotionally Controlled, Behavioural, Socially Confident, Independent mindedness, Democratic, Raw score emotional control, Raw score Understanding emotions external

c Dependent Variable: Building Working Relationships

${ }^{*} p<0.01$ 


\subsection{HIERARCHICAL REGRESSION ANALYSIS WITH GAINING COMMITMENT}

\section{Model Summary}

\begin{tabular}{|l|l|r|r|r|}
\hline Model & R & R Square & $\begin{array}{c}\text { Adjusted R } \\
\text { Square }\end{array}$ & $\begin{array}{c}\text { Std. Error of } \\
\text { the Estimate }\end{array}$ \\
\hline 1 & $.601(\mathrm{a})$ & .361 & .278 & .56780 \\
2 & $.603(\mathrm{~b})$ & .364 & .265 & .57275 \\
\hline
\end{tabular}

a Predictors: (Constant), Relaxed, Affiliative, Socially Confident, Behavioural, Independent mindedness, Democratic b Predictors: (Constant), Relaxed, Affiliative, Socially Confident, Behavioural, Independent mindedness, Democratic, Raw score Understanding emotions external

\section{ANOVA(c)}

\begin{tabular}{|l|l|r|r|r|r|l|}
\hline Model & & $\begin{array}{c}\text { Sum of } \\
\text { Squares }\end{array}$ & df & Mean Square & F & Sig. \\
\hline 1 & Regression & 8.377 & 6 & 1.396 & $4.331^{*}$ & $.002(\mathrm{a})$ \\
& Residual & 14.831 & 46 & .322 & & \\
& Total & 23.208 & 52 & & & \\
2 & Regression & 8.445 & 7 & 1.206 & $3.678^{\star}$ & $.003(\mathrm{~b})$ \\
& Residual & 14.762 & 45 & .328 & & \\
& Total & 23.208 & 52 & & & \\
\hline
\end{tabular}

a Predictors: (Constant), Relaxed, Affiliative, Socially Confident, Behavioural, Independent mindedness, Democratic b Predictors: (Constant), Relaxed, Affiliative, Socially Confident, Behavioural, Independent mindedness, Democratic, Raw score Understanding emotions external c Dependent Variable: Gaining Commitment * $p<0.01$ 


\subsection{HIERARCHICAL REGRESSION ANALYSIS WITH DEVELOPING OTHERS}

\section{Model Summary}

\begin{tabular}{|l|l|r|r|r|}
\hline Model & $\mathrm{R}$ & R Square & $\begin{array}{c}\text { Adjusted R } \\
\text { Square }\end{array}$ & $\begin{array}{c}\text { Std. Error of } \\
\text { the Estimate }\end{array}$ \\
\hline 1 & $.576(\mathrm{a})$ & .331 & .270 & .62863 \\
2 & $.642(\mathrm{~b})$ & .413 & .312 & .61024 \\
\hline
\end{tabular}

a Predictors: (Constant), Tough minded, Democratic, Outgoing, Relaxed

b Predictors: (Constant), Tough minded, Democratic, Outgoing, Relaxed, Raw score emotional control, Raw score emotional recognition and expression, Raw score Understanding emotions external

ANOVA(c)

\begin{tabular}{|l|l|r|r|r|r|r|}
\hline Model & & $\begin{array}{c}\text { Sum of } \\
\text { Squares }\end{array}$ & df & Mean Square & \multicolumn{1}{c|}{ F } & Sig. \\
\hline 1 & Regression & 8.612 & 4 & 2.153 & $5.448^{\star}$ & $.001(\mathrm{a})$ \\
& Residual & 17.388 & 44 & .395 & & \\
& Total & 26.000 & 48 & & & \\
2 & Regression & 10.732 & 7 & 1.533 & $4.117^{*}$ & $.002(\mathrm{~b})$ \\
& Residual & 15.268 & 41 & .372 & & \\
& Total & 26.000 & 48 & & & \\
\hline
\end{tabular}

a Predictors: (Constant), Tough minded, Democratic, Outgoing, Relaxed

b Predictors: (Constant), Tough minded, Democratic, Outgoing, Relaxed, Raw score emotional control, Raw score emotional recognition and expression, Raw score Understanding emotions external

c Dependent Variable: Developing Others

* $p<0.01$ 


\subsection{HIERARCHICAL REGRESSION ANALYSIS WITH PROBLEM SOLVING}

\section{Model Summary}

\begin{tabular}{|l|r|r|r|r|}
\hline Model & $\mathrm{R}$ & R Square & $\begin{array}{c}\text { Adjusted R } \\
\text { Square }\end{array}$ & $\begin{array}{c}\text { Std. Error of } \\
\text { the Estimate }\end{array}$ \\
\hline 1 & $.517(\mathrm{a})$ & .267 & .223 & .62716 \\
2 & $.573(\mathrm{~b})$ & .328 & .273 & .60669 \\
\hline
\end{tabular}

a Predictors: (Constant), Tough minded, controlling, Evaluative

b Predictors: (Constant), Tough minded, controlling, Evaluative, Raw score emotional management

\section{ANOVA(c)}

\begin{tabular}{|l|l|r|r|r|r|l|}
\hline Model & & $\begin{array}{c}\text { Sum of } \\
\text { Squares }\end{array}$ & df & Mean Square & F & Sig. \\
\hline 1 & Regression & 7.167 & 3 & 2.389 & $6.074^{\star}$ & $.001(\mathrm{a})$ \\
& Residual & 19.666 & 50 & .393 & & \\
& Total & 26.833 & 53 & & & \\
2 & Regression & 8.798 & 4 & 2.199 & $5.976^{\star}$ & $.001(\mathrm{~b})$ \\
& Residual & 18.036 & 49 & .368 & & \\
& Total & 26.833 & 53 & & & \\
\hline
\end{tabular}

a Predictors: (Constant), Tough minded, controlling, Evaluative

b Predictors: (Constant), Tough minded, controlling, Evaluative, Raw score emotional management

c Dependent Variable: Problem Solving

$* p<0.01$ 


\subsection{HIERARCHICAL REGRESSION ANALYSIS WITH STRESS}

\section{TOLERANCE}

\section{Model Summary}

\begin{tabular}{|l|l|r|r|r|}
\hline Model & R & R Square & $\begin{array}{c}\text { Adjusted R } \\
\text { Square }\end{array}$ & $\begin{array}{c}\text { Std. Error of } \\
\text { the Estimate }\end{array}$ \\
\hline 1 & $.489(\mathrm{a})$ & .239 & .177 & .43344 \\
2 & $.526(\mathrm{~b})$ & .277 & .185 & .43125 \\
\hline
\end{tabular}

a Predictors: (Constant), Emotionally Controlled, Behavioural, Independent mindedness, Worrying

b Predictors: (Constant), Emotionally Controlled, Behavioural, Independent mindedness, Worrying, Raw score emotion direct cognition, Raw score emotional control

\section{ANOVA(c)}

\begin{tabular}{|l|l|r|r|r|r|r|}
\hline Model & & $\begin{array}{c}\text { Sum of } \\
\text { Squares }\end{array}$ & df & Mean Square & F & Sig. \\
\hline 1 & Regression & 2.887 & 4 & .722 & $3.842^{*}$ & $.009(\mathrm{a})$ \\
& Residual & 9.206 & 49 & .188 & & \\
& Total & 12.093 & 53 & & & \\
2 & Regression & 3.352 & 6 & .559 & $3.004^{*}$ & $.014(\mathrm{~b})$ \\
& Residual & 8.741 & 47 & .186 & & \\
& Total & 12.093 & 53 & & & \\
\hline
\end{tabular}

a Predictors: (Constant), Emotionally Controlled, Behavioural, Independent mindedness, Worrying

b Predictors: (Constant), Emotionally Controlled, Behavioural, Independent mindedness, Worrying, Raw score emotion direct cognition, Raw score emotional control

c Dependent Variable: Stress Tolerance

${ }^{*} p<0.01$ 
APPENDIX 5: CONCEPTUAL LINKAGES BETWEEN THE OPQ32I, NEO, BAR-ON AND SUEIT DIMENSIONS

\begin{tabular}{|c|c|c|c|}
\hline OPQ & NEO & Bar-On & SUEIT \\
\hline $\begin{array}{l}\text { Behavioural - concerns how interested } \\
\text { people are in why others - and } \\
\text { themselves behave as they do, in what } \\
\text { motivates people and “makes them } \\
\text { tick”. High scores: Introspective, also } \\
\text { believe in analyzing the behaviour of } \\
\text { others and themselves and thinking } \\
\text { through what people's motives and } \\
\text { reactions are likely to be. Look at the } \\
\text { "human side" of a problem and make } \\
\text { decisions, which take into account their } \\
\text { view of human nature. Low scores: } \\
\text { disinterested in psychology or theories } \\
\text { of motivation, take little interest in why } \\
\text { people behave as they do. Thinking } \\
\text { about human behaviour is not a major } \\
\text { concern, and may act without } \\
\text { considering the likely reaction from } \\
\text { others involved. Don't spend too much } \\
\text { time dwelling on own actions. }\end{array}$ & $\begin{array}{l}\text { Openness - The degree to which a } \\
\text { person is imaginative and curious as } \\
\text { opposed to concrete minded and } \\
\text { narrow in thinking. } \\
\text { High scores: tend to be liberal and } \\
\text { approach problems in new and } \\
\text { innovative ways. } \\
\text { Intense interest in novelty, variety, } \\
\text { and experience for its own sake: open } \\
\text { people are imaginative, sensitive, } \\
\text { flexible, curious and independent, } \\
\text { whereas closed people are down-to- } \\
\text { earth, businesslike and traditional. } \\
\text { Open individuals possess emotional } \\
\text { sensitivity meaning that they feel } \\
\text { distress as well as joy mere keenly } \\
\text { than others. Are in some respects } \\
\text { emotionally vulnerable. Perceptive, } \\
\text { analytical, and introspective, displays } \\
\text { intellectual engagement, need for } \\
\text { cognition. Closed individuals deny } \\
\text { inner conflicts and avoid noxious } \\
\text { stimuli. } \\
\text { Facets: Openness to fantasy, } \\
\text { aesthetics (emotional perception and } \\
\text { awareness), feelings (experience a } \\
\text { wide range of emotions of feelings), } \\
\text { actions, ideas, values. } \\
\text { Individuals scoring high in openness } \\
\text { claim that they }\end{array}$ & $\begin{array}{l}\text { Emotional Self-Awareness - The } \\
\text { ability to recognize and understand } \\
\text { one’s feelings and emotions, } \\
\text { differentiate between them, know what } \\
\text { caused then and why. } \\
\text { Flexibility - the ability to adjust one's } \\
\text { emotions, thoughts, and behaviours to } \\
\text { changing situations and conditions } \\
\text { Reality testing - The ability to assess } \\
\text { the correspondence between what is } \\
\text { experienced and what in reality exists } \\
\text { (the subjective vs. the objective) } \\
\text { Independence - Ability to be self- } \\
\text { reliant and self-directed in one's } \\
\text { thinking and actions and to be free } \\
\text { from emotional dependency }\end{array}$ & $\begin{array}{l}\text { Understanding Emotions } \\
\text { External - the ability to identify } \\
\text { and understand the emotions of } \\
\text { others and those manifest in } \\
\text { external stimuli, e.g. workplace } \\
\text { environments and staff meetings }\end{array}$ \\
\hline
\end{tabular}




\begin{tabular}{|c|c|c|c|}
\hline$\overline{\text { OPQ }}$ & NEO & Bar-On & SUEIT \\
\hline $\begin{array}{l}\text { Tough Minded - concerns how } \\
\text { difficult people are to upset, how thick- } \\
\text { skinned they are and how genuiniely } \\
\text { unhurth they feel when criticized. High } \\
\text { scores: tend to be unconcerned with } \\
\text { what others thing of them and do not } \\
\text { over-react to personal criticism. Feel } \\
\text { they can remain col lheaded when } \\
\text { things are getting personal. Low scores: } \\
\text { concerned about how others see them } \\
\text { and affected by adverse criticism, may } \\
\text { become too emotionally involved in } \\
\text { situations where their own feelings } \\
\text { have been hurt. } \\
\text { (Saville, Cramp \& Henley 2004) }\end{array}$ & $\begin{array}{l}\text { Neuroticism - The degree to which a } \\
\text { person is anxious and insecure, as } \\
\text { opposed to calm and self-confident. } \\
\text { High scores: are prone to mood } \\
\text { swings, have little emotional stability, } \\
\text { and are anxious and prone to } \\
\text { depression. } \\
\text { Facets: Angry hostility, depression, } \\
\text { self-consciousness, impulsiveness, } \\
\text { vulnerability. } \\
\text { (Costa \& Mccrae, 1992; Kaplan \& } \\
\text { Sacuzzo , } 2001\end{array}$ & $\begin{array}{l}\text { Happiness - the ability to feel } \\
\text { satisfied with one’s life, to enjoy } \\
\text { oneself and others, and to have fun. } \\
\text { Self-regard - the ability to look at and } \\
\text { understand oneself, respect and accept } \\
\text { oneself, accepting one’s perceived } \\
\text { positive and negative aspects as well } \\
\text { as one’s limitations and possibilities. } \\
\text { Impulse control - the ability to resist } \\
\text { or delay a impulse, drive or temptation } \\
\text { to act. A capacity for accepting one’s } \\
\text { aggressive impulses, being composed } \\
\text { and controlling aggression, hostility } \\
\text { and irresponsible behaviour. } \\
\text { Stress tolerance - the ability to } \\
\text { withstand adverse events and stressful } \\
\text { situations without falling apart by } \\
\text { actively and confidently coping with } \\
\text { stress } \\
\text { (Bar-On ,1997; McCrae,2000) }\end{array}$ & $\begin{array}{l}\text { Emotional Control - the extent to } \\
\text { which one can effectively control } \\
\text { emotional states experienced at } \\
\text { work such as anger, frustration, } \\
\text { anxiety and stress } \\
\text { Emotional Management - the } \\
\text { ability to manage positive and } \\
\text { negative emotions within oneself } \\
\text { and others } \\
\text { (Palmer \& Stough, 2001) }\end{array}$ \\
\hline
\end{tabular}

